National Library of Canada

Collections Development Branch

Canadian Theses on

Mictofiche Service
Bibliotheque nationale du Canada

Direction du développernent des collections

Service des theses canadiennes sur microfiche

NOTICE

AVIS

s.

The quality of this microfiche is heavily dependent upon the quality of the original thesis submitted for microfilming. Every effort has been made to ensure the highest quality of reproduction possible.

If pages are missing, contact the university which granted the degree.

Some pages may have indistinct print especially if the original pages were typed with a poor typewriter ribbon or if the university sent us a poor photocopy.

Previously copyrighted materials (journal articles, published tests, etc.) are not filmed.

Reproduction in full or in part of this film is govemed by the Canadian Copyright Act, R.S.C. 1970, c. C-30. Please read the authorization forms which accompany this thesis.
La qualite de cette microfiche dépend grandement de la qualité de la thèse soumise au microfilmage. Nous avons tout fait pour assurer une qualité supérieure de reproduction.

S'il manque des pages, veuillez communiquer avec l'université qui a conféré le grade.

La qualité d'impression de certaines pages peut laisser à désirer, surtout si les pages originales ont été dactylographiées à l'aide d'un ruban usé ou si l'université nous a fait parvenir une photocopie de mauvaise qualite.

Les documents qui font dejjà l'objet d'un droit d'auteur (articles de revua examens publies, etc.) ne sont pas microfilmés.

La reproduction, mème partielle, de ce microfilm est soumise à la Loi canadienne sur le droit d'auteur, SRC 1970, c. C-30. Veuillez prendre connaissance des formules d'autorisation qui accompagnent cette thèse.
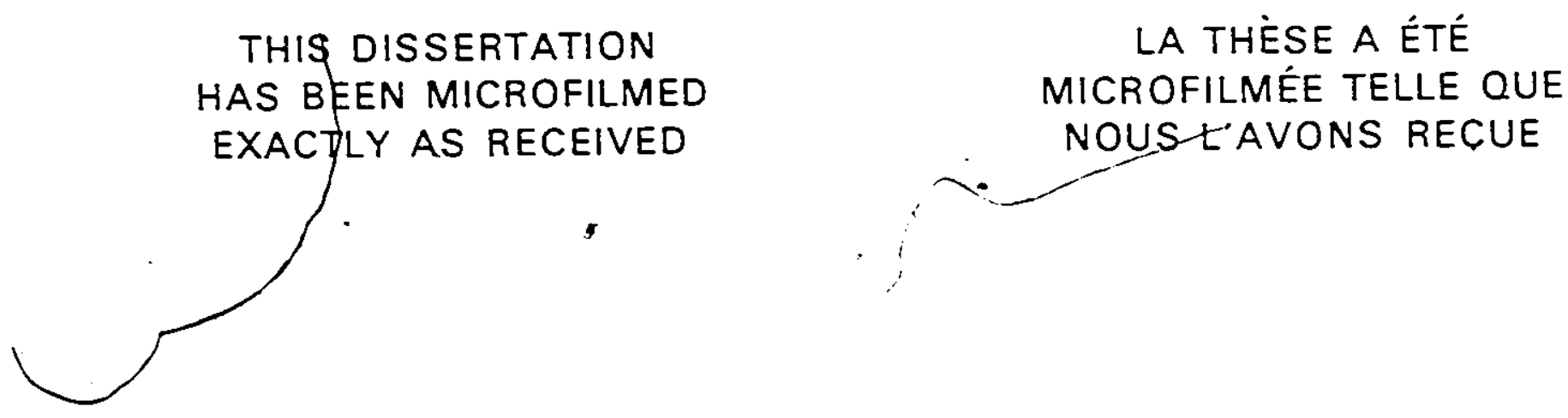


\title{
ORGANIC SULFUR CHEMISTRY
}

\section{EPOXY SULFONES}

II. OXIDATION OF SULFUR-STABILIZED CARBANIONS

III. $\alpha$-LITHIO SULFONES

\author{
by \\ John Michael Decesare
}

Thes is submitted to the School of Graduate

Studies in partial fulfillment for the requirements for the degree of Ph.D. in Chemistry

$$
\begin{gathered}
\text { University of Ottawa } \\
\text { Ottawa, Ontario }
\end{gathered}
$$

John Michael Decesare, 1979

(C) John Michael Decesare, Ottawa, Canada, 1980. 


\section{I \\ ABSTRACTS}

\section{PART I}

\section{Epoxy Sulfones}

$\gamma$ and $\delta$-Epoxy sulfones have been shown to undergo cyclization to 3-phenylsulfonylcycloalkanois upon treatment with 2 equivalents of $\mathrm{CH}_{3} \mathrm{MgI}$. It was found that the resultant cycloalkanols are formed in a highly stereospecific manner with the phenylsulfonyl and hydroxyl groups occupying a cis relationship to each other. This stereochemistry was determined by an $x$-ray structure determination on 3-pheny $1-3$-phenylsulfonylcyclobutanol. The cyclization reaction was found to require 2 equivalents of Grignard reagent.<smiles>[R]C(CC1CO1)C1CO1</smiles>

$$
n=1,2
$$

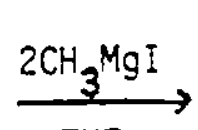

THF $-78^{\circ} \rightarrow \mathrm{RT}$

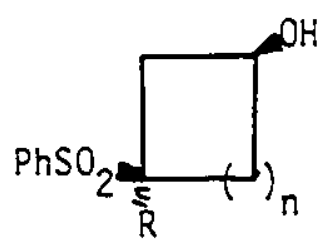

The parent cycloaikanols $(R=H)$ could be readily substituted in the 3-position by treatment with 2 equivalents of methyllithium followed by trapping with various electrophiles.

The 3-alkyl-3-phenylsulfonylcycloalkanols could be readily converted into cyclobutenones and cyclopent-2-enones by treatment with Jones 
reagent and then triethylamine.

The 3-phenyisulfonylcyclobutanols were readily desulfonylated by treatment with $6 \% \mathrm{Na}(\mathrm{Hg})$ amaigam.

Several mechanistic aspects of the Grignard induced epoxy suifone cyclization were also investigated. 
III

PART II

Oxidation of Sulfur-Stabilized Carbanions

The oxidation of $\alpha$-lithic sulfur-stabilized carbanions was attempted with several types of reagents. Oxidation of $\alpha-l i t h i o$ benzhydryl phenyl sulfone was found to proceed smoothly upon treatment with $\mathrm{O}_{2}$ or $\mathrm{S}_{S}$. The reaction with $S_{S}$ may constitute a potential method for the synches is of diary thioketones. Attempts to affect the desired oxidation of other sulfur-stabilized carbanions failed. 
V

\section{ACKNOWLEDGEMENTS}

I would like to thank the following :

Professor T. Durst for his guidance, extreme patience and enthusiasm throughout my studies:

Other members of the staff, especially Dr. Fraser and Dr. Alper for helpful suggestions and valuable advice;

Margie Glinski for the tedious task of proofreading;

Trudy Jones for the typing of the thesis;

My wife Dorothy for her encouragement.

$\hat{\oplus}$ 


\section{VI}

TABLE OF CONTENTS

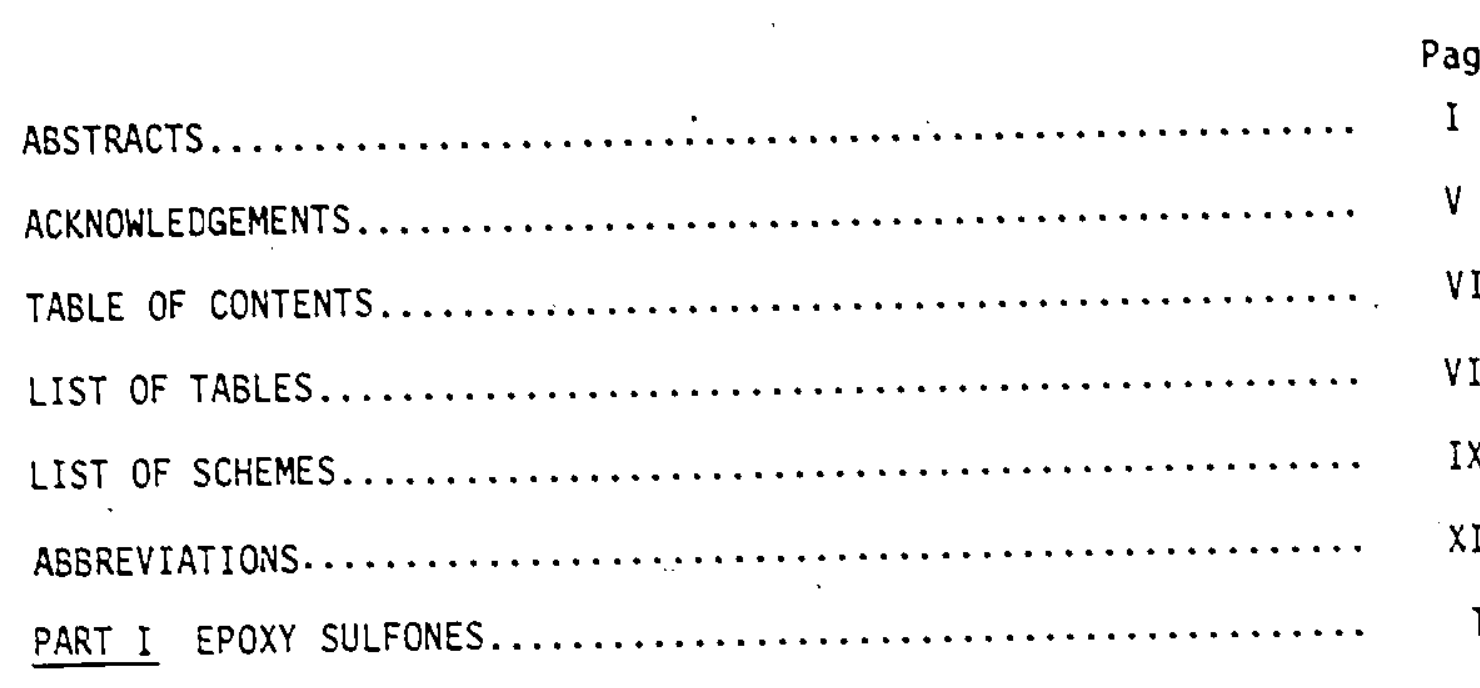

Introduction $. . \ldots \ldots \ldots \ldots \ldots \ldots \ldots \ldots \ldots \ldots \ldots \ldots \ldots, 2$

Results and Discussion.......................... 26

Preparation of Epoxy Sulfones....................... 31

Sase Induced Cyclizations........................... 41

Synthesis of Non-Sulfur Containing Derivatives............. 59

Attempted Cyclopropene Synthesis.................... 74

Stereochemistry and Mechanism....................... 78

Conclusions Regarding Epoxy Sulfone Cyclization............ 93

Grignard Induced Cyclization of Epoxy Nitriles and Epoxy

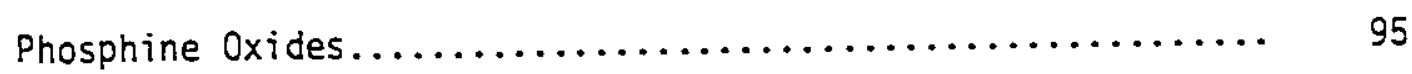

PART II OXIDATION OF SULFUR-STABILIZED CARBANIONS............. gو

Introduction................................... 100

Results and Discussion......................... 108

Conclusions................................. 114 
PART III $\alpha$-LITHIO SULFONES.

Introduction. ................................. 117

Synthes is of Starting Materials.................... IIs

Results and Discussion....................... 121

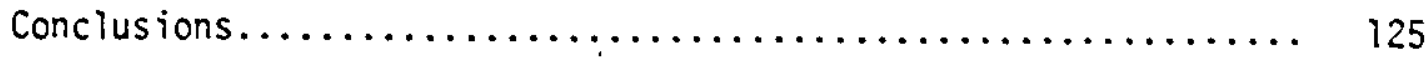

$I_{H}$ and ${ }^{13_{C}}$ NMR of $\alpha$-Sulfonyl Carbanions $\ldots \ldots \ldots \ldots \ldots \ldots \ldots . \ldots \ldots$

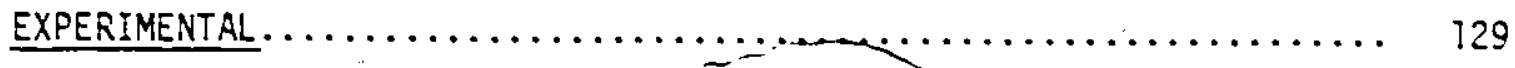

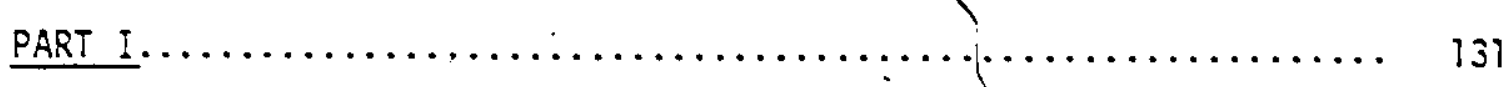

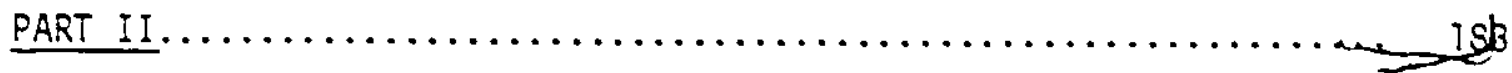

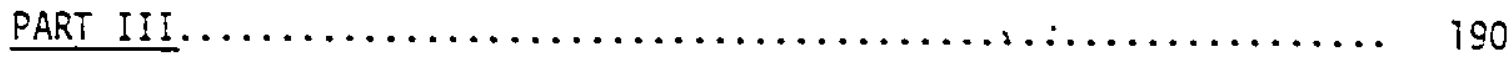

REFERENCES

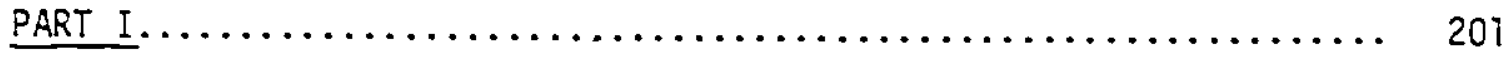

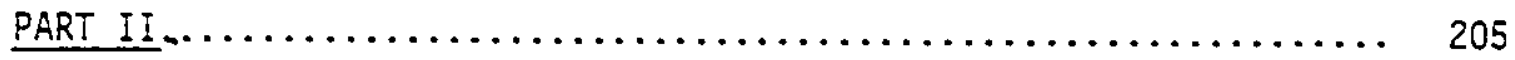

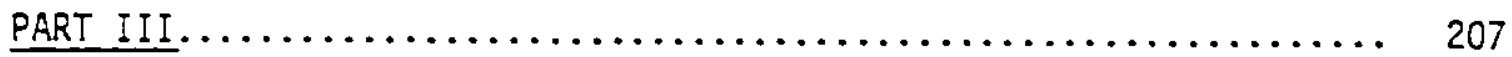

CLAIMS TO ORIGINAL RESEARCH...................... 208 


\section{VIII}

\section{LIST OF TABLES}

TABLE

PART I

I. Cyclization of S-Epoxy Ketones and Esters.............. 16

II. Sase Induced Cyclization of $\gamma$-Epoxy Sulfones.............. $2 S$.

III. Alkylation of 3 -Phenylsulfonyl Cycloalkanols............... 64

IV. Conversion of 3-Phenylsulfonyl Cycloalkanols into 3-Substituted Cyclobutenones and Cyclopent-2-enones.................. $6 i$

v. Synthetic Scope of Epoxy Sulfone Cyclization............... 69

VI. Base Requirement of Epoxy Sulfone Cyclization.............. 91 PART III

\section{\&}

I. ${ }^{13} \mathrm{C}$ MMR Data for Cis and Trans-2,6-Diphenyithiane-1,1-Dioxide. : 122 


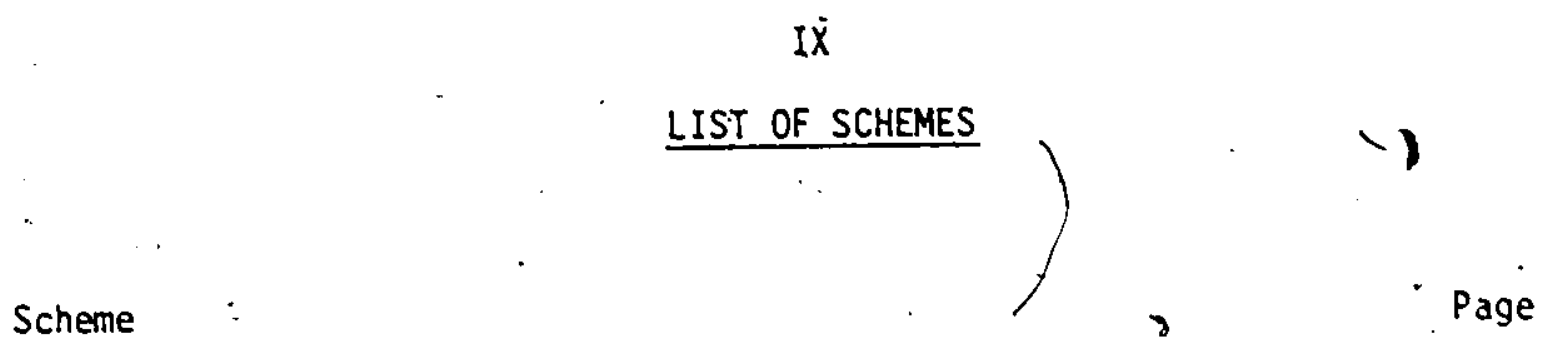

\section{PART I}

1. Mechanism for the Formation of 3-Phenylsuifonylcyclobutanol from the Grignard Induced Cyclization of 3-Phenyisulfonyl1,2 -epoxybutane................................. 29

2. Synthesis of 5 -Phenylsuifonyi-but-l-ene............. 31

3. Synthesis of 5-Phenylsulfonyl-1,2-epoxypentane.......... 33

4. Synthesis of Aldehydes 64 and $65 \ldots \ldots \ldots \ldots \ldots \ldots \ldots \ldots \ldots \ldots$

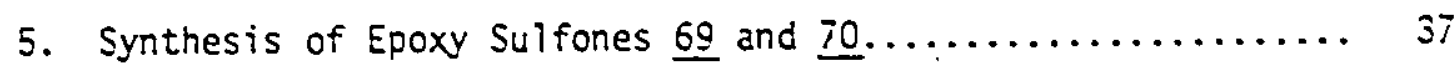

6. Stereochemical Course of $\gamma$-Epoxy Suifone Cyclization....... 43

7. "One-Pot" Preparation of Cyclobutanols and Cyclopentanols... 46

8. Mechanism for the "One-Pot" Preparation of 3-Phenylsulfony? cyclobutanols............................. 48

9. Mechanism for the "One-Pot" Preparation of 3-Phenyisulfonyl cyclopentanots............................. 49

10. Mechanism for the Formation of 2-Phenyl-3-Phenylsulfony? cyclopentanol............................... 53

i1. $\alpha, \beta$ - Unsaturated Ketones from $\varepsilon$-Keto Sulfones............ 60

12. Alkylation of 3 -Phenylsulfonylcycloalkanols........... 63

13. Potential Synthesis of 2,3-Disubstituted Cyclopentenones..... 68

14. Synthesis of Cyclobutenone....................... 70 


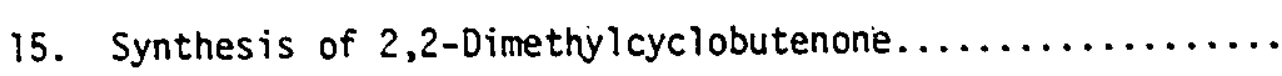

16. Mechanism for the Formation of 3-Phenylsulfonyl

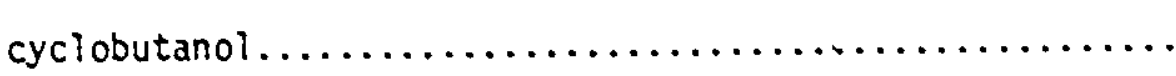

17. Mechanism for the Conversion of $\gamma$-Epoxy Sulfones into Cyclopropyl Methanols......................... 93 PART II

1. Conversion of Nitriles into Ketones $. . . \ldots \ldots \ldots \ldots . . . . .103$ PART III

1. Synthes is of 4-t-butylthiane-l,l-dioxide............. 120

2. Reaction of a-Lithio Suitone Carbanions with Electrophiles 124

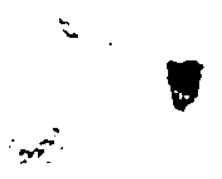




\section{ABBREVIATIONS}

IR - infrared

NMR - IH nucléar magnetic resonance

${ }^{13} \mathrm{C}$ NMR $-{ }^{3} \mathrm{C}$ nucléar magnetic resonance

TLC - thin layer chromatography

THF - tetrahydrofuran

MCPEA - m-chloroperbenzoic acid

MeLi - methyllithium

M.S. - mass spectrum

$\mathrm{M}^{+}$- parent molecular ion

$\mathrm{LiAlH}_{4}$ - Tithium aluminum hydride

TEBA - triethylbenzylammonium chloride

LDA - lithium diisopropyl amide

DMSO - dimethylsulfoxide

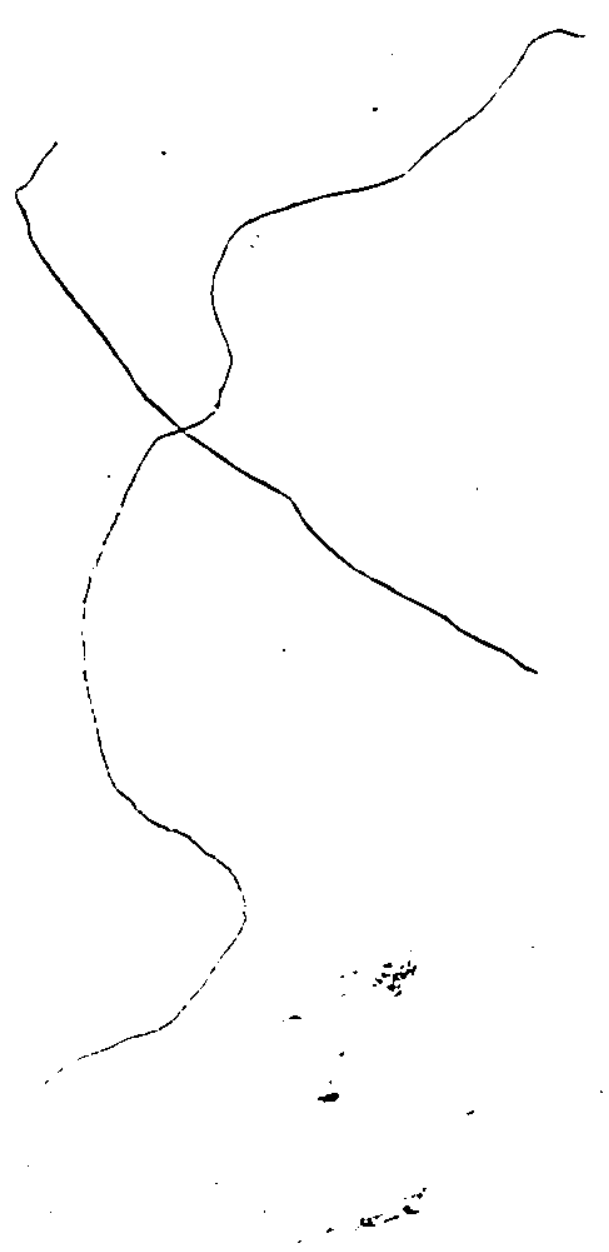


$-1-$

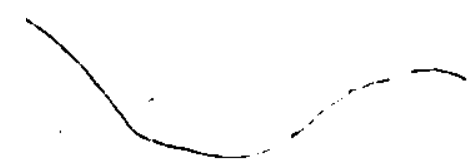

\section{PART I}

EPOXY SULFONES 


\section{INTRODUCTION}

The intermolecular reaction of epoxides with nucleophiles has been extensively studied, both from a synthetic and a mechanistic point of view $(1-3)$.

The intramolecular reaction, which has received far less attention, has been shown to be synthetically useful in the construction of various ring systems. The reaction of interest can be generalized as depictediow.
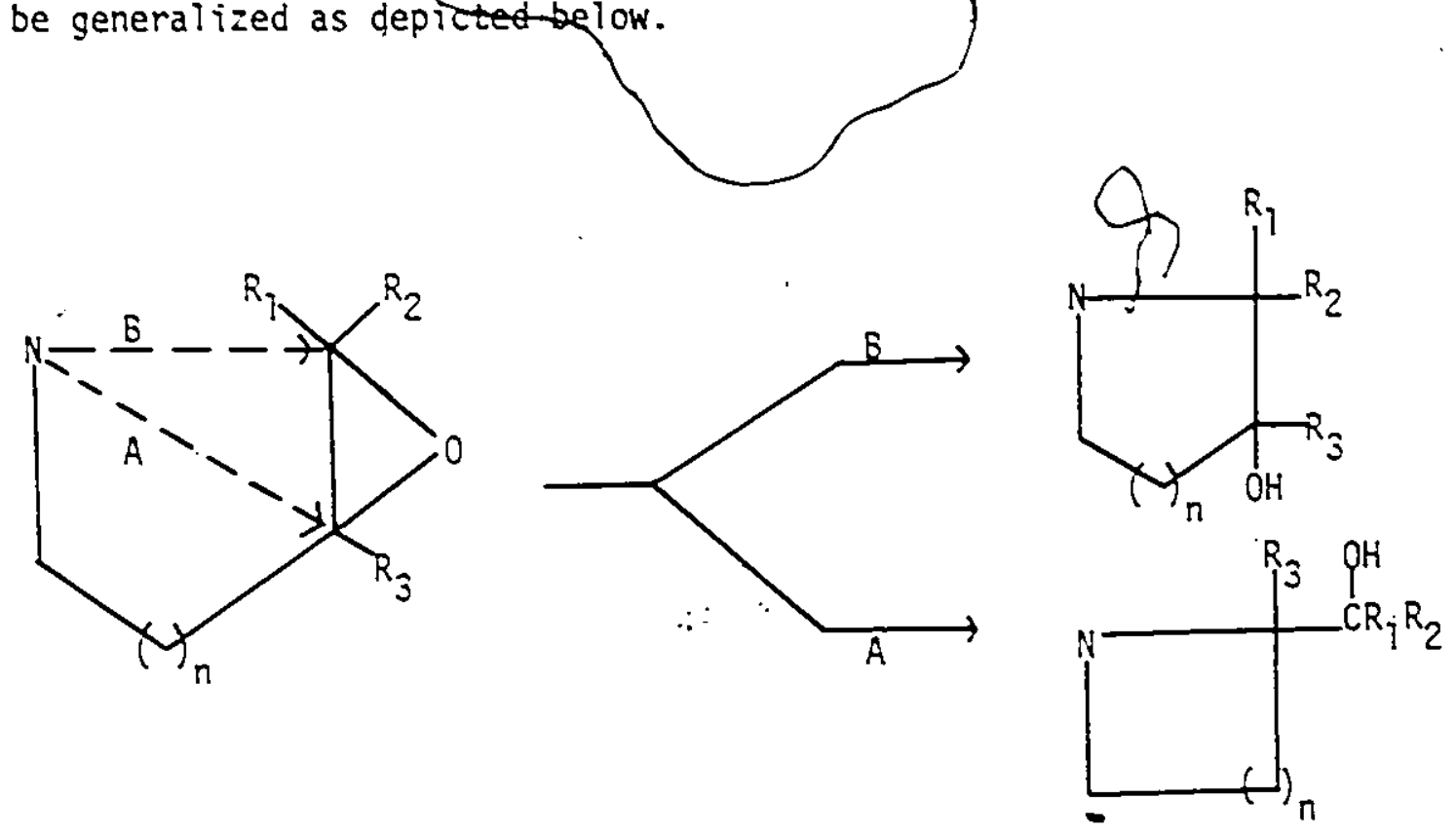

Two modes of attack by the internal nucleophile (N) on the epoxide ring may be envisaged. One, involving attack at the near end of the epoxide may be termed exo-cyclization (PATH A) and the other, involving attack at the more remote position of the epoxide (PATH B), endo-cyclization. It is instructive to examine the stereolectronic requirements of both these ring forring processes. 
Exo-Cyclization: (PATH A)

This process corresponds closely to the Baldwin (4) exotetrahedral and exo-trigonal ring forming cyclizations; both of which are favoured processes for the ring sizes 3 to 7 .
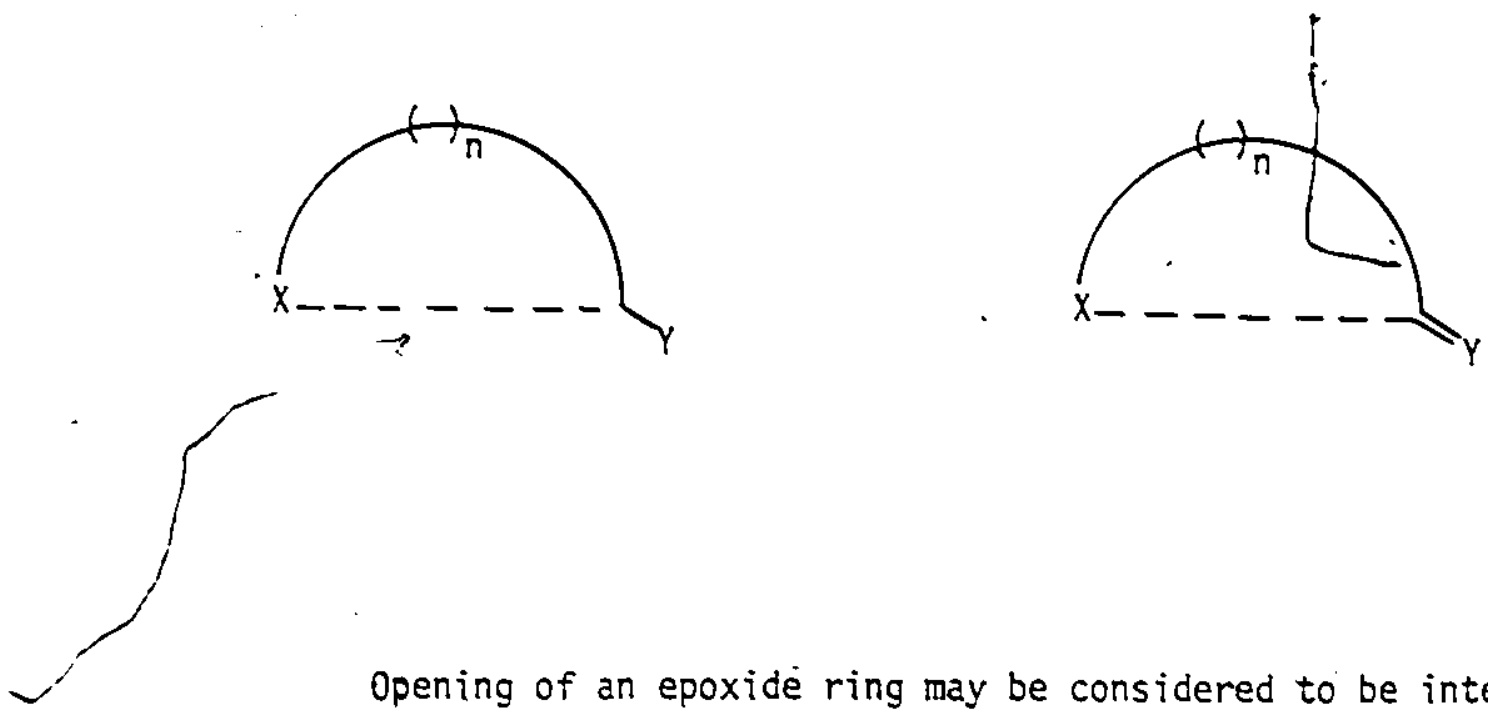

Opening of an epoxide ring may be considered to be intermediate between these two ring closures and no problem is encountered in satisfying the stereolectronic demands for the exo-transition state. The required colinearity between the incoming nucleophile and the oxirane oxygen is easily attained for $n=2,3,4,5,6$.

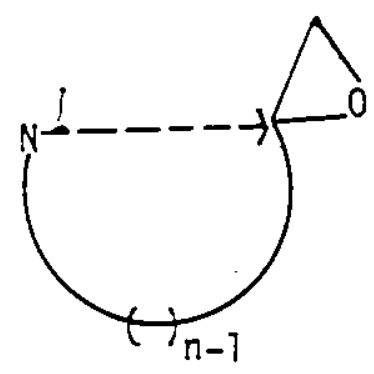


The relative ease of ring closure is thus expected to follow the well established trend of $3>5>6>7,4$. (5)

Endo-Cyclization (PATH B)

In this mode of opening of the epoxide the colinearity requirement is not as easily met. For example, closure of the epoxide I requires considerable bond distortion in order to attain the proper geometry for backside attack. Formation of a six-membered ring $2 \underline{2}$ via this pathway seems to be more feasible. Formation of a four-membered ring from epoxide $\underline{3}$ is not possible.

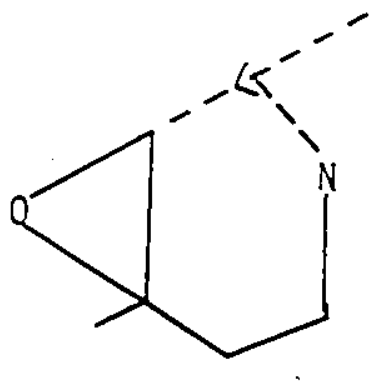

I

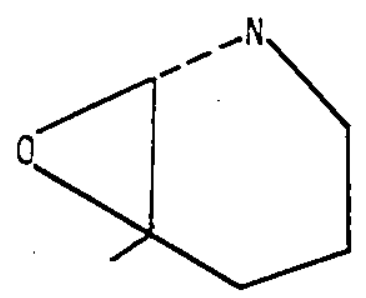

2

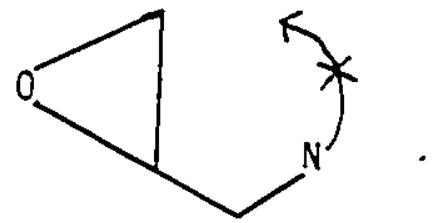

$\underline{3}$

The importance of this col inearity requirement was first demonstrated by Eschenmoser (6). He reported that under all conditions studied methyl transfer of $\underline{4}$ to $\underline{5}$ proceeds intermoleculariy. This was ascribed to the difficulty of effecting backside displacement by the anion $\underline{6}$. Intramolecular transfer would have required an $\mathrm{S}_{i j} 2$ substitution at the methyl carbon with retention of configuration. 
$-5-$

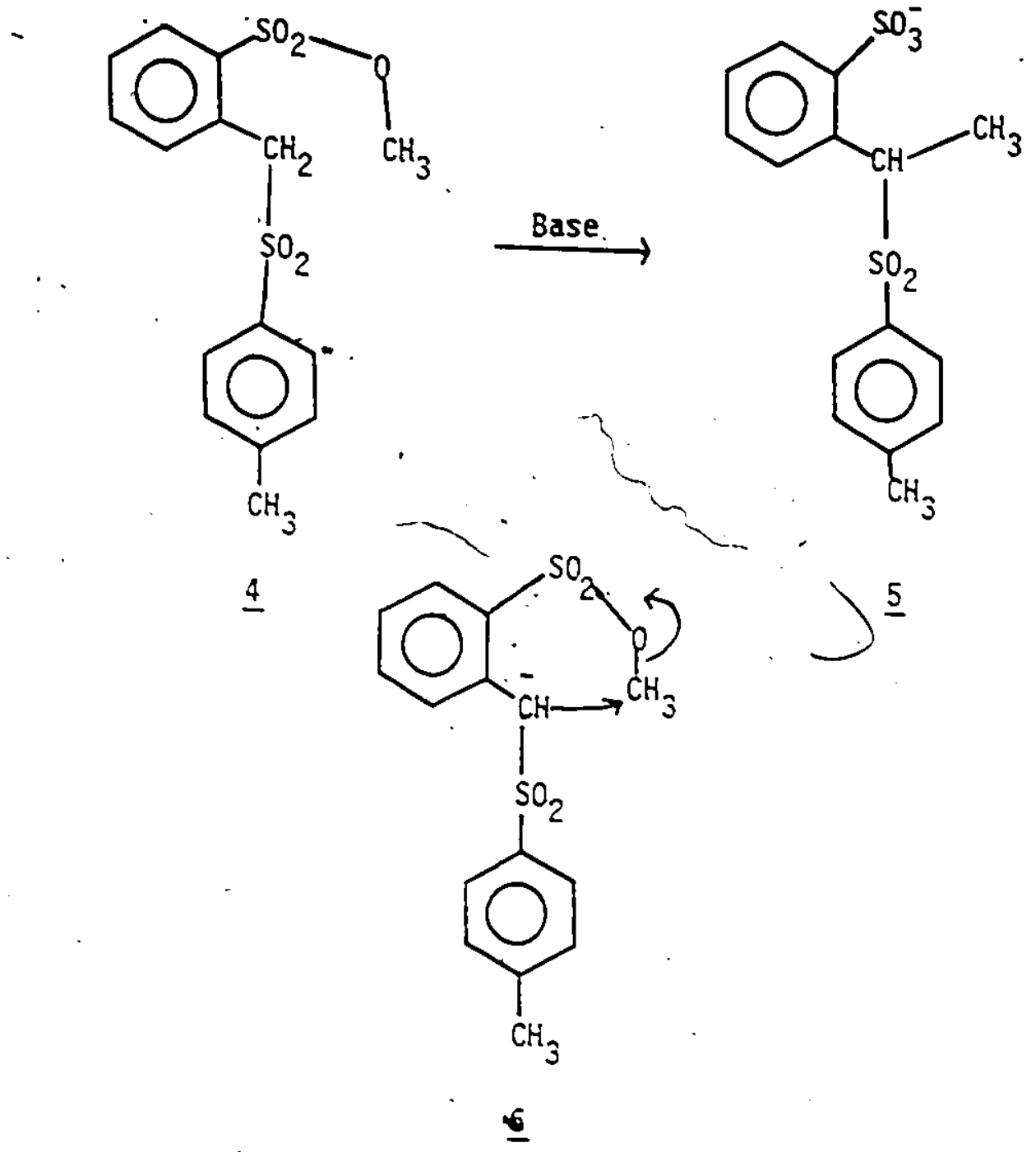

The exo mode of cyclization would be predicted, a priori, to be the preferred pathway, however, other factors need to be considered such as epoxide stereochemistry, relative degree of substitution on the epoxide, nature of the nuclegptiile and solvent effects.

These will be illustrated examination of the relevant iterature in this field. Reactions will be classified according to the nature of the nucleophile.

(i) Stabilized Carbanion Nucleophiles

(ii) Heteroatom Nucleophiles 
(i) Stabirized Carbanion Nucleophiles

Epoxy Nitriles

The major impetus for the development of the intramolecular epoxide cyclization*. reaction as an important synthetic tool came from the work reported by Stork and coworkers $(7,5)$. These authors showed that the regiochemistry of the reaction is controlled both by the substitution pattern of the epoxide and the colinearity requirement. Thus, they found that treatment of rigid epoxides of type $\underline{I}$ with one equivalent of potassium amide in liquid ammonia-glyme resulted in attack of the carbanion at the more remote position of the epoxide ring leading to formation of the hydroxy nitriles $\underline{\mathrm{S}}$. The cis ring junction follows from the mode of ring opening.

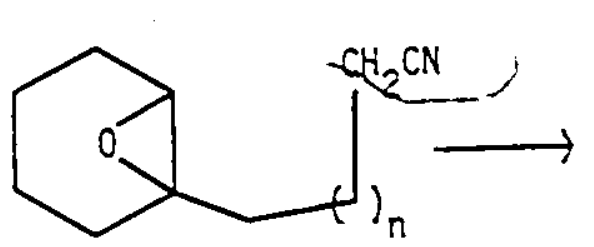

I $n=1,2$

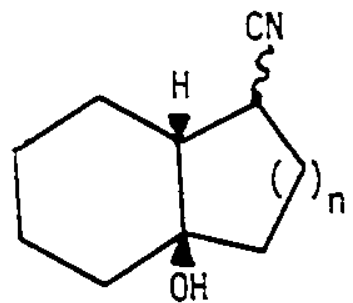

$\underline{8}$

$n=1 \quad 75 \%$

$n=2 \quad 70 \%$

* intramolecular epoxide cyclization will be used to refer to formation

- of a cycle via intramolecular attack of a nucleophile on an epoxide. 
The preference for the formation of the larger ring was ascribed to the steric/constraints imposed on the system with attack at the quaternary centre being less favourable than that at a tertiary carbon. It was also noted that the six-membered ring was formed considerably faster than the five-membered ring ( $2 \mathrm{hr}$. vs $7 \mathrm{~min}$.$) . This was$ rationalized in terms of the aforementioned colinearity requirement. ie. easier attainment of colinearity in the formation of a six membered ring via endo attack.

With equal substitution on the epoxide ring exo attack was found to be preferred as is shown in the conversion of 9 to 10 .
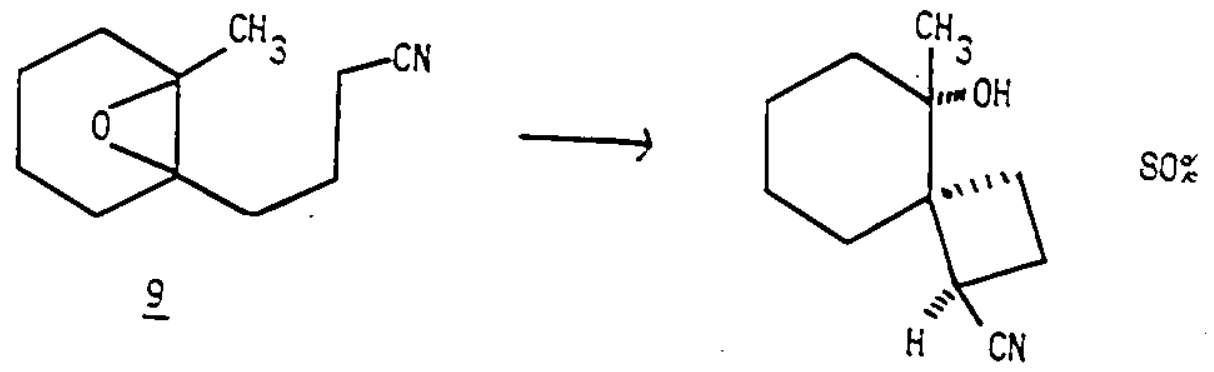

10

Stork also studied the cyclization of non-rigid epoxy nitriles. The overall results are presented below. 

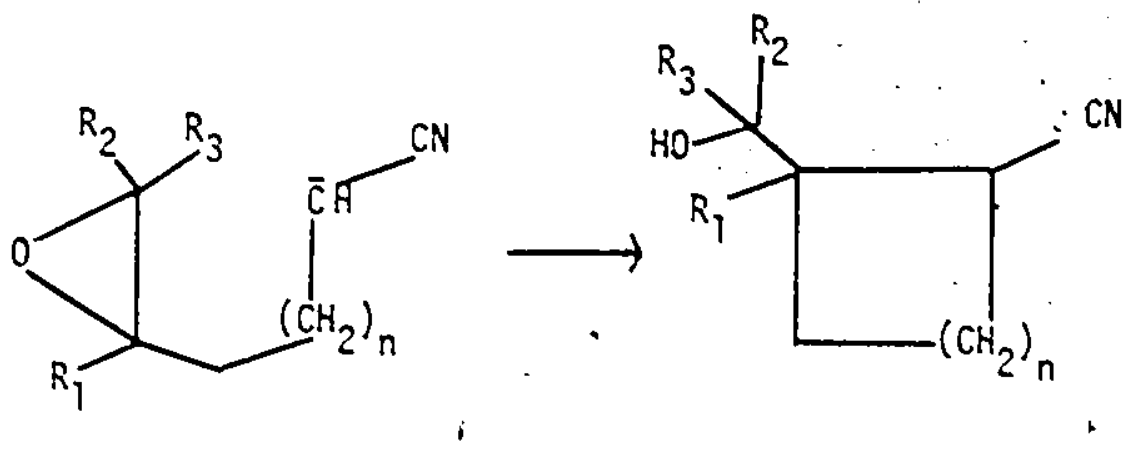

$$
\begin{aligned}
& \left.\left.R_{1}, R_{2}=H ; R_{3}=a\right\rceil k y\right\rceil \\
& \left.\left.R_{1}=H ; R_{2}, R_{3}=a\right\rceil k y\right\rceil \\
& \left.R_{1}, R_{2}, R_{3}=a\right\rceil k y l^{\prime}
\end{aligned}
$$

$$
n=0,1,2,3
$$

In the case of $n=0$, cyclopropanes are formed exclusively, regardless of the degree of substitution on the epoxide ring. This is not surprising since endo attack to form a four membered ring is most unilikely $(n=1,2,3)$. Stork came to the conclusion that with equal substitution on the epoxide ring the smaller ring is always formed preferrentialiy (exo attack). The case of $(n=1)$ merits special attention since this constitutes a non-photochemical synthesis of fourmembered rings.

The use of an epoxide cyclization reaction to form a four membered ring had been previously reported ( 9 ) in the synthesis of the tricyclo-octane system 11 . 

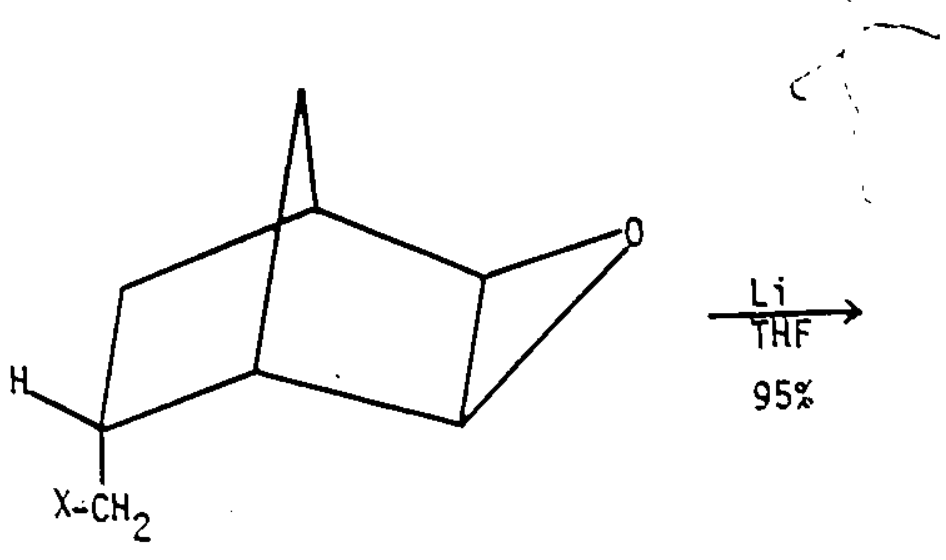

$\mathrm{x}=\mathrm{Br}, \mathrm{Cl}$

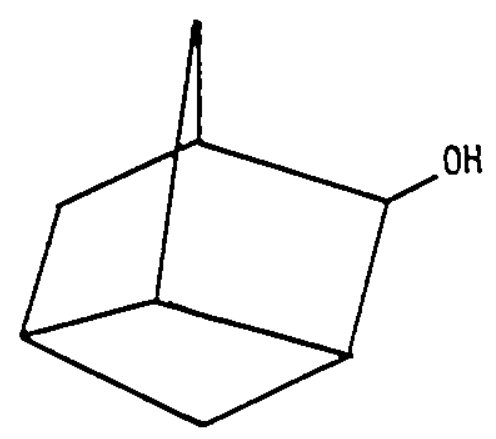

II

Stork demonstrated the utility of the epoxy nitrile cyclization by a synthesis of the sex phermone $(t)$ grandisol 14 . The key step was cyclization of the epoxy nitrile 12 to the trans-cyclobutane derivative 13.

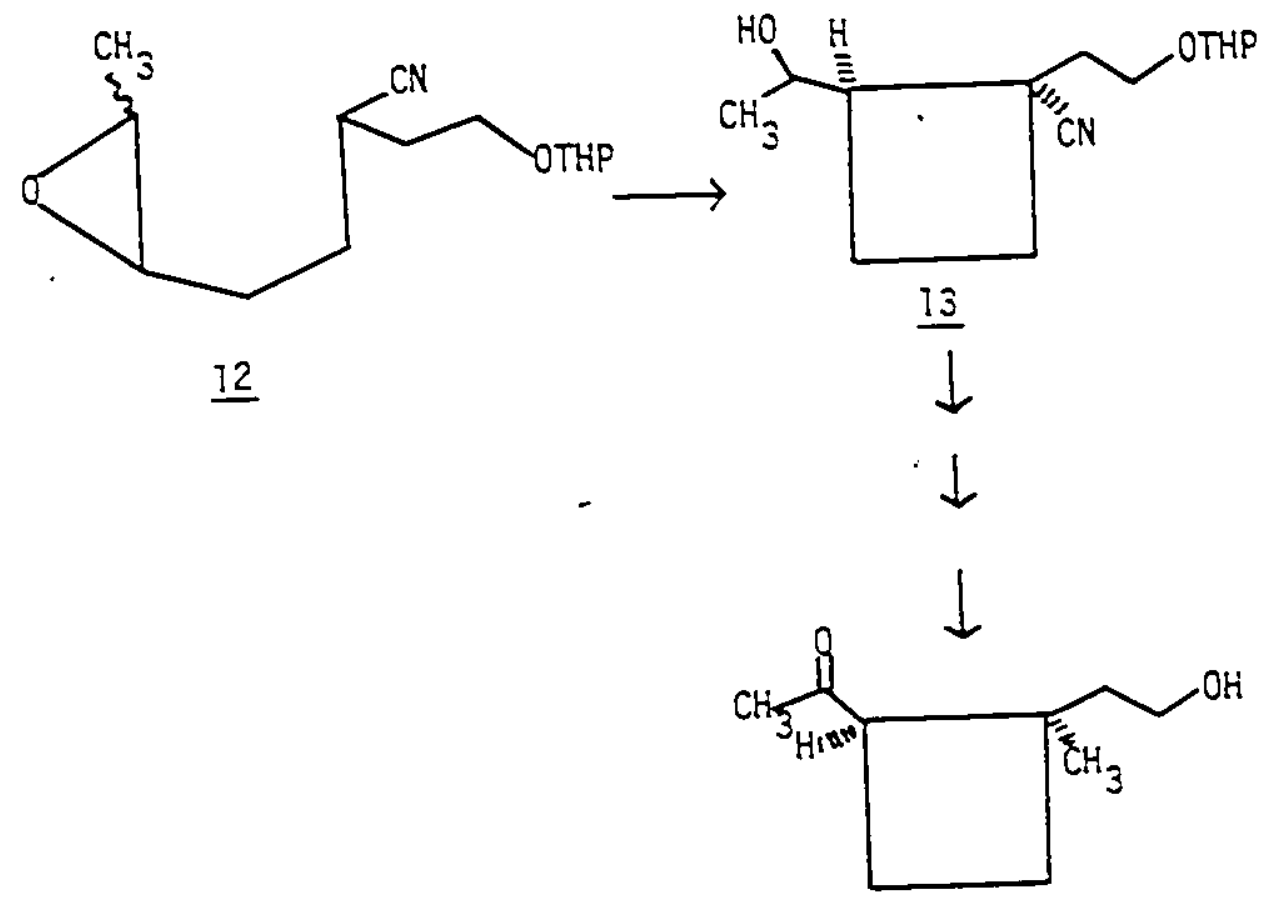


Stork's conclusions regarding epoxy nitrile cyclizations were later challenged by Lallemand and Onanga (10). These authors concluded that the stereochemistry about the epoxide ring is the important factor in controlling the regiochemistry in epoxy nitrile cyclizations. Thus, they reported that treatment of the cis epoxide 15 with sodamide in THF gave only the cyclobutane derivative 16 .

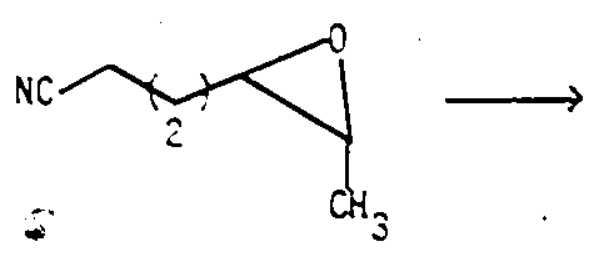

$\underline{15}$

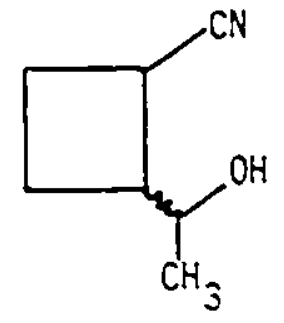

$\underline{16}$

$\bullet$

In contrast, reaction of the trans epoxide 17 under identical conditions, resulted in the fomation of both four and five-membered ring products 16 and $\underline{18}$ with the five-membered ring predominating in an approximately $2: 1$ ratio.<smiles>CC1OC1CCC#N</smiles>

17

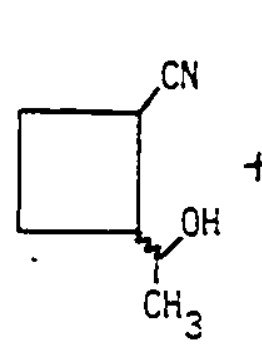

16<smiles>C[C]1C(Cl)CC[C@@H]1O</smiles>

18 
The authors suggested that these results can be explained on steric grounds. In the case of the cis epoxide 15 attack at $\mathbf{C}-5$ is hindered by the presence of the methyl group, whereas in the case of the trans epoxide 17 no steric hinderance to attack is present. The observed product distribution from the reaction of the trans epoxide 17 was suggested to arise from a combination of "statistical and geometric factors".

An examination of molecular models suggests that a similar amount of steric shielding is present in both the cis and trans epoxides with respect to attack at $\mathrm{C}-5$. The Lallemand and Onanga results thus appear difficult to rationalize and a closer scrutiny of the role of epoxide stereochemistry in the reaction appears justified.

Other workers have made use of the epoxy nitrile cycilization reaction in synthesis. For example, Achini and Oppoizer (11) showed that treatment of epoxy aminonitriles 19 with potassium amide in liquid ammonia-ether for $1 \mathrm{hr}$. at $-60^{\circ} \mathrm{C}$ lead to formion of the pyrrolidine derivatives 20 in yields of $63-67 \%$.

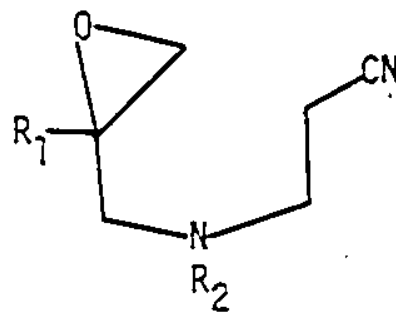

$\underline{19}$
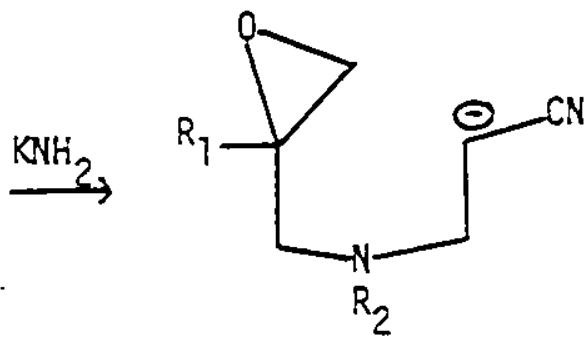

$\underline{19 a-i}$

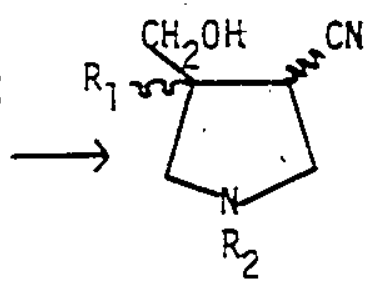

$\underline{20}$ 
Attack of the nitrile-stabilized carbanions 19a was found to occur exclusively at the more substituted carbon atoms of the epoxide rings. This is in contrast to Stork's observations that similarily substituted epoxy nitriles give six-membered rings preferentially. The possibility of participation of the nitrogen atom in the above systems could be considered.

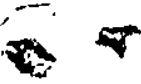

\section{Epoxy Sulfides}

Intramolecular cyclization of epoxy suifides has been shown to be useful in the synthesis of medium ring and macrocyclic terpenoids. Thus, Kodama et al (12) reported that reaction of the epoxy sulfide 21 with $n=b u t y l l i t h i u m$ at $-7 S^{\circ}$, in the presence of DABCD, leads to the monocyclic alcohol $22 a$ in $62 \%$ yield. Desulfurization of $22 a$ with iithium-ethylamine afforded the fourteen-membered ring diterpene $( \pm)$ nephtenol $22 \mathrm{~b}$ in $30 \%$ yield. Dehydration of $\underline{22 b}$ with thionyl chloride in pyridine furnished the tetraene 23 in $95 \%$ yield.

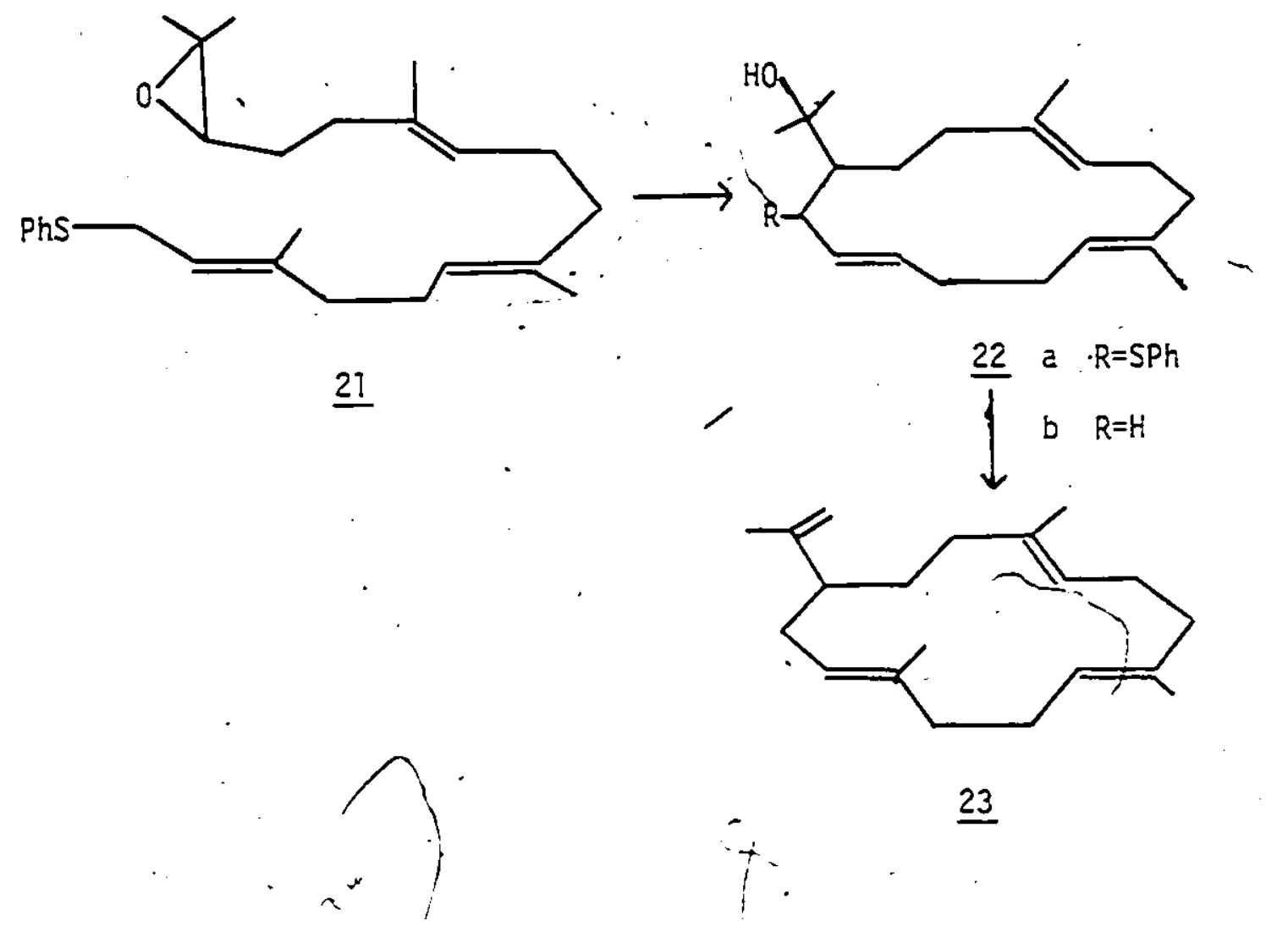


Such an approach has also been used in the synthesis of the $6 E(13)$ and $6 Z$ (14) isomers of hedycaryols.

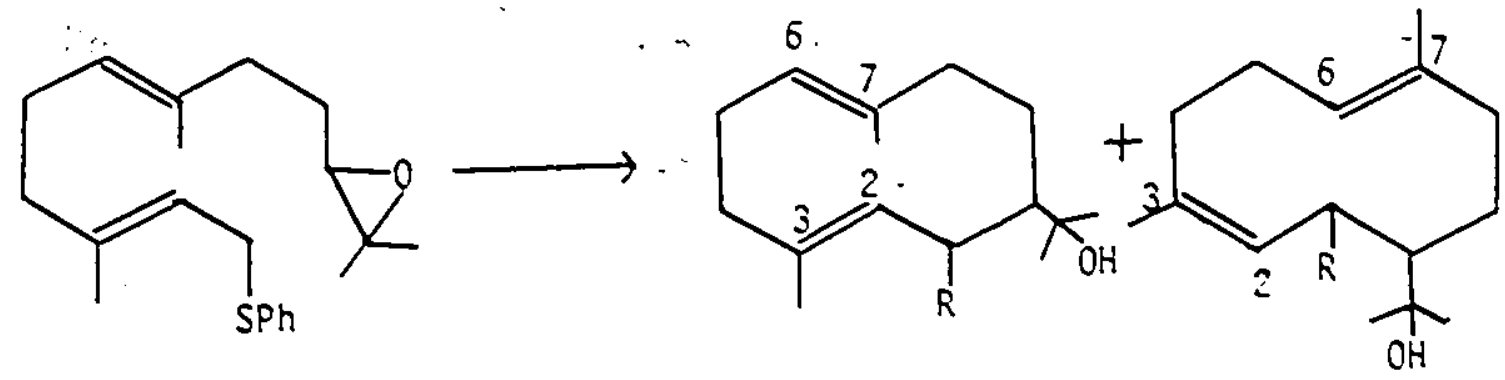

(2E, 6E)

$(2 z, 6 E)$

$\because \quad 35 \% \quad 25 \%$
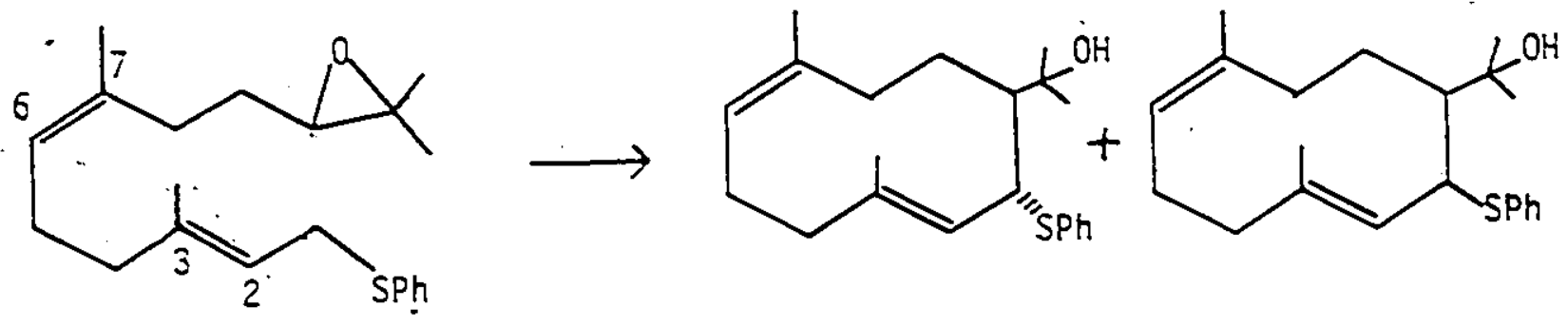

(2E, 6Z)

(2E, 6Z)

$35 \%$

$15 \%$ 
In another study by Rautenstrauch, (15) reaction of the geranyl derivative 24 with butyllithium in THF resulted in the formation of a complex mixture of products in $65 \%$ overall yield. The reaction exhibited neither regio- or stereosedectivity.
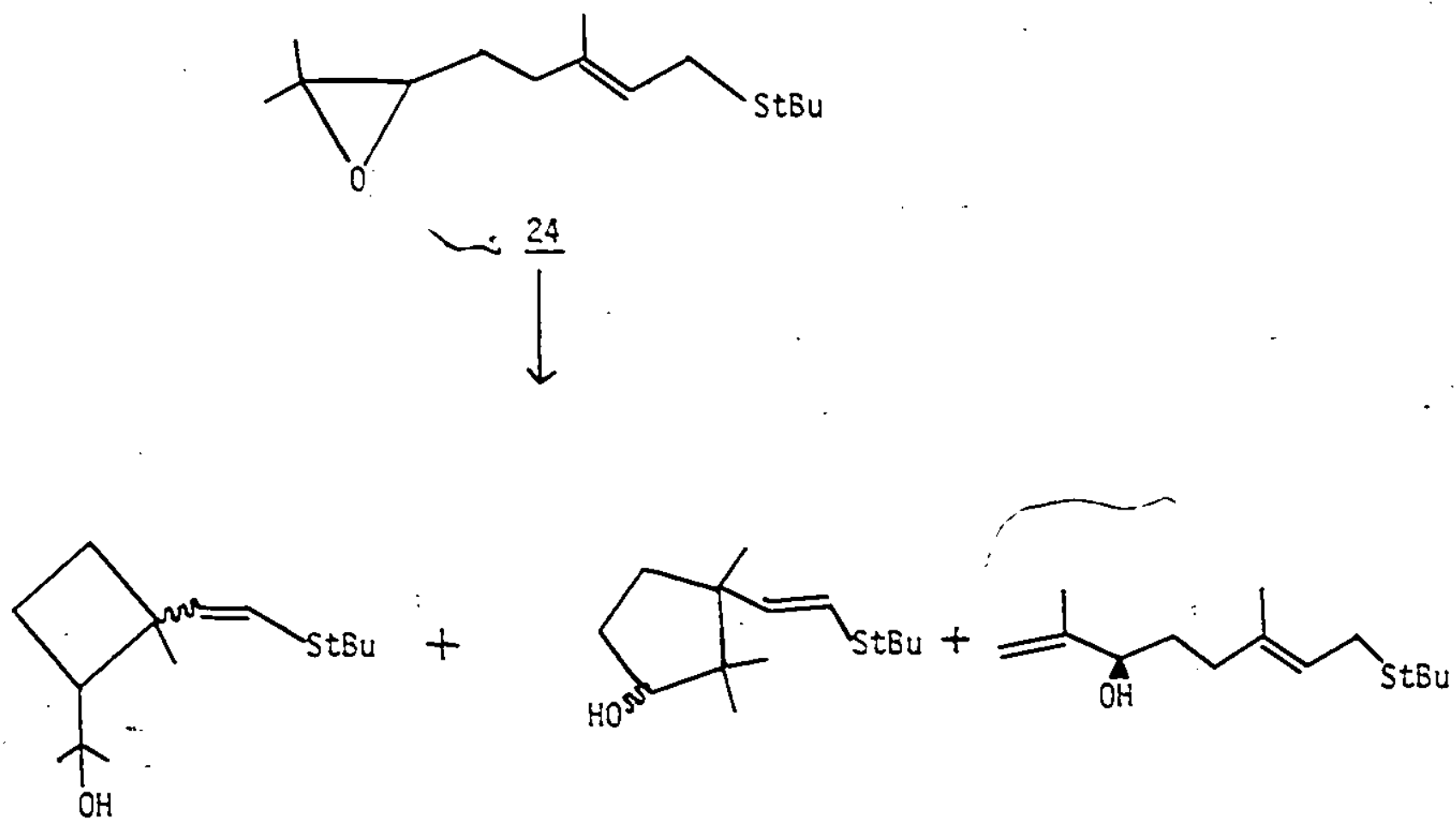


\section{Epoxy Ketones and Esters}

The reaction of $\mathrm{Y}$-epoxy ketones with bases ( $\mathrm{NaOH}, \mathrm{KOtBu}$ ) yields invariably, via C-alkylation, the corresponding cyclopropyi derivatives (16). 0-alkylation leading to the dihydrofuran and pyran derivative is not competitive with cyclopropane ring fomation.

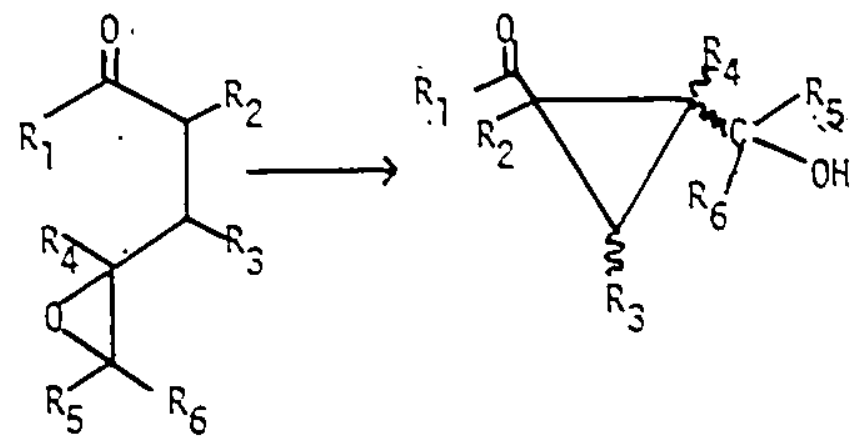

The corresponding $r$-epoxy esters were found to behave similarily.

The reaction products from $\delta$-epoxy diesters or keto esters under basic conditions were found to depend markedly on the nature of the substituents which stabilized the carbanion $(17,18)$. These results are sumarized in Table $I$. 
TABLE I

Cyclization of $\delta$-Epoxy Ketones and Esters

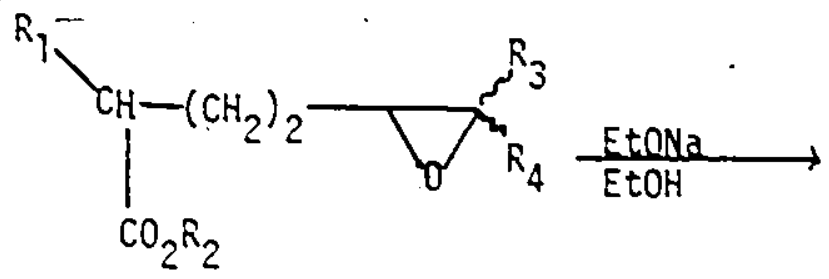

\begin{tabular}{|l|l|l|l|l|}
\hline $\mathrm{R}_{1}$ & $\mathrm{R}_{2}$ & $\mathrm{R}_{3}$ & $\mathrm{R}_{4}$ & \\
\hline $\mathrm{CO}_{2} \mathrm{CH}_{3}$ & $\mathrm{CH}_{3}$ & $\mathrm{CH}_{3}$ & $\mathrm{CH}_{3}$ & \\
\hline $\mathrm{CO}_{2} \mathrm{Et}$ & $\mathrm{Et}$ & $\mathrm{H}$ & $\mathrm{H}$ & \\
\hline $\mathrm{C}_{6} \mathrm{H}_{5} \mathrm{CO}$ & $\mathrm{Et}$ & $\mathrm{H}$ & $\mathrm{H}$ & $\mathrm{N}$ \\
\hline $\mathrm{CH}_{3} \mathrm{CO}$ & $\mathrm{CH}_{3}$ & $\mathrm{CH}_{3}$ & $\mathrm{CH}_{3}$ & \\
\hline
\end{tabular}


Epoxy ketones have found application in the synthesis of the sabina ketone $\underline{25}(19)$ and the norcarone $\underline{26}(20)$..
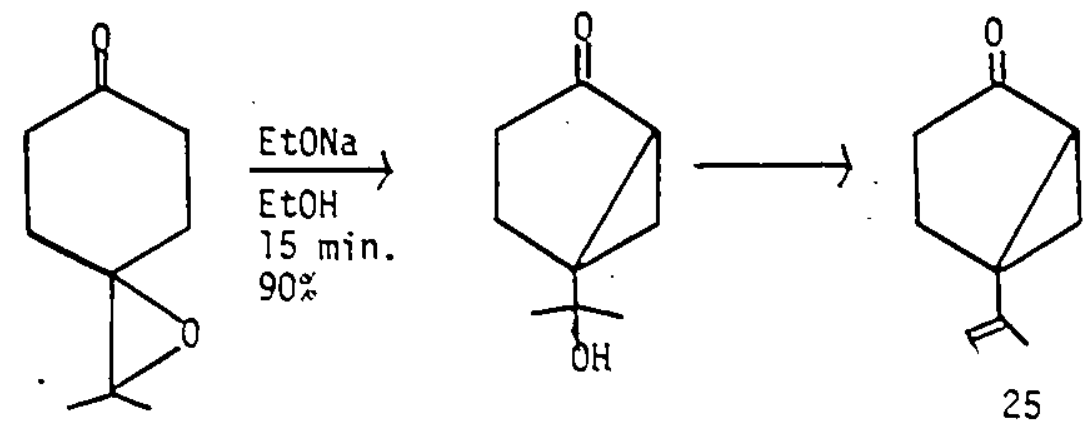

\section{$\underline{25}$}
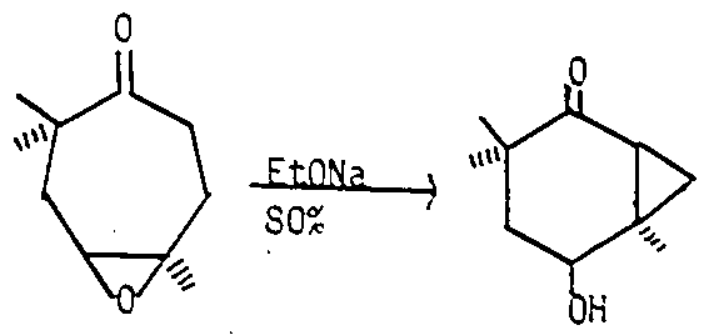

$\underline{26}$

More remote cyclizations have also been shown to be possible. For example, Hodgson et al (21) reported that treatment of the epoxy ketone 27 with potassium t-butoxide/t-butanol resulted in an $80 \%$ yield of the tricyclic system 28 .

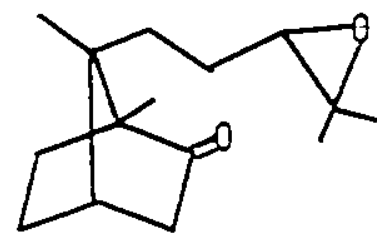

27

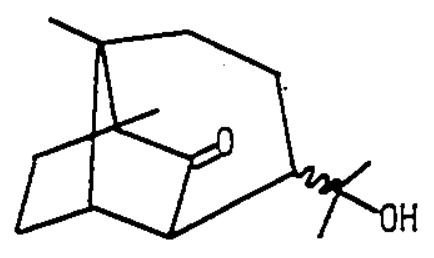

$\underline{28}$ 
The key step in one approach (22) to the total synthes is of trans-chrysanthemic acid 31 was the base-promoted cyclization of the epoxy ester 29 furnishing the trans-cyclopropane $\underline{30}$.

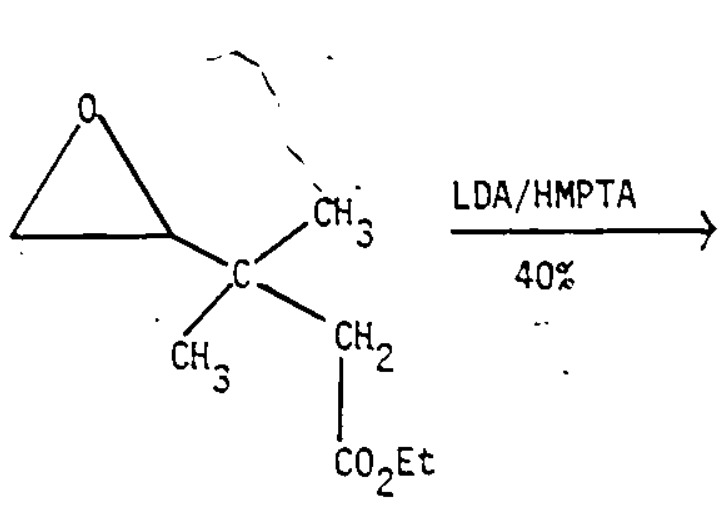

$\underline{29}$
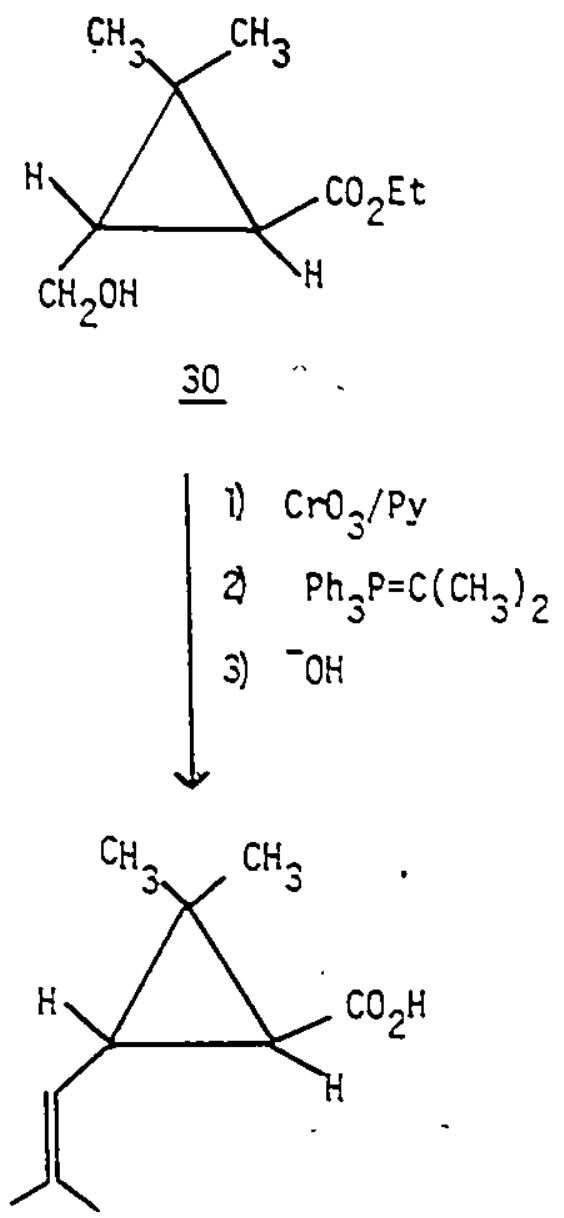

31 
Epoxy Phosphonium Ylides

In 1977 Turcant and Le Carre (23) reported the first examples of the involvement of phosphorus stabilized anions in an epoxide cyclization reaction. These authors studied the cyclization of epoxy phosphonium ylides of type $\underline{32}$.

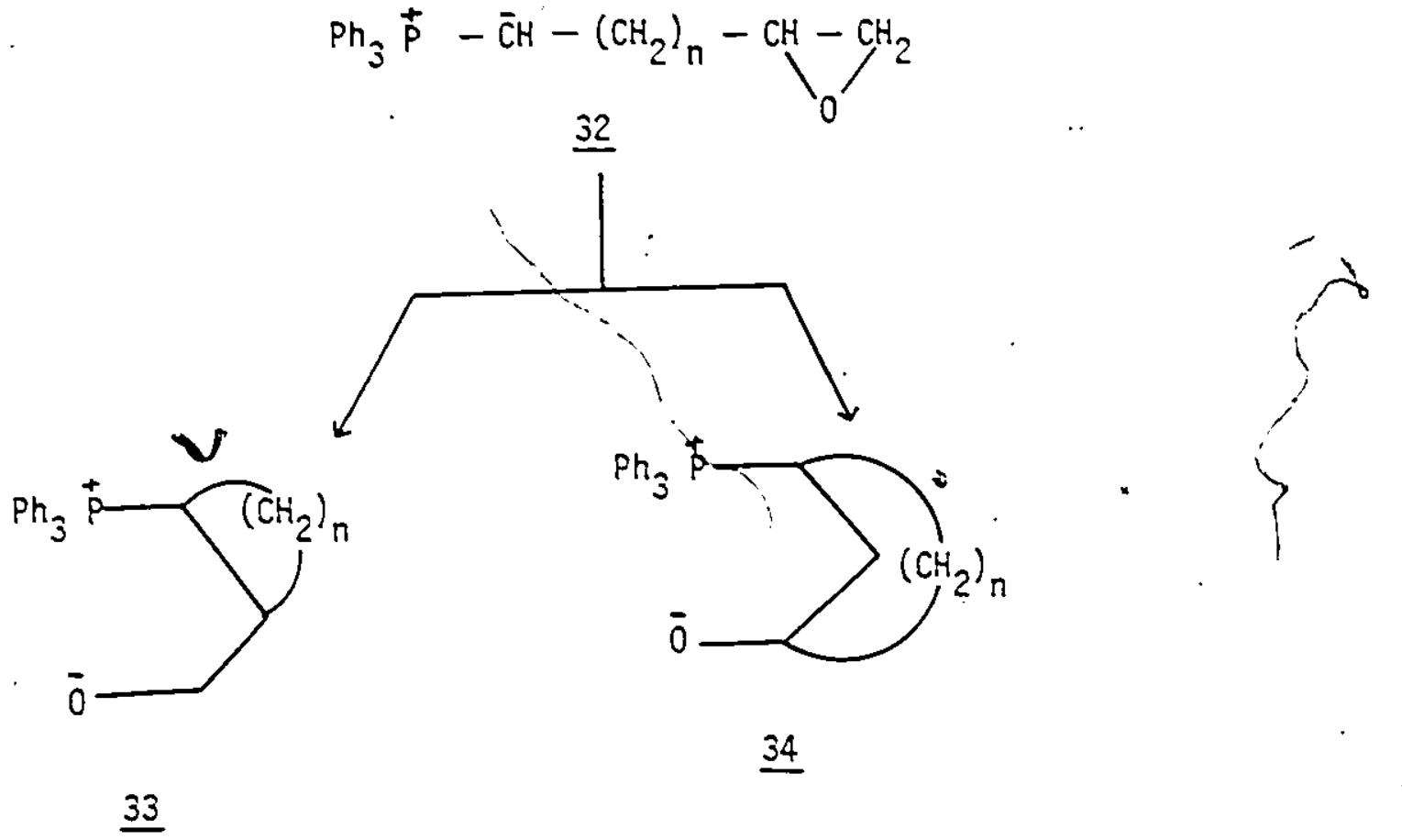

Two types of cyclization products, $\underline{33}$ and $\underline{34}$ were observed. The results obtained by these authors are presented below. 
Cyclization of Epoxy Phosphonium Ylides 32

\begin{tabular}{|c|c|c|c|}
\hline$\underline{\mathrm{n}}$ & \multicolumn{2}{|c|}{ Relative Yields } & Total Yields \\
\hline 1 & $\underline{33}$ & $\underline{34}$ & $\frac{33}{\underline{3}}+\underline{34}$ \\
\hline 2 & 100 & 0 & 90 \\
\hline 3 & 20 & 50 & 56 \\
\hline 4 & 60 & 40 & 43 \\
\hline
\end{tabular}

As expected, when $n=1$ the cyclopropane derivative is the only product. The other cases $(n=2,3,4)$ seem anomalous. Particularly unusual is the exclusive formation of the seven-membered ring vs the six membered ring when $n=4$. In general, it appears that attack at the unsubstituted terminal carbon is preferred possibly due to steric hindrance involving the large triphenyiphosphonium group. 
(ii) Heteroatom Nucieophiles

\section{Epoxy Mercaptans}

Johnson et al (24) reported that cyclization of the epoxy mercaptide $\underline{35}$ furnished 2-thianorbornan-6-ol $\underline{36}$ in $23 \%$ yieid.

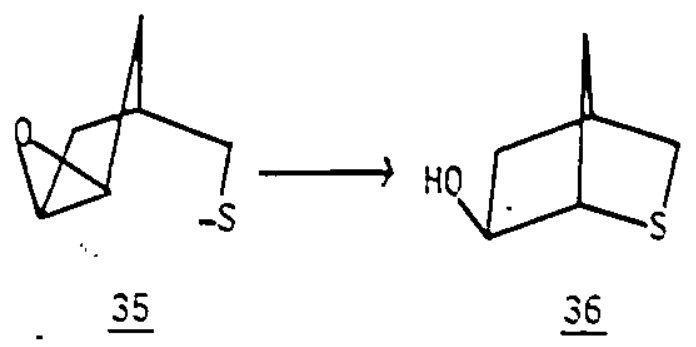

Epoxy Amides

Synthesis of the azaadamantol system 39 was effected by ring closure of the epoxy amide $3 \bar{j}$ to the amide alcohol $3 S$ which was subsequently reduced with diborane in THF (25).
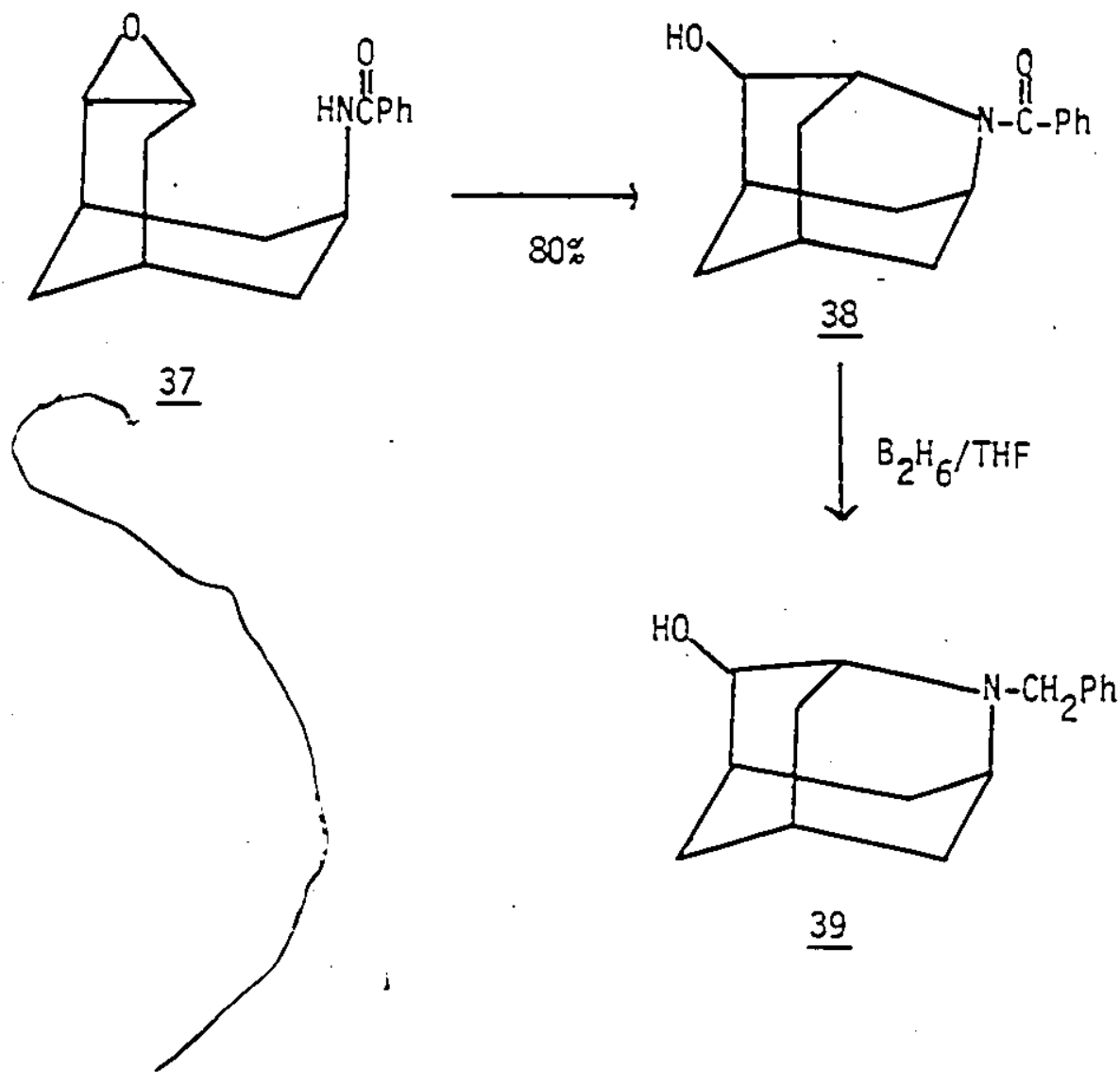

$\underline{39}$ 


\section{Epoxy Alcohols}

Epoxy alcohols have received considerable attention in many diverse areas. Thus, Spurlock and Fayter (26) obtained 2-oxa-aorboran-6-ol 41 via potassium t-butoxide promoted ring closure of the epoxy alcohol $\underline{40}$.

$\because$

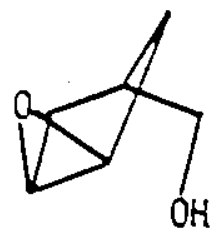

40

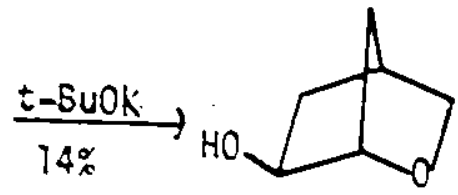

41

The carbohydrate literature is replete with examples of the opening of an oxirane ring by an appropriately situated hydroxyl group (2i). Migrations of the epoxide ring in systems of type 42 are well known.
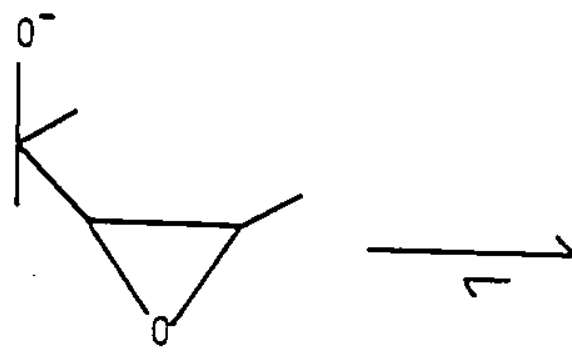

$\underline{42}$

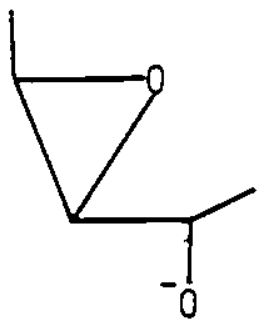

$s$<smiles>CC</smiles> 
Many examples of more remote cyclizations are available. For example, reaction of the $\underline{D}$-galactoside $\underline{43}$ with base afforded the $\underline{D}$-gulopyranoside 44 .

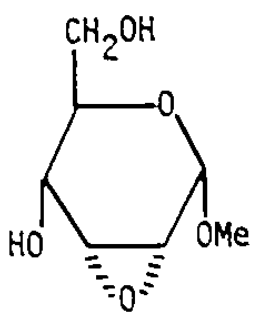

$\underline{43}$

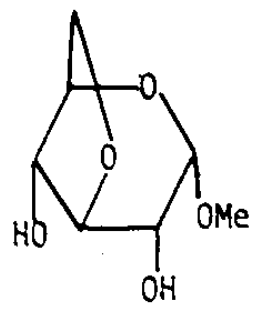

44

运

Another area of investigation was the synthes is (2S) of the chromanol derivative 47 . The formation of 47 by reaction of 45 with dimethyisulfonium methyi ide presumably occurs through the intermediacy of the epoxy alkoxide 46 .

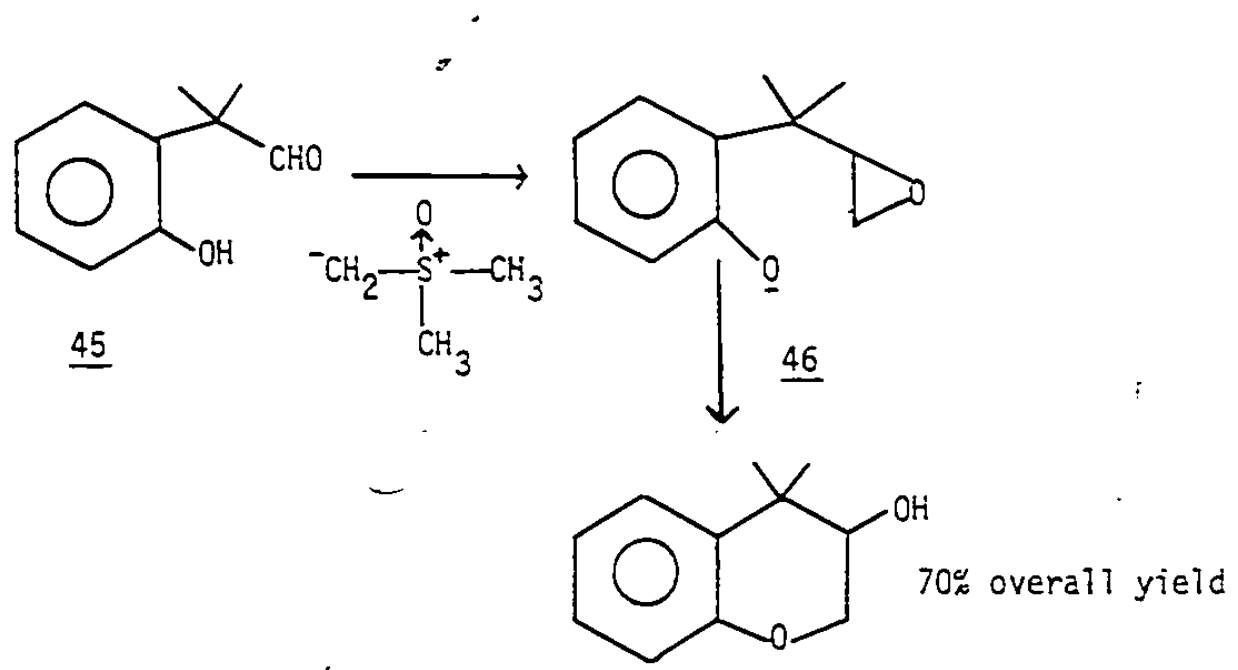


Masamune et al (29) reported that epoxy alcohols of the type 48 react with ten equivalents of KOH in aqueous DMSO to furnish tha oxetane derivatives $\underline{49}$ as the sole cyclization products. No five membered ring products were observed.

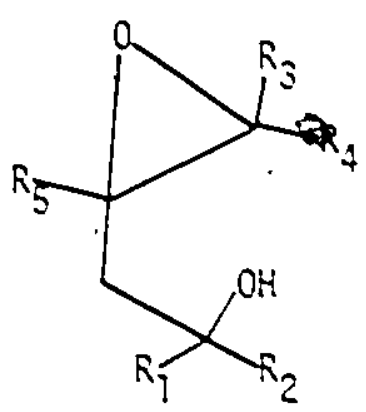

$\underline{4 S}$

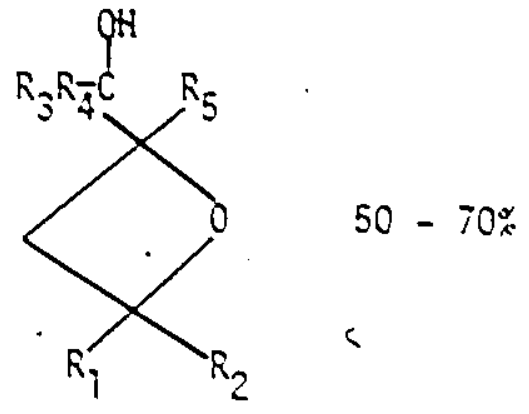

$\underline{49}$

These authors (30) also examined the influence of epoxide stereochemistry on the regiochemistry of the epoxy alcohol cyclization reaction. They reported that treatment of either the cis or trans derivative of 50 ( $a$ and $b$ ) gave essentialiy the same result, namely, formation of the oxetane derivative 5 I.

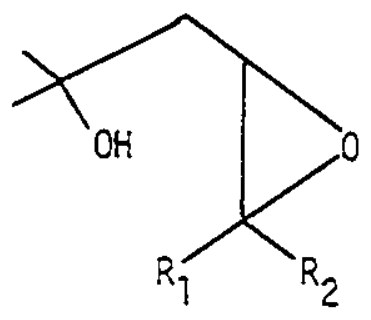

50 a $\mathrm{R}_{7}=\mathrm{C}_{6} \mathrm{H}_{13}, \mathrm{R}_{2}=\mathrm{H}$

b $\mathrm{R}_{7}=\mathrm{H}, \mathrm{R}_{2}=\mathrm{C}_{6} \mathrm{H}_{73}$

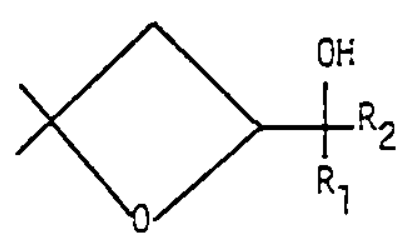

$\underline{51}$ 
$-25-$

These results are in contrast to those of Lallemand and Onanga (10) who showed that in epoxy nitrile cyclidations the epdxide.

- stereochemistry was a dominant factor in governing the regiochemistry of the cyclization. However, the two reaction systems differ widely (ie. solvent, base, nucleophile) and strict comparison may not be justified.

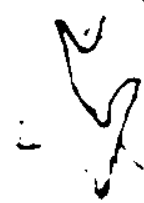

$-x=$ 

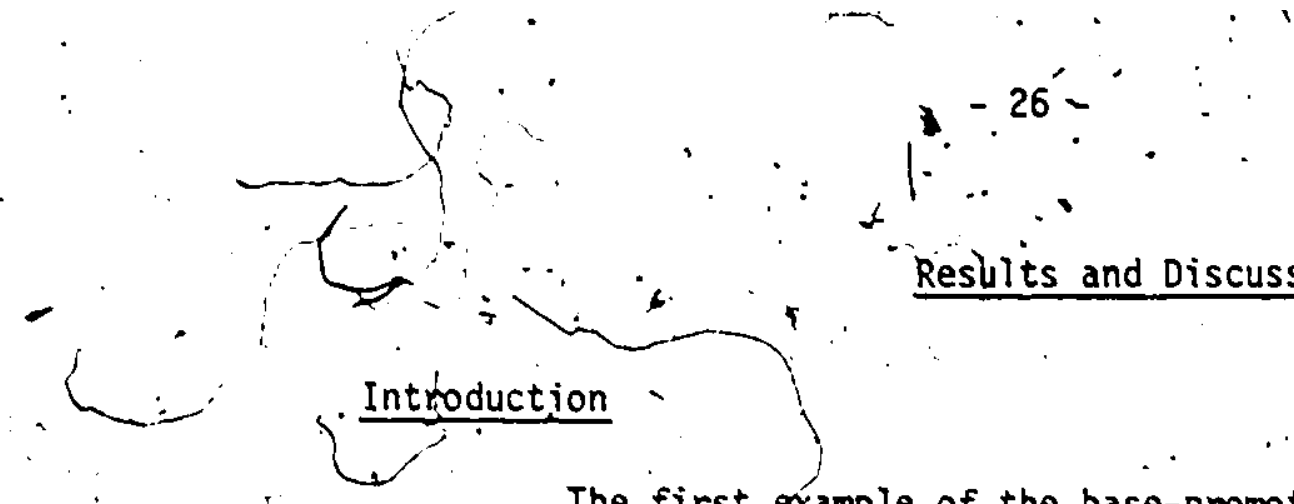

The first example of the base-promoted cyclization of epoxy suifdpes was. reported by Gaoni (31). Thus, he found that treatment of r-epgxy suifones with n-butyllithium in hexane at $-15^{\circ}$ yielded the trans-l- arylsulfonyl-2- (hydroxyalkyl) cyclopropanes in yields of S0-95\%.
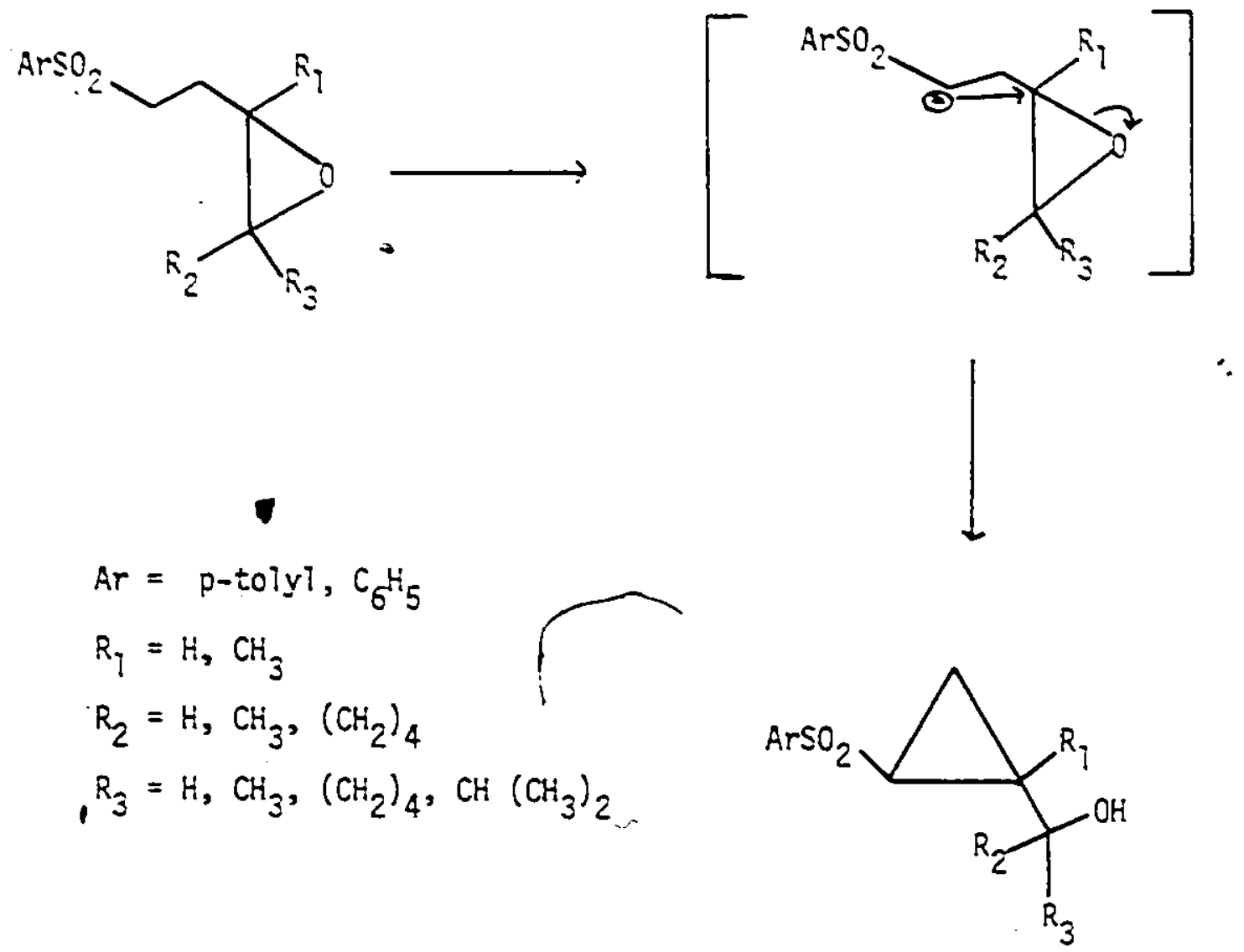
The exclusive formation of cyclopropyl derivatives is in agreement with Stork!s (8) observation of cyclopropane formation in the $r$-epoxy nitrile series and both sets of results may be interpreted in terms of the colinearity requirement (4).

The cyclization of $\gamma$-epoxy sulfones was also studied by Corbel and Durst (32). These authors also observed that the reaction of - $r$-epoxy sulfones with LDA furnished cyclopropane derivatives, in agreement with Gaoni's observations. However, additionaliy they found that the ring size of the product can be altered from three to four by changing the base from $\mathrm{LDA}$ (or $\mathrm{CH}_{3} \mathrm{Li}$ ) to $\mathrm{CH}_{3} \mathrm{MgI}$.

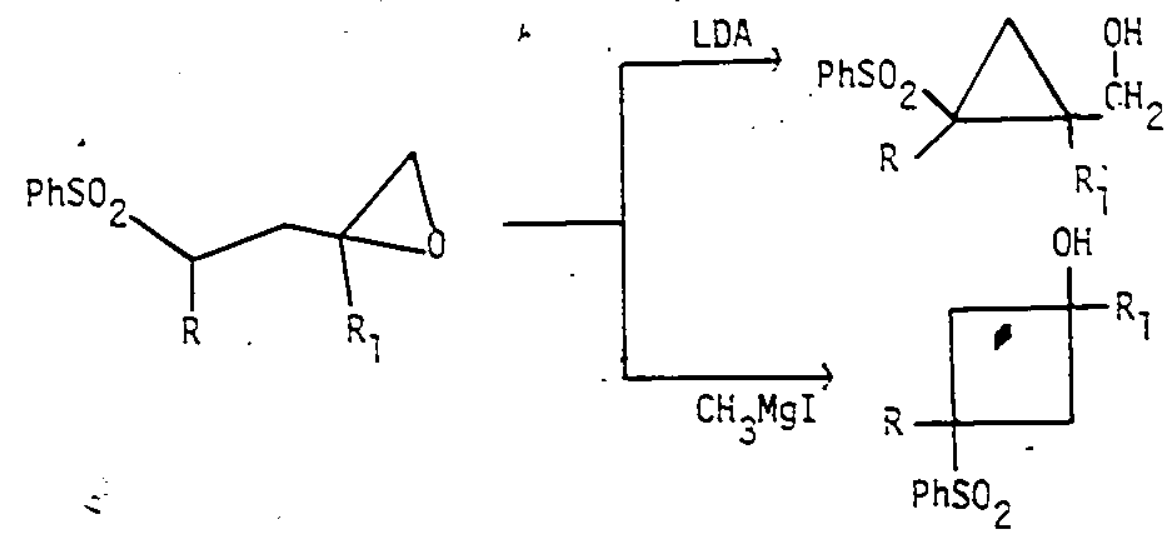

Cyclobutanol formation with the Grignard reagent as base was observed only in the case of terminaliy unsubstituted $\gamma$-epoxy sulfones. In contrast the $1,2-d i s u b s t i t u t e d$ epoxides gave only cyclopropylmethanol derivatives irrespective of the base employed. These results are summarized in Table II. 


\section{TABLE II}

Base Induced Cycilization of $r$-Epoxy Sulfones

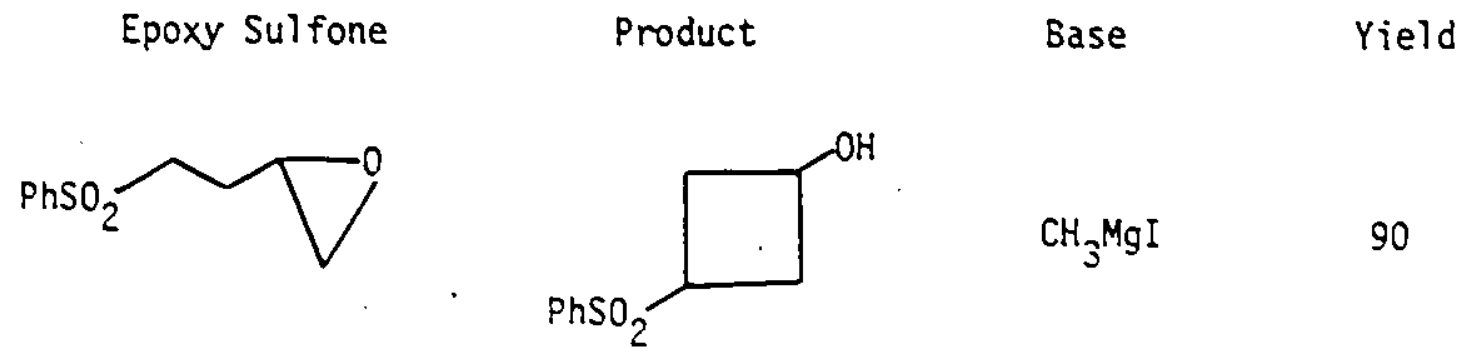<smiles>CC1(CC[R6]#P)CO1</smiles><smiles>CC1(O)CC([18OH])C1</smiles><smiles>c1ccc(CC(Cc2ccccc2)C2CO2)cc1</smiles><smiles></smiles><smiles>[R]C(CC1CO1)[R5]([H])([H])[H]</smiles><smiles>[R]C1([R6]([H])([H])[O-])CC(O)C1</smiles><smiles>C[As]</smiles>

$92 \mathrm{R}=\mathrm{C}_{4} \mathrm{H}_{9}$ $95 \mathrm{R}=\mathrm{C}_{6} \mathrm{H}_{13}$

$$
\mathrm{R}=\mathrm{C}_{4} \mathrm{H}_{9}, \mathrm{C}_{6} \mathrm{H}_{13}
$$
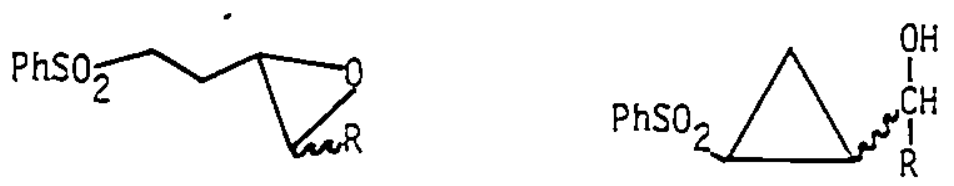

$\mathrm{CH}_{3} \mathrm{MgI}$

$70 \mathrm{R}=\mathrm{Ph}$

$35 \mathrm{R}=\mathrm{CH}_{3}$

$\mathrm{R}=\mathrm{Ph}, \mathrm{CH}_{3}$

LDA

$98 \mathrm{R}=\mathrm{Ph}$

$71 \quad \mathrm{R}=\mathrm{CH}_{3}$ 
Corbel and Durst briefly studied the mechanism of the cyclobutanol formation. Their proposed mechanism (Scheme 1) involves initial opening of the epoxide to generate the iodoalkoxide in a regiospecific manner. This is followed by formation of the a-sulfonyl carbanion which subsequently-cyclizes to the cyclobutanol. Support for the mechanism was obtained by isolating the halohydrin after quenching the reaction mixture at low temperature and showing that this substance was converted to the cyclized product by treatment with two equivalent of $\mathrm{CH}_{3} \mathrm{MgI}$.

Scheme I
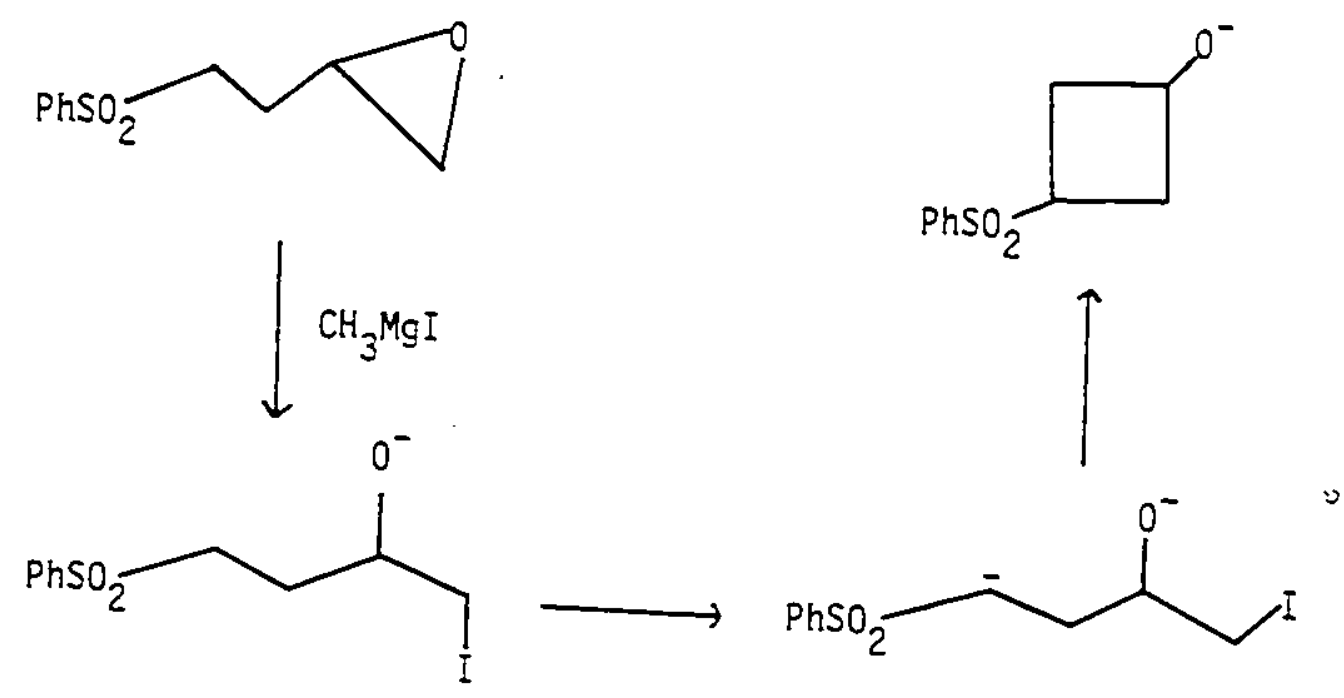
The 3-phenylsulfanyl cyclobutanols obtained above were converted into 3-substituted cyclobutenones in $80-95 \%$ overaf? yield.

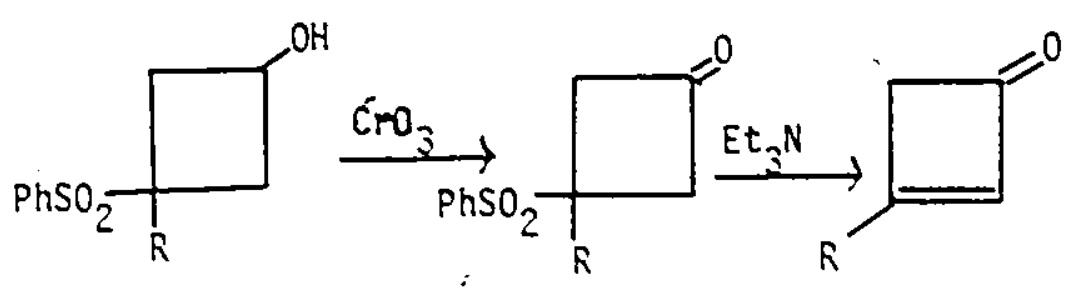

$\mathrm{R}=\mathrm{Ph}, \mathrm{C}_{4} \mathrm{H}_{9}, \mathrm{C}_{6} \mathrm{H}_{13}$

Due to the interest in epoxides as useful synthetic intermediates, (33) a more extensive study, both from the synthetic and mechanistic points of view, of the epoxy sulfone reaction seemed warranted. 


\section{Preparation of Epoxy Sulfones}

The epoxy sulfones required for this study were prepared by relatively standard procedures. The routes chosen for the individual epóxides are described below.

\section{r-Epoxy-sulfones}

A key intermediate in the preparation of a variety of $\gamma$-epoxy sulfones was the unsaturated sulfone 53 . This substance, NMR $8: 2.1-2.6$ $(\mathrm{m}, 2 \mathrm{H}), 2.9-3.3(\mathrm{~m}, 2 \mathrm{H}), 4.7-6.0(\mathrm{~m}, 3 \mathrm{H})$ and $7.3-7.9(\mathrm{~m}, 5 \mathrm{H})$, was prepared in two steps from thiophenol and 4-bromo-l-butene (Sheme 2).

\section{Scheme 2}

PhS $^{-} K^{+}+$<smiles>C=CCC[BiH]</smiles>
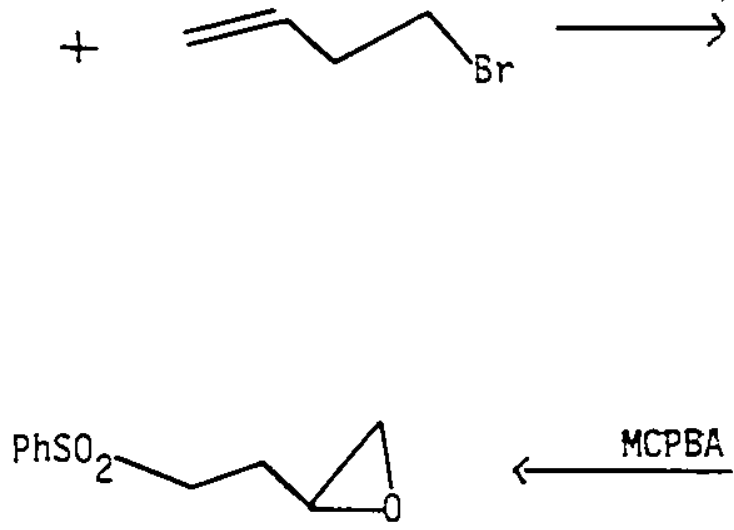

$\underline{54}$

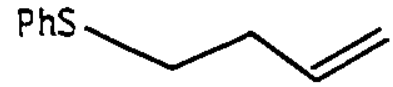

52

2MCPBA

MCPBA<smiles>C=CCCC[18OH]</smiles>

$\underline{53}$ 
Thus, the reaction of phenylthiolate with 4-bromo-1-butene furnished the olefin 52 , NMR $\delta: 2.1-2.6(\mathrm{~m}, 2 \mathrm{H}), 2.8-3.2(\mathrm{~m}, 2 \mathrm{H}), 4.9-6.3$ $(\mathrm{m}, 3 \mathrm{H})$, and $7.7-7.5(\mathrm{~m}, 5 \mathrm{H})$, in $90 \%$ yield. Careful oxidation of $\underline{52}$ at room temperature with two equivalents of MCPBA provided the sulfone$\underline{53}$ in $85 \%$ yield after chromatography. Because of the difference in the rates of oxidation of the sulfide to the sulfone vs epoxidation of the olefinic bond, no problems were encountered in stopping the reaction at the olefin sulfone 53 stage.

Epoxidation of $\underline{53}$ with one equivalent of MCPBA in refluxing methylene chloride overnight vielded the epoxy sulfone $\underline{54}$ in $95 \%$ yieid. The structure of 54 was confirmed by the absence of olefinic hydrogens in the NMR and appearance of the characteristic epoxide multiplets in the $\delta 2.4-3.3$ region.

Epoxy sulfones bearing alkyl substituents a to the sulfonyl grouping were readily obtained by first alkylating $\underline{53}$ via its a-suifonyl carbanion followed by epoxidation with MCPBA. The structure of these compounds were established on the basis of their spectroscopic properties and the method of synthesis. (see Experimental Section)

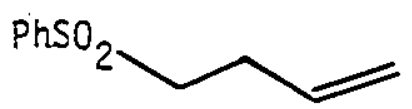

$\underline{53}$

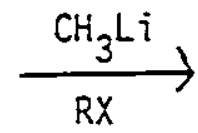

RX
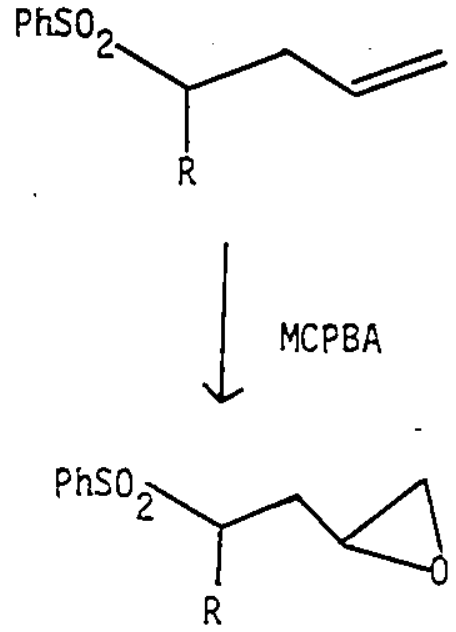
(ii) S-Epoxy Sulfones

The important intermediate, 1-phenylsul fonylpent-4-ene 57 . NMR $\delta: 1.4-2.4(\mathrm{~m}, 4 \mathrm{H}), 2.9-3.2(\mathrm{~m}, 2 \mathrm{H}), 4.7-5.9(\mathrm{~m}, 3 \mathrm{H})$, and 7.2-7.9 $(\mathrm{m}, 5 \mathrm{H})$, required in the synthesis of $\delta$-epoxy sulfones was prepared as shown in Scheme 3 .

\section{Scheme 3}
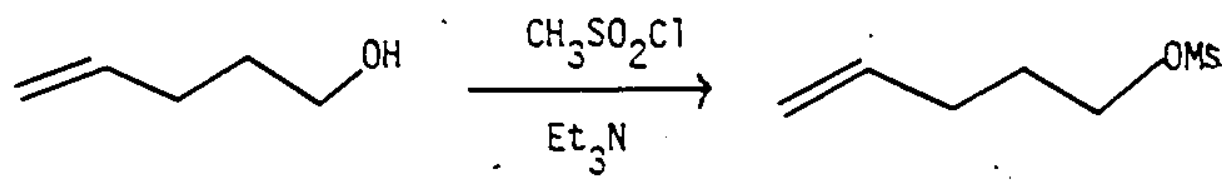

$$
\int^{\frac{55}{P h S^{-} K^{+}}}
$$

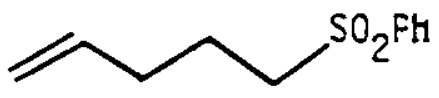

- 57<smiles>CCCCCCCCCCCC</smiles><smiles>O=S(=O)(O)CCCC1CO1</smiles>

$\underline{58}$

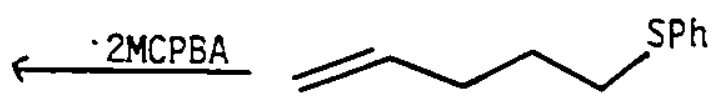

56 
Commercially available 4-penten-1-0l was mesylated with methanesulfonyl chloride providing $\underline{55}$ in $96 \%$ yield: NMR $8: 1.5-2.3$ $(m, 4 H), 2.9(s, 3 H), 4.15(t, J=6 H z, 2 H), 4.7-6.0(m, 3 H)$. Reaction of the mesylate $\underline{55}$ with potassium phenythiolate in methanol afforded the olefin 56 , NMR $\delta: 1.4-2.4(\mathrm{~m}, 4 \mathrm{H}) \mathrm{m} 2.79(\mathrm{t}, \mathrm{J}=7 \mathrm{~Hz}, 2 \mathrm{H}), 4.7-6.0(\mathrm{~m}, 3 \mathrm{H})$, $7.0-7.4(\mathrm{~m}, 5 \mathrm{H})$, in $97 \%$ yield. Oxidation of 56 with two equivalents of MCPBA gave 57 in $66_{*}^{*}$ yield. Further treatment of 57 with one equivalent of MCPBA provided the parent $\delta$-epoxy sulfone $\underline{5 S}$ in $90 \%$ yield. This compound was also more efficiently obtained (90\% isolated yieid) by the one-pot oxidation and epoxidation of $\underline{56}$ with three equivalents of MCPBA. The structure of the epoxy sulfone $\underline{58}$ was supported by the NMR data. $\delta: 1.2-2.2(\mathrm{~m}, 4 \mathrm{H}), 2.4-4.3(\mathrm{~m}, 5 \mathrm{H}), 7.3-\mathrm{S} .1$ $(m, 5 H)$.

The 1-benzyi derivative 60 which was required was prepared by treating 57 with n-butylithium at $-70^{\circ}$ and then quenching with benzyl bromide. This provided a $64 \%$ yield of the benzyi derivative 59 . NMR c: 1.5-2.3 $(\mathrm{m}, 4 \mathrm{H}), 2.5-3.5(\mathrm{~m}, 3 \mathrm{H}), 4.6-5.7(\mathrm{~m}, 3 \mathrm{H}), 7.0-8.0(\mathrm{~m}, 5 \mathrm{H}) ; \mathrm{IR}$ 1140 and $1300 \mathrm{~cm}^{-1},\left(\mathrm{SO}_{2}\right), 1640(\varepsilon=\mathrm{C})$. Epoxidation of 59 with MCPBA furnished the epoxy sulfone 60 in $95 \%$ yield. NMR peaks for 60 occurred at $0: 1.3-3.5(\mathrm{~m}, 1 \mathrm{OH})$ and $6.9-7.9(\mathrm{~m}, \mathrm{IOH})$ and the IR spectrum showed no teminal $E=C$ stretch. 

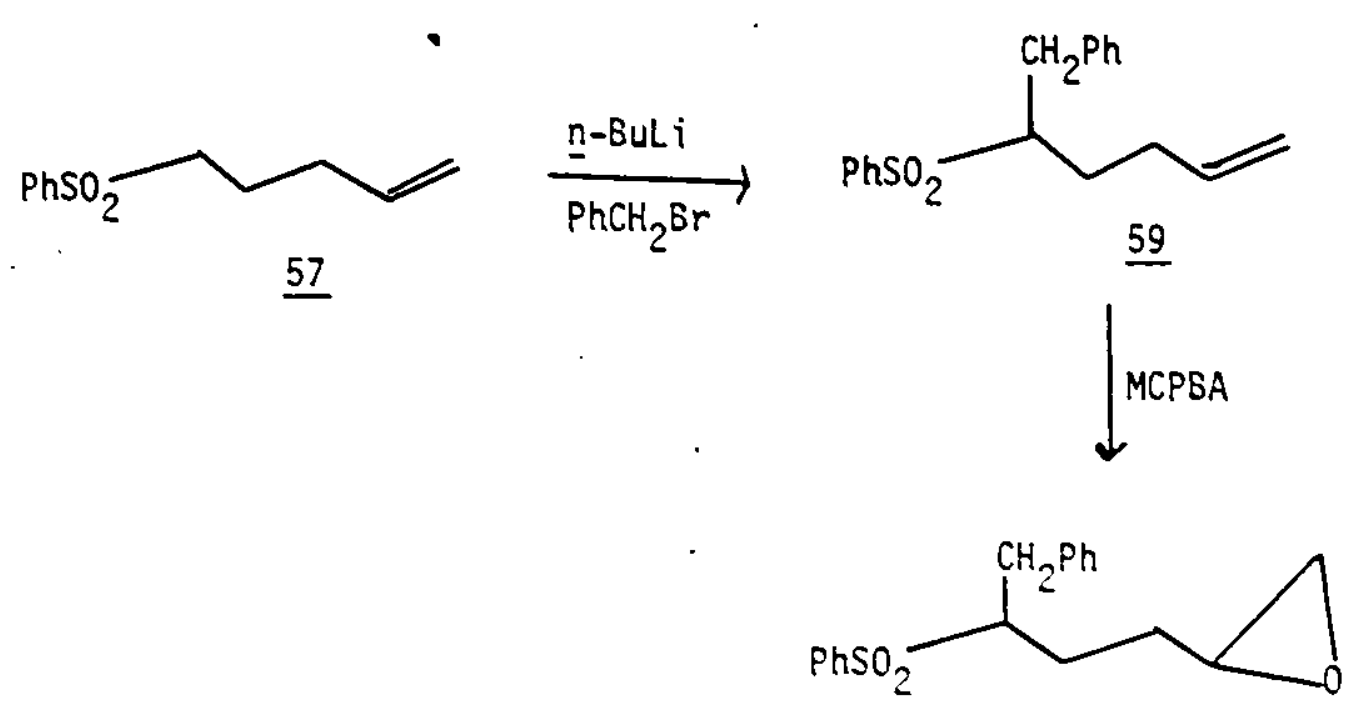

$\underline{60}$

The two disubstituted epoxides $\underline{69}$ and $\underline{70}$ used in this study were prepared starting from tetrahydrofuran according to schemes 4 and 5 .

Treatment of tetrahydrofuran with acetyl chioride under zinc chloride catalysis furnished the chloroester in $56_{*}^{*}$ yield. NMR $\varepsilon=1.4-2.1(\mathrm{~m}, 4 \mathrm{H}), 2.00(\mathrm{~s}, 3 \mathrm{H}), 3.4-3.7(\mathrm{~m}, 2 \mathrm{H}), 3.9-4.3(\mathrm{~m}, 2 \mathrm{H})$. This' reaction is very exothemic and external cooling (fee bath) is essential to contain the reaction if carried out in a 0.5 mole sale.

The chloroester 61 was reacted with phenylmercaptide and when the displacement reaction was tomplete as judged by TLC the ester was saponified by addition of excess potassium hydroxide. The hydroxy sulfide 62, NMR $0: 1.5-1.9(\mathrm{~m}, 4 \mathrm{H}), 2.6-3.1(\mathrm{~m}, 2 \mathrm{H}), 3.2-3.7(\mathrm{~m}, 3 \mathrm{H}, 2 \mathrm{H}$ after $\dot{\mathrm{D}}_{2} \mathrm{O}$ exchange) and $6.8-7.2(\mathrm{~m}, 5 \mathrm{H})$; IR $3440 \mathrm{~cm}^{-1}(\mathrm{OH})$, was subsequently oxidized with two equivalents of MCPBA which provided the hydroxy sulfone 63 in $70 \%$ chromatographed yijeld. NMR $0: 1.4-2.0(\mathrm{~m}, 3 \mathrm{H}), 2.6-2.9$ (1H, exchanges with $\left.\mathrm{D}_{2} \mathrm{O}\right), 3.16(t, \mathrm{~J}=7 \mathrm{~Hz}, 2 \mathrm{H}), 3.58(t, j=6 \mathrm{~Hz}, 2 \mathrm{H}), 7.4-7.9$ $(\mathrm{m}, 5 \mathrm{H}) ; 1 \mathrm{R} 3475 \mathrm{~cm}^{-1}(\mathrm{OH})$. The above hydroxy sulfone was also prepared 


\section{Scheme 4}
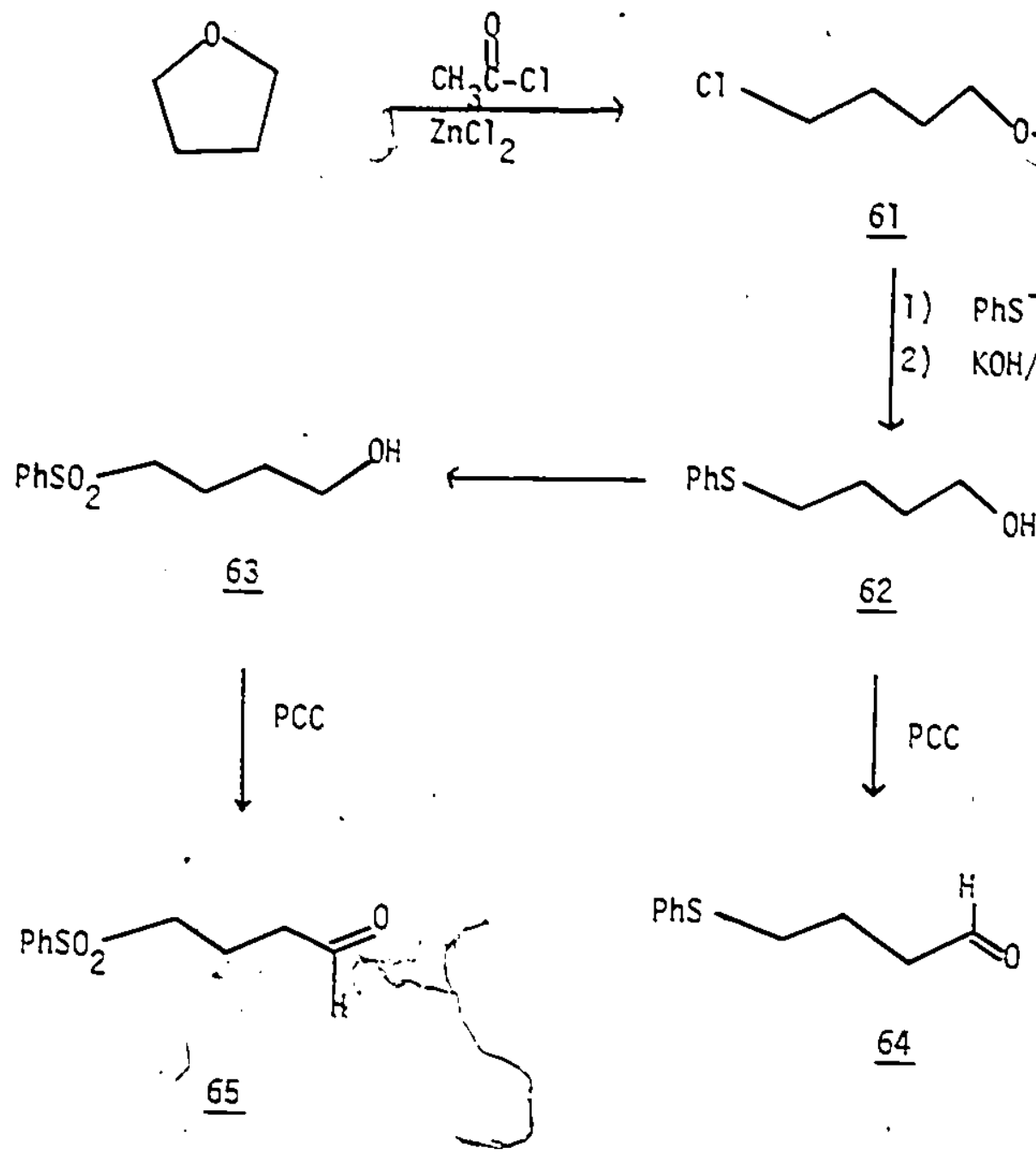<smiles>CC(=O)OCCCCCl</smiles>

6I

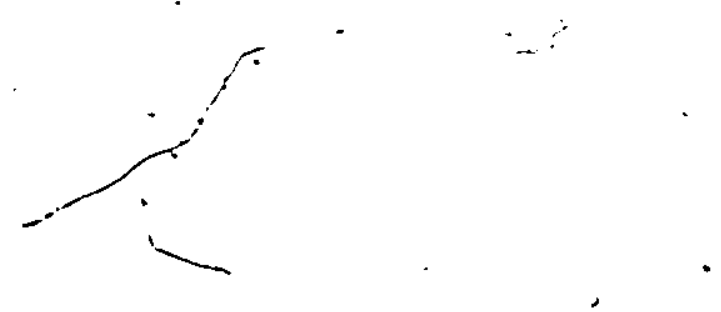




\section{- $\quad$ Scheme 5}

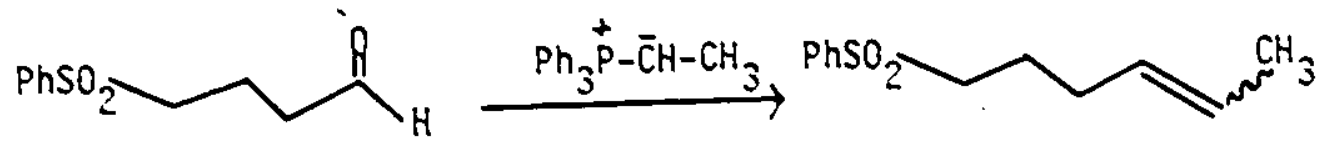

65
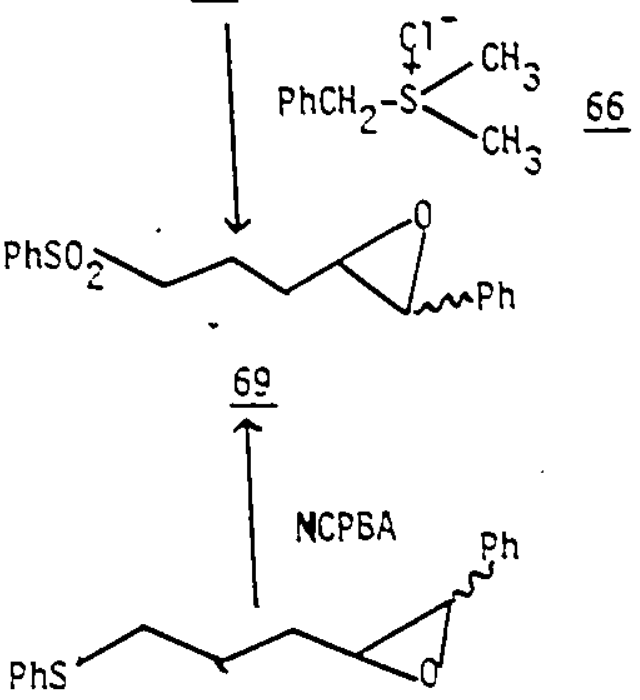

$\underline{6 S}$
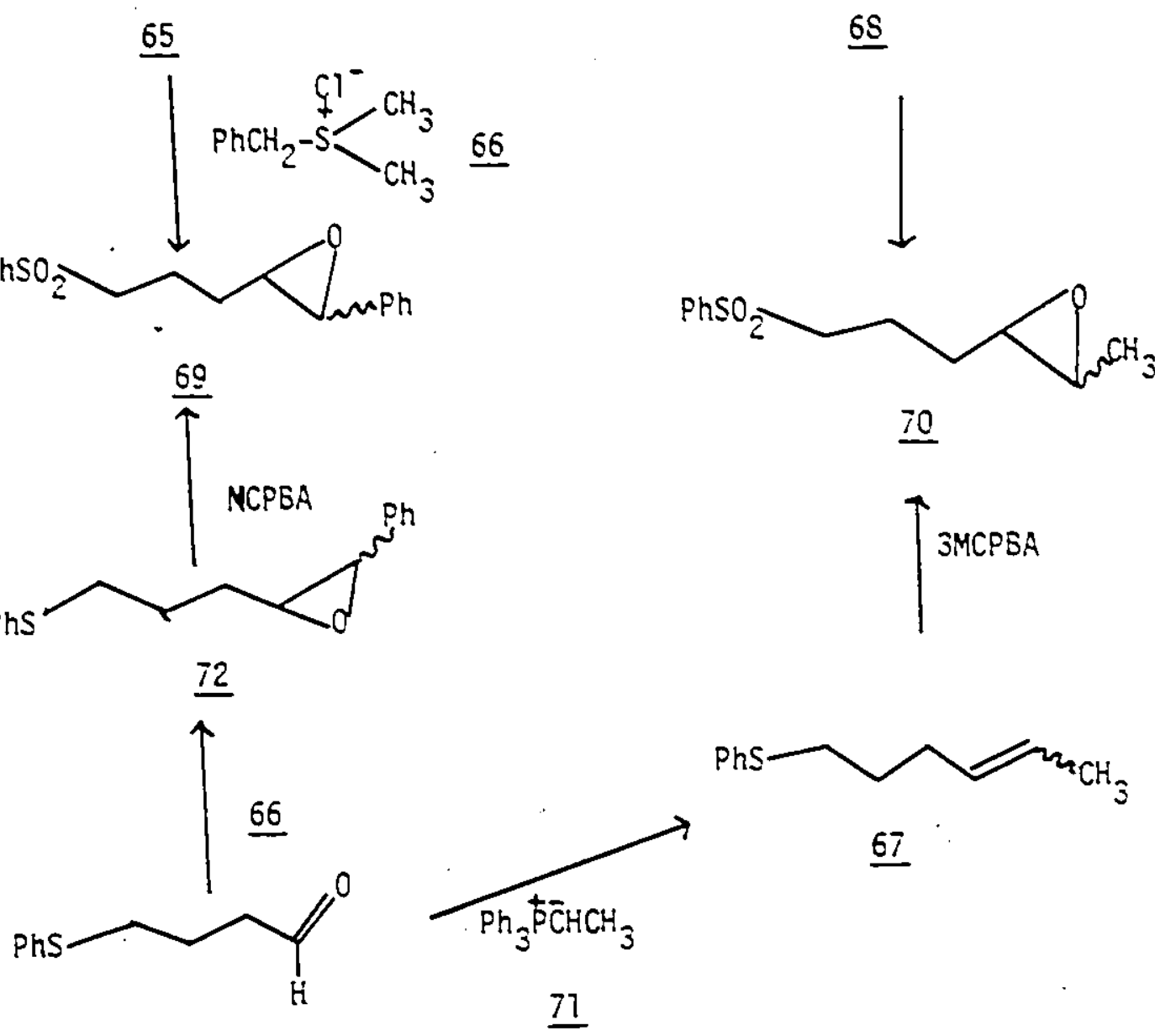

64 
in $70 \%$ yield by hydroboration of the olefin $\underline{53}$.

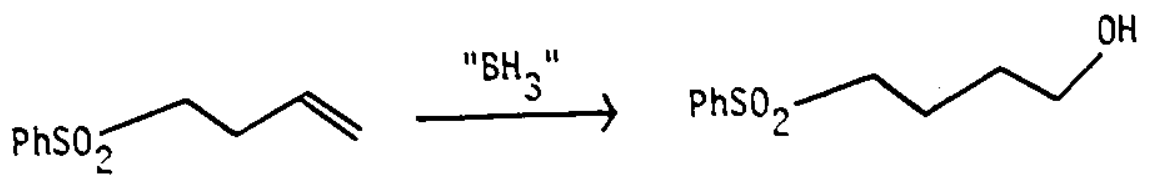

53

Oxidation of the alcohols $\underline{62}$ and $\underline{63}$ with Corey's (34) procedure (PCC-pyridinium chlorochromate in methyiene chloride) provided the correspondind al dehydes in only 20-30\% vield. Attempts to improve these yields by varying the rate of addition of the alcohol, volume of soivent, and insuring anhydrous conditions were not, successfui. However, by addition of four equivalents of sodium carbonate to the suspension of PCC in methylene chloride the vields of aldehydes could be increased to the $70 \%$ range.

The structure of the aldehydes was confimed by the NMR and If data. Aidehyde 64 showed NMR peaks at $\varepsilon: 1.3-1.9(\mathrm{~m}, 2 \mathrm{H}), 2.1-2.6(\mathrm{~m}$, $2 \mathrm{H}), 2.83(\mathrm{t}, \mathrm{J}=7 \mathrm{~Hz}, 2 \mathrm{H}, 6.8-7.2(\mathrm{~m}, 5 \mathrm{H})$ and $10.00(\mathrm{~s}, 7 \mathrm{H})$. Couping of the aidehydic hydrogen was not observed at $60 \mathrm{MHz}$ in $\mathrm{CBCl}_{3}$ solution. The infrared spectrum showed the carbonyl stretch at $1710 \mathrm{~cm}^{-1}$. NMR signals for aidehyde 65 were observed at $\hat{c}: 1.8-2.2(\mathrm{~m}, 2 \mathrm{H}), 2.70(\mathrm{t}$, $\mathrm{J}=6 \mathrm{~Hz}, 2 \mathrm{H}), 3.20(\mathrm{t}, \mathrm{J}=6 \mathrm{~Hz}, 2 \mathrm{H}), 7.4-7.9(\mathrm{~m}, 5 \mathrm{H})$ and $9.74(\mathrm{~s}, 7 \mathrm{H}) ; \mathrm{TR}$ absorptions were at $1715 \mathrm{~cm}^{-1}(\mathrm{C}=0)$ and $1150,1310\left(\mathrm{SO}_{2}\right)$.

Reaction of the sulfone aidehyde 65 with dimethyibenzyisulfonium chioride 66 (prepared by refluxing an aqueous solution of benzyl chioride and dimethyi sulfide (35)) under phase-transfer conditions gave the epoxy sutfone 69 in $50 \%$ yield as a clear oil afiter chromatography. NMR peaks occurred at $\tilde{c}: 1.5-2.1(\mathrm{~m}, 4 \mathrm{H}), 2.8-3.4(\mathrm{~m}, 3 \mathrm{H}$ ), 3.56 and 4.40 (two 
doublets, $J=2$ and $4 \mathrm{~Hz}, \mathrm{IH})$ and $7.1-7.9(\mathrm{~m}, 10 \mathrm{H})$. Integration of the two doublets centered at 3.56 and 4.40 gave an $55: 15$ trans/cis epoxide ratio based on the trans isomer having the smaller coupling constant. The infrared spectrum showed the sulfone stretch at 1155 and 1300 $\mathrm{cm}^{-1}$.

The chloride salt of $\underline{66}$ is required in the phase transfer reaction. Attempted reaction of $65^{\circ}$ with the bromide salt of $\underline{66}$ was 2 not successful. This may be attributed to deactivation of the phase transfer catalyst whereby bromide ion is transported from the aqueous phase in preference to hydroxide ion.

Reaction of 65 with ethylidenetriphenyiphosphorane $\underline{\text { II gave }}$ the olefin 6 s in oniy $25 \%$ vield. NMR $\varepsilon: 1.1-2.3(\mathrm{~m}, 7 \mathrm{H}), 2.9-3.3(\mathrm{~m}, 2 \mathrm{H})$, $4.9-5.6(\mathrm{~m}, 2 \mathrm{H}), 7.3-i .9(\mathrm{~m}, 5 \mathrm{H}) ;$ IR $1600 \mathrm{~cm}^{-1}(\mathrm{C}=\mathrm{C})$. Usual epoxidation of this material with MCPBA afforded the epoxy suifone $\underline{\text { I0 }}$ in $92 \%$ vield as a clear $0 i l$ which showed NMR peaks at $\delta: 1.18(d, J=5 H z)$ and 1.30 $(d, J=5 H z) \cdot 3 H, 1.0-2.2(m, 4 H), 2.3-3.4(m, 4 H)$ and $7.4-7.8(m, 5 H)$. The relative intensity of the two methyl doublets indicated that the epoxy sulfone 70 thus obtained was a 50:50 cis/trans mixture. The infrared specturm of 70 showed sulfone absorption at 1150 and $1310 \mathrm{~cm}^{-1}$. Epoxidation of the sulfide 64 with the sulfonium sait $\underline{66}$. provided the epoxy sulfide $\underline{72}$ which was oxidized to the sulfone $\underline{69}$ in $60 \%$ overall yieid.

The sulfide aldehyde $\underline{64}$ was also reacted with the yijde of $\underline{71}$, thus furnishing a $91 \%$ yield of the olefin 67 . NMR $\dot{\varepsilon}: 1.0-1.7(\mathrm{~m}, 7 \mathrm{H})$, $1.7-2.3(\mathrm{~m}, 2 \mathrm{H}), 2.80(\mathrm{t}, \mathrm{J}=6 \mathrm{~Hz}, 2 \mathrm{H}), 4 . \lambda-4.4 \mathrm{~m}, 2 \mathrm{H}), 6.7-7.1(\mathrm{~m}, 2 \mathrm{H})$; IR $1600 \mathrm{~cm}^{-1} \quad(\mathrm{C}=\mathrm{C})$. The use of the sulfilde in the Wittig reaction. was a large improvement compared to the use of the sulfore $(90 \%$ vs $25 \%)$. 
$-40-$

The major reason for the vast increase in yield can be ascribed to the $\therefore \quad$ greater ease of separating the sulfide olefin 67 from other polar impurities (eg. triphenylphosphine oxide).

Oxidation and epoxidation of 67 with three equivalents of MCPBA provided the epoxy sulfone 70 in $55 \%$ yield. Examination of the NMR indicated that this material was also a 50:50 mixture of cis and trans isomers. 


\section{Base Induced Cyclizations}

The cyclization reactions were carried out following the procedures developed by corbel. The reactions employing methylmagnesium iodide as the Dase were carried out as follows; the appropriate epoxy sulfone was dissolved in freshiy distilled THF and then cooled to $-78^{\circ}$ under nitrogen, this was followed by addition of the required amount of standardized methylmagnesium iodide in ether. The resultant white suspension was allowed to warm to room temperature and then let stir for periods of 12-4S hrs., depending on convenience. After this period, the reaction was quenched with a saturated solution of. ammonium chloride and worked up in the usual manner.

Reactions involving LDA or $\underline{n}-$-BULi as the base were carried out in an analogous manner.

x-Epoxy Sulfones

The cycilization of epoxy sulfone 54 had been studied by Corbel. It was repeated in order to acquaint myself with the experimental conditions and to further characterize the product. The reaction was carried out a number of times and yields of 75-90\%, comparable to Corbel's $96 \%$ reported yield, were generaliy obtained.

8

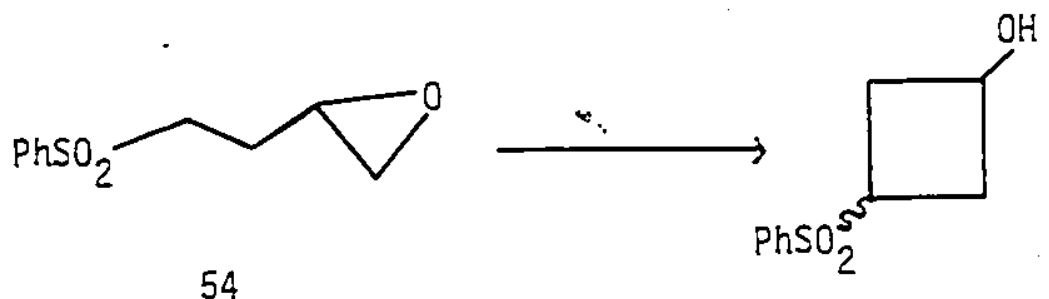


The cyclobutanol structure 73 was supported by the spectral and analytical data. The infrared spectrum of 73 displayed the hydroxyl band at $3500 \mathrm{~cm}^{-1}$ and the sulfone grouping at 1130 and $1300 \mathrm{~cm}^{-1}$. The ${ }^{I} H$ and ${ }^{13} C$ NMR data presented below were also consistent with the assigned structure.

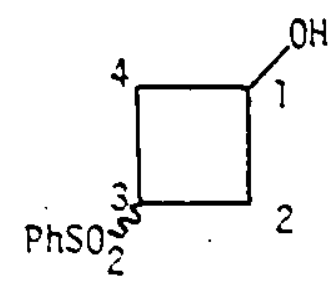

$i_{H N M R}$

$$
\begin{aligned}
& 0: \quad 2.3-2 . S(\mathrm{~m}, 4 \mathrm{H}), \mathrm{C}_{2}, \mathrm{C}_{4}-\mathrm{H} \\
& -3.95(\mathrm{~d}, \mathrm{IH}, \mathrm{OH}) \\
& 3.1-3.5(\mathrm{~m}, 7 \mathrm{H}), \mathrm{C}_{3}-\mathrm{H} \\
& 4.0-4.6(\mathrm{~m}, \mathrm{TH}) \mathrm{c}_{1}-\mathrm{H} \\
& \\
& 7.4-S .0(\mathrm{~m}, 5 \mathrm{H}) \text { aromatics }
\end{aligned}
$$

${ }^{13} \mathrm{C} \quad \mathrm{NMR}$

$$
\begin{array}{ccccc}
c_{1} & 60.9 & \text { (d) } & c_{1} & 64.0 \\
c_{2} \text { and } c_{4} & 34.3 & \text { (t) } t \cdot c_{2} \text { and } c_{4} & 33.6 \\
c_{3} & 48.5 & \text { (d) } & c_{3} & 52.5
\end{array}
$$

It was observed that if the reaction was carried out for a reasonably short time (8-12 hrs.) using only two equivaients of base essentially one isomer was observed judging from the one proton multiplet for $\mathrm{CH}-\mathrm{OH}$ centered at $\delta: 4.2$. In contrast, ionger reaction times (24 hrs.) or large excesses of $\mathrm{CH}_{3} \mathrm{MgI}$ gave an approximate 2:I isomeric mixture as evidenced by appearance of a second multiplet 
centered at $\delta: 4.4$. The ${ }^{13} \mathrm{C}$ NMR spectrum also substantiated the existence of two isomers. (ie. doubling up of ${ }^{13} \mathrm{C}$ signals).

These results indicate that the parent cyclobutanol was probably formed in a highly stereoselective manner (see also section on Stereochemistry) and then underwent isomerization via the intermediacy of the dianion $\underline{74}$ (Scheme 6 ).

\section{Scheme 6}

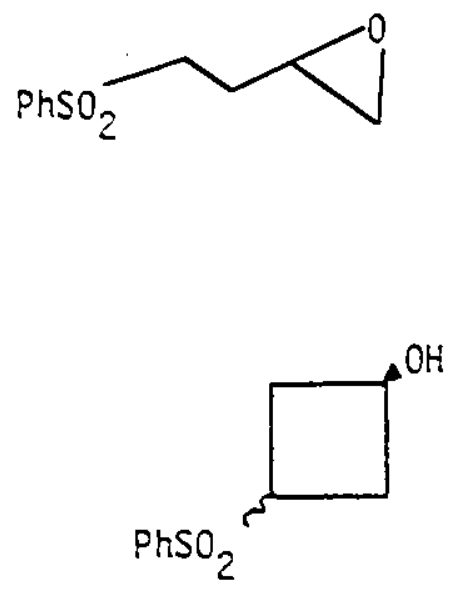

$\underline{73}$
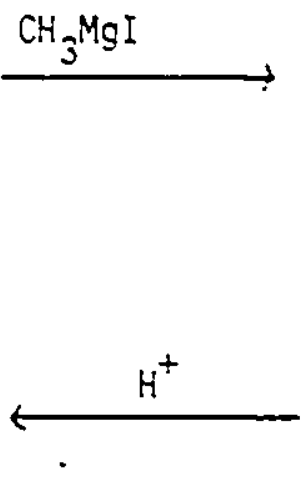

$\mathrm{PhSO}_{2}$

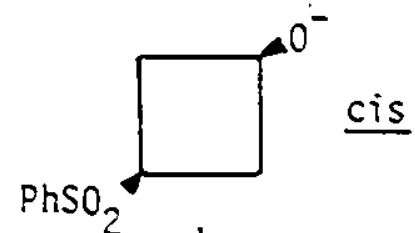

2
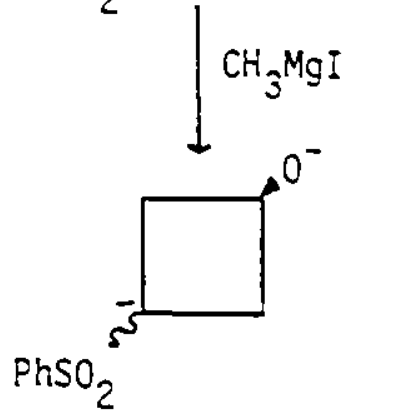

$\underline{74}$

cis and trans

As was described in the introduction to this section Corbei had studied both the LDA-and $\mathrm{CH}_{3}$ MgI-catalyzed cyclization of a variety of substituted r-epoxy sulfones and shown that with terminal epoxides the $\mathrm{CH}_{3} \mathrm{MgI}$ mediated cyclization always afforded 3-phenylsulfonylcyclobutanols. The relative stereochemistry between the hydroxyl and phenylsulfonyl groups in both 3-phenylsulfonylcyclobutanols and-cyclopentanols is depicted as cis throughout the thesis. Evidence for this assignment is presented in the section on stereochemistry. 


\section{$\delta$-Epoxy Sulfones}

Cyclization of the $\delta$-epoxy sulfone 58 with methylmagnesium iodide afforded the cyclopentanol 75 in $75 \%$ yield after chromatography.
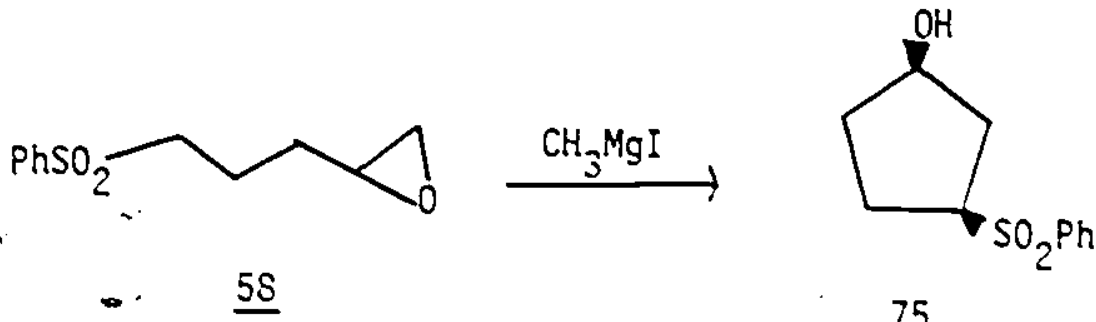

$\underline{75}$

This clear, viscous oil showed 'H NMR peaks at $8: 3.5-3.9$ $(\mathrm{m}, \mathrm{iH})$ and $4.2-4.6(\mathrm{~m}, \mathrm{lH})$ assignable to the hydrogens on the carbons bearing the $\mathrm{SO}_{2} \mathrm{Ph}$ and $\mathrm{OH}$ groups respectively. In addition, peaks due to three methylene units $(1.7-2.4, \mathrm{~m})$, the $\mathrm{OH}(2.9-3.1)$ and the aryl group $(7.4-7.9)$ were observed.

In contrast, treatment of the above epoxy sulfone 58 with LDA gave only starting material and intractable products which were not identified. A similar result had been observed by Lallemand and Onanga (10) who reported that treatment of the epoxy nitrile 76 with sodamide in dry THF gave, in contrast to epoxy nitriles which with teminal substituents gave cyclic products, "no reaction" presumably meaning that no cyclization products were obtained.
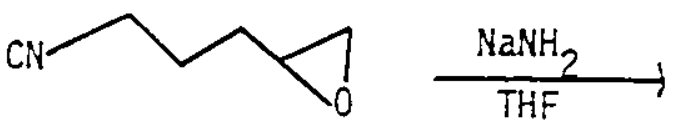

no cyclization products 
The reason for the behaviour of $\underline{58}$ and $\underline{76}$ with $L D A$ is not clear. Three competing reactions are possible for the intermediate $\alpha$-cyano or $\alpha$-sulfonyl carbanions.

(i) exo-cyclization to give a cyclobutyl methanol

(ii) endo-cyclization affording cyclopentanol derivatives, and

(iii) intermolecular epoxide opening probably at the terminal position to give dimeric and polymeric species.

Presumabiy pathway (iii) becomes the most favoured process because it is sterically unhindered and suffers neither from the colinearity problem associated with the 5-endo process or the enthalpy problem generaliy associated with the formation of four-membered rings.

The reaction of 58 with $L D A$, as was the case with most other epoxy sulfone cyclizations, was carried out at a concentration of approximately $0.02 \mathrm{M}$. No further dilution studies were carried out in this particular case.

$\frac{\text { "One-Pot" Preparation of Cyciobutanols }}{\text { and Cyclopentanols }}$

The preparation of some 3-phenylsulfonyl cyclobutanols and cyclopentanols was achieved under "one-pot" conditions according to Scheme 7 .

Thus, reaction of phenyi methyl sulfone 77 with one equivalent of $\mathrm{CH}_{3} \mathrm{Li}$ in THF containing $5 \%$ hexamethylphosphoramide (HMPTA) at $-70^{\circ}$ followed by sequential addition of epibromohydrin ( $n=1$ ) and $\mathrm{CH}_{3} \mathrm{MgI}$ and warming to room temperature overnight gave the parent 
cyclobutanol $(n=1) \underline{73}$ in $46 \%$ yield.

\section{Scheme 7}

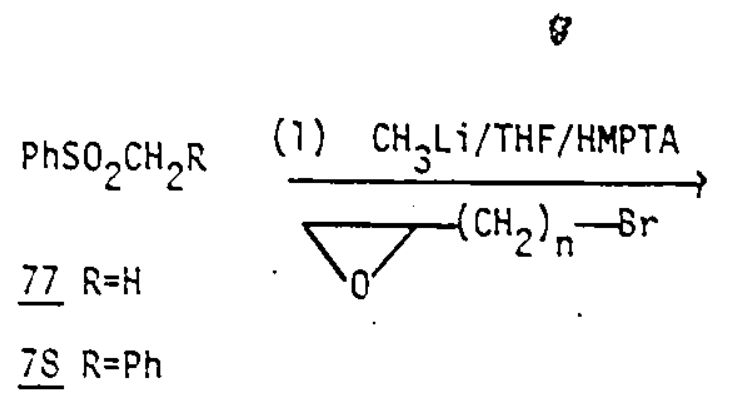<smiles>[Y]C(C=CC(=O)O)C1CO1</smiles>

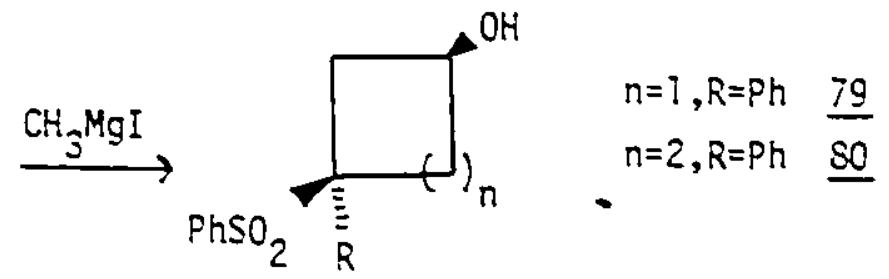

Replacement of phenyl methyl sulfone in the above sequence with benzyi phenyl suifone $(\mathrm{R}=\mathrm{Ph}) \underline{78}$ provided the 3-phenyl cyclobutanol derivative 79 in $60 \%$ yield. This white solid (mp $132^{\circ}$ from $\mathrm{CH}_{2} \mathrm{Cl}_{2} / \mathrm{CCl}_{4}$ ) showed NMR signals at $\hat{0}: 2.9-3.3$ ( $\mathrm{m}, 5 \mathrm{H}$, $4 \mathrm{H}$ after $\mathrm{O}_{2} \mathrm{O}$ exchange), 4.18 (quintet, $\mathrm{J}=6,5 \mathrm{~Hz}, \mathrm{iH}$ ), and $6.8-7.7(\mathrm{~m}, 1 \mathrm{OH})$. An $x$-ray of this material is reported in the section on Stereochemistry.

The parent cyclopentanol 75 was obtained in $35 \%$ yield via the above sequence using phenyl methyl sulfone $\underline{77}$ and 4-bromo-1,2-epoxy butane $(n=2)$ as the two starting components.

Also prepared by this route, beginning with benzyl phenyl sulfone $\underline{78}$ and 4-bromo-1,2-epoxybutane was 3-phenylsulfonylcyciopentanol 
derivative 80 . This viscous oil, obtained in $75 \%$ yield, displayed NMR peaks at $8: 2.0-3.4(\mathrm{~m}, 6 \mathrm{H}), 3.4-3.8(1 \mathrm{H}, \mathrm{OH}), 4.2-4.6(\mathrm{~m}, 7 \mathrm{H})$, and 7.0-7.6 $(\mathrm{m}, 1 \mathrm{OH})$. The infrared spectrum of $\underline{80}$ showed the $\mathrm{OH}$ stretch at $3500 \mathrm{~cm}^{-1}$ and the $\mathrm{SO}_{2}$ group at 1130 and $1300 \mathrm{~cm}^{-1}$. The use of AMPTA as a cosolvent (36) in the above "one-pot" reactions.was absolutely necessary since reactions attempted without it did not yield any appreciable amounts of cyclization products.

Surprisingly, the attempted "one-pot" reaction employing butyl phenyl sulfone and 4-bromo-l,2-epoxybutane gave the cyclization product in less than $5 \%$ yield. Examination of the crude NMR indicated that the starting material constituted the vast majority ( $95^{\circ}$ ) of the crude reaction mixture. This lack of success may be due to - inefficient aikylation of the a-sulfonyl carbanion possibly due to increased steric effects in the anion.

\section{Mechanism of the "One-Pot" Reactions}

Two modes of attack by the a-sulfonyl carbanion on the bromo epoxides $(n=1,2)$ may be envisaged; these are shown in Scheme 8 and discussed below.

Attack of the carbanion via path $A$ results in formation of the $\gamma$-epoxy sulfone which subsequentity cyclizes via the usual alkoxide intermediate to the 3-phenylsulfonyl cyclobutanol.

Attack of the anion at the primary site of the epoxide (path B) initially yields the same bromo alkoxide intermediate and thus the same cyclobutanol product. Therefore, product analysis does not allow differentiation of the two processes. 
Scheme 8

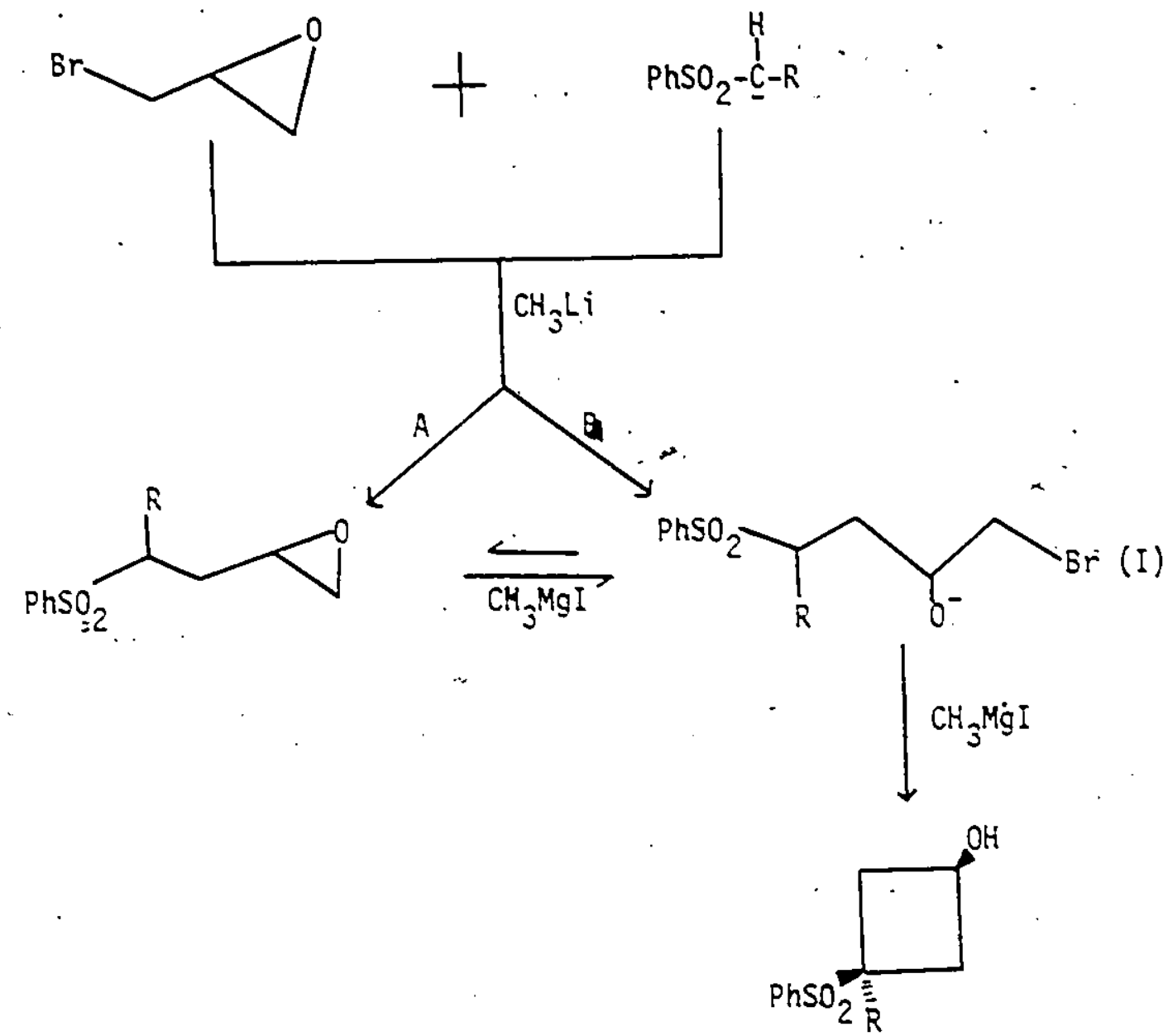

A similar situation exists in the reaction of the a-sulfony? carbanions and 4-bromo-1,2-epoxybutane. (Scheme 9)

In path $A$, displacement of bromide ion from 4-bromo-1,2epoxybutane by the a-sulfonyl carbanion results in formation of a f-epoxy sulfone which subsequently can undergo cyclization via the usual halohydrin intermediate.

Opening of the epoxide (path B).fumishes the $\gamma$-halohydrin. intermediate which upon cyclization affords the identical cyclopentanol derivatives as in path $A$. 
Scheme 9

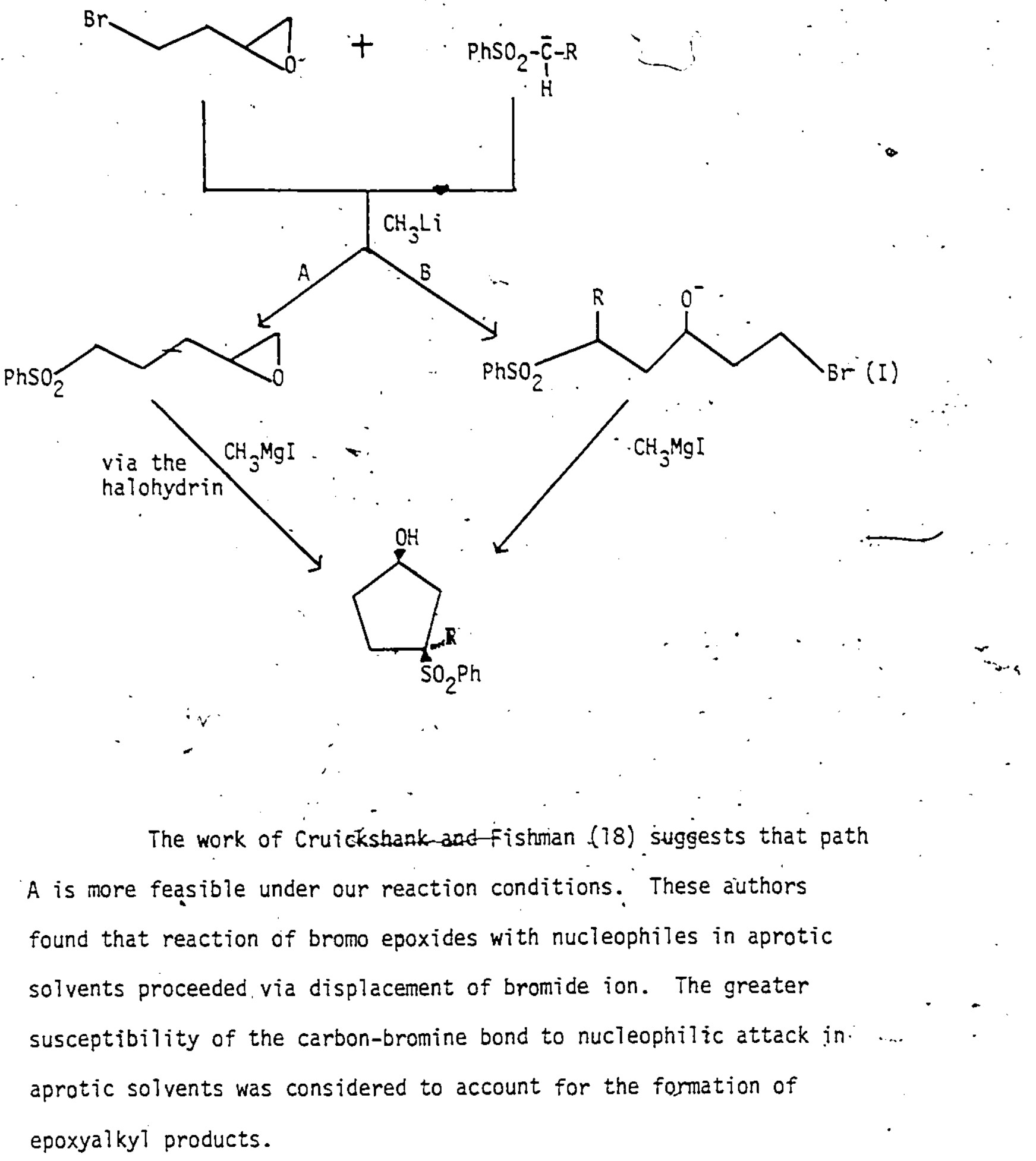



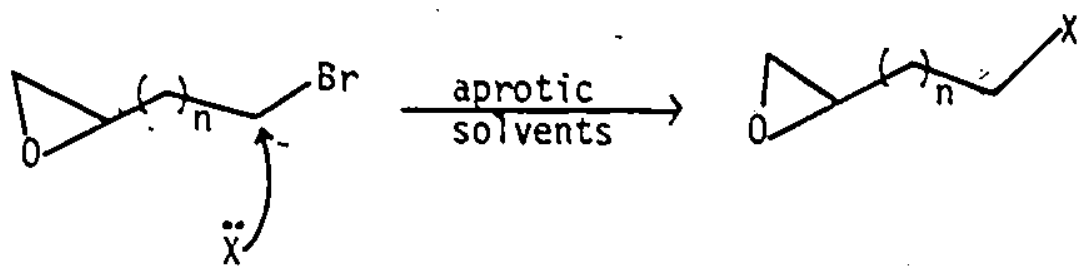

The use of protic solvents (alcohols) resulted in attack by the nucleophile at the primary oxirane carbon. This behaviour was accounted for in terms of the weakening of the carbon-oxygen bond in alcoholic solvents, due to hydrogen bonding, such that nucleophitic attack at the primary oxirane position becomes favoured.
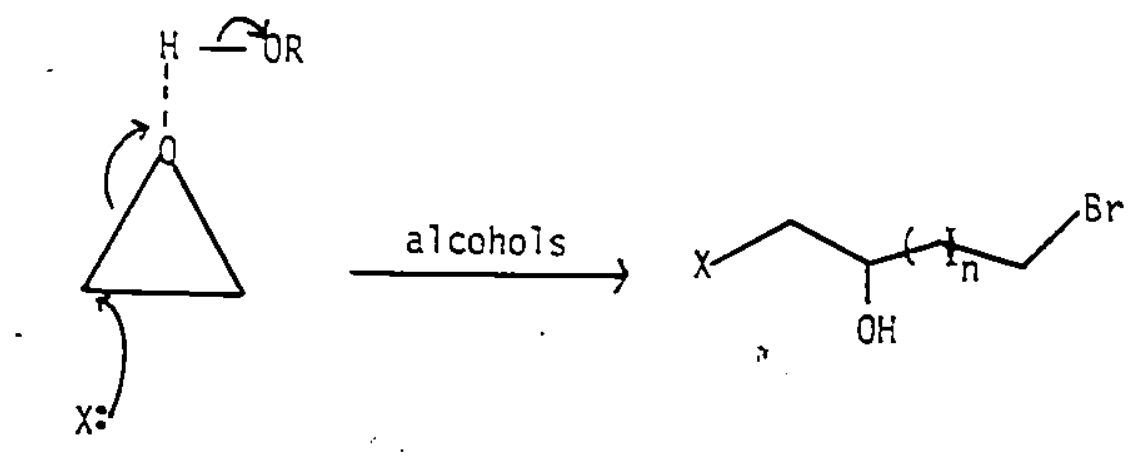

The above work, coupled with our own observation that the product obtained in the initial step (epoxide and a-sulfonyl carbanion) has an $R_{f}$ comparable to an authentic sample of the corresponding epoxy sulfone suggests that the initial alkylation product is formed via path A.

\section{Internally Substituted Epoxy Sulfones}

The $r$-epoxy sulfone $\underline{69}$, when treated with two equivalents of $\mathrm{CH}_{3} \mathrm{MgI}$ furnished the cyclopentanol 81 in $67 \%$ yield. 

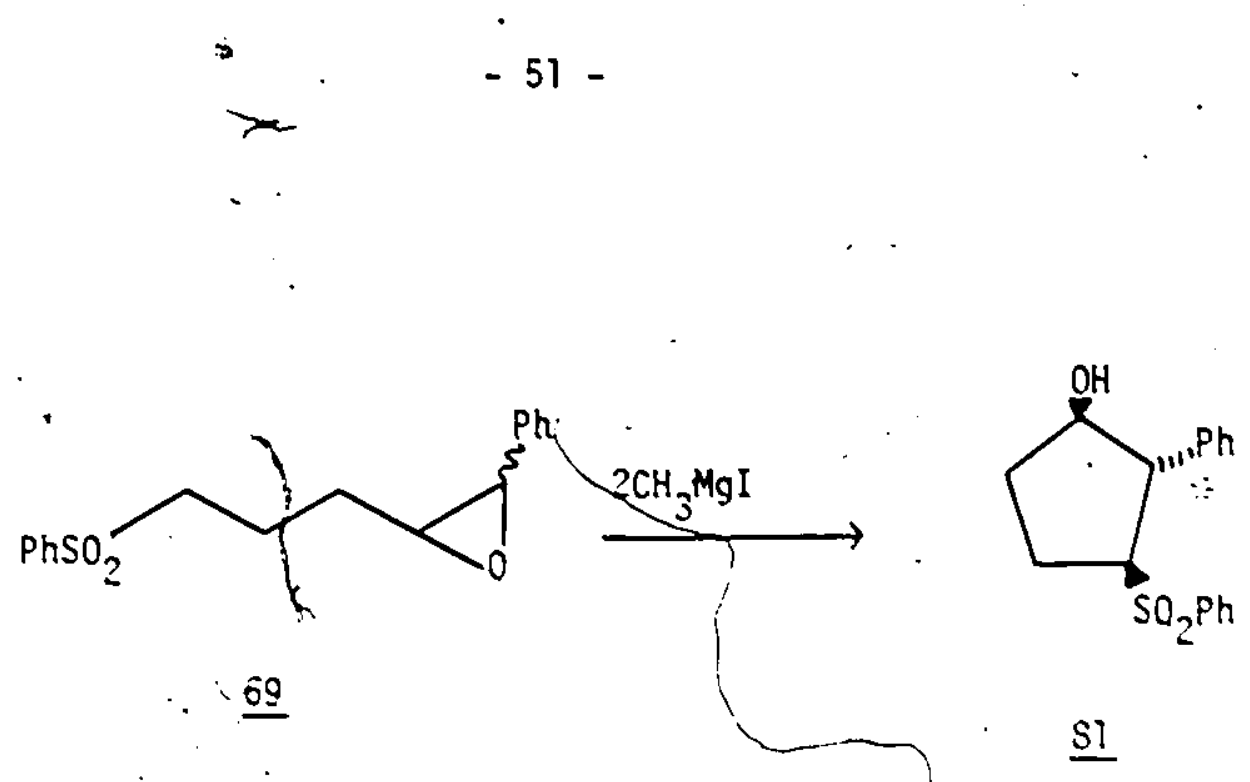

Compound $\underline{\mathrm{Sl}}$ (m.p. 105-106 from $\mathrm{CH}_{2} \mathrm{Cl}_{2}$ /hexane) exhibited NMR peaks at $\varepsilon: 1.7-2.6)\left(\mathrm{m}, 5 \mathrm{H}, 4 \mathrm{H}\right.$ after $\mathrm{D}_{2} \mathrm{O}$ exchange $), 3.2-3.4(\mathrm{~m}, 1 \mathrm{H})$, $3.5-3.5(\mathrm{~m}, i \mathrm{H}), 3.9-4,2(\mathrm{~m}, \mathrm{iH})$ and $6.5-7 . s(\mathrm{~m}, 10 \mathrm{H})$. The infrared spectrum showed the $\mathrm{OH}$ bond at $3500 \mathrm{~cm}^{-1}$ and the $\mathrm{SO}_{2}$ band at 1145 and $1310 \mathrm{~cm}^{-1}$. The assigned structure was also consistent with the ${ }^{13} \mathrm{C}$ NMR data which is presented below.

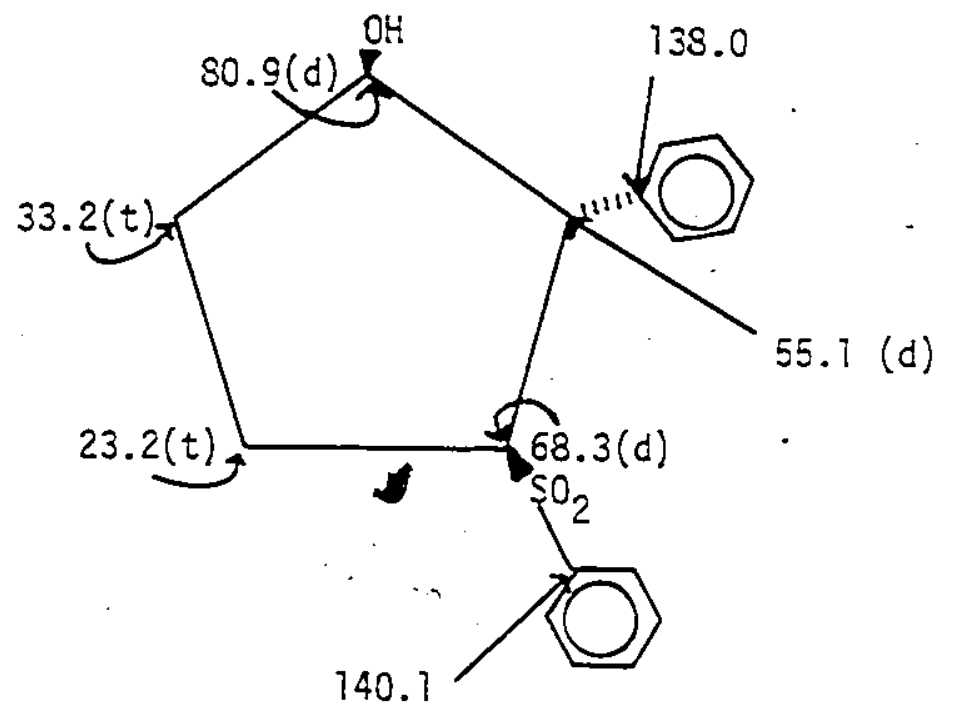




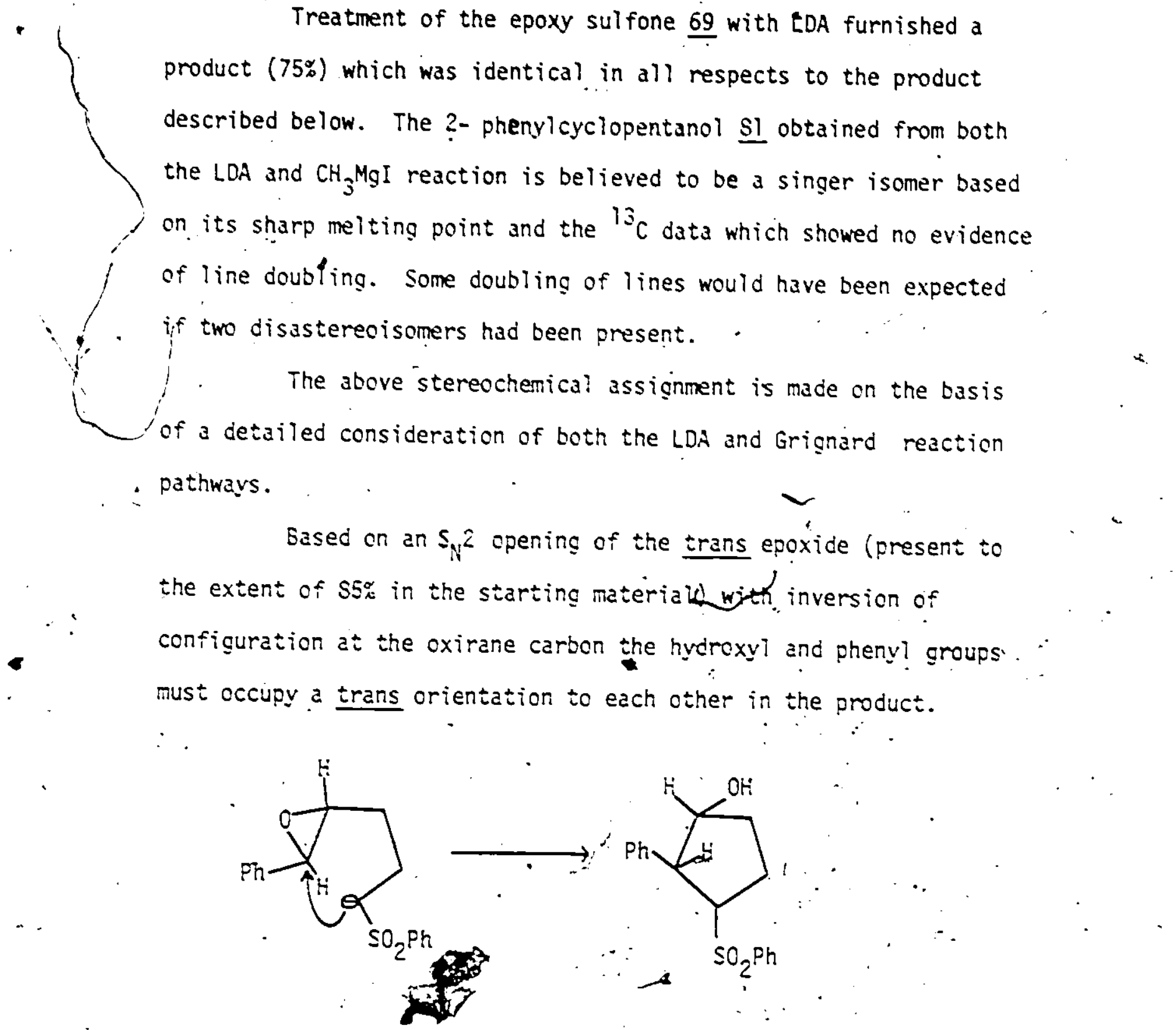

The cis orientation of the phenylsulfonyl and hydroxyl groups is assigned on the basis of evidence presented later (Stereochemstry section) regarding the relative stereochemistry of these groups in the $\mathrm{CH}_{3}$ MgI-mediated reaction. In addition this isomer, which is probably themodynamically more stable, may aristse via base-catalyzed epimerization of the C-3 carbon. 
- It was initially considered quite surprising that the same product was obtained from the LDA and Grignard reactions respectively. An examination of the mechantsmifor the formation of the cyclopentanol (Scheme 10$)$ from the $\mathrm{CH}_{3} \mathrm{MgI}$ reaction allows one to suggest an explanation.

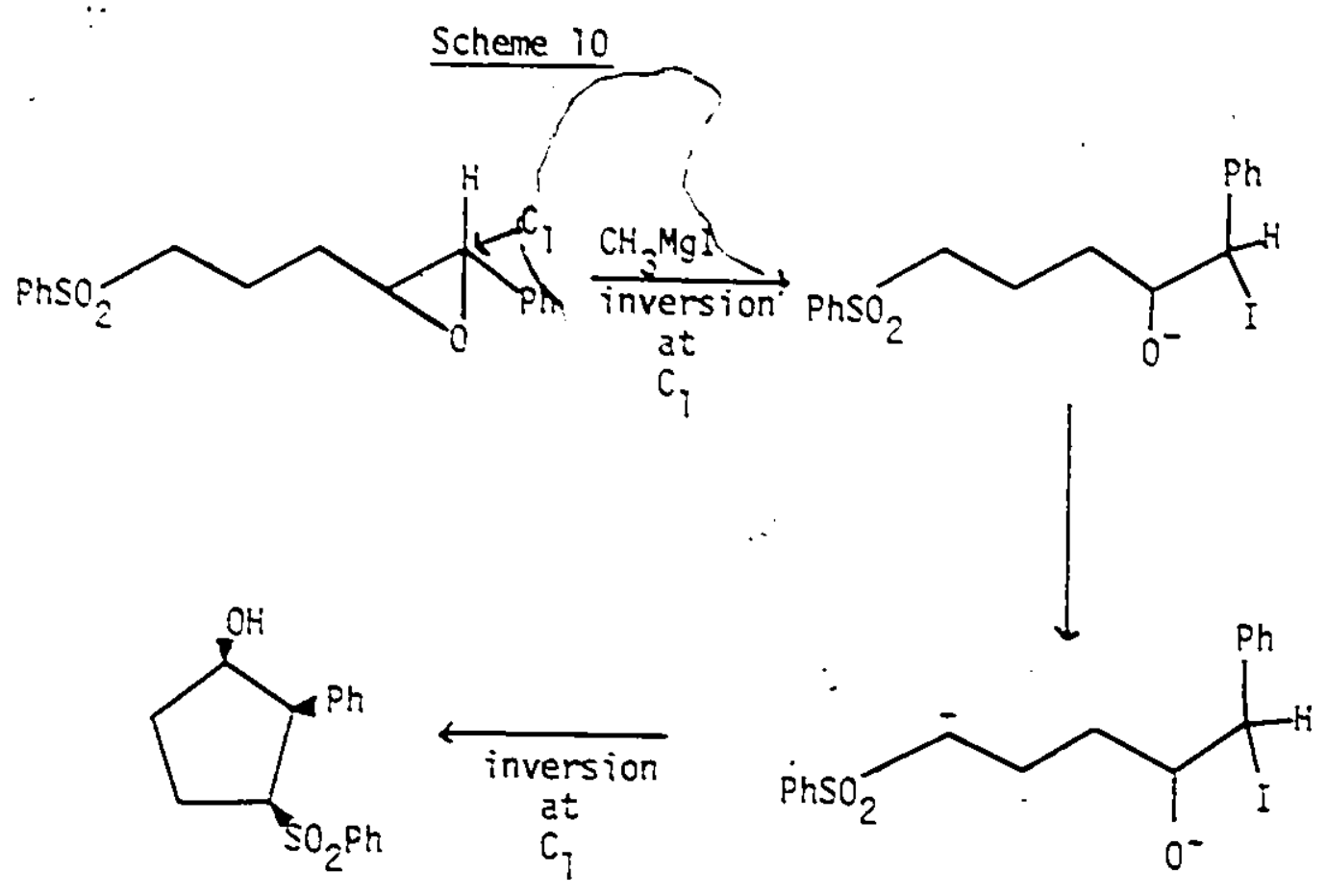

Initial opening of the epoxide to the iodo alkoxide proceeds with inversion of configuration at $C-l$. Subsequent a-sulfonyl anion formation followed by intramolecular $S_{N} 2$ displacement of the iodide (another inversion at C-l) would involve overall net retention of configuration at $\mathrm{C}-1$, thus leading to a cis disposition of the hydroxyl and phenyl groups in the cyclopentanol product. As has been indicated in the discussion of the LDA reaction such a cis arrangement is not possible in the LDA reaction. Since the same product is obtained in 
both reactions racemization at $f-1$ in the iodo alkoxide is reguired prior to cyclization. The mechanism of such an exchange may involve iodide catalyzed epimerization at-f- 1 .
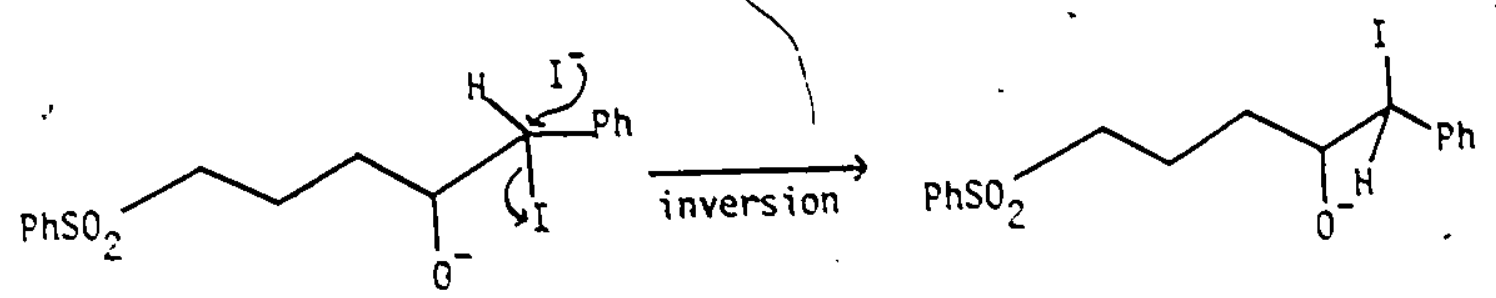

Cyclization of the diastereomer leading to trans hydroxy? and phenylsuifonyl groups is expected to be considerabiy faster than that leading to a product in which all three adjacent substituents are in a cis arrangement. That such a cyclization is unfavourable is also indicated by the fact that no cis product was observed in the LDA reaction of the epoxy sulfone 69 which was $15 \%$ cis as determined by NMR. Presumably the cis epoxy sulfone remains unreacted under LDA conditions.

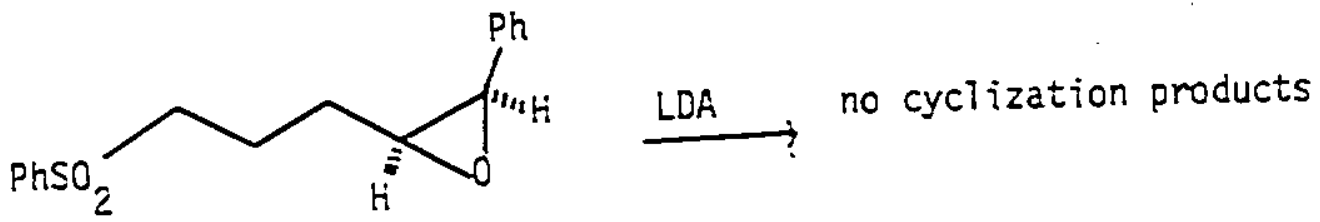


Grignard induced cyclization of the methyl epoxy sulfone $\underline{70}$ afforded the 2- methylcyclopentanol derivative $\underline{82}$ as a clear oil in $50 \%$ yield.
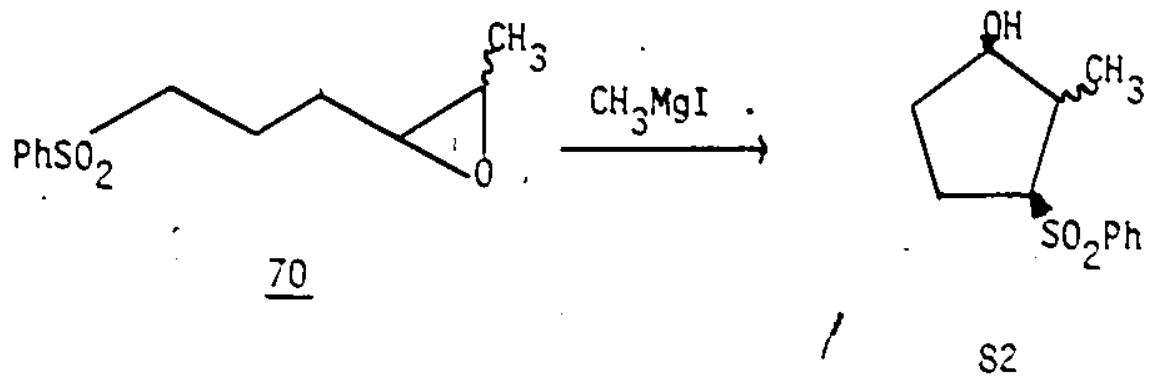

$\$ 2$

The ${ }^{7} H$ NMR of 82 showed signals at $\delta: 1.02(d, J=6 H z, 3 H), 1.6-2.5(\mathrm{~m}$, $5 \mathrm{H}), 2.5-2.9(\mathrm{iH}, \mathrm{OH}), 3.0-3.3(\mathrm{~m}, \mathrm{IH}), 3.6-3.9(\mathrm{~m}, 1 \mathrm{H})$, and $7.4-7.9(\mathrm{~m}$, $5 \mathrm{H})$; iR $3450(\mathrm{OH})$. and $1150,1300 \mathrm{~cm}^{-1}\left(\mathrm{SO}_{2}\right)$.

The ${ }^{1{ }} \mathrm{C}$ NMR data, shown below also supported the assigned structure.

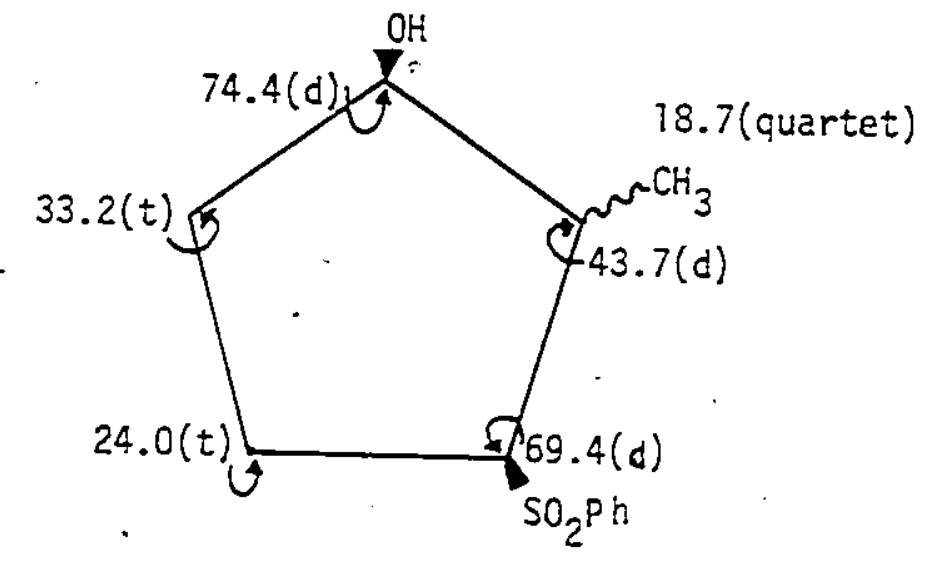


The structure of $\underline{82}$ was further verified by careful Jones oxidation to the keto sulfone $\underline{83}$ which showed the carbonyl stretch at, $1750 \mathrm{~cm}^{-1}$ in its infrared spectrum and NMR peaks at $\delta 1.13(d, J=6 \mathrm{~Hz}$, $3 H), 2.0-2.5(m, 5 H), 3.3-3.5(m, i H)$ and $7.5-5.0(m, 5 H)$.

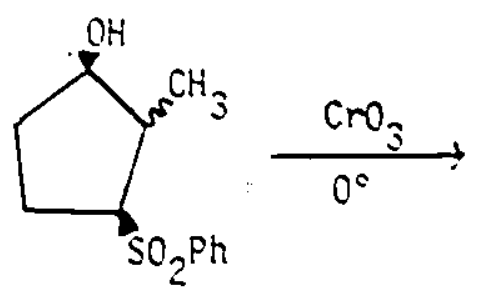

$\underline{\mathrm{S}}$

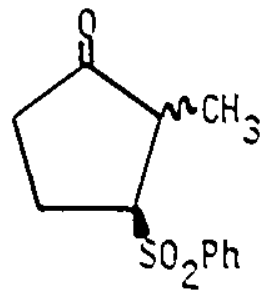

$\underline{83}$

The epoxy sulfone 70 , when reacted with $L D A$ provided a product whose structure was not established.

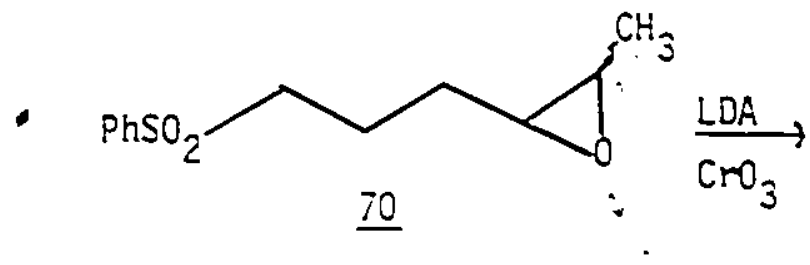

The ${ }^{13} \mathrm{C}$ NMR spectrum of the product (s) indicated twelve nonaromatic carbons suggesting a dimeric structure. Assignments from the off-resonance partially coupled spectrum were not possible due to extensive overlap. The infrared spectrum showed that $\mathrm{OH}\left(3400 \mathrm{~cm}^{-1}\right)$ and sulfone $\left(1155,1378 \mathrm{~cm}^{-1}\right)$ units were present. Treatment of the above compound(s) with $\mathrm{CrO}_{3}$ followed by $\mathrm{NEt}_{3}$ yielded a product which 
Q

WMR had retained the $\mathrm{PhSO}_{2}$ grouping; no olefinic hydrogens were present. The infrared spectrum of this product indicated that oxidation had occurred as evidenced by disappearance of. the hydroxyl band and appearance of carbonyl stretching frequencies at 1715 and $1745 \mathrm{~cm}^{-1}$. The above data suggests that a p-hydroxy sulfone unit is not present since the base treatment should have resulted in the elimination of $\mathrm{PhSO}_{2} \mathrm{H}$ and formation of an enone. The available data are somewhat conflicting and it is not possible to suggest a structure for this reaction product $(s)$.

Conclusions

Some mechanistic aspects of the Grignard reaction have already been described. A further and more complete discussion is presented in the section on Mechanism.

6 The results obtained with the LDA reactions of internaliy substituted epoxy sulfones $\underline{69}$ and $\underline{70}$ are contrary to expectations based on literature precedence. Formation of the cyclopentanol derivative 81 from the phenyl epoxy sulfone 69 is contrary to Stork's $(\bar{l}, 8)$ prediction of preferrentiai cyclobutane formation with equal substitution on the epoxide. Cyclopentanol, formation is not unexpected considering the work reported by La?lemand and Onanga (is) who reported that reaction of trans c-epoxy nitriles with sodamide in dry THF afforded a mixture of cyclobutyl and cyclopentyi derivatives in a 2/1 katio with the cyclopentane derivatives predominating whereas reaction of the cis epoxides gave exclusiveiy syclobutyl derivatives.

In our cyclization of 69 no cyclobutyl derivatives were 
observed. Possibly the presence of the phenyl group which is known to accelerate $S_{N} 2$ reactions at the benzylic position accounts for this result.

Faiture of the methyl epoxy sulfone $\underline{70}$ to give monomeric cyclic products was completely contrary to all expectations. Since the starting epoxy sulfone 70 was a 50:50 cis/trans mixture both fourand five-membered ring products were expected; but unfortunately none were obtained. 


\section{Synthesis of Non-Sulfur Containing Derivatives}

From the 3-Phenylsulfonyl Cycloalkanols

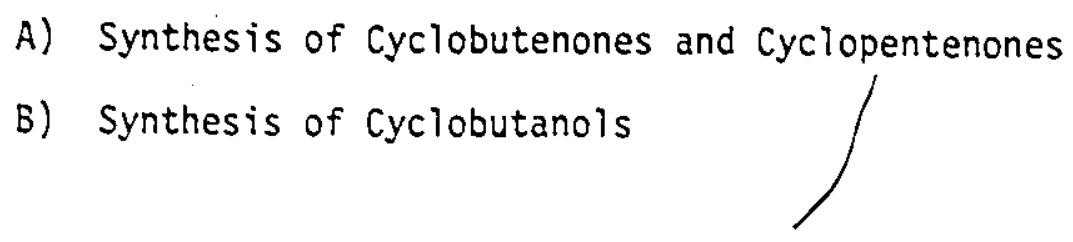

Introduction

One of the general goals of our research is to utilize sulfurstabilized carbanions to direct formation of $\mathrm{C}-\mathrm{C}$ bonds and then remove the sulfur function thereby generating sulfur free compounds. It was therefore decided to apply the known methods for removal of $\mathrm{PhSO}_{2}$ from the 3 -phenyisulfonylcycloalkanols.

\section{(i) Reductive elimination}

The work of the two groups, Kondo (37) in Japan and Julia (38) in France, have shown that $\beta$-keto sulfones are excellent precursors to a, B-unsaturated ketones. An application of this elimination to the synthesis of more complex enones starting from simple vinyl ketones is sumarized in Scheme 11. Typically an aryl-or a?kylsulfonyl group $B$ to a ketone can be simply removed by treatment with mild bases such as triethylamine or DBU in methylene chioride. 

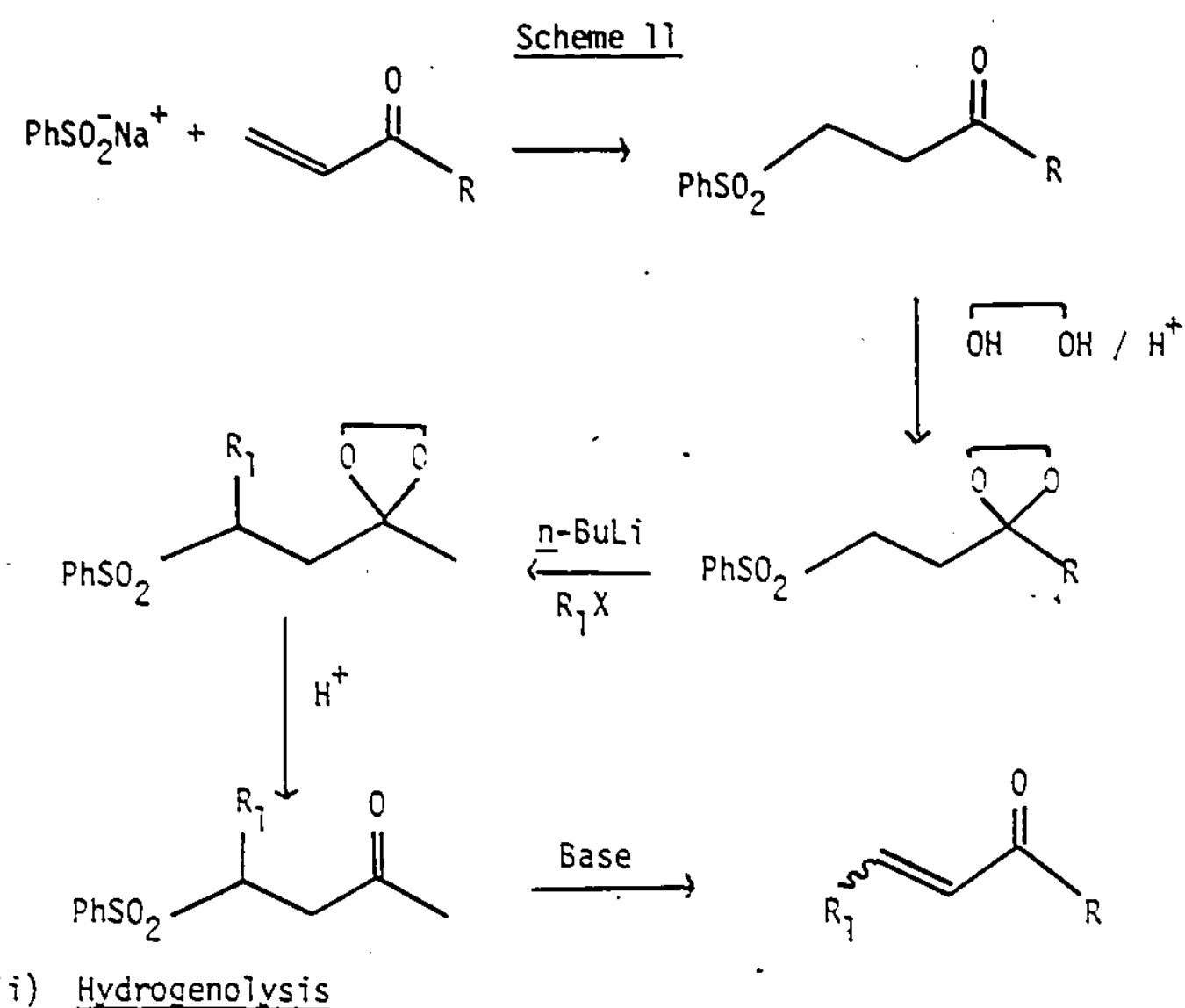

(ii) Hydrogenoivsis

Many methods for replacement of a phenylsulfonyl group with hydrogen have been worked out.

$$
\mathrm{R}-\mathrm{SO}_{2} \mathrm{Ph} \longrightarrow \mathrm{R}-\mathrm{H}
$$

The most important of the methods availabie for the transformation of a $\mathrm{C}-\mathrm{S}$ bond into a $\mathrm{C}-\mathrm{H}$ bond have been Raney nickel (39), Tithium in alkylamines (40) and sodium amalgam (41). Reduction of aryl alkyl sulfones can sometimes be complicated by reduction of the aromatic ring without cleavage of the alkyi sulfur bond. The most effective method of removing the phenylsulfonyl group is that of posner and Brunelle (41). Treatment of sulfones 84 with $6 \% \mathrm{Na}$ amalgam in 
refluxing absolute ethanol provides excellent yieids of the desulfonylated materials $\underline{85}$.<smiles>[Y]C([Y])C(=O)Oc1ccccc1</smiles>

$\underline{54}$

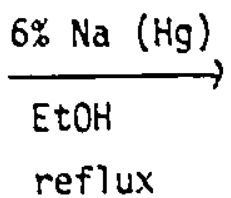

reflux<smiles>[Y]CC[Y]</smiles>

$\underline{S 5}$

A milder procedure for the effective removal of the phenyisulfonyl group from $\alpha$-phenylsulfonyl esters has been developed by Trost et al (42). Treatment of the sulfones $\underline{S 6}$ with excess $6 \%$ $\mathrm{Na}(\mathrm{Hg})$ in methanol containing four equivalents of disodium hydrogen phosphate at room temperature led to excelient yields of desulfonylation products $\underline{\mathrm{Si}}$.

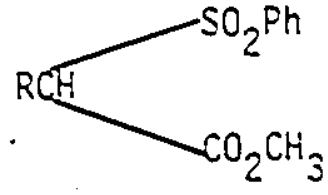

86

$$
\stackrel{\sigma_{*}^{*} \mathrm{Na}(\mathrm{Hg})}{\longrightarrow} \quad \mathrm{RCH}_{2} \mathrm{CO}_{2} \mathrm{CH}_{3}
$$$$
\text { R.T. }
$$ 
(iii)

Oxidative Elimination

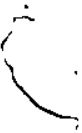

The possibility of oxidative removal of the phenylsulfonyl group to give a ketone has not been described in the literature. It was briefly investigated during this work and will be described in part II of the thesis.

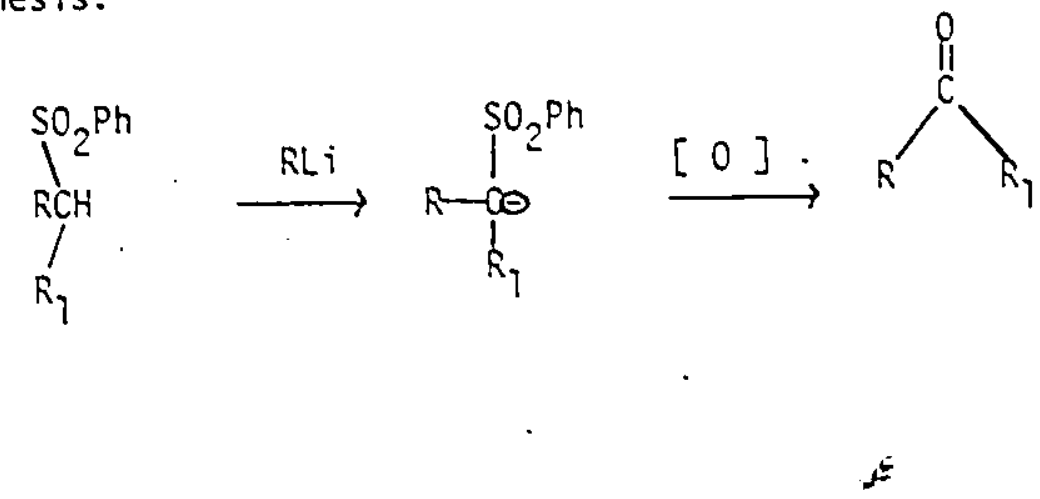

A) Sunthesis of Crclobutenones and Cvclopentenones

Since the epoxy sulfone cyclization led to 3 -phenylsuifonyi cyclobutanols and cyclopentanols it was recognized that simple oxidation to the corresponding cycloalkanones followed by mild base treatment would result in the formation of cyclobutenones and cyciopentenones.

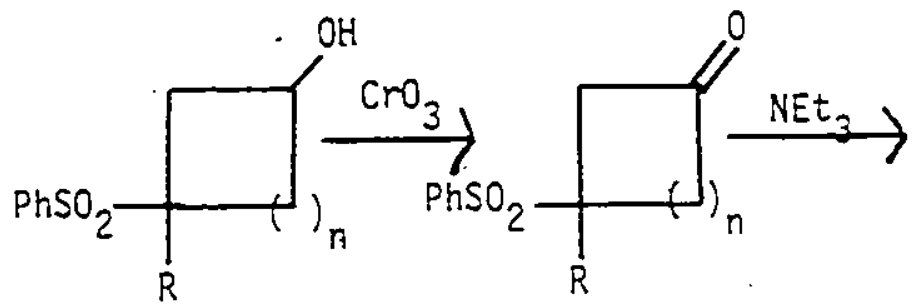

$\underline{88}$

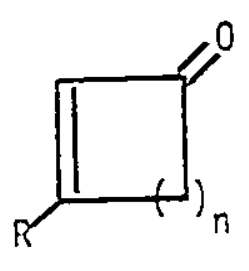

$\underline{89}$ 
The scope of this route, especially to a variety of 3substituted derivatives $\underline{89}$ is relatively wide since a variety of 3substituted derivatives of $\underline{88}$ can be prepared by two possibie routes.

The first consists of starting with an appropriately substituted epoxy sulfone. This route has been applied to $Y$ and $\delta$-epoxy sulfones.

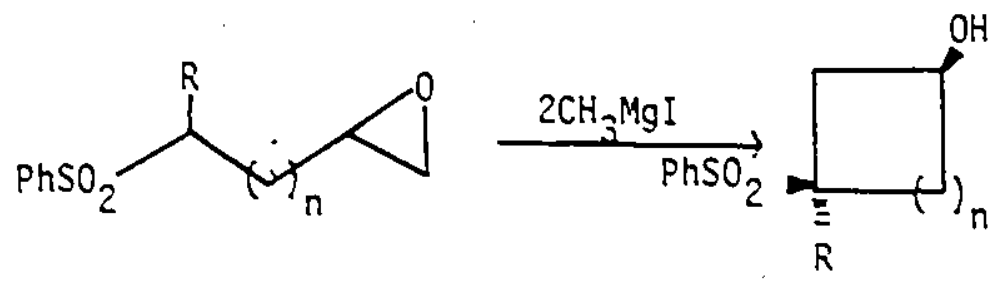

$$
n=1,2
$$

A more versatile route involves the use of the readily available parent compounds $\underline{73}$ and $\underline{75}$. (Scheme 12)

\section{Scheme 12}

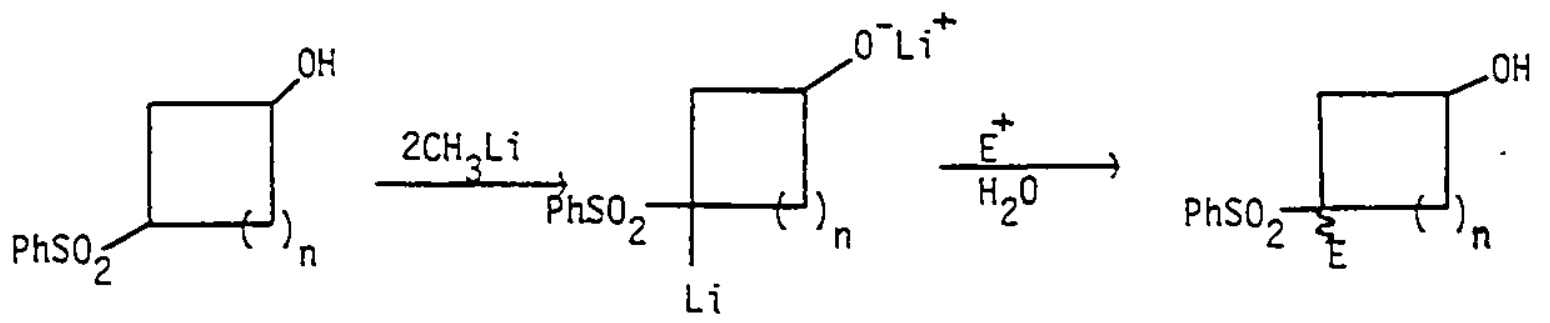

그 $n=1$

$\underline{75} \quad n=2$

The alkylation reactions were carried out by treatment of the parent cycloalkanol with two equivalents of methyllithium at $-70^{\circ}$ in THF, followed by trapping of the a-sulfonyl carbanion with various electrophiles (Table III). No 0-alkylation products were 
observed under these conditions.

The reported yields in Table III are for chromatographically pure compounds. The structures of these compounds were established on the basis of their spectral and analytical data (see Experimental Section). The yields of products derived from the alkylation reaction are remarkably high considering that a quarternary center is being generated. For example, the bulky a-sulfonyl carbanion (which can be considered equivalent to a neopentyl situation) is readily trapped $(71 \%)$ by the secondary halide, isopropyl bromide.

The formation of diastereomeric mixtures was observed via the alkylation route. This was not important since oxidation converted both diastereomers into the same product.

Table III

Alkylation of 3-Phenylsulfonyl Cycloalkanols

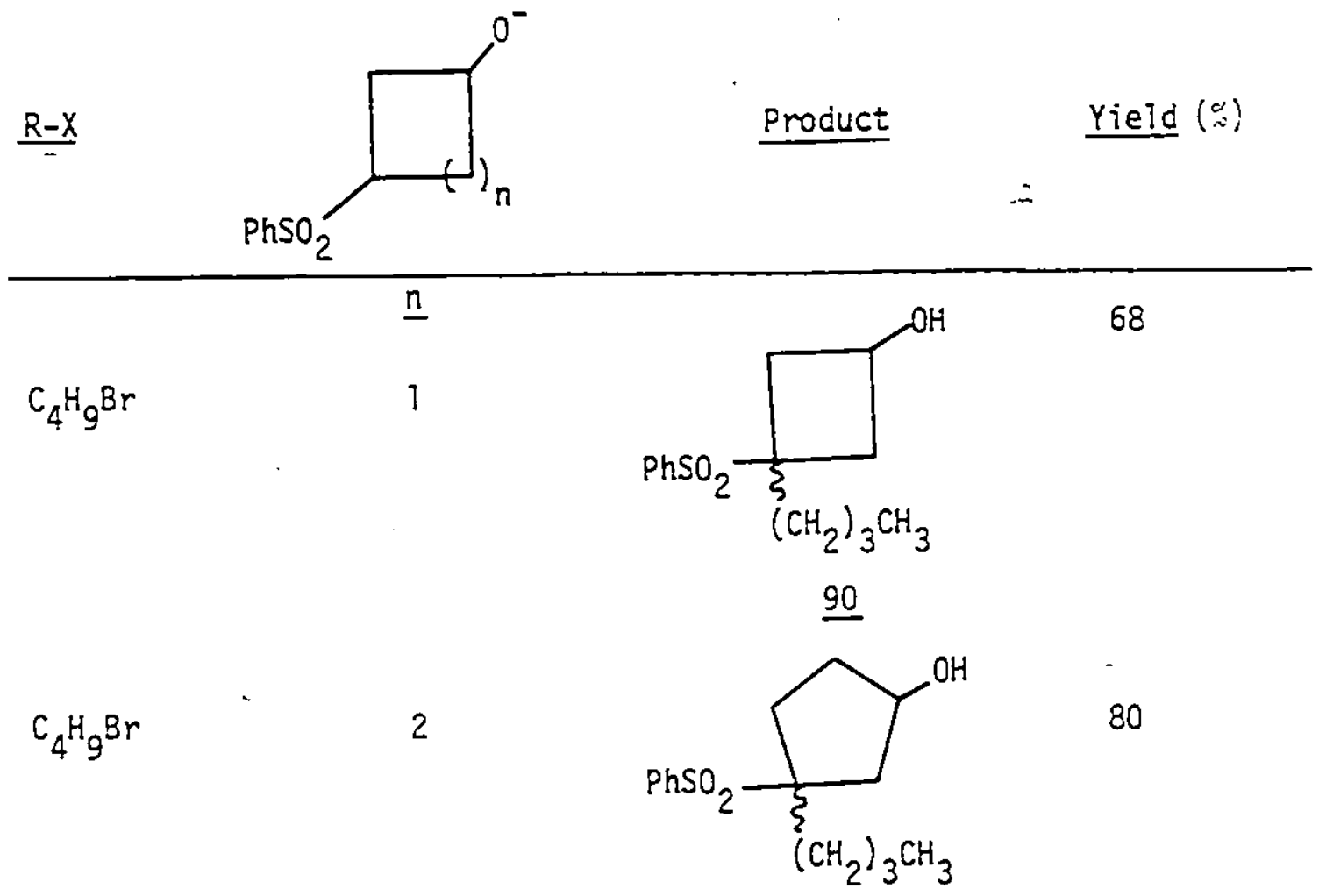


Table III (cont'd)

$C_{7} H_{15} 8 r$

$\mathrm{PH}_{2} \mathrm{CH}_{2} \mathrm{Br}$

2

$\left(\mathrm{CH}_{3}\right)_{2} \mathrm{CHBr}$

$i$

1
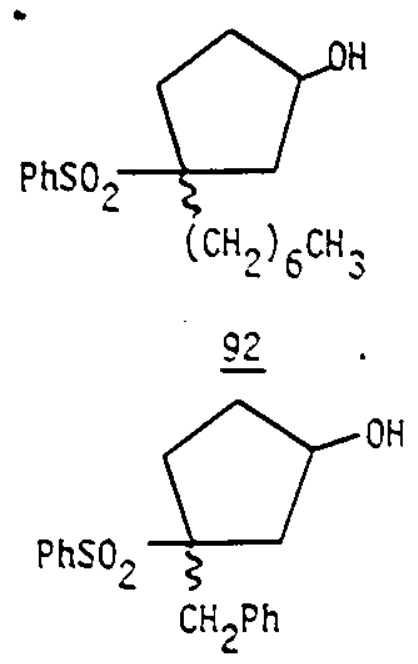

93

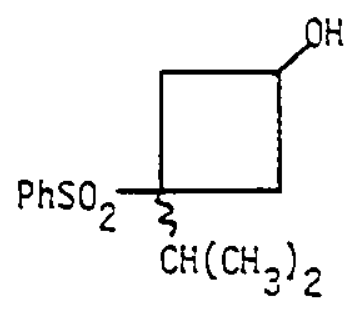

$\underline{94}$

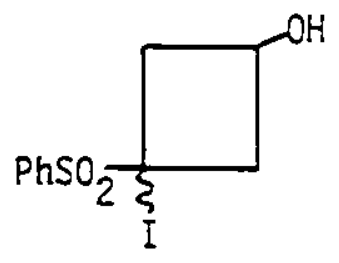

$\underline{95}$

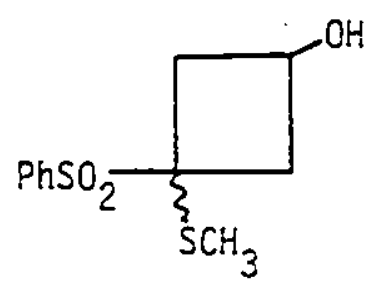

$\underline{96}$

$\mathrm{CH}_{3}-\mathrm{S}-\mathrm{S}-\mathrm{CH}_{3}$

1

* 64\% based on $I_{2}$ 
Oxidation and Elimination Reactions of the 3-Phenylsulfonyl Crcloalkanols

The cyclobutenones and cyclopentenones obtained via the oxidation/elimination route are presented in Table IV. Oxidation of the cyclobutanols and cyclopentanols with Jones reagent (43) led in excellent yields (generally 90*) to the corresponding ketones. The s-sulfonylcyclobutenones could be isolated and purified readily. Subsequent treatment with triethylamine in methylene chloride at room temperature furnished the cyclobutenones. Due to the ease of eimination of the phenylsulfonyl sroup from the 3-phenyisulfonyl cyciopentanones, these intermediate compounds were usually not purified but converted directly to the cyclopentenones. When the crude oxidation product was examined by TLC the presence of cyciopentenones was observed.

The cyciobutenones showed the carbonyl frequency at about $1760 \mathrm{~cm}^{-1}$ and the olefinic stretch at $1580-1600 \mathrm{~cm}^{-1}$ in the infrared spectra. The NMR of these substances each had two slightly broadened singiets at about $\bar{c} 3.2(2 \mathrm{H})$ and 5.8-6.0 (1H) assignabie to the remaining methylene and olefinic hydrogens in the ring.

The various 3-alkylcyciopentenones each showed a one proton multiplet in the $55.9-6.0$ region assignabie to the olefinic hydrogen in the ring. The carbonyl and olefinic frequencies in the infrared were observed at $1700-1720 \mathrm{~cm}^{-1}$ and at $1620-1630 \mathrm{~cm}^{-1}$ respectively.

Also accessible by the oxidation/elimination route is 2phenylcyclopentenone 102 which was obtained in $75 \%$ yieid by treatment of 


\section{Crable IV}

Conversion of 3-Phenylsulfonyl Cycloalkanols into

3-Substituted Crclobutenones and Crclopentenones

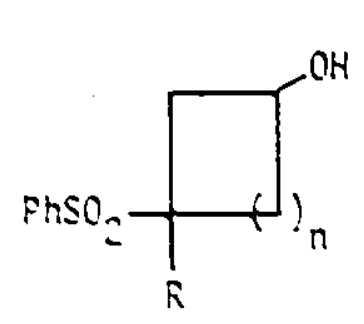

$\underline{n}$

1

I

$i$.

I

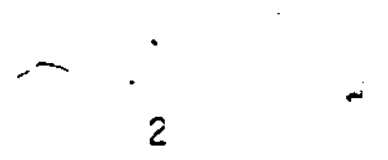

2

2

2

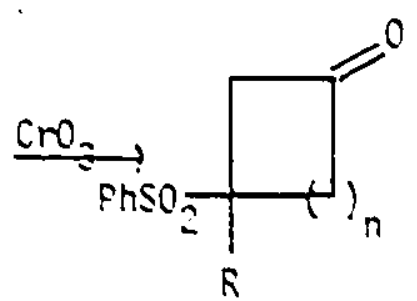

$\underline{R}$

$\mathrm{Ph}$ *

$n-C_{-1} H_{15}^{*}$

$\mathrm{C}_{4} \mathrm{H}_{9}^{*}$

iso $-\mathrm{C}_{3} \mathrm{H}_{7}$

gi.

$\mathrm{Ph}$

$\underline{98}$

$\mathrm{CH}_{2} \mathrm{Ph}$

99

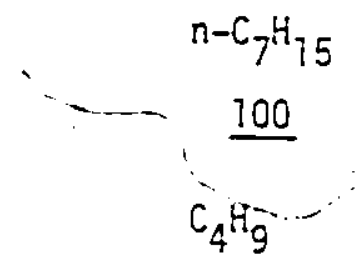

101<smiles>CCNC1=CC(=O)C1</smiles>

\& Yield

so

S3

so

\$2

75

87

75

85

* Prepared by B. Corbe? 
$\because \quad 81$ under the usual conditions. The structure of 102 was established on the basis of its m.p. $67-68^{\circ}$ (Lit. $\left.71^{\circ}\right)(44)$ and its spectral data. In particular, the carbonyl stretch at $1725 \mathrm{~cm}^{-1}$ (Lit. 1726)(44) and the deshielding of $H_{A}(57.34-7.45)$ by the proximate s-phenyl and s-carbonyl groups.

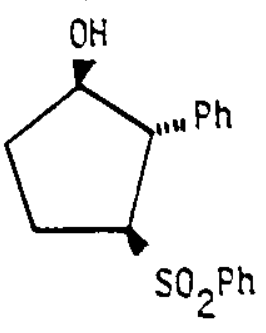

si

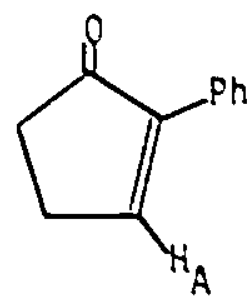

102

In principle this route mav also be applied to the synthesis of 2,3-disubstituted cyclopentenones starting from 2-substituted-3 phenyisulfonyl cyclopentanols as is itlustrated in Scheme 13. Such intemediates 103 have been used as prostaglandin precursors (45).

\section{Scheme 13}
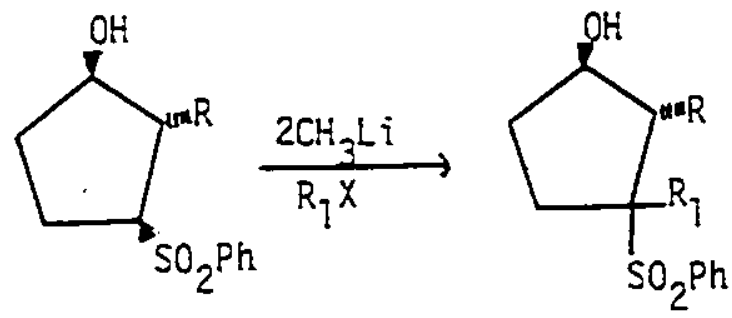

1) $\stackrel{\mathrm{CrO}_{3}}{\longrightarrow}$

2) $\mathrm{NEt}_{3}$<smiles>[R]C1=C([R])CCC1</smiles>

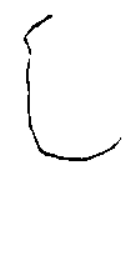
$\mathrm{R}=\mathrm{CH}_{3}, \mathrm{Ph}$ 
The synthetic scope of the epoxy sulfone cyclization reaction as applied to enone synthes is is sumarized in Table $v$.

Table $v$

Synthetic Scope of Epoxy Sulfone Cyclization<smiles>O=C(O)C([AlH2])CC1CO1</smiles><smiles></smiles>

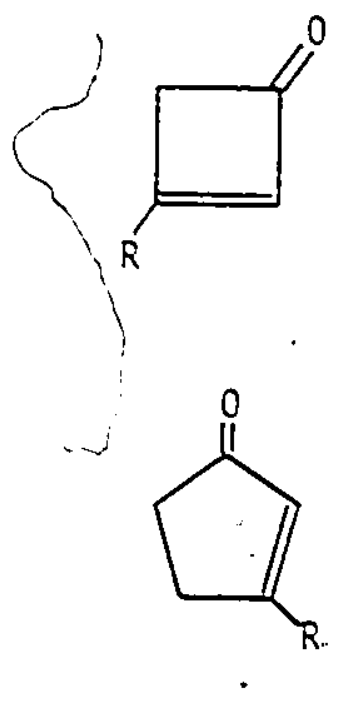

4

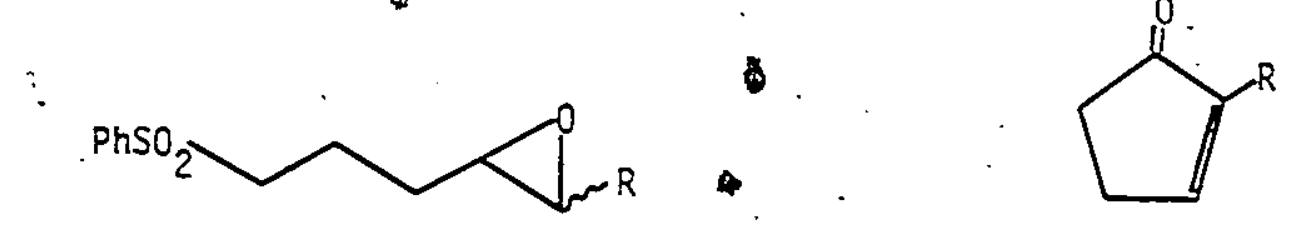

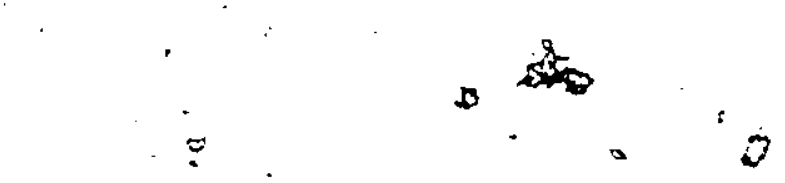

0<smiles>[R10]C(CCC1OC1[R7])C(=O)O</smiles><smiles>[R]C1=C([R])C(=O)CC1</smiles>

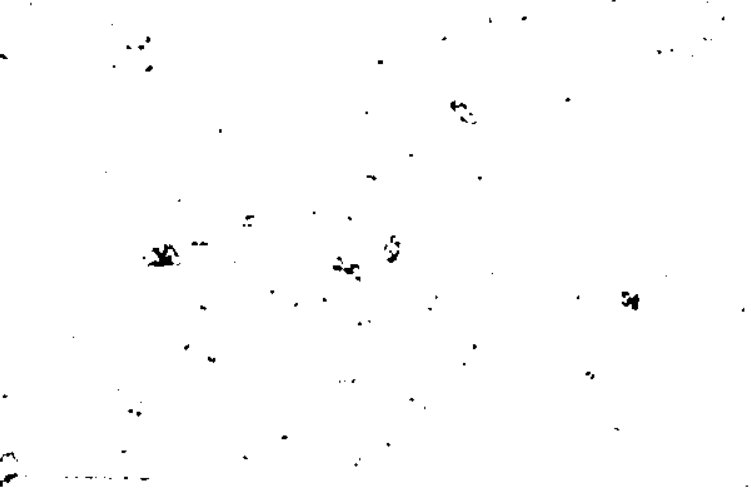




\section{Other Routes to Cyclobutenones and Cyclopentenones}

Cyclobutenones

The synthesis of cyclobutenones has most often involved cycloaddition of ketenes or allenes to unsaturated systems.

Thus, the first reported (46) isolation of cyclobutenone 104 involved cycloaddition of allene to acrylonitrile as the initial step. (Scheme 14)
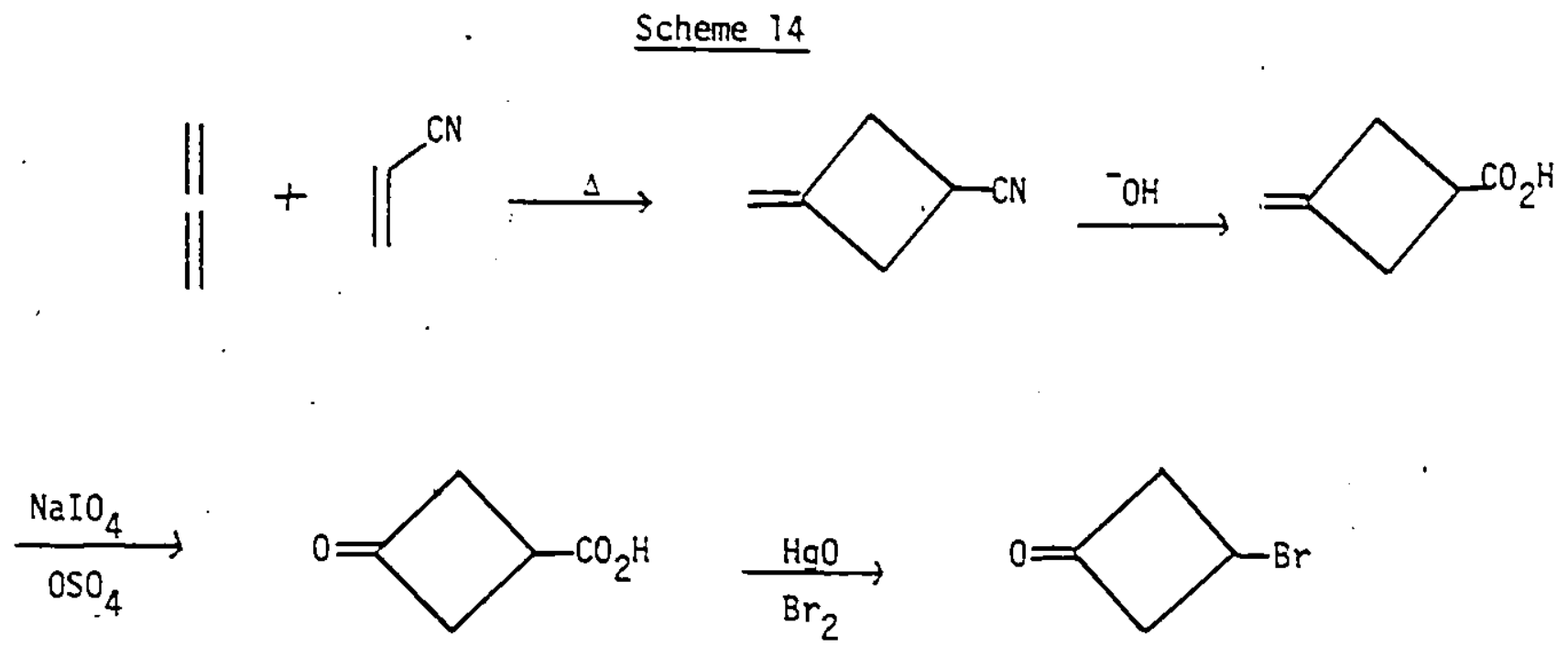

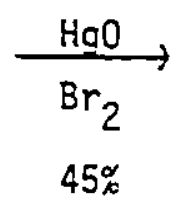

$45^{\circ}$

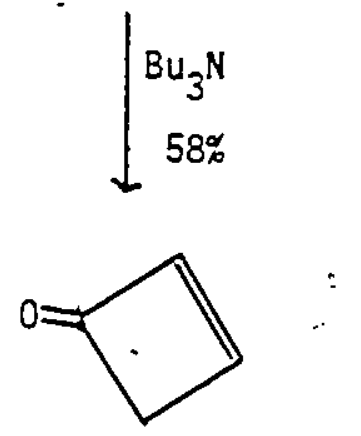

104

Wasserman and coworkers (47) prepared various 3-substituted 
derivatives of 104 by first carrying out a cycloaddition between ketene and ethoxyacetylene to yield $\underline{105}$. The ethoxy group can easily be replaced by the alkyl or aryi group of a Grignard reagent via an addition-el imination sequence.

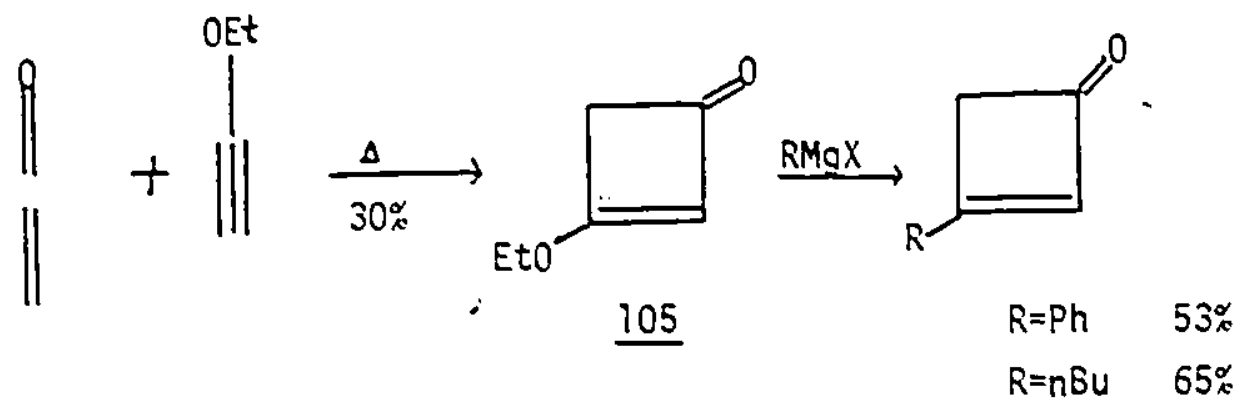

A more recent approach to cyclobutenones has involved the silica catalyzed elimination of alcohols from 3-alkoxy cyclobutenones (4S). These 3-a]koxy derivatives 106 were obtained by reaction of ketenes with vinyi ethers.

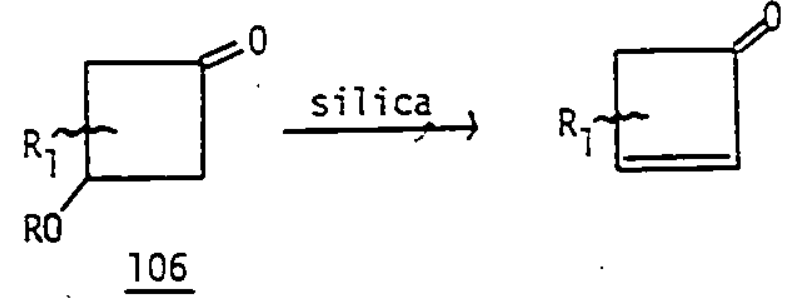

Kelly and McNutt (49) have show that vinyi sulfides also add to some ketenes. For example, 4,4-dimethyl-3-thiomethyl cyclobutenone 107 was prepared from methyl vinyl sulfide and dimethy? ketene. Subsequent methylation followed by elimination of dimethyl sulfide furnished 4;4-dimethycyclobutenone 108 in $40 \%$ overall yield. (Scheme 15) 


\section{Scheme 15}<smiles>C=C[C-]C(C)=C=O</smiles><smiles>CCC1CC(=O)C1(C)C</smiles>

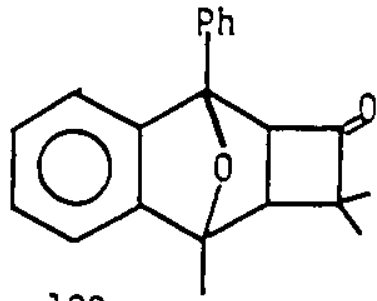

109
107

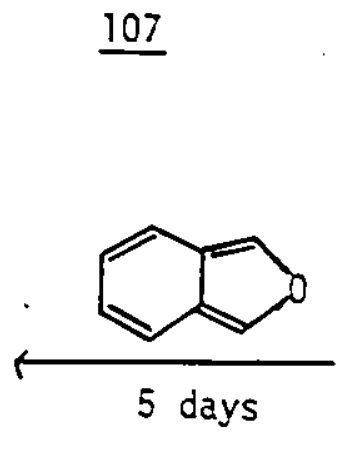

RT

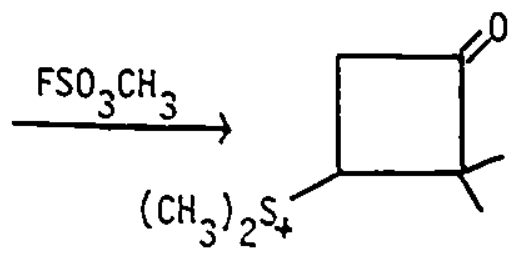

quinol ine DMSO

These authors also provided the first demonstration of the Diels-Aider reactivity of a cyclobutenone by trapping 108 with $1,3-$ diphenylisobenzofuran to give 109 in $62 \%$ yield. Trapping of 108 with cyclopentadiene also proceeded in "good" yield but required $\mathrm{BF}_{3}\left(\mathrm{Et}_{2} \mathrm{O}\right)_{2}$ catalysis.

Our own attempt to trap the cyclobutenone 110 with trans, trans-hexa-2,4-diene was not successful. The effect of varying reaction conditions and the use of more active dienes was not investigated due to a lack of time.

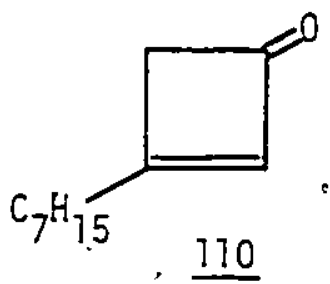<smiles>C/C=C\C=C/C</smiles>

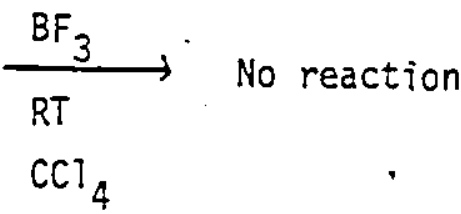


Our route adds significantly to the availaple synthetic methodology for the synthesis of cyclobutenones, mainly, since an initial cycloaddition reaction to ketenes or allenes is not required.

\section{Cyclopentenones}

Cyclopentenones are accessible via several other routes.

The most important of these routes, aldol condensation of $\gamma$-diketones, is well described in House's monograph "Modern Synthetic Reactions " (50).<smiles>CC(=O)CCC(C)=O</smiles>

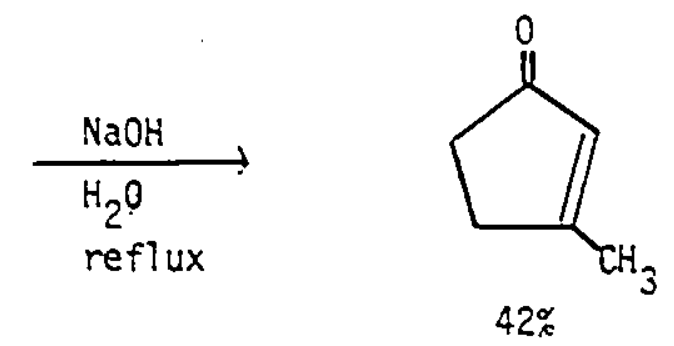<smiles>CC(=O)CCC(=O)C[AsH]</smiles>

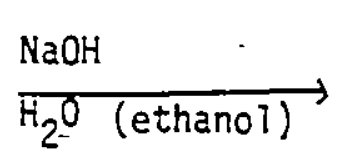
refiux<smiles>CC1=C(C=S)C(=O)CC1</smiles>

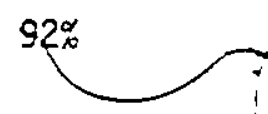

Recent work in this area has concentrated on developing new routes

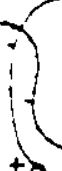
1,4 diketones (51).

Another route to 2,3-disubstituted cyclopentenones employing B-epoxy sulfone 111 has recently been reported by Conrad and Fuchs (52).

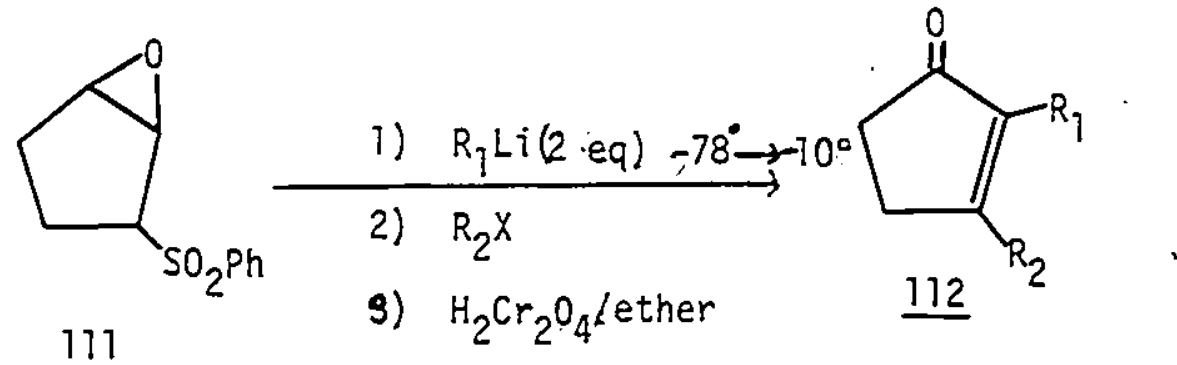

111

4) $D B U$ 
- Treatment of the epoxy sulfone 111 with two equivalents of an alkyl lithium results in formation of the dianion 114 via initial conjugate opening of the epoxide followed by Michael addition to the $a, \beta$-unsaturated sulfone 113 . Addition of an alkylating agent to 114 provides, after quenching, the same types of hydroxy sulfones which we obtained via $\delta$-epoxy sulfone cyclization.

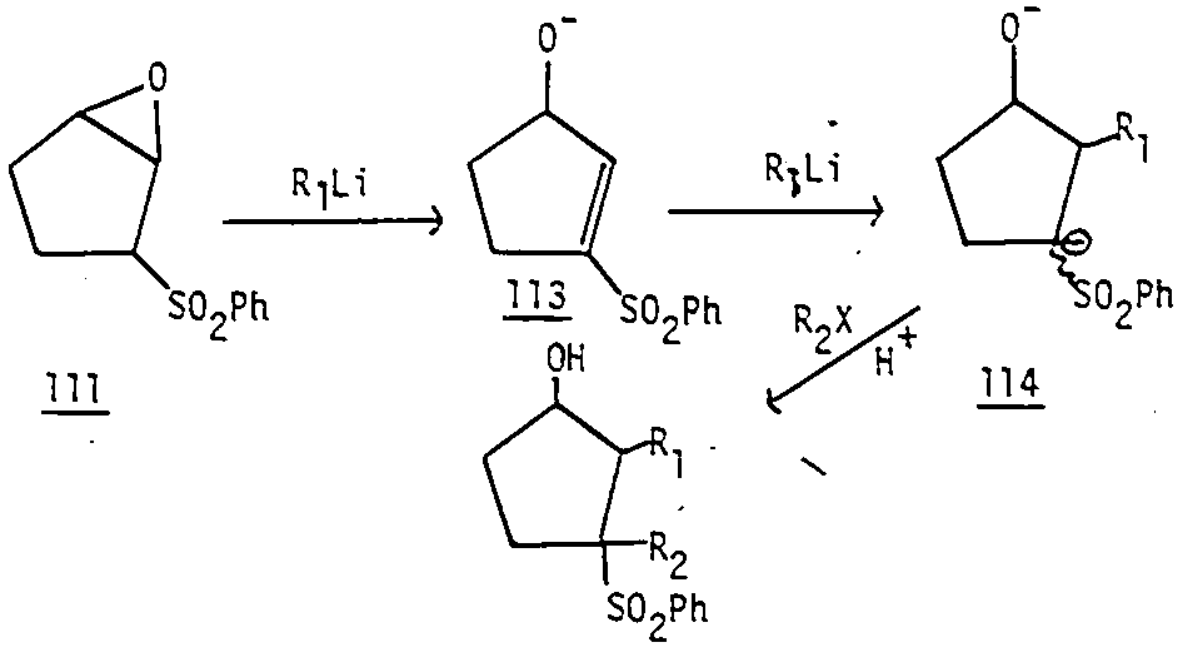

Attempted Cyclopropene Synthesis

Based on the relative ease of elimination of $\mathrm{PhSO}_{2}$ from 8-keto sulfones in the four and five-membered ring series we considered the same type of elimination of $\mathrm{PhSO}_{2} \mathrm{H}$ from 115 to generate cyclopropenes 116 in which the double bond was conjugated to a carbonyl group.
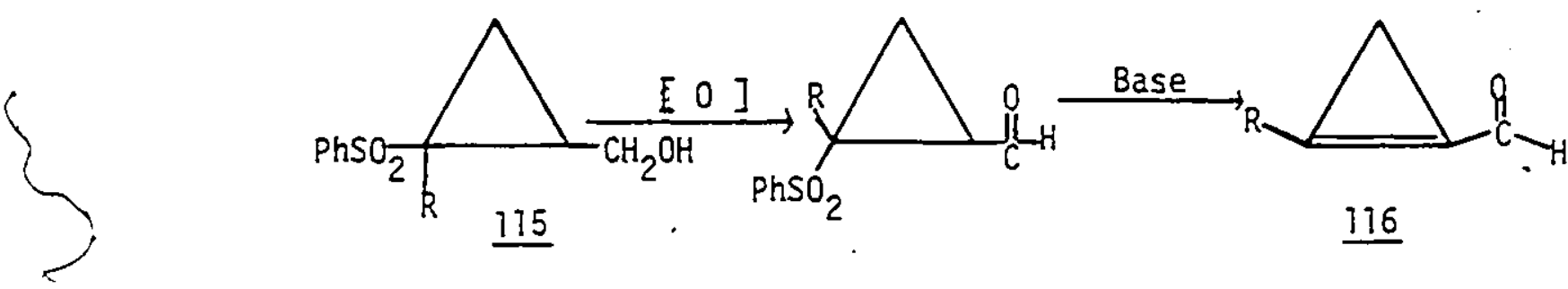
The reactions were to be attempted with systems bearing an alkyl group at $\mathrm{C}-1$. Compounds $\underline{115}$ were considered to be most readily available from 117 by $\mathrm{C}$-alkylation of the dianion 118 similar to that described for the four and five-membered ring series.

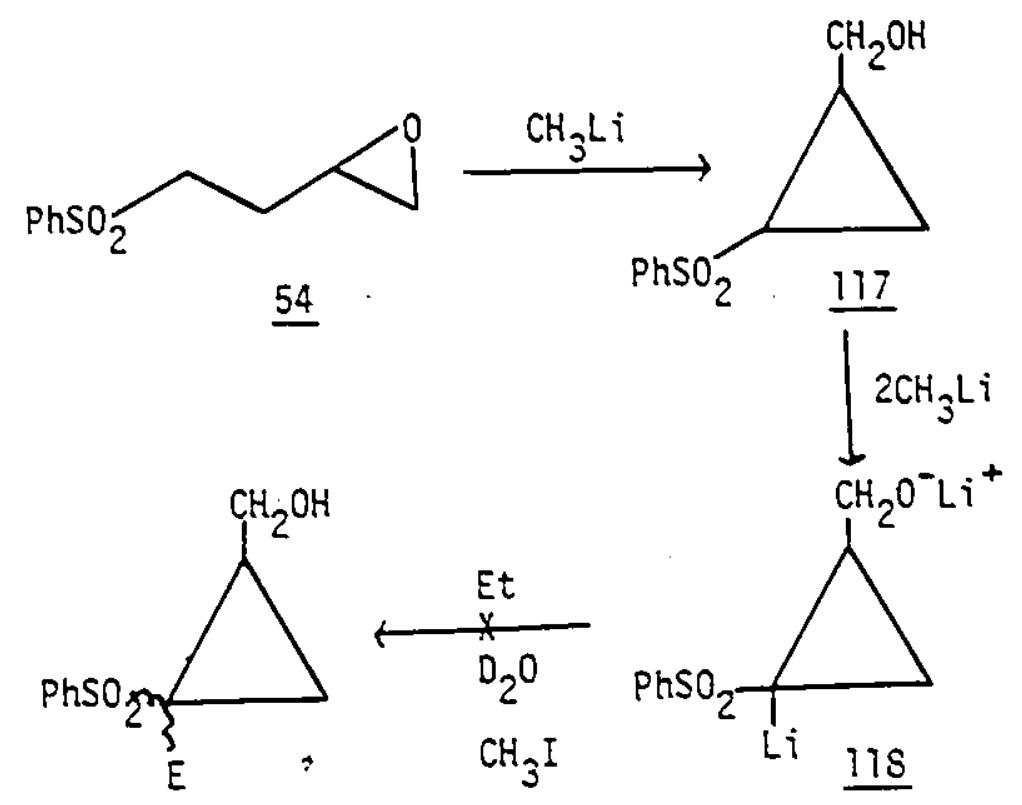

Attempts to generate and trap the dianion 118 of the cyclopropyl sulfone 117 were, however, not successful. The cyclopropyl derivative 117 when treated with two equivalents of $\mathrm{CH}_{3} \mathrm{Li}$ at either $-78^{\circ}$ or room temperature followed by quenching with $D_{2} \mathrm{O}$ or iodomethane shows no incorporation of either deuterium or a methyl group. A possible explanation for these results may be that the dianion is not formed under our conditions. This is unlikely considering the ease with which cyclopropyl sulfones have been alkylated. For example, Chang and Pinnick (53) obtained excellent yields in alkylations of cyclopropyl phenyl sulfone 119 . 


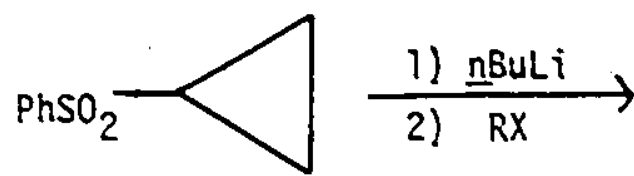

119

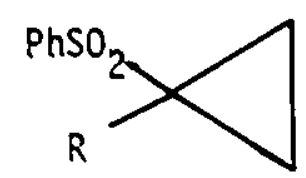

85\%

$$
\mathrm{R}=\mathrm{CH}_{3}, \mathrm{CH}_{2} \mathrm{Ph}, \mathrm{al} \mathrm{kyl}
$$

Furthermore, we and others have had no difficulty in alkylating 1,3-dianions of the type shown below.

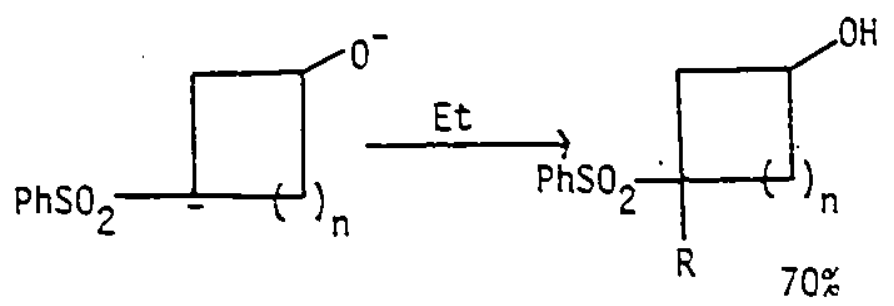

A more plausible explanation is that the dianion 118 , once formed, undergoes reaction with the solvent THF thereby generating the alkoxide, olefin and enolate.

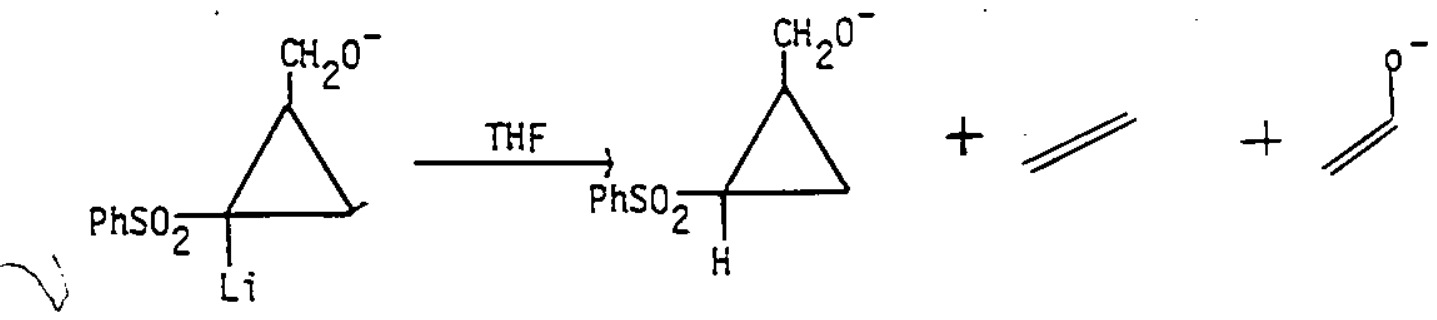

Similar unusual behaviour has been observed by Trost (54) in the case of the related sulfoxide 120. He too was unable to trap the dianion 121. with typical electrophiles such as aldehydes and ketones. It was shown that generdion of the dianion 121 in THF-d resulted in formation of the deutero denjuative 122 . 


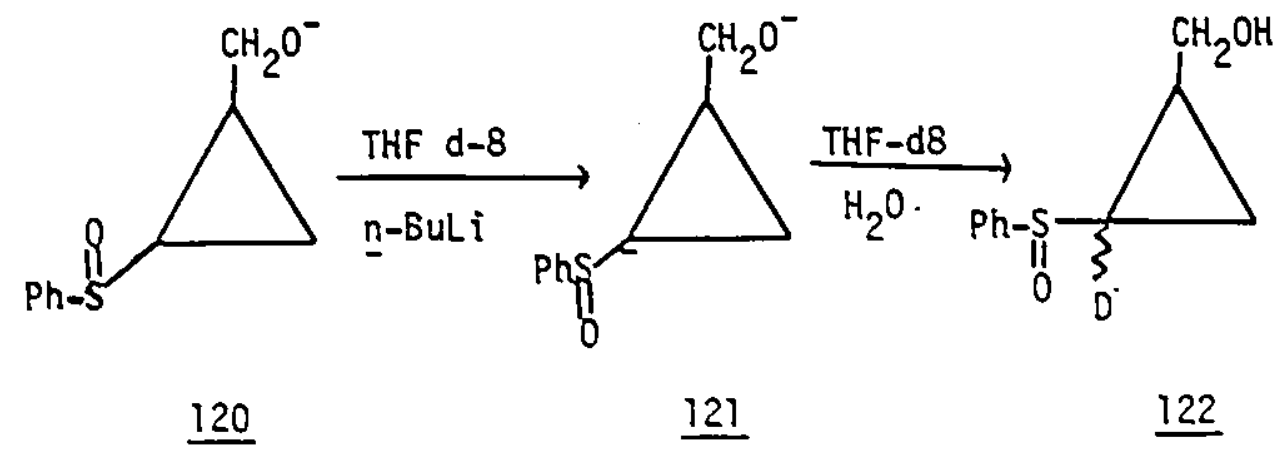

Part B-Cyclobutanols

The preparation of cyciobutanols was carried out according to the Trost (42) procedure. Thus, treatment of the s-phenylsulfonyl cyclobutanols $\underline{79}$ and $\underline{123}$ with excess $\mathrm{Na} / \mathrm{Hg}$ in "Spectrograde" methanol containing four equivalents of sodium dihydrogen phosphate resulted in the desulfonylated products $\underline{124}$ and $\underline{125}$ in 80 and $85 \%$ isolated yields respectively.

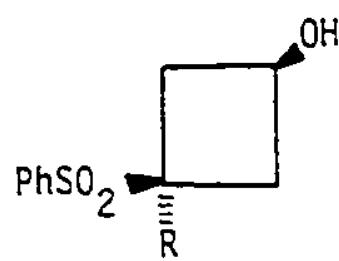

$\mathrm{R}=\mathrm{Ph} \quad 79$ $\mathrm{R}=\mathrm{CH}_{2} \mathrm{Ph} \quad \underline{723}$

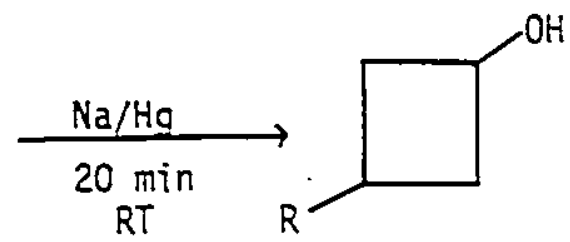

$\mathrm{R}=\mathrm{Ph} \quad \underline{124} \quad 80 \%$ $\mathrm{R}=\mathrm{CH}_{2} \mathrm{Ph} \quad \underline{125} \quad 85 \%$

Removal of the phenylsulfonyl group was evidenced by (i) the disappearance of the sulfone bands in the infrared spectra of 124 and 125 and (ii) the loss of the characteristic NMR signals due to the phenylsulfonyl group. Thus, both cyclobutanols showed the hydroxyl band at $3500 \mathrm{~cm}^{-1}$ in their infrared spectra. The 3-phenylcyciobutanol 124 showed NMR peaks at $07.7-2.9(\mathrm{~m}, 5 \mathrm{H})$ assignable to the methylene hydrogens and the hydroxyl hydrogen, $03.7-3.9(\mathrm{~m}, \mathrm{IH})$ and $03.9-4.6(\mathrm{~m}, \mathrm{lH})$ assignable to the hydrogen at $c_{3}$ and $c_{1}$ respectively. The aromatic hydrogens at 
$\$ 7.2$ appeared as a slightly broadened singlet.

The benzyl derivative $\underline{125}$ exhibited NMR peaks at $51.5-2.8$

$(\mathrm{m}, \mathrm{SH}, 4.0-4.7(\mathrm{~m}, \mathrm{lH})$ and 7.3 (broadened singlet, $\mathrm{IH}$ ).

\section{Stereochemistry and Mechanism}

Introduction

The preliminary investigations of the mechanism of the Grignard induced epoxy sulfone cyclization, as carried out by Co and Durst (32), led to the following proposal for the formation of the cyclobutanols. (Scheme 16)

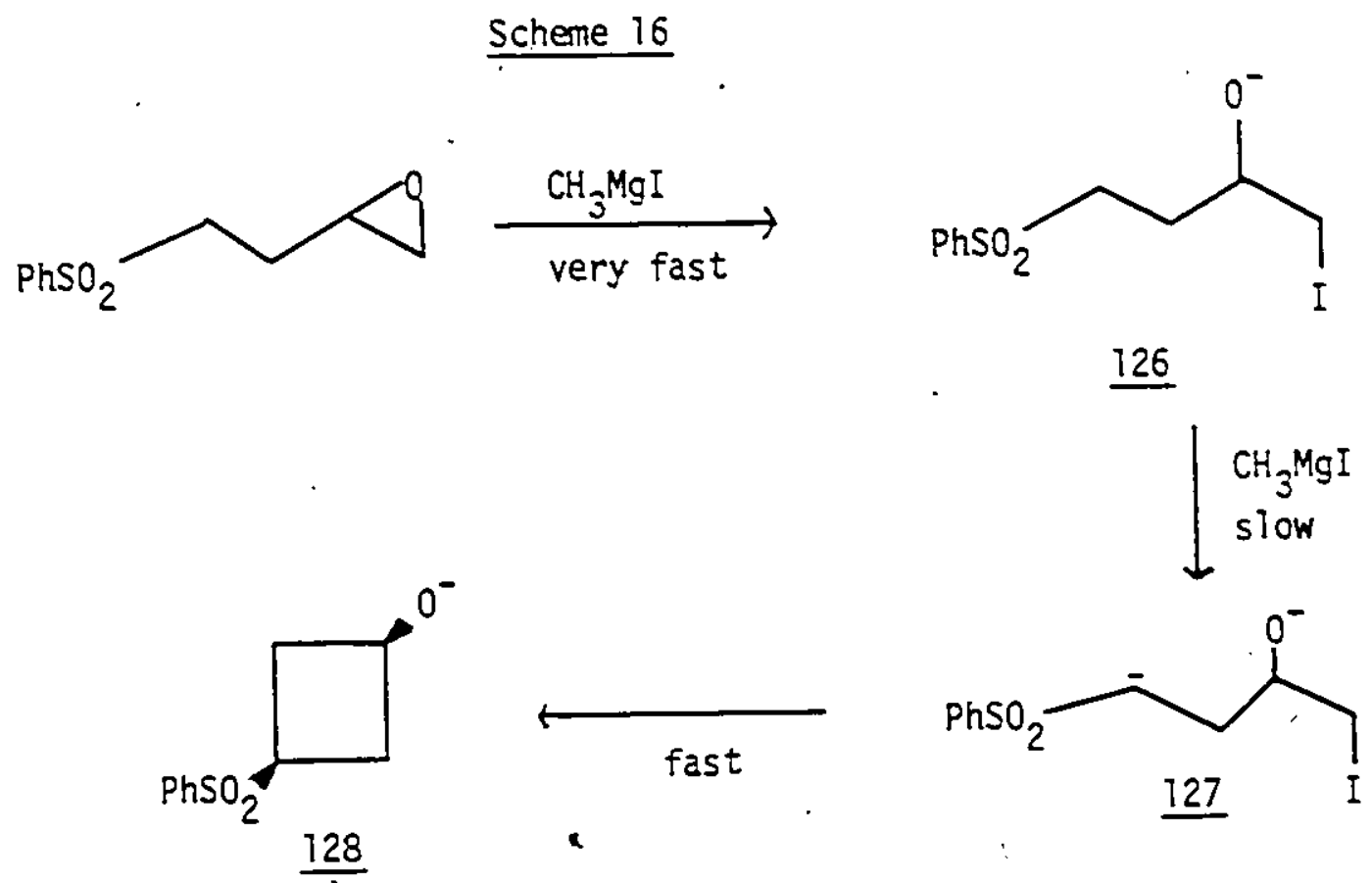

The reaction proceeds by initial opening of the epoxide to the iodoalkoxide 126. This intermediate was isolated as the iodohydrin and subsequently converted to the cyclobutanol by treatment with two equivalents of $\mathrm{CH}_{3} \mathrm{MgI}$. Formation of the alkoxide $\underline{126}$ is followed by proton abstraction 
$\alpha$ to the phenylsulfonyl group and subsequent cyclization of $\underline{127}$ and 128. Both the ring opening reaction (55) and $\alpha$-suifonyl Grignard formation (56) have ample literature precedent.
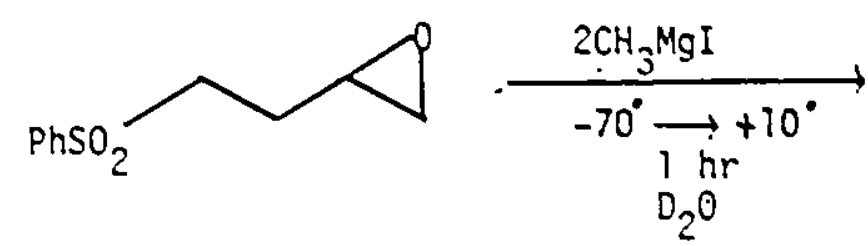<smiles>[124I]</smiles><smiles>[2H]C([18OH])CC(O)CI</smiles><smiles>[AsH2]=[AsH2]</smiles><smiles>O[C@H]1C[C@H](O)C1</smiles>

- Some evidence follive rates of the various steps involved in the cyclization was a the (32) by quenching the reaction at $10^{\circ}$ with $\mathrm{O}_{2} \mathrm{O}$. Deuterium incorporation in the ipdofydrin was observed to the extent of $30 \%$, indicating that ring opening of the epoxide is fast relative to a-sulfonyl Grignard formation. The partial deuterium incorporation suggests that cyclization of the intermediate a-sulfonyl Grignard reagent is not instantaneous, thus allowing some building of the concentration of 127 .

A number of aspects of the cyclization reaction still remained to be investigated, most importantiy, the stereochemical course of the cyclization and the necessity of two equivalents of Grignard reagent to affect cyclization.

Stereochemical Aspects

As was noted earlier only one of the two possible diastereomers was obtained in the cyclization of the epoxy sulfones bearing an alkyl 
or aryl substituent $\alpha$ to the phenylsulfonyl group despite the fact that the starting materials consisted of diastereomeric mixtures. The chiral center a to the phenylsulfonyl group is eliminated during the course of the cyclization via a-sulfonyl carbanion epimerization. $\Delta$

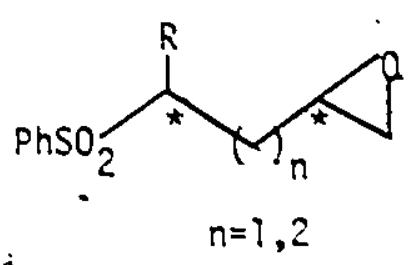<smiles>[Y][C@]1([As])C[C@@H](O)C1</smiles>

The formation of only one isomer in the case of the a-substituted derivatives was ascertained by comparing the NMR of both the crude and purified products with that of the diastereomeric mixture prepared by C-alkylation of the parent hydroxysulfones.

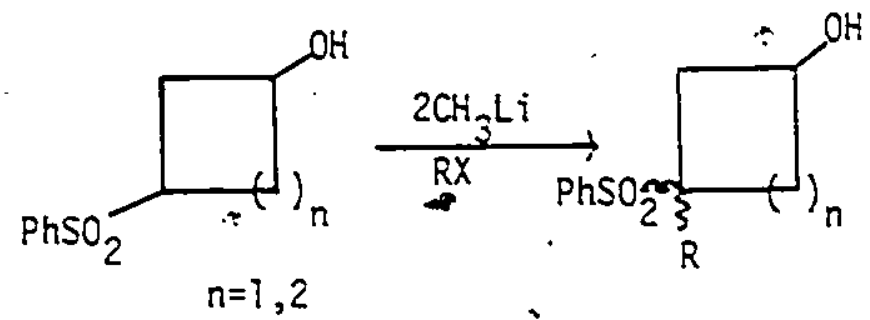

For example, in the case of the cyclobutanois 129 obtained via the alkylation route two distinct areas of abserption were observed for $H_{A}$ usualily in the vicinity of $8 \dot{4} \cdot 0-4.3$ and $84.3-4.6$. The products 130 obtained via cyclization of the a-substituted derivatives displayed $H_{A}$ absorption at $04.0-4.3$ with no trace of the other isomer befog detected.

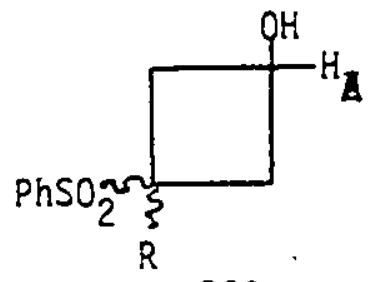

.129

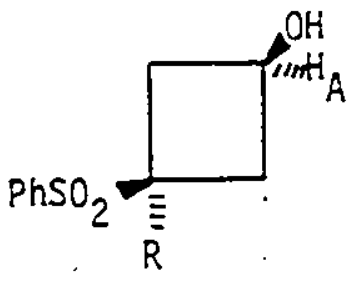

130 
It was also shown that cyclization of $\delta$-epoxy sulfones proceeds with high stereospecificity. Thus, alkylation of the parent cyclopentanol with benzyl bromide resulted in the formation of both diastereomers as evidenced by the appearance of two approximately equal intensity singlets for the benzylic hydrogens at $\$ 2.96$ and 83.04. In contrast, cyclization of the epoxy sulfone 60 with two equivalents of $\mathrm{CH}_{3} \mathrm{MgI}$ furnished a product 132 which showed $\mathrm{CH}_{2} \mathrm{Ph}$ absorption only at 82.96 . No trace of the isomer absorbing at $\$ 3.04$ was observed in the crude NMR of the reaction mixture.
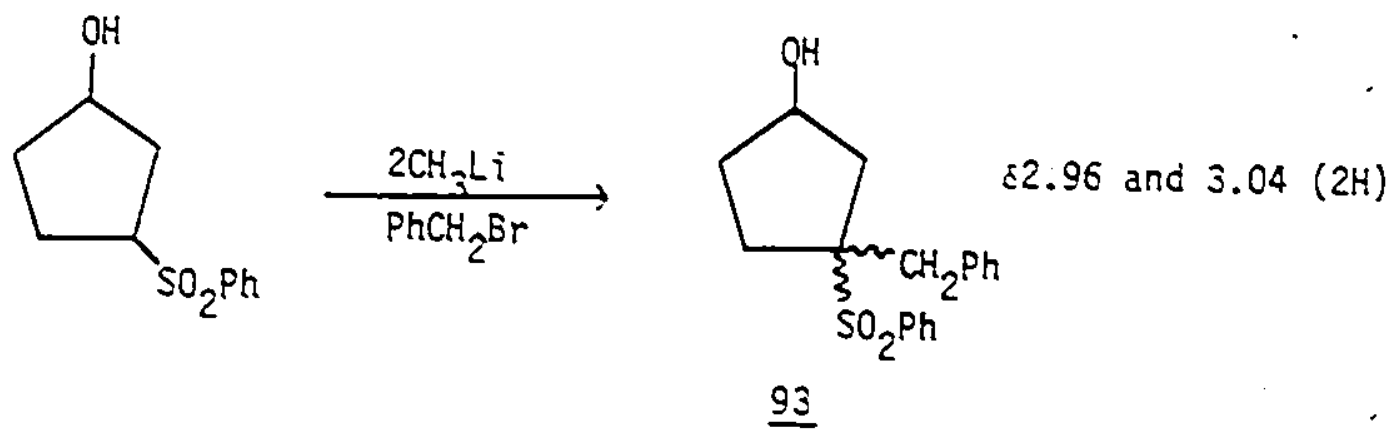

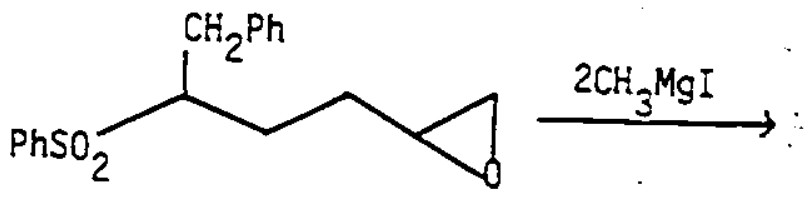
$\underline{60}$

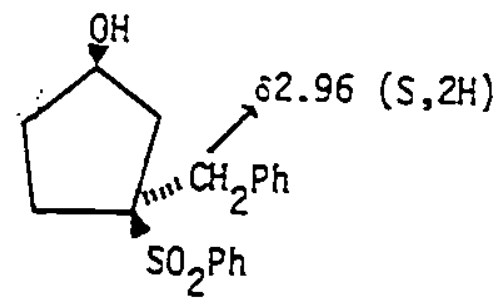
132

Having thus established the generation of only one diasteremer in the cyclization of $\alpha$-substituted $\gamma$ and $\delta$-epoxy sulfones there remained the problem of determining which diastereomer was formed. It was not possible to separate the diastereomeric mixture obtained in the 
alkylation reaction, thus pure samples of both diastereomers could not be obtained. This ruled out the possibility of using dipole moment measurements in the determination of the relative configuration of the $\mathrm{OH}$ and $\mathrm{PhSO}_{2}$ groups since pure samples of both isomers are required. The ' $H$ NMR did not provide any handle on which to base a conclusive assignment of stereochemistry. Two main problems in this area were the overlap of signals and the flexibility of the four-membered ring ${ }^{\circ}$ creating an averaging effect on coupling constants (no fixed dihedral relationships between the various hydrogens).

It was noted that the $\mathrm{CH}-\mathrm{OH}$ of the cycloalkanols, produced via cyciization of the a-substituted epoxy sulfones, always appeared at lower $\varepsilon$ (or upfield) in the ${ }^{\prime} H$ NMR relative to the two areas of absorption observed for $\mathrm{CH}-\mathrm{OH}$ for the product obtained via alkylation of the parent cycioalkanol (ie. benzyl cyclopentanol discussed above): Thus all $\mathrm{CH}_{3} \mathrm{MgI}$ cyclization products would seem to belong to the same relative stereochemicai class. Possibly the observed upfield shift of the $\mathrm{CH}-\mathrm{OH}$ in the cyclization products may be due to less deshielding . of $\mathrm{CH}-\mathrm{OH}$ in the product having a cis orientation of phenylsulfonyl and hydroxyl groups.

Since a spectral approach to the problem did not seem to be definitive, it was decided to have an X-ray crystal structure determination carried out on one of the crystalline cyclization products.

It proved possible to grow suitable crystals of 79 from methanol and a crystal structure determination was performed by Dr. J. Blount at Hoffmann-LaRoche, Nutley, New Jersey. The relative stereochemistry II as determined by $x$-ray is that shown below and in Figure 1 with a 


\section{Figure I}

Computer Generated Representation of 79 as Determined by X-Ray Crystallography

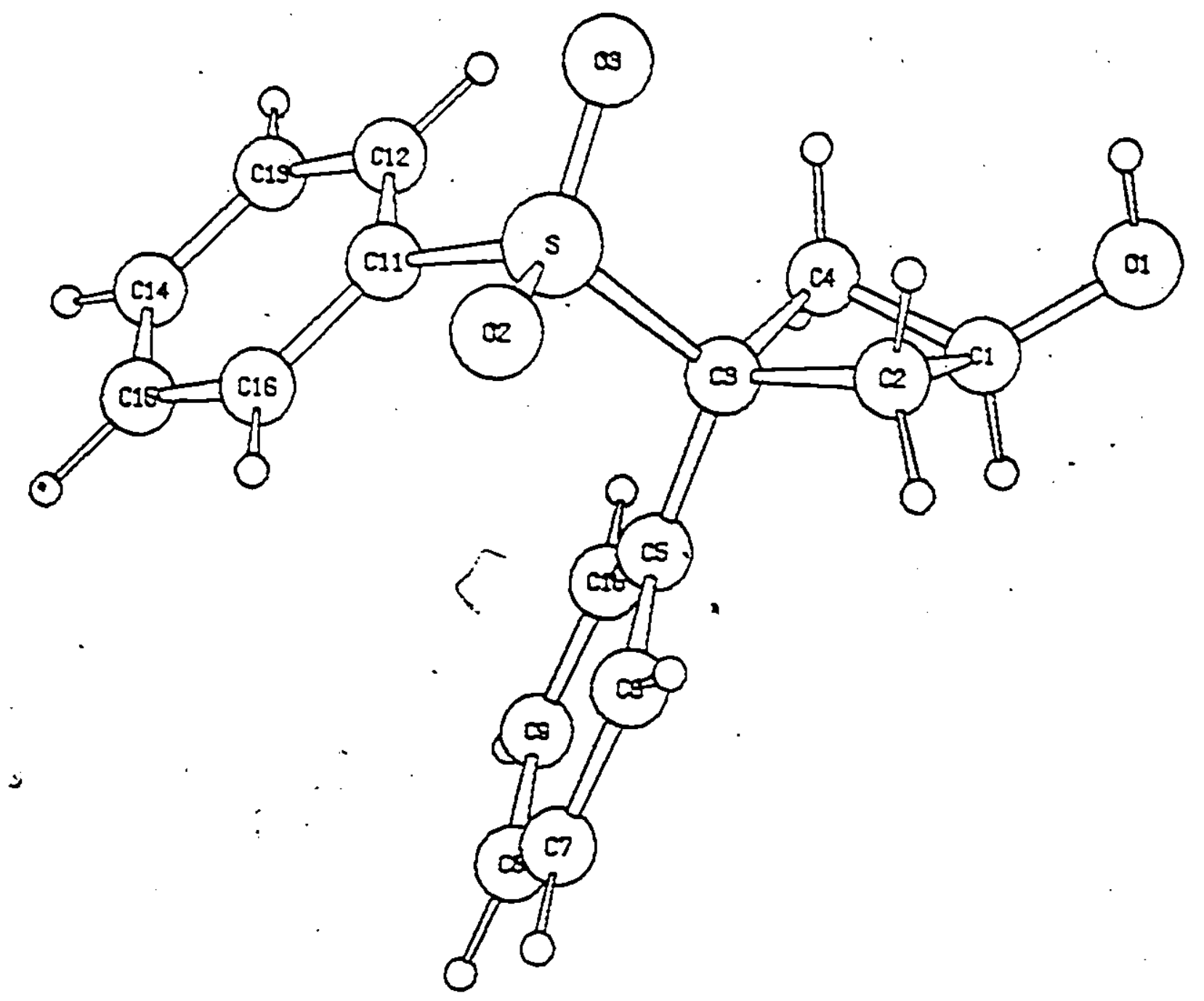


$\leq$

cis arrangement of the phenysulfonyl and hydroxyl groups.

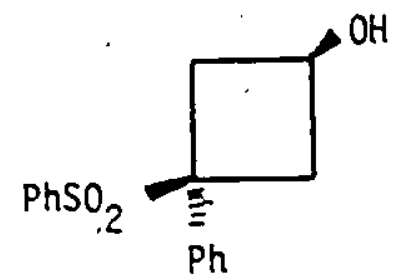

To acceunt for this specificity a complex of the type shown below is suggested to be present during the cyclization.

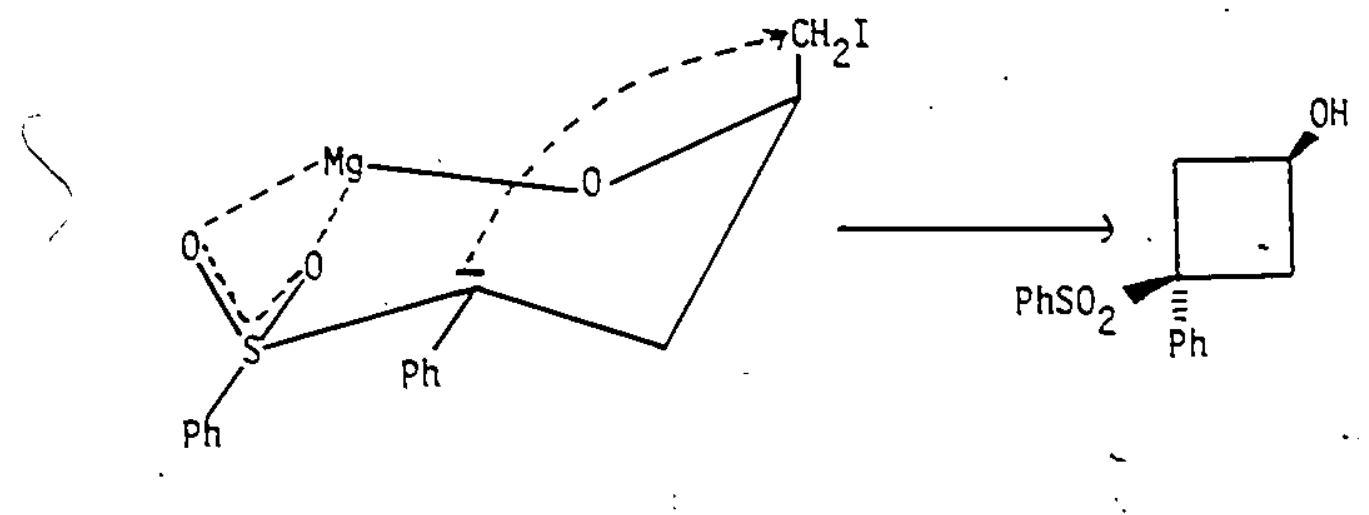

The alkoxide oxygen and the sulfone group are disposed in a cis orientation due to chelation by the magnesium cation. The iodomethyl group is required to be in a pseudo-axial position for backside attack by the a-sulfonyl carbanion.

Even though sulfone oxygens are not very basic, it is suggested that a-sulfonyl carbanion formation enhances the basic character of the sulfone oxygens to such an extent that coordination to the magnesium cation is more feasible.

This increased oxygen basicity upon a-carbanion formation is supported by the work of Marquet (57) who observed a $60 \mathrm{~cm}^{-1}$ lowering of both $\mathrm{SO}_{2}$ bands in the infrared spectra $\mathrm{PhSO}_{2} \mathrm{CH}_{2} \mathrm{Li}$ vs. $\mathrm{PhSO}_{2} \mathrm{CH}_{3}$. This 
result suggests that the sulfur-oxygen bonds have taken on more single bond character with partial dispersion of the negative charge onto the sulfone oxygens. The sulfone bands in infrared spectra usually occur at $1310-1350 \mathrm{~cm}^{-1}$ and $1120-1160 \mathrm{~cm}^{-1}$ whereas the $S=0$ stretching frequency in sulfoxides, compounds in which the $\mathrm{S}-\mathrm{O}$ bond is high dipolar and capable of acting as an $\mathrm{H}$-bond acceptor, occurs around 1040-1060 $\mathrm{cm}^{-1}$.

It was thought that the importance of the chelation in controlling the stereochemical outcome of the cyclization might be tested by 0 -alkylation of the intermediate haloalkoxide, thereby reducing the strong $-0-\mathrm{Mg}$ interaction. To this end, the protected bromohydrin 135 was prepared as shown below.

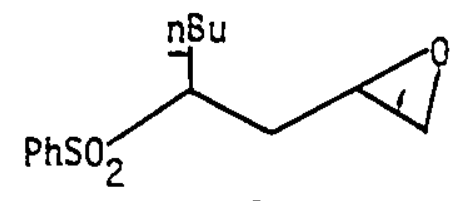

$\underline{133}$

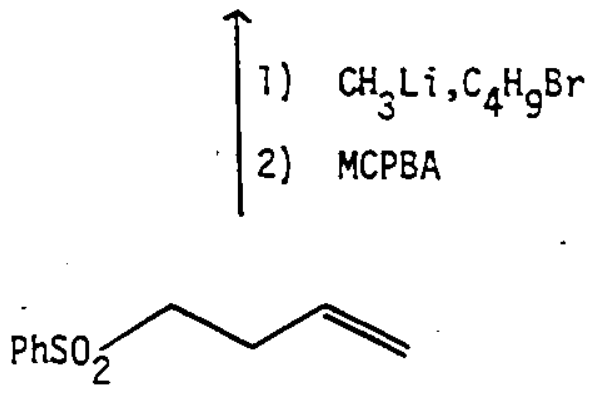

$\underline{53}$
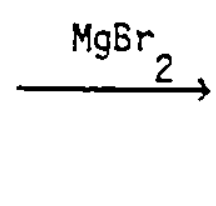

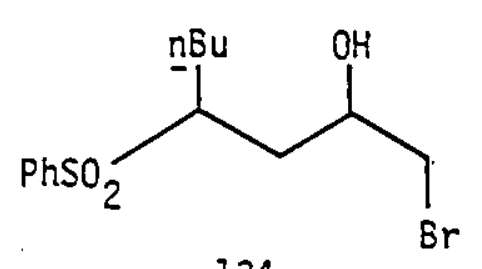

$\underline{134}$

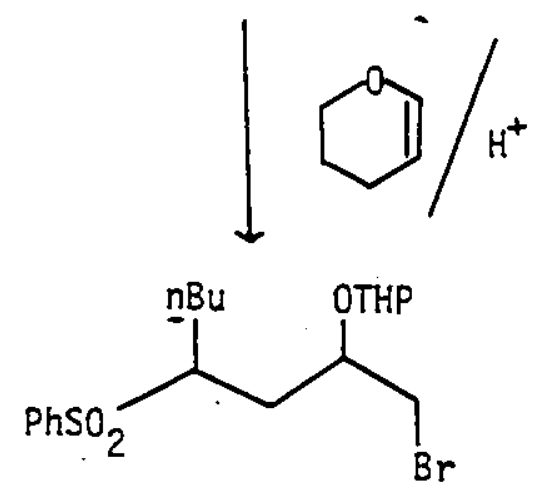

$\underline{135}$

Treatment of 135 with $\mathrm{CH}_{3} \mathrm{MgI}$ was then expected to give the corresponding cyclobutane derivative possibly as a mixture of diastereomers, which after removal of the THP group, could be compared to $\$ 37$ of knewn: stereochemistry. 

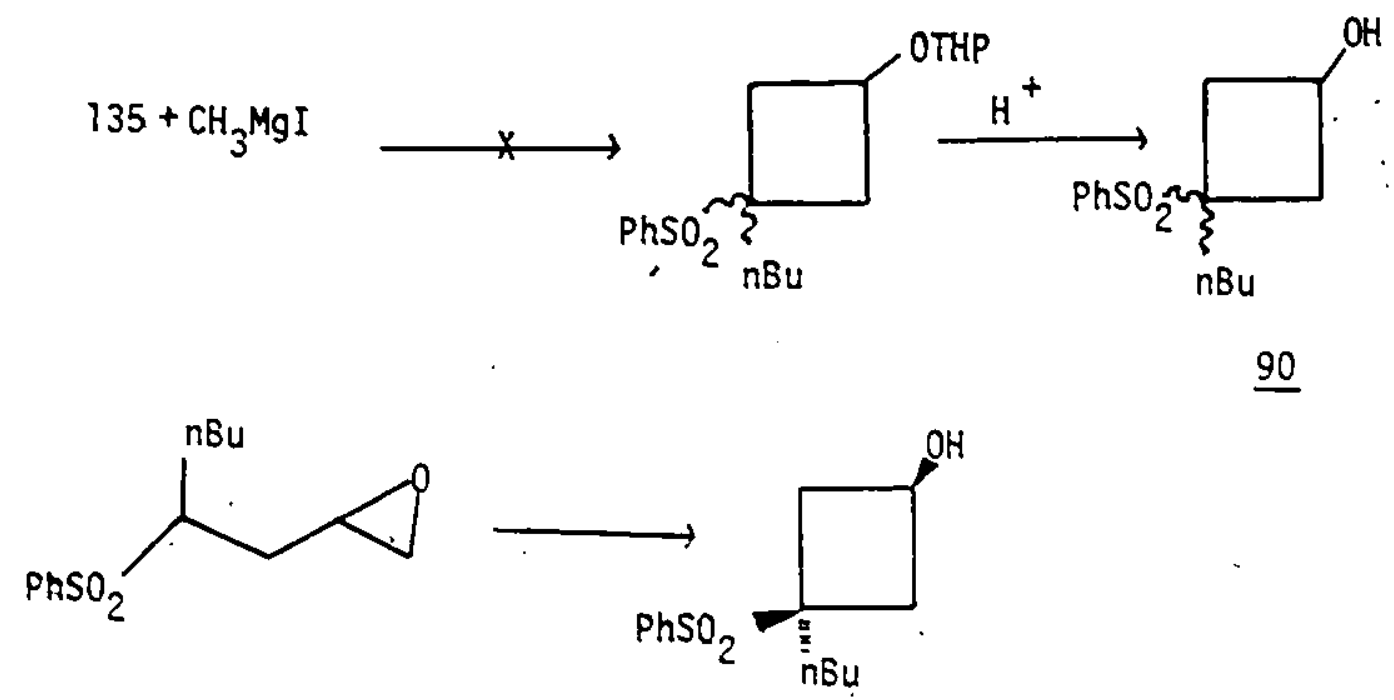

137

However, under a variety of reaction conditions $(1,2.5,3$ equivalents of $\mathrm{CH}_{3} \mathrm{MgI}$, reaction times of $12 \mathrm{hrs}$. to 7 days) the only observed products were starting material and the corresponding iodide fomed via bromide-iodide exchange.

This result was quite unexpected. One possible explanation for the reluctance of the THP derivative $\underline{135}$ to undergo cyclization may be increased steric congestion about the reaction centre. In order to reduce this aspect, cyclization of the THP derivative of 138 was attempted. Once again, no cyclization product was observed and only the starting material 139 was recovered after hydrolysis. Hydrolysis of the reaction product with $\mathrm{HCl} / \mathrm{MeOH}$ resulted in an $80 \%$ recovery of the iodohydrin 138 . 


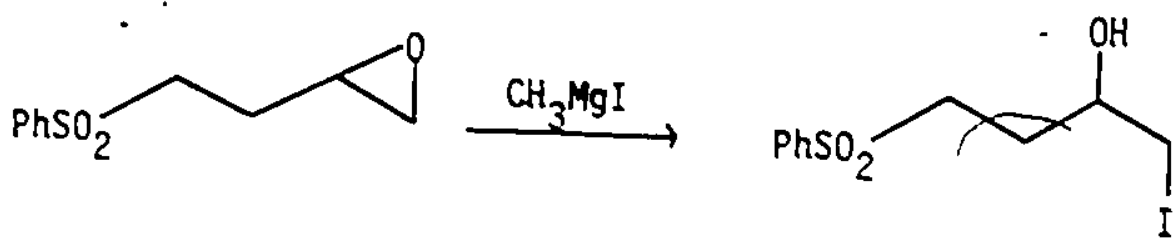

138<smiles>C1CCOCC1</smiles>

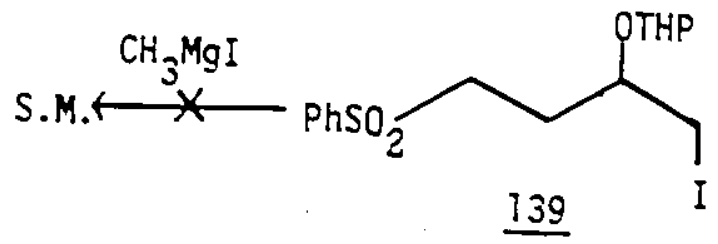

In order to rule out in situ quenching of the Grignard reagent one reaction trial was quenched with benzophenone after twenty four hours. Chromotagraphy of the reaction mixture gave starting material $(90 \%)$ and an $85 \%$ yield of 1,1 -diphenylethanol.

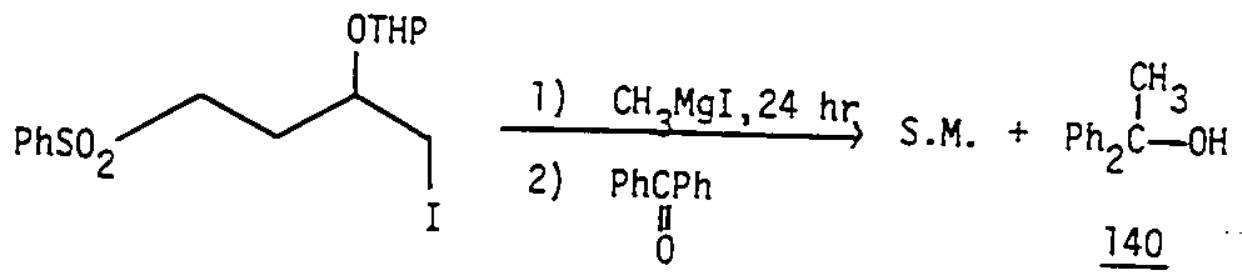

It was possible to show that the presence of the hydroxy? group is not essential in the cyclization reaction since 4-iodobuty] sulfone was readily converted into cyclobutyl phenyl sulfone upon treatment with $\mathrm{CH}_{3} \mathrm{MgI}$ (see below). Thus, one is left with the conclusion that THP derivatives of $\underline{135}$ and $\underline{139}$ do not readily cyclize due to steric reasons. Consequently we were unable to obtain 
experimental evidence for our earlier suggestion of a chelate complex in the cyclization reaction.

Synthesis of Cyclobutyl Phenyl Sulfone

The required bromosulfone 141 was prepared in $18 \%$ yield by reaction of sodium phenysulfinate with excess dibromobutane in absolute ethanol.

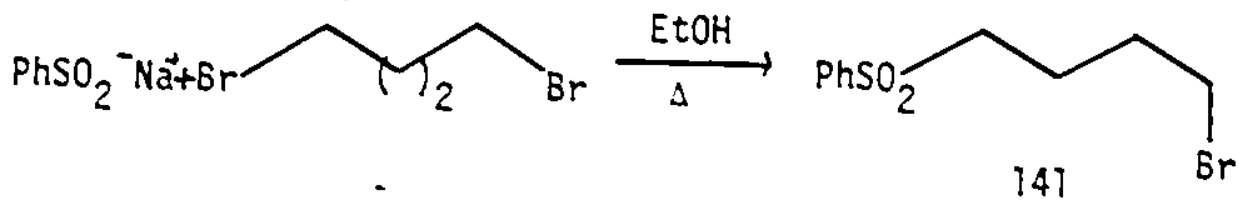

Treatment of 141 with one equivalent of $\mathrm{CH}_{3} \mathrm{MgI}$ for tweive hours at room temperature followed by quenching with a saturated ammonium chloride solution resulted in the product distribution (determined by NMR) shown below.
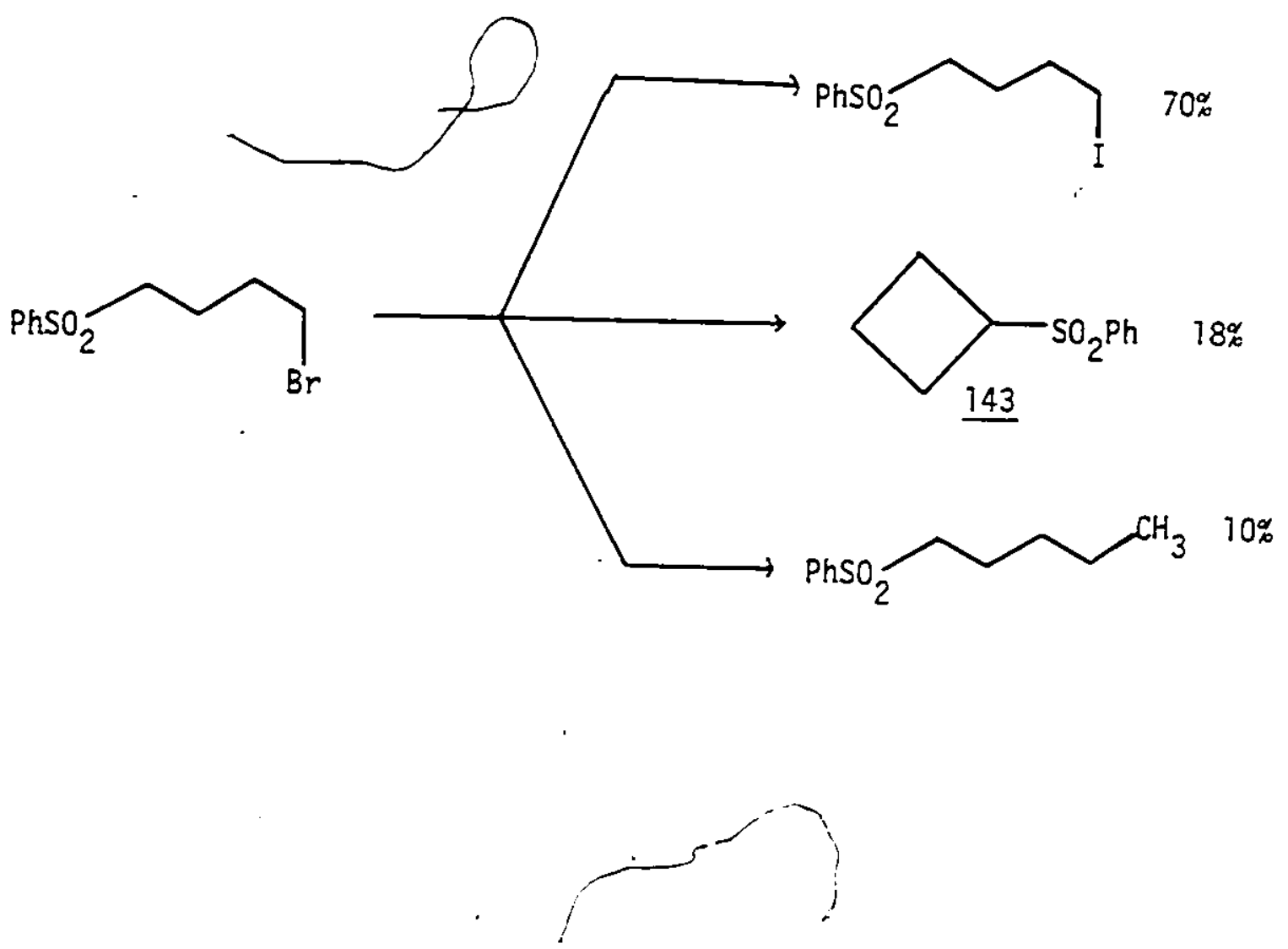
Formation of 142 occurs via halide exchange between iodide and bromide. Recrystallization of the crude reaction mixture furnished a pure sample of the iodosulfone 142 which was identical in all respects to an authentic sample prepared by reaction of 141 with sodium iodide.<smiles>BrCCCCOc1ccccc1</smiles><smiles>[Tl]CCCCCOc1ccccc1</smiles>

142

The cyclobutyl sulfone 143 arises by intramolecular displacement of halide ion by the a-sulfonyl carbanion of 141 or 142 .

The 1-phenyisuifonyl pentane 144 resuits from displacement of halide ion by the methyl group of the Grignard reagent.

Reaction of the iodosulfone 142 with one equivalent of $\mathrm{CH}_{3} \mathrm{MgI}$ for twenty four hours at room temperature yielded a mixture of 143 . 142 and 144 in 45,45 , and $10 \%$ yields respectiveiy.

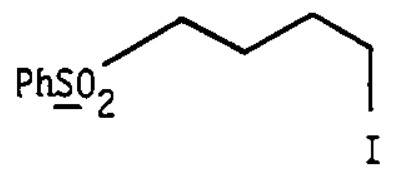

$\underline{142}$

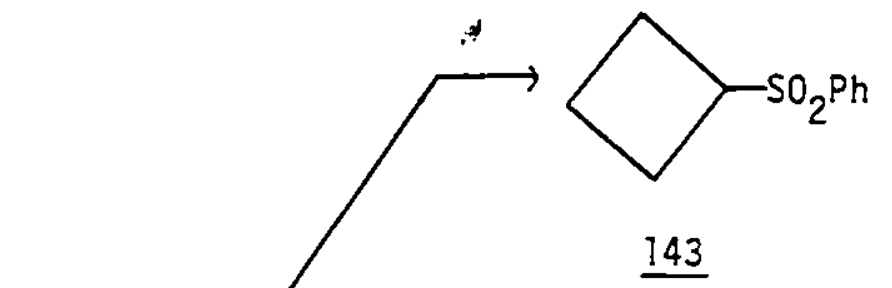

$\underline{143}$

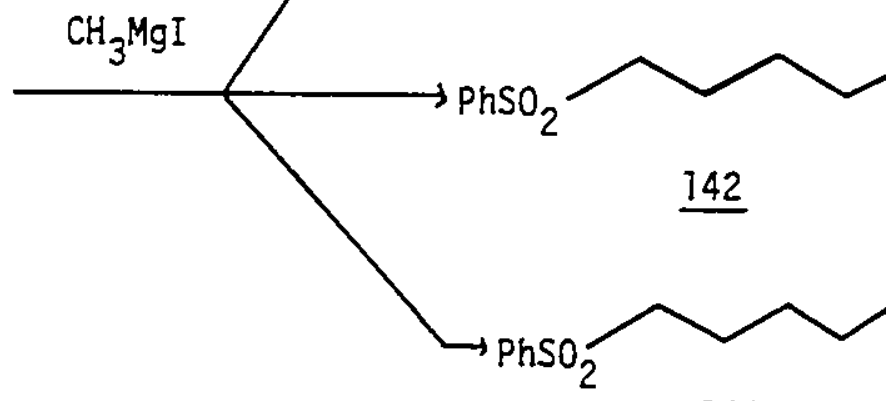

144 
With two equivalents of $\mathrm{CH}_{3} \mathrm{MgI}$ at room temperature for twenty four hours 142 furnishes the cyclobutyl sulfone 143 in $90 \%$ yield. Thus the coupling of $\mathrm{CH}_{3} \mathrm{MgI}$ with 142 to yield 144 is not competitive with $\therefore$ ring formation when two equivalents of $\mathrm{CH}_{3} \mathrm{MgI}$ were used.
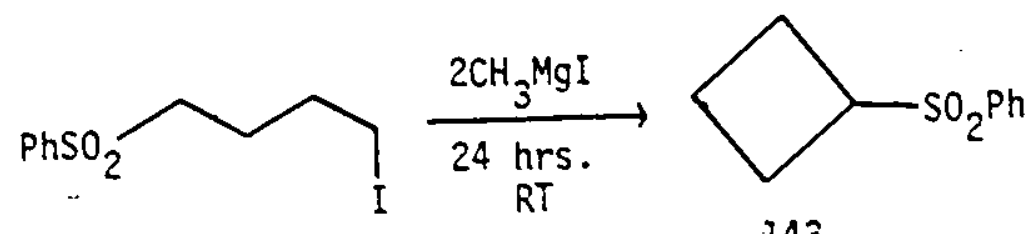

143

Base Requirements of Epoxy Sulfone Cyclization

The cyclization of epoxy sulfones was found to require two equivalents of Grignard reagent. This conclusion was drawn from a study of the reaction of the epoxy sulfone 54 , in parallel runs, with one and two equivalents of Grignard reagent, respectively.

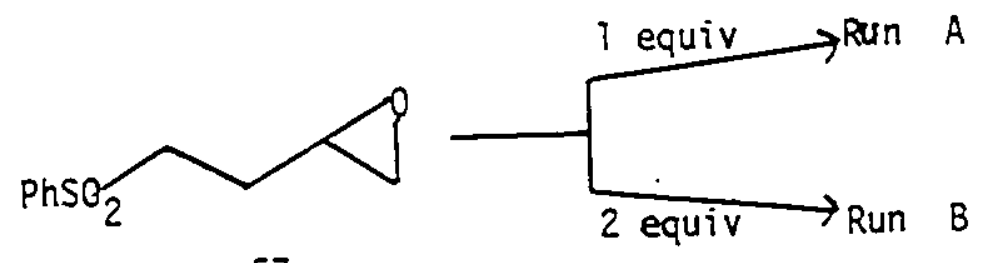

$\underline{57}$

The Grignard reagent was standardized immediately before use. The two reactions were run in THF under nitrogen. The addition of the Grignard reagent was carried out at $-78^{\circ}$ and the reactions were allowed to warm to room temperature. Aliquots $(1 \mathrm{ml}$ ) were taken via syringe at various time intervals. The one $\mathrm{ml}$ al iquots were quenched with saturated ammonium chloride solution and extracted with $20 \mathrm{ml}$ of ether. Drying and evaporation of the organic phase furnished a material which was 
examined by ${ }^{\prime} H$ NMR. The results are presented in Tabie VI. The only product observed in Run $A$ (one equivalent) after $52 \mathrm{hrs}$. was the iodohydrin, whereas in Run B (2 equivalents) cyclization was complete in twenty five hrs. as determined by ${ }_{H}$ NMR. Upon quenching the reaction mixture gas evolution was observed in both cases; indicating that active Grignard reagent remained in both cases.

The requirement of two equivalents of Grignard reagent may be rationalized in the following manner. Reaction of the epoxy sulfone 54 with one equivalent of $\mathrm{CH}_{3} \mathrm{MgI}$ initially furnishes the intermediate 145 .
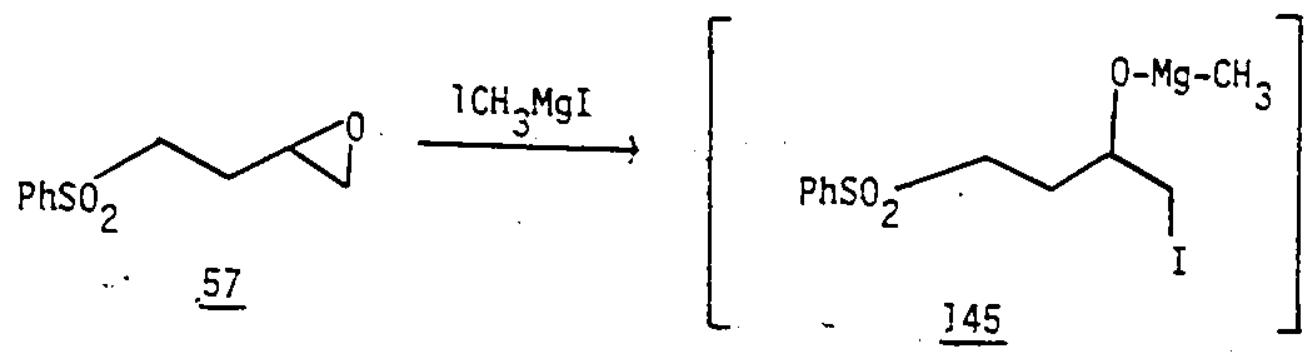

Cyclization of the intermediate 145 requires proton abstraction, a to the phenyisuifonyl group, by a methylmagnesium species present in solution. It is suggested that this key step is hampered by the decreased basicity of the methyi group due to coordination of the magnesium to the oxygen. Replacement of iodine by oxygen results in greater positive character being instilled on the magnesium (is. electronegativity of oxygen (3.5) vs iodine (2.5)). This in turn strengthens the $\mathrm{Mg}-\mathrm{CH}_{3}$ bond thas reducing the basic character of the methyl group. 


\section{TABLE VI}

\section{Base Requirement of Epoxy Sulfone Cyclization}

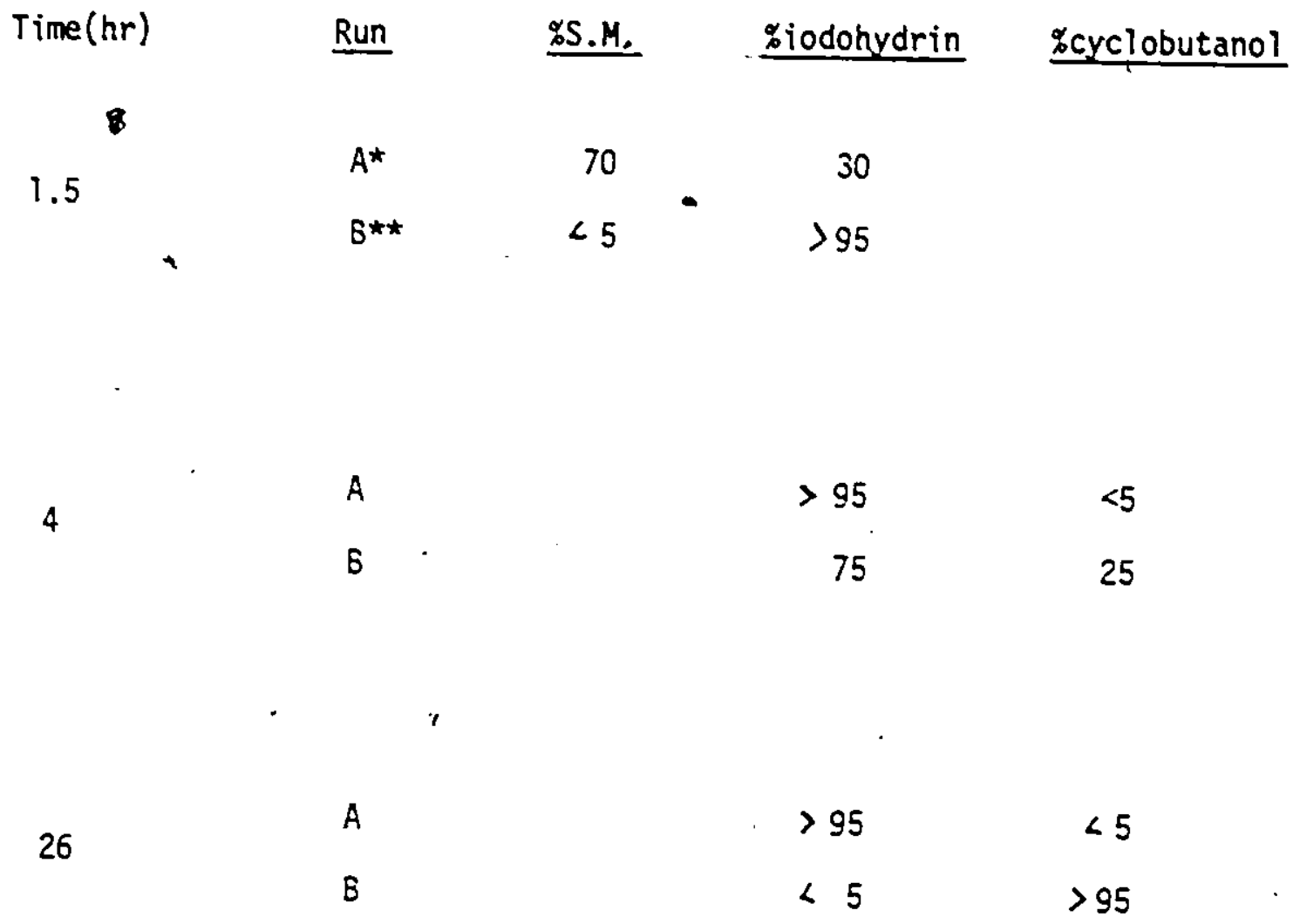

52

A

B
$>95$

$<5$

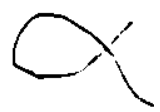

$<5$

$>95$

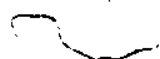

$A^{*}$ (one equivalent of $\mathrm{CH}_{3} \mathrm{MgI}$ )

$B \star$ (two equivalents of $\mathrm{CH}_{3} \mathrm{MgI}$ )

Above values are approximate 


\section{Conclusions Regarding Epoxy Sulfone Cyclizations}

y-Epoxy Sulfones - Cyclobutanols

The mechanism for the formation of cyclobutanols from $r$-epoxy sulfones has been discussed previously. This conversion may be sumarized as follows.
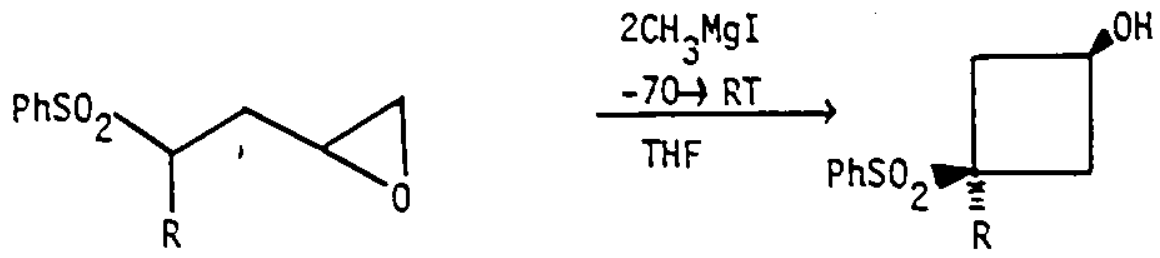

\section{y-Epoxy Sul fones - Cyclopropyl Methanols}

As was mentioned previously corbel showed that $r$-epoxy sulfones which are substituted at the teminal position give cyclopropyl derivatives when treated with $\mathrm{CH}_{3} \mathrm{MgI}$. This divergent bëhaviour is easily rationalized on the basis of Scheme 17 .

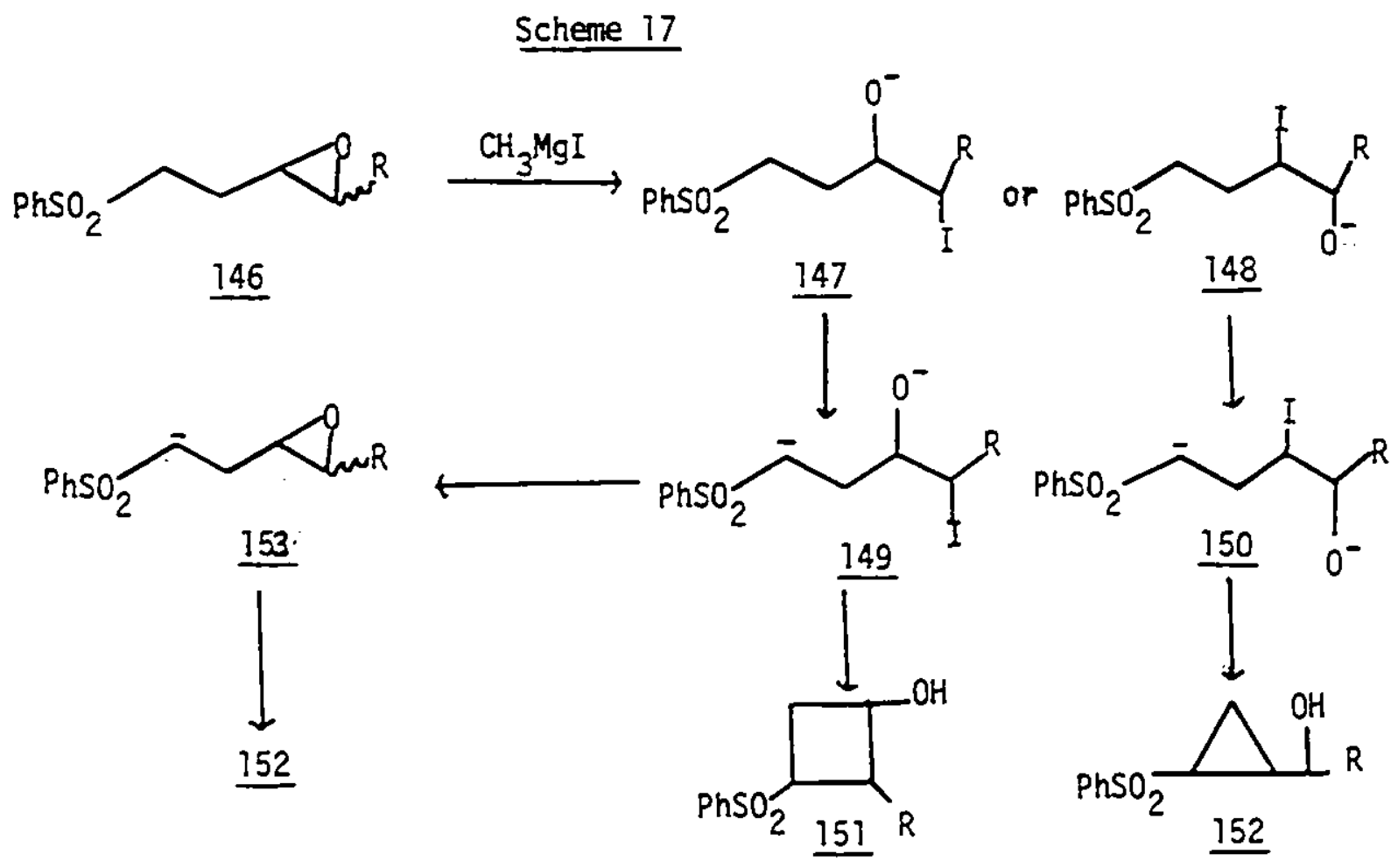


The ring opening of 146 , in contrast to that of $\underline{54}(R=H)$ would not be expected to be highly regioselective and thus results in the formation of both alkoxides 147 and 148 . Grignard formation from these species results in $\underline{149}$ and 150 respectively. Cyclization of $\underline{150}$ and $\underline{152}$ is known to be much faster than that of 149 to 151 , thus allowing the possibility of generating the epoxide 153 which can then cyclize to 152. Durst and Corbel showed the feasibility of such a type of scheme by generating the iodohydrin related to $149(R=P h)$ and showing that under typical treatment with $\mathrm{CH}_{3} \mathrm{MgI}$, only the cyclopropyl sulfone $152(R=P h)$ was obtained.

\section{E-Epoxy Sulfones - Cyclopentanols}

It was observed that $\delta$-epoxy sulfones form only 3phenylsulfonyl cyclopentanols upon reaction with $\mathrm{CH}_{3} \mathrm{MgI}$, irrespective of the substitution pattern about the epoxide. A scheme similar to that above, which explained the preferrential formation of $\underline{152}$ from $\underline{146}$ suggests that of the two possible ring opened intermediates $\underline{154}$ and $\underline{155}$, cyclization of the former, which results in the formation of a fivemembered ring should be kinetically preferred. Intermediate $\underline{155}$ can recyclize to the initial epoxide and répen again to $\underline{154}$ and hence 156 .
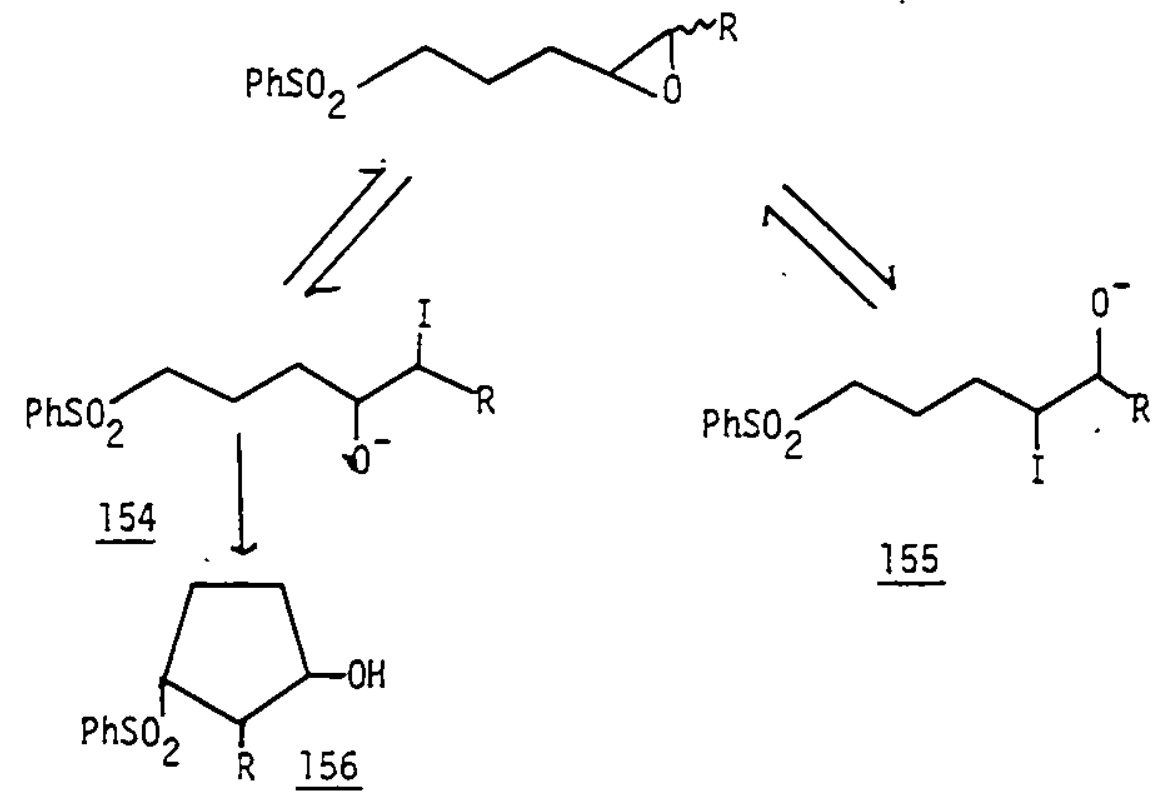


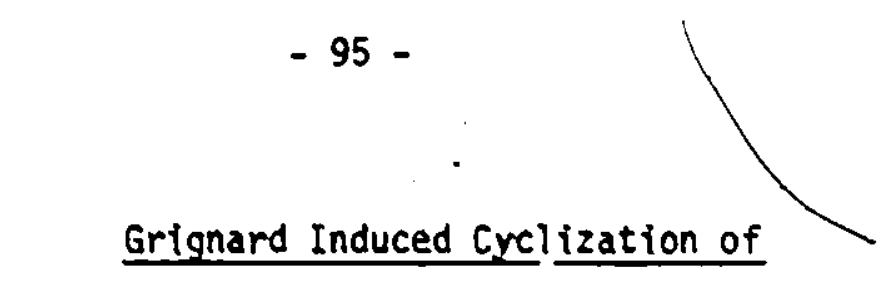

Epoxy Nitriles and Epoxy Phosphine Oxides

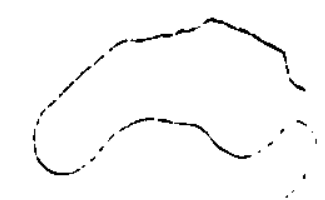

The $\mathrm{CH}_{3} \mathrm{MgI}$ induced cyclization of epoxy sulfones can also be applied to Stork's epoxy nitriles and to a limited extent to epoxy phosphine oxides.

Stork (S) had shown that r-epoxy nitriles; when treated with LDA, furnished cyclopropyl derivatives. No mention was made of the yields in such reactions

The cyclization of $r$-epoxy nitriles was subsequently reinvestigated by Corbel and Durst (32). These authors found, in agreement with Stork's results, that cyclopropane derivatives are the only cyclic products obtained from reaction of $\gamma$-epoxy nitriles with LDA. The cyclopropyl derivatives were obtained in yields of $43-94 \%$.

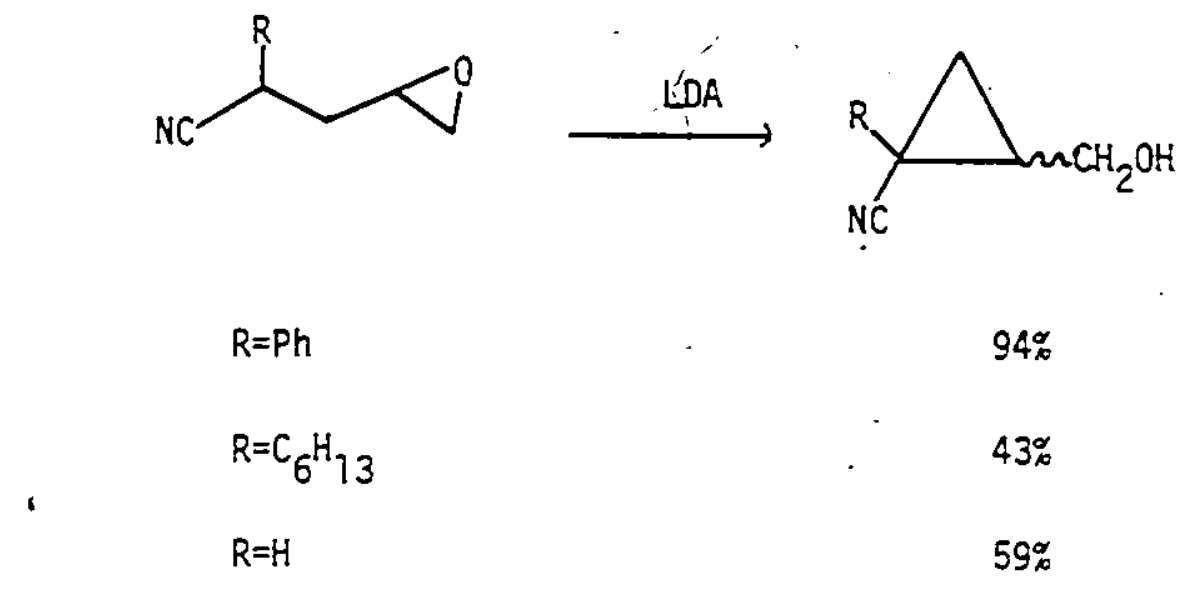

Treatment of the same starting materials 157 with two equivalents of $\mathrm{CH}_{3} \mathrm{MgI}$ resulted in the formation of 3-cyanocyclobutanols 158 in yields of $40-70 \%$. A similar cyclization of the $\hat{c}$-epoxy nitrite 160 gave 3-cyano-3-phenylcyclobutanol 161 in $80 \%$ yield. 
<smiles>[R]C(C#N)CC1CO1</smiles>

$\underline{157}$

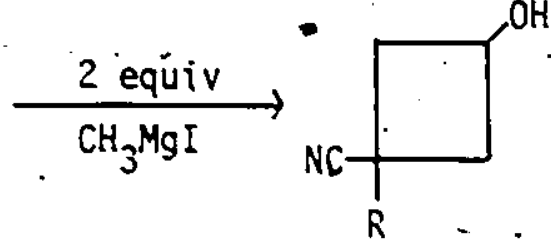

158

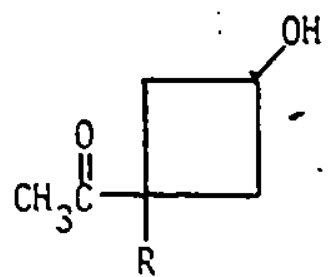

$\underline{159}$

$$
\mathrm{R}=\mathrm{H}, \mathrm{C}_{6} \mathrm{H}_{13}, \mathrm{Ph}
$$

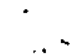<smiles>N#CC(CCC1CO1)c1ccccc1</smiles>

160

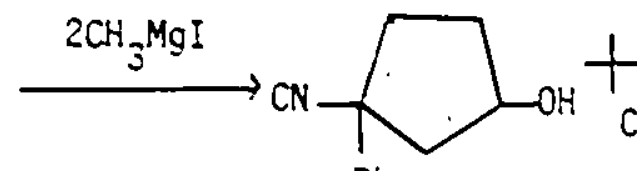

Ph

$\underline{161}$

In the epoxy nitrile series the amount of Grignard reagent employed is more crucial' than for epoxy sulfones where excess' Grignard reagent does not produce undesirable side products. In fact, both the cyciobutyl and cyclopentyl nitriles $\underline{158}$ and $\underline{161}$ were contaminated with about $10 \%$ of the corresponding methy 1 ketones $\underline{159}$ and $\underline{162}$, the result of further reaction of the nitrile alkoxide with excess $\mathrm{CH}_{3} \mathrm{MgI}$. Grignard addition to the nitrile must occur after cyclization to 163 since formation of a dianion from 164 is not possible with the Grignard reagent as base. It is somewhat surprising that addition of the Grignard reagent to the nitrile is much slower than a-carbanion formation and subsequent cyclization to the cycloalkanol. As in the case of the 
epoxy sulfones one isomer is formed with high stereoselectivity in the cyclization of both $\gamma$ and s-epoxy nitriles.

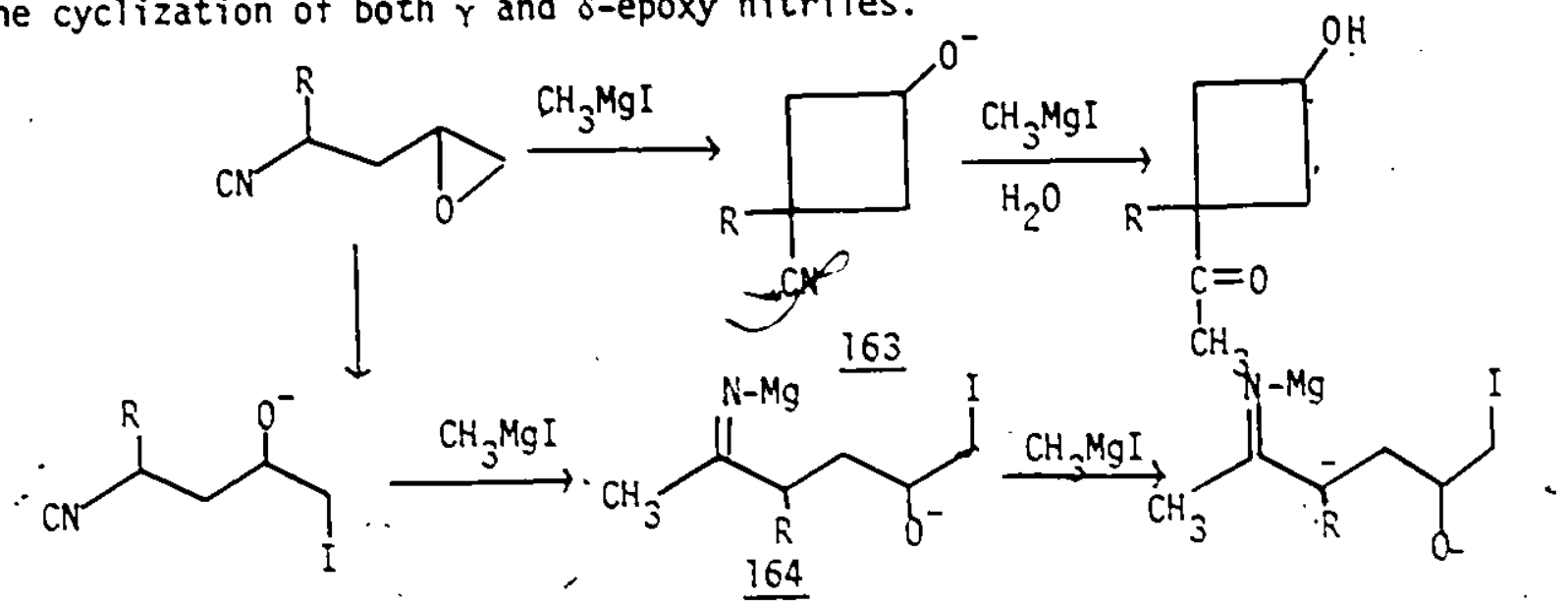

The formation of the keto alcohols is best avoided by first opening the epoxide ring with $\mathrm{MgBr}_{2}$ and then adding one equivalent of $\mathrm{CH}_{3} \mathrm{MgI}$. Such a procedure vields optimum amounts of the desired cyclobutylnitriles. For example, the cyclobutyl derivative 166 was pbtained in $50^{\circ}$ yield from the epoxy nitrile 165 by this approach.<smiles>N#CC(CC1CO1)c1ccccc1</smiles><smiles>CCC1(c2ccccc2)CC(O)C1</smiles>

166

If the 3-acetyl derivatives are the desired product they can best be obtained by reaction of the epoxy nitriles with about four equivalents of $\mathrm{CH}_{3} \mathrm{MgI}$.<smiles>N#CC(CC1CO1)c1ccccc1</smiles>

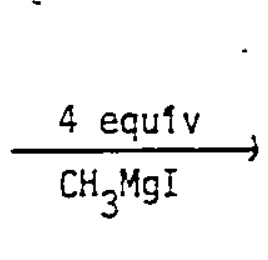<smiles>CC(=O)C1(c2ccccc2)CC(O)C1</smiles> 
The above findings of Corbel and Durst greatly add to the value of $r$-epoxy nitriles since they can be converted into either three or four-membered ring products depending on the base employed.

Epoxy Phosphine Oxides-

Treatment of the r-epoxy phosphine oxide 167 was shown by Corbel (6S) to provide the expected cyclopropane derivative 168 . The cyclobutanol derivative 169 was obtained by treatment of 167 with $\mathrm{CH}_{3} \mathrm{MgI}$. This provides an example, though limited, of a functional. group which is compatibie with the conditions employed in the Grignard reaction. With $R=a l k y l$ in this series no cyclization took place presumably because of the inability of $\mathrm{CH}_{3} \mathrm{MgI}$ to form a-phosphine oxide carbanions from 167 unless $R=P h$.<smiles>[R]C(CC1CC1)[PH]([R6])=O</smiles>

$167 \mathrm{R}=\mathrm{Ph}$
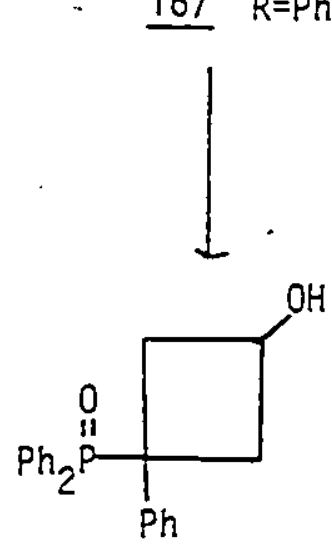

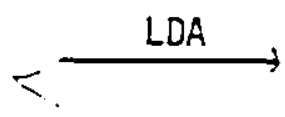

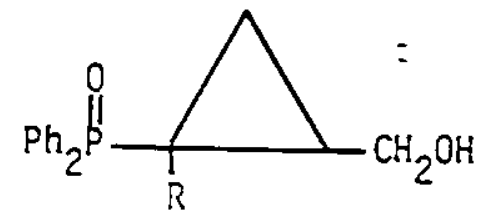

168 
- 99 -

-

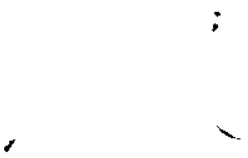

PART II

OXIDATION OF SULFUR-STABILIZED CARBANIONS -

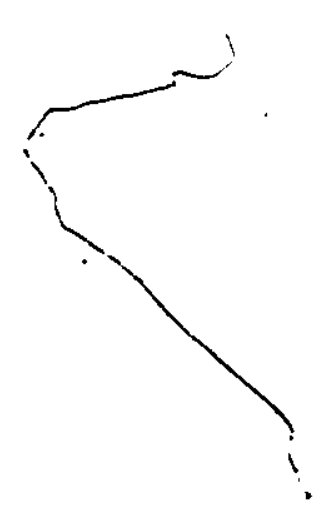

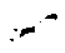


INTRODUCTION

The reaction of organolithium compounds with molecular oxygen has been long known. For example, alkyllithiums (methyllithium, phenyllithium) oxidize so energeticaliy in air that spontaneous ignition occurs. Muller and Toppel (1) obtained, after hydrolysis, a 75\% yield of n-butyl alcohol by the reaction of n-butyl lithium with oxygen diluted with nitrogen.

$$
\underline{\text { n-EuLi }} \stackrel{\mathrm{O}_{2}}{\longrightarrow} \underline{\mathrm{n}}-\mathrm{BuOH}
$$

Recent efforts in this field have been largely devoted to the oxidation of lithio carbanions adjacent to electron withdrawing groups. Such a process can lead to $\alpha$-hydroxy or hydroperoxy derivatives. The electron withdrawing groups which have been found to be compatible with the above process will be briefly described.

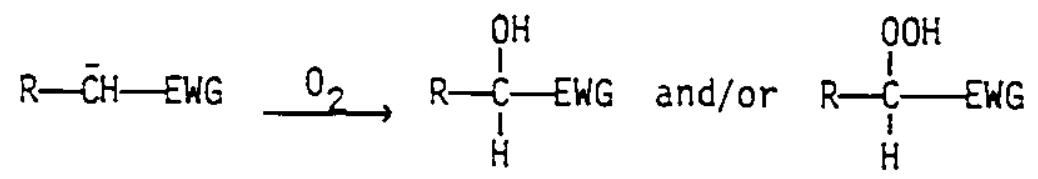

Carboxylic Acids and Esters

It was found by Konen et al (2) and others $(3,4)$ that treatment of esters $I$ with LDA followed by introduction of $\mathrm{O}_{2}$ resulted in the formation of hydroperoxy esters $\underline{2}$ in yields of $40-70 \%$. 


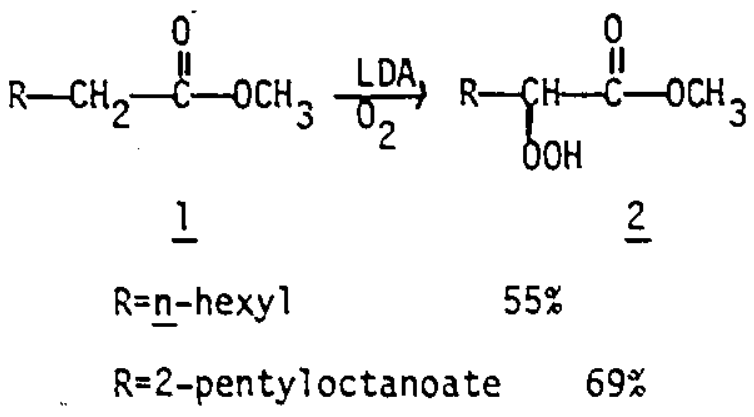

The major side products were the corresponding 2-hydroxy derivatives.

These authors also studied the reactions of dianions of carboxylic acids $\underline{3}$ with $\mathrm{O}_{2}$ and obtained hydroperoxides 4 in about $30 \%$ yieid. Such compounds 4 are important biological intermediates. The low yields of $\underline{4}$ were due to carbanion reduction of the intermediate peroxide $\underline{5}$ thus giving $\underline{6}$.

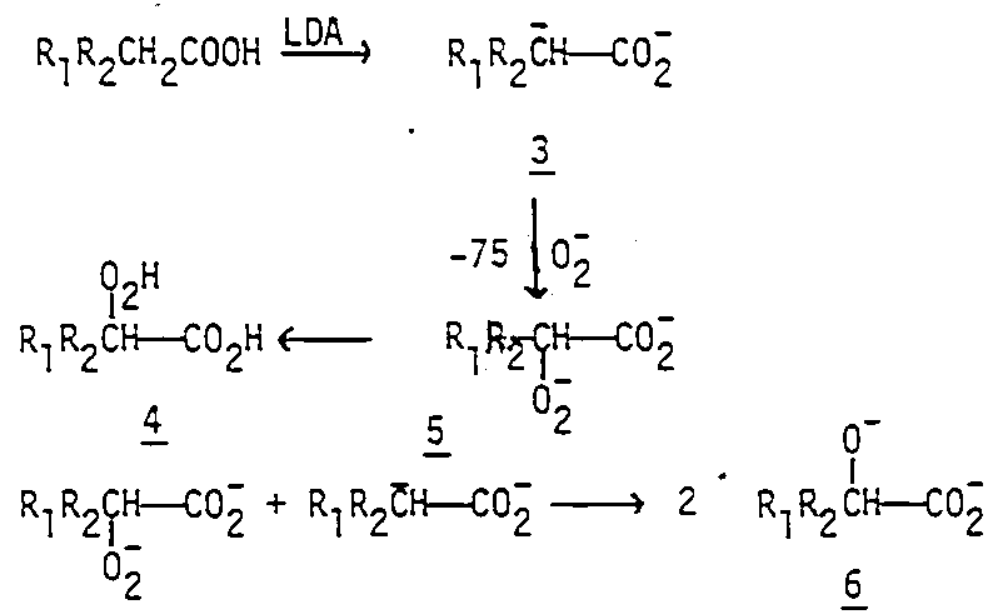

This competitive reduction could be minimized by inverse addition of the carbanion to ether saturated with $0_{2}$. This procedure improved the yields of the hydroperoxides to about $60 \%$.

The 2-hydroxy acids or esters could be made the major products by carrying out the oxygenation at $25^{\circ}$ rather than $-78^{\circ}$. These 
conditions afforded a $90 \%$ yield of products consisting of an $85 / 15$ ratio of 2-hydroxy to 2-hydroperoxy derivatives.

Nitriles

It has been demonstrated (5) that the carbanion generated next to the nitrile function is susceptible to oxidation by molecular oxygen. The carbanion $\underline{s}$ was generated by reaction of the nitrile $\underline{Z}$ with LDA. Introduction of $\mathrm{O}_{2}$ into the reaction mixture resulted in formation of the intermediate peroxy derivative $\underline{g}$. The presence of this intermediate was verified by quenching $\underline{g}$ with aqueous acid or acetyl chloride and subsequent isolation of the a-hydroperoxy nitrile 10a or the acetate 100 , respectively Reduction of 10 with an acidic $\mathrm{SnCl}_{2}$ solution gave the cyanohydrin 11 which on subsequent exposure to aqueous $\mathrm{NaOH}$ afforded the ketone $\underline{12}$. For example, $\underline{Z}\left(\mathrm{R}_{1}=\mathrm{CH}_{2} \mathrm{Ph}, \mathrm{R}_{2}=\mathrm{CH}_{3}\right)$ was converted to $\underline{10 a}, \underline{I 1}$ and $\underline{12}$ in isolated yields of 92,89 and $98_{\kappa}^{\circ}$, respectively (Scheme 1 ).

The above methods, which represents the conversion of a nitrile, $R_{1} R_{2} C H C N$, to a ketone $R_{1} R_{2} C=0$, having one less carbon, was found to be applicable to dialkyl, diaryl and alkyl and nitriles. The overali yields ranged between 65 and $90 \%$.

In contrast to the above examples, primary nitriles were oxidized to aldehydes in relatively low yields. The low yields were ascribed to formation of carboxylic acids during the oxidation process. 


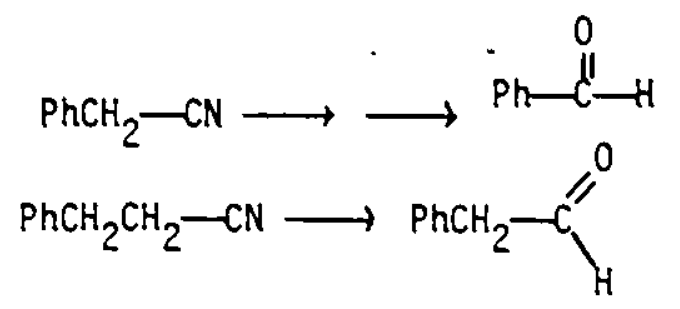

$\because$

H<smiles>[R]C([R])([R])C#N</smiles>

- 1<smiles>[R]C([R20])([R])[N]</smiles>

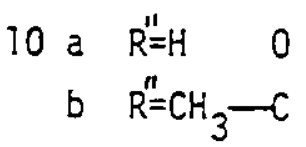

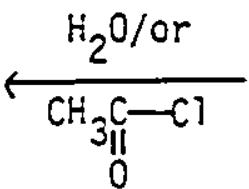

$\downarrow^{\mathrm{SnCl}} 2$<smiles>[R]C([R7])(O)C#N</smiles>

11

Scheme I
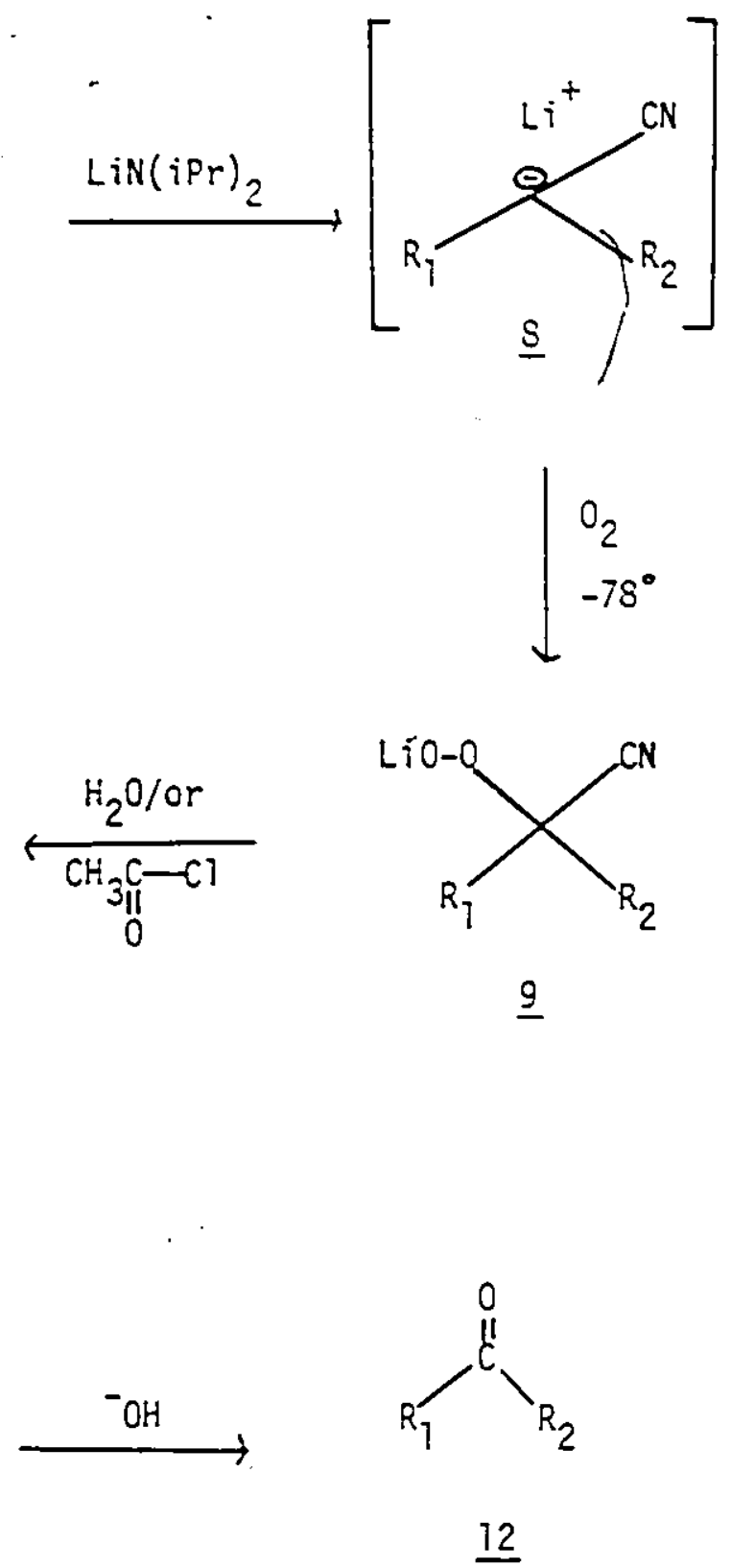

$\mid \begin{gathered}0_{2} \\ -78^{\circ}\end{gathered}$

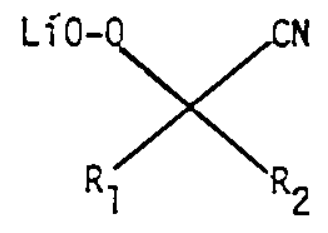

$\underline{9}$ 
Amides

The carbanions generated in the reactions of $N, N$-dialkyl amides with LDA were found (6) to undergo rapid oxidation, under mild conditions, when treated with molecular oxygen. This procedure was found to be quite efficient and general for a-hydroxylation of amides.

Amide

$\mathrm{CH}_{3} \mathrm{CH}_{2} \mathrm{CONMe}_{2}$

$\mathrm{CH}_{3} \mathrm{CH}_{2} \mathrm{CH}_{2} \mathrm{CONMe}_{2}$

1

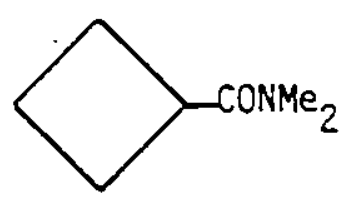<smiles>CN1CCCCC1=O</smiles>

a-hydroxy derivative

$\mathrm{CH}_{3} \mathrm{CH}(\mathrm{OH}) \mathrm{CONMe}_{2}$

$\mathrm{CH}_{3} \mathrm{CH}_{2} \mathrm{CH}(\mathrm{OH}) \mathrm{CONMe}_{2}$

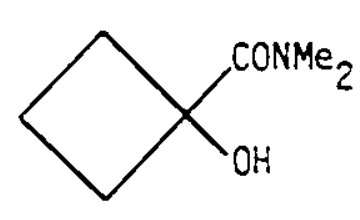<smiles>CN1CCCC(O)C1=O</smiles>

S5

S1

Yield ( $\because)$

72

so

Miscellaneous

Rauchschwalbe and Schiosser (7) have shown that allylic carbanions, prepared by treatment of olefins with $t-B u 0^{-} \mathrm{K} / \mathrm{sec}-\mathrm{BuLi}$ can be regioselectively oxidized by treatment with dimethoxyfuroroborane followed by decomposition of the intermediate borane with hydrogen peroxide. 

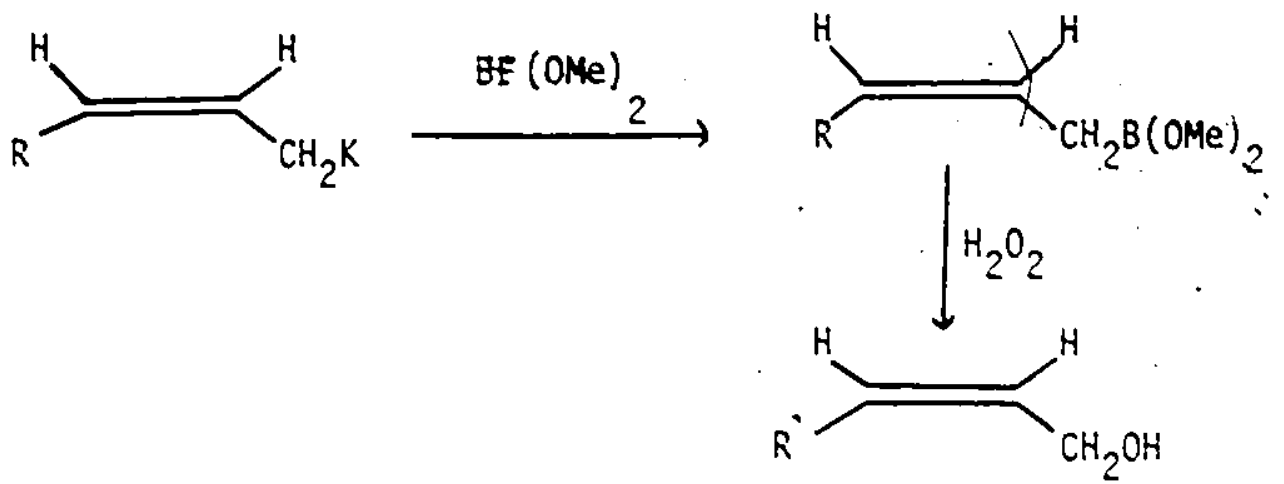

Thus, metallation of isoprene followed by reaction with BF(OMe $)_{2}$ and $\mathrm{H}_{2} \mathrm{O}_{2}$ gave the allylic alcohol $\underline{13}(E / Z=92: S)$ in $65_{*}^{\circ}$ yield.

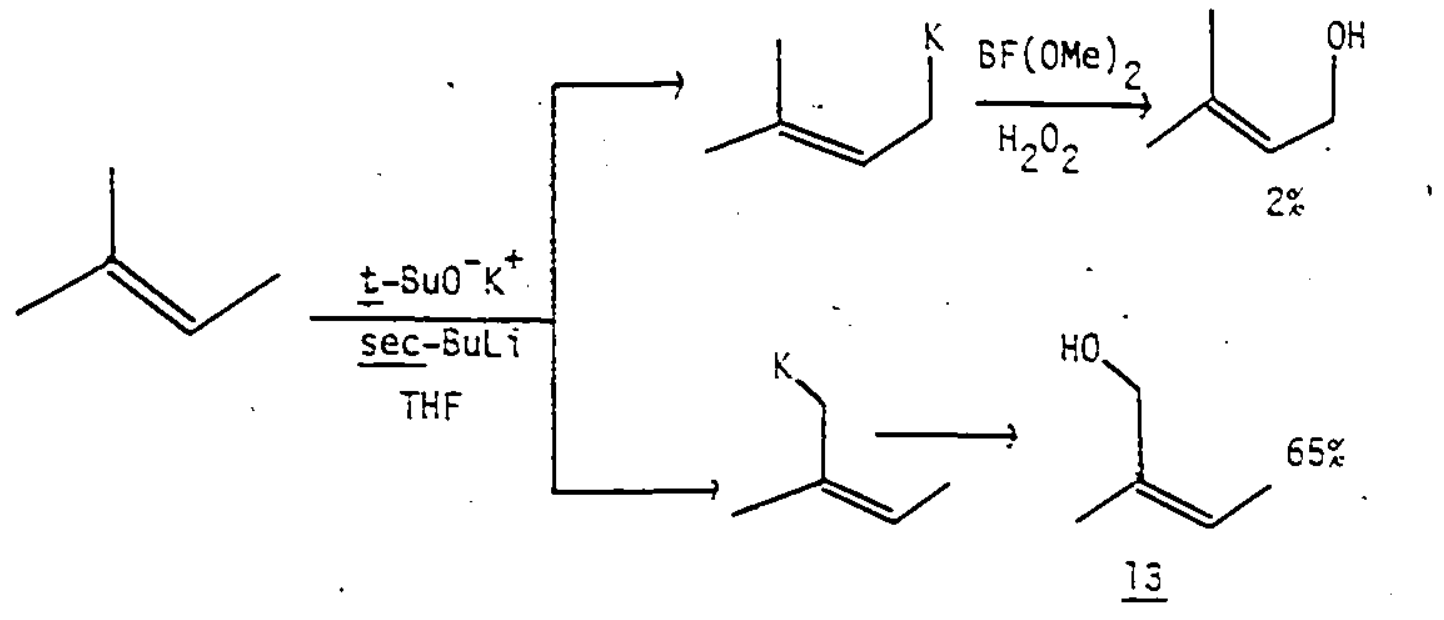

\section{Mechanistic Considerations}

The transformation of an organolithium reagent to the corresponding alcoholate ordinarily occurs in two distinct steps (8).

$$
\begin{aligned}
\mathrm{RLi}+\mathrm{O}_{2} & \longrightarrow \mathrm{ROOLi} \\
\mathrm{ROOLi}+\mathrm{RLi} & \longrightarrow 2 \mathrm{ROLi}
\end{aligned}
$$

The formation of the organolithium peroxide was confinmed by walling and Buckler (9). These authors oxidized n-butyl lithium in diethyl ether with $\mathrm{O}_{2}$ at -78 and obtained, after hydrolysis, the corresponding 
hydroperoxides in $35 \%$ yieid.

The mechanism for the initial formation of the hydroperoxide is not known. Various theories have been put forth $(10)$. These include (i) a free radical chain process:

$$
\begin{aligned}
& R^{-}+\mathrm{ROO} \longrightarrow \mathrm{ROO}^{-}+\mathrm{R}^{\circ} \\
& \mathrm{R}^{*}+\mathrm{O}_{2} \longrightarrow \mathrm{RO0^{ \circ }}
\end{aligned}
$$

(ii) a one step reaction between the carbanion and oxygen;

$$
\therefore \mathrm{F}^{-}+\mathrm{O}_{2} \longrightarrow \mathrm{ROO}^{-}
$$

(iii) a one-electron transfer between the carbanion and oxvgen followed by collapse of the intenmediate 14 to the hydroperoxide carbanion.

$$
\mathrm{R}^{-}+{ }^{3} \mathrm{O}_{2} \longrightarrow\left[\mathrm{R} \cdot \mathrm{PP}^{-} \mathrm{S}^{-}\right] \longrightarrow \mathrm{RC}_{2}^{-}
$$

Process $(i i)$ is considered highiy unitikeiy since a change in spin multiplicity must accompany bond formation.

Some evidence has been recently presented supporting process

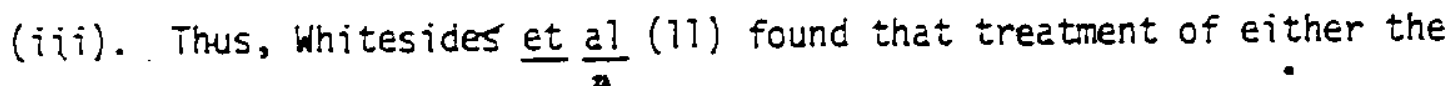
$E$ or $Z$ isqmers of 1-1ithio-1-phenyi-l-butene with $O_{2}$ at $-7 \varepsilon^{c}$ resulted in partial loss of stereochemistry about the double bond. A linear vinyl radical was suggested as a plausible intermediate to rationalize the loss of stereochemistry. 


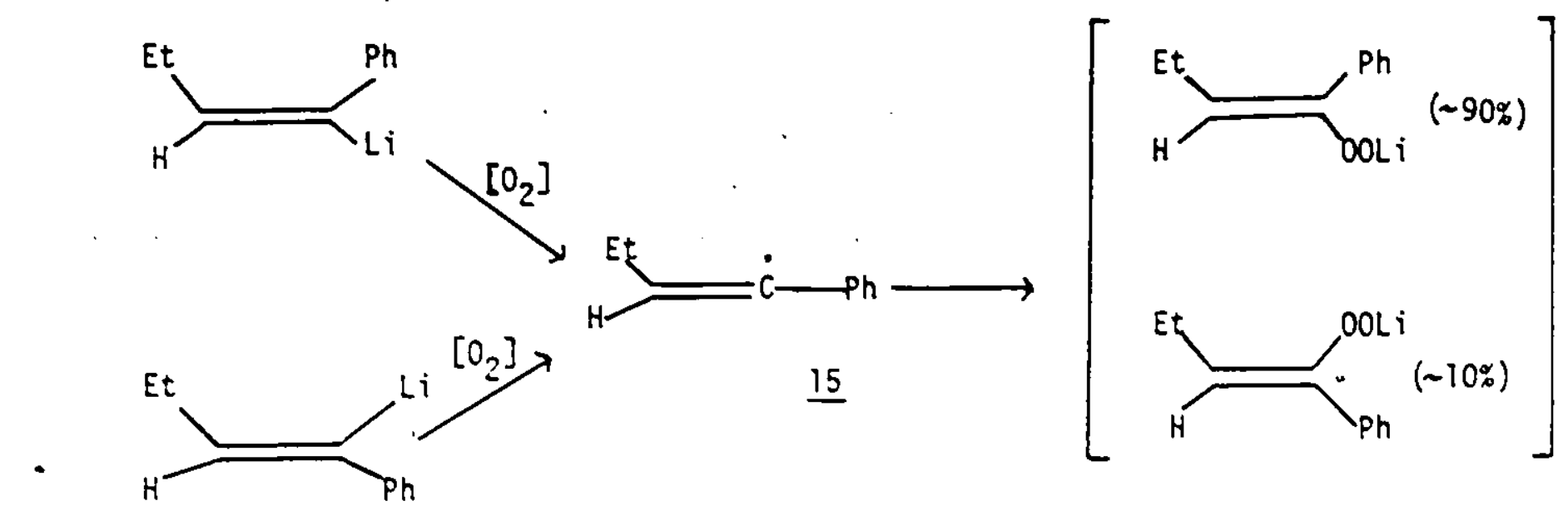

In contrast treatment of the same vinyl lithiums with lithium t-butyl peroxide gave enolates with retention of stereochemistry suggesting that free radicals are not invoived in this process.
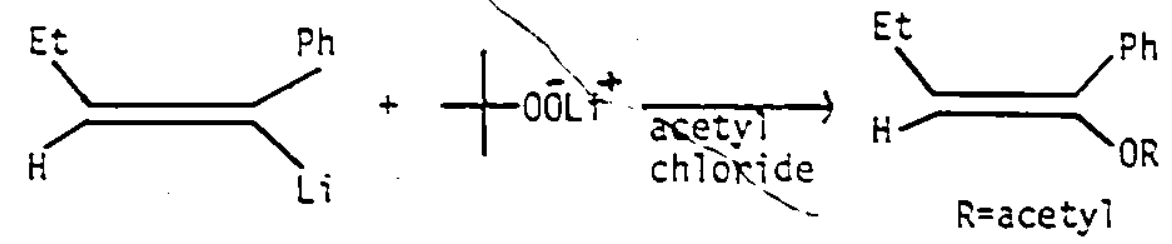

The oxygen transfer between the lithio peroxide and the lithio carbanion is somewhat surprising. The mechanism has not been investigated. It could conceivably be depicted as sflown below.<smiles></smiles> 


\section{Results and Discussion}

To date, there has been no report of the conversion of the sulfone unit into its a-hydroxy derivative and subsequently to the corresponding aldehyde or ketone.

Formation of aldehydes and ketones from a-hydroxy sulfones upon treatment with base is a well established process (12).

$$
\mathrm{RCH}_{2}-\mathrm{SO}_{2} \mathrm{Ph} \longrightarrow \mathrm{R}_{\mathrm{H}}^{\mathrm{RH}}-\mathrm{SO}_{2} \mathrm{Ph} \equiv \mathrm{RCHO}+\mathrm{PhSO}_{2} \mathrm{H}
$$

Such a conversion could greatiy extend the use of sulfone chemistry in symthesis. A simple alkyl phenyl sulfone, readily prepared from an alkyl halide, could thus be converted after alkyiation and oxidation into a ketone. The overall process is shown below.

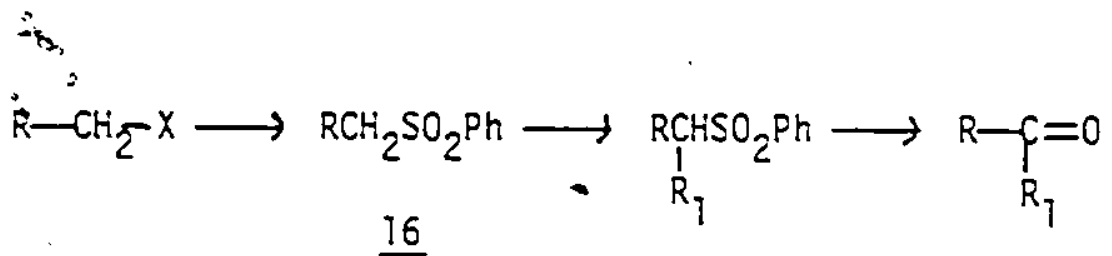

The species 16 can be considered the equivalent of the acy? anion $\mathrm{RC}_{11}^{\mathrm{G}}$ (13).

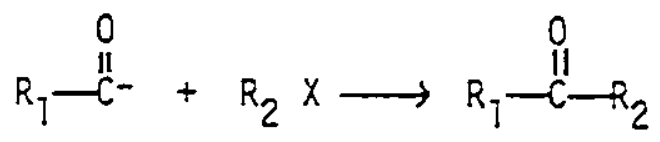


Ketone Generating Systems

The only system studied in which it was possible to affect $\alpha$-sulfonyl carbanion oxidation and hence ketone formation was benzhydryl phenyl sulfone 17 .<smiles></smiles>

17<smiles>CCCC</smiles>

RT<smiles>O=C(c1ccccc1)c1ccccc1</smiles>

$75 \%$

Reaction of the red-coloured carbanion solution of if with

dry oxygen at room temperature resulted in the dissipation of the colour within five minutes. Workup gave benzophenone is in $75 \%$ isolated yield.

It was also possibie to affect oxidation of the carbanion of 17 with elemental sulfur. Addition of sulfur to a solution of the carbanion at $-78^{\circ}$ gave immediately a greenish blue solution. As the reaction mixture was allowed to warm to roon temperature a deep blue colour developed. This deep blue colour is attributed to the formation of thiobenzophenone. Workup of the reaction mixture fumished a blue solid 19 which after standing in air for $24 \mathrm{hrs}$. was converted to benzophenone in an overall yield of $95 \%$. The instability of thioketones in air and their conversion to the corresponding ketones is well known (14). 
<smiles>O=P(O)(O)C(c1ccccc1)c1ccccc1</smiles><smiles>CCCCC(C)C</smiles><smiles>O=C(c1ccccc1)c1ccccc1</smiles><smiles>S=C(CS)c1ccccc1</smiles>

19

The reaction of diaryl phenylsulfonyl carbanions with $S_{S}$ may constitute a potential method for the preparation of diaryl thioketones $\underline{22}$. The required starting sulfones 21 may be prepared simply by treatment of benzhydrol derivative 20 with phenylsulfinic acid. Other methods of preparing diaryl thioketones have involved, for example, addition of $P_{2} S_{5}$ to benzophenone derivatives (i5).

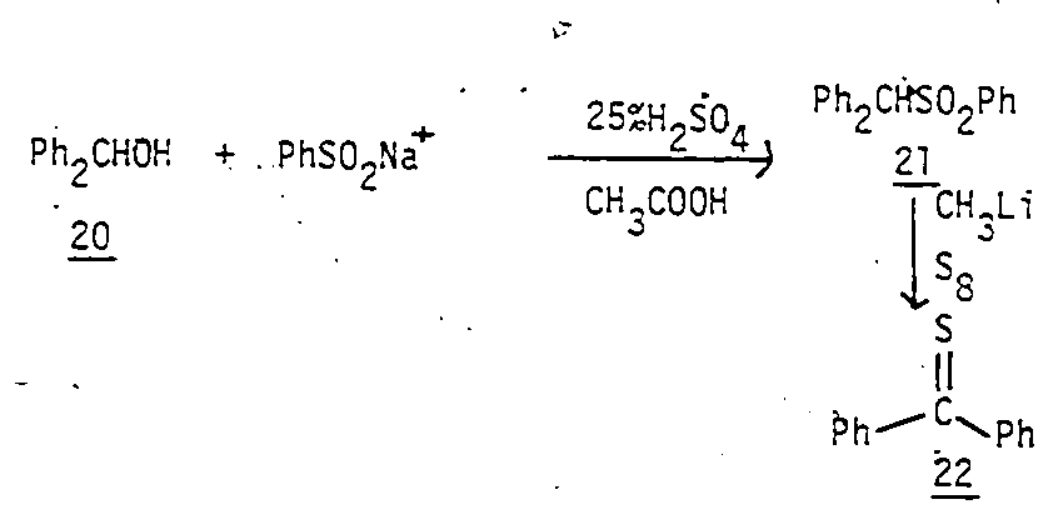

Our attention then turned to the system 23. Attempted oxidation of its carbanion proved fruitless and starting material was recovered when the carbanion was treated with $\mathrm{O}_{2}$ at $-78^{\circ}$ or at room temperature, while reaction with $\mathrm{BF}$ (OMe) ${ }_{2} / \mathrm{H}_{2} \mathrm{O}_{2}$ following Schlosser's methodology was also unsuccessful. Some reaction did occur in the latter case but no acetophenone could be detected in the NMR of the 
crude product.<smiles>CC(c1ccccc1)C(C)(C)c1ccccc1</smiles>

$\underline{23}$

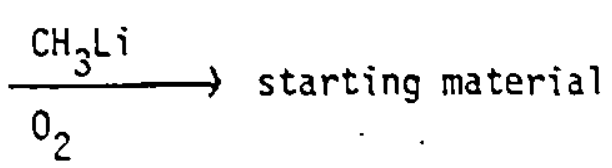

$$
\stackrel{\mathrm{CH}_{3} \mathrm{Li}}{\mathrm{SF}(\mathrm{OMe})_{2} / \mathrm{H}_{2} \mathrm{O}_{2}} \rightarrow \text { ? }
$$

Conversion of cis 4-t-butyl phenyl sulfone 24 to 4 -t-butyl the carbanion of 24 with oxygen or $B F(\mathrm{OMe})_{2} / \mathrm{H}_{2} \mathrm{O}_{2}$ resulted in recovery of epimerized starting material in the former and unidentified materials for the latter experiment:

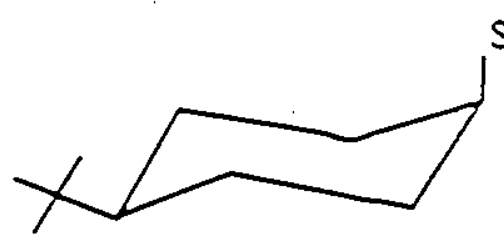

$\underline{24}$ $\mathrm{SO}_{2} \mathrm{Ph}$

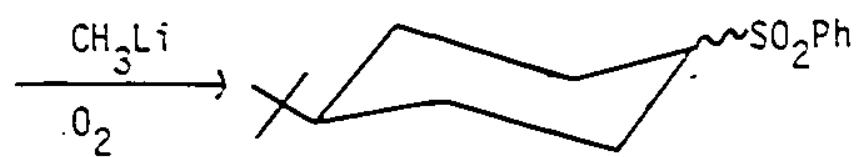

RT

Aidehyde Generating Systens

These efforts involved attempted generation of benzaldehyde from the reaction of various a-carbanions of suifur derivatives with $\mathrm{O}_{2}$

$$
\begin{aligned}
& \mathrm{PhCH}_{2} \mathrm{X} \\
& x=\mathrm{SO}_{2} \mathrm{Ph} \\
& x=\mathrm{SOPh} \\
& x=\mathrm{SO}_{2} \mathrm{~N}\left(\mathrm{CH}_{3}\right)_{2}
\end{aligned}
$$$$
\longrightarrow
$$$$
\text { Ph- } \stackrel{0}{\mathrm{C}}-\mathrm{H}
$$ 
Thus, the carbanion of benzyl phenyl sulfone $\underline{25}$ when treated with molecular oxygen, at $-78^{\circ}$, furnished traces of benzaldehyde as evidenced by its distinctive odour and comparative TLC behaviour.

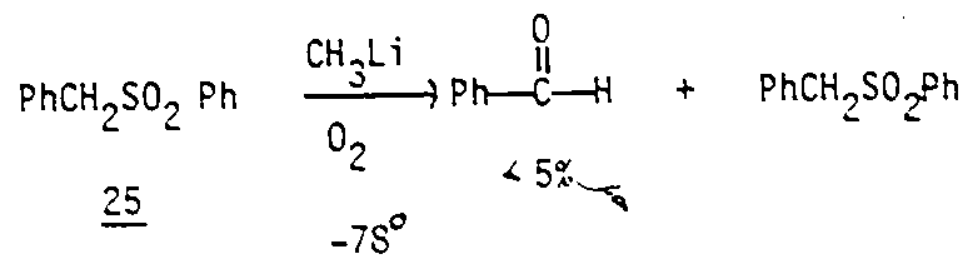

When the reaction was carried out at "room temperature, the sole observed product was the hydroxy suifone 26 which was generated by addition of the initial carbanion of $\underline{25}$ to benzaldehyde.

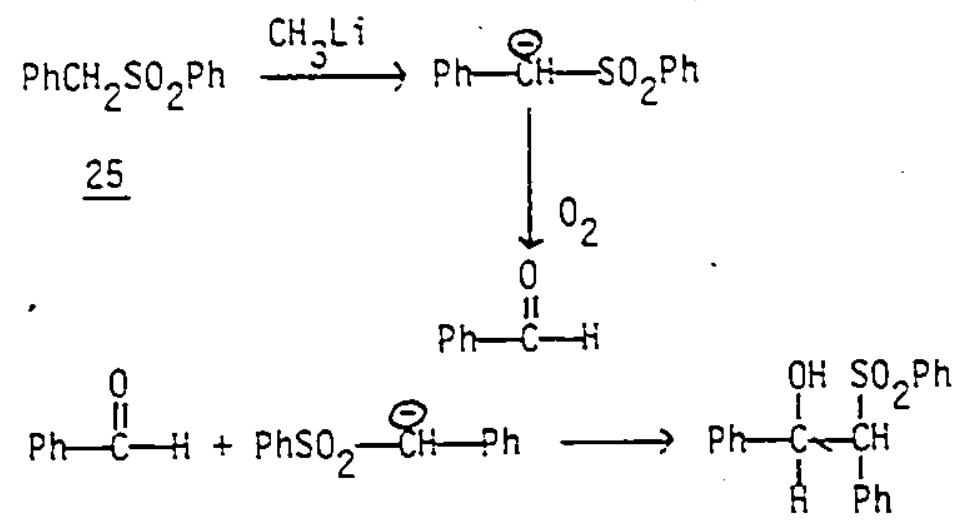

26

Formation of the adduct $\underline{26}$ suggests that decomposition of the intermediate iithio peroxide to benzaldehyde at $25^{\circ}$ proceeds faster than formation of this peroxide (assuming that the initial electron transfer step is not reversible) and also that addition of the carbanion to benzaldehyde is faster than aldehyde generation, otherwise benzaldehyde would accumulate. 
It was felt that if the electron transfer step could be enhanced, thus possibly resulting in more rapid formation of benzaldehyde, adduct formation might be depressed.

The reaction was repeated in the presence of $\mathrm{CuCl}_{2}$, an electron acceptor, but once again adduct formation was the only observed product.

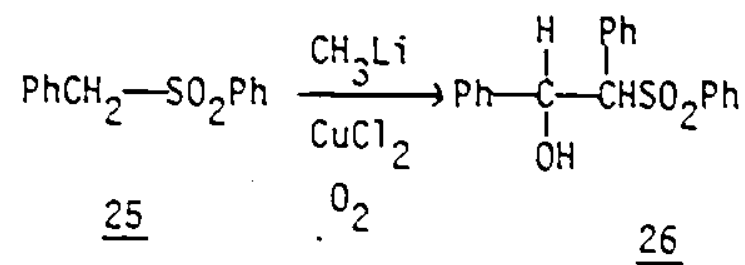

Other unsuccessful methods which were attempted for the oxidation of the carbanion of $\underline{25}$ are sumarized below.

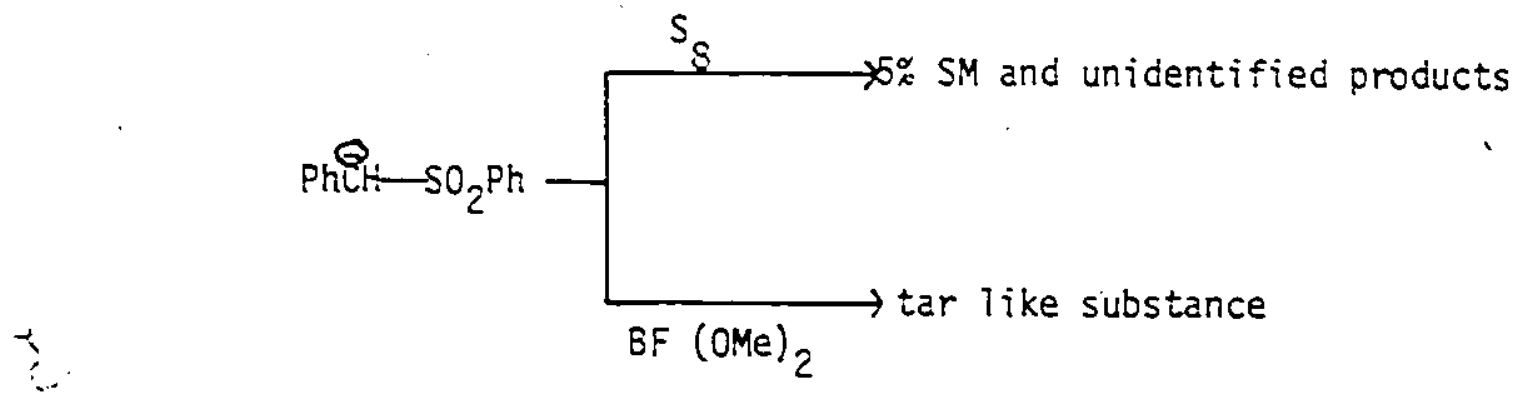

The effect of changing the oxidation state of the sulfur was also briefly investigated.

The sulfonamide 27 when treated with $\mathrm{CH}_{3} \mathrm{Li}$, followed by $\mathrm{O}_{2}$, at either $-78^{\circ}$ or $0^{\circ} \mathrm{C}$ provided $80^{\%}$ recovery of starting material and $20 \%$ of a material which was not isolated but which appeared to be the adduct $\underline{28}$ similar to the product encountered with the oxidation of benzyl phenyl sulfone. No benzaldehyde was detected, either by NMR or TLC. 


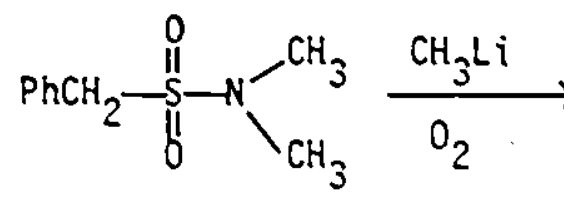<smiles>CN(C)S(=O)(=O)Cc1ccccc1</smiles>

\section{0\%}

$\underline{27}$<smiles>CN(C)S(=O)(=O)C(O)c1ccccc1</smiles>

$20 \%$

Sulfoxide

The carbanion of benzyl phenyl sulfoxide 29 , generated at room temperature by treatment with $\mathrm{CH}_{3} \mathrm{Li}$, was found to be unreactive towards molecular oxygen. Quenching of the reaction mixture with $D_{2} O$, after oxygenation, followed by acidification with ammonium chioride resulted in $90^{*}$ recovery of the a-mono-deutero derivative.

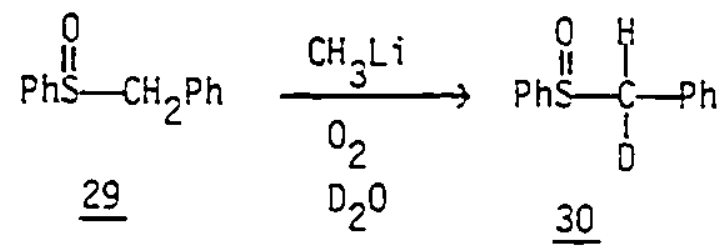

Conclusions

The attempted oxidations of the ketone generating systems which were described above gave results which are difficult to rationalize. For example, why did oxidation of the carbanion bearing two phenyl groups proceed smoothly while the phenyl methyl analog was completely unreactive under the same reaction conditions? 
- The reaction of the benzylic sulfur carbanions with $\mathrm{O}_{2}$ appeared to be sensitive to the oxidation state of the sulfur. Thus the sulfone 25 was oxidized via its carbanion to the extent of $50 \%$, the sulfonamide carbanion 27 gave in: oxidation, whereas in the lithio carbanion of the sulfoxide 29 no oxidation was observed. 
- $116-$

7

PART III

a-Lithio Sulfones

$-$

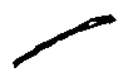


Structure and Stereochemistry of their Reaction with Electrophiles.

\section{Introduction}

The major impetus for the work described in this part af the thesis was due to some unusual results of Legault and Durst (1) in connection with reactions of the lithio derivatives of cis and trans-2,6-diphenylthiane-1,1-dioxide. These authors noted that the carbanion of the cis diphenyl sulfone I when quenched with $\mathrm{H}_{2} \mathrm{O}$ at $-7 \mathrm{~S}^{\circ}$ resulted in the formation of the trans derivative $\underline{2}$ exclusively.
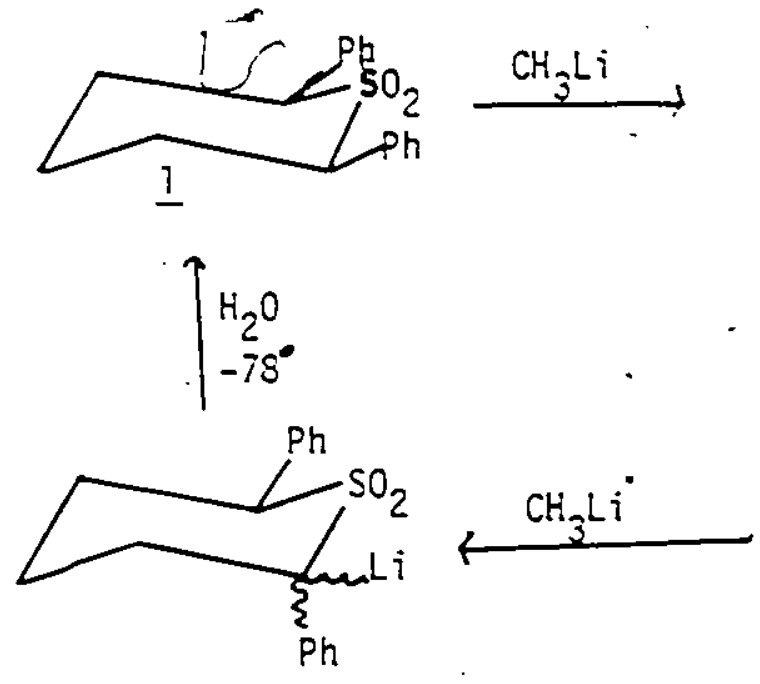
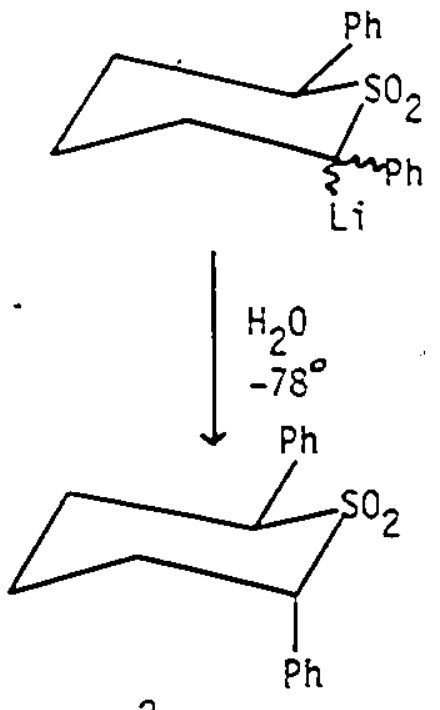

$\underline{2}$

More interestingly, they claimed that treatment of the trans isomer 2 with plethylithium followed by quenching with $\mathrm{H}_{2} \mathrm{O}$ at $-78^{\circ}$ resulted in formation of the cis isomer 1 . These results were quite remarkable in that both compounds 1 and 2 were ciaimed by-Legauit and Darstito have undergone deprotonation 
and subsequent protonation in a stereospecific manner with net inversion at the carbanion centre. These initial findings were considered sufficiently intriguing to merit closer scrutiny.

Thus, it was decided to reexamine Legault's original results with respect to the formation and reaction of the carbanions of the cis and trans diphenyl sulfones $\underline{I}$ and $\underline{2}$ with several electrophiles and to determine if the two carbanions interconverted at higher temperatures.

Another goal of this project was to examine the carbanions generated from the diphenyi sulfones $\underline{I}$ or $\underline{2}$ and the conformationally rigid 4-t-butyl sulfone $\underline{\underline{3}}$ via ${ }_{H} H$ and/or ${ }^{13} \mathrm{C}$ NMR spectroscopy.
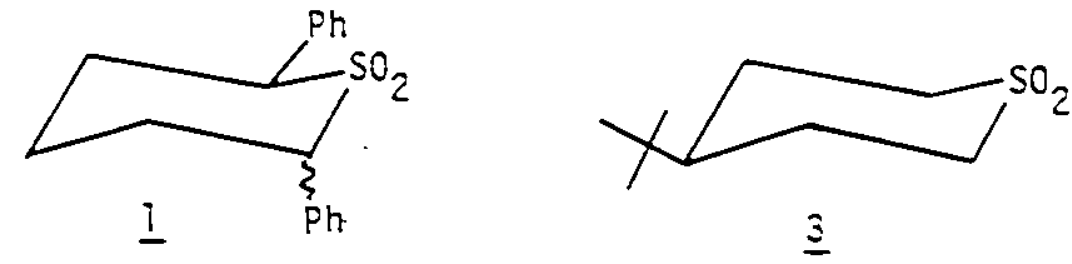

Synthes is of 1 and 3

The sulfone I was prepared according to the following equation.

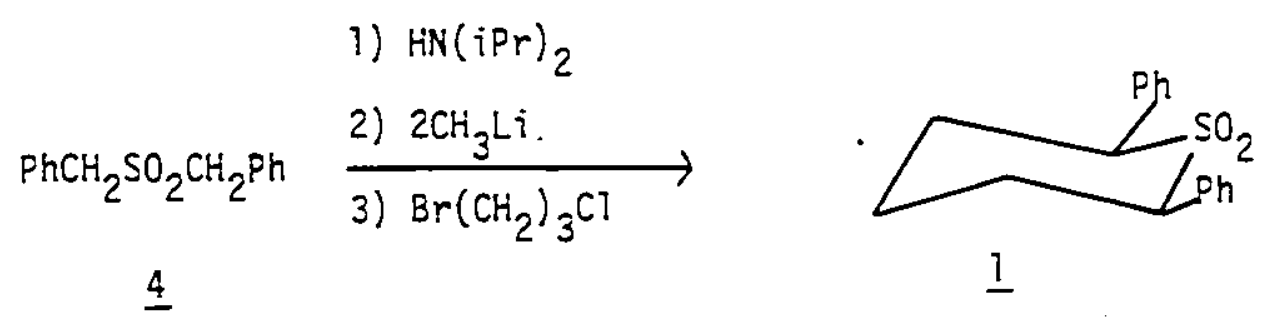


Thus, reaction of the dianion of dibenzyl sulfone 4 with one equivalent of bromochloropropane at $-78^{\circ}$, followed by warming to room temperature resulted in an $50 \%$ yield of the cis diphenyl sulfone 1. The structure and cis stereochemistry of the product was assigned on the basis of the spectral data. In particular the axial benzylic hydrogens $(s=5.16 \mathrm{ppm}$ ) showed $\mathrm{J}$ 's of 11.9 and $3.1 \mathrm{~Hz}$ consistent with the assigned cis structure. Other signais were observed at 1.5-2.9, $(m, 6 H)$ and $7.2-7.6,(m, 10 H)$.

The 4-t-butylthiane-1,1-dioxide 3 was prepared according to a method suggested to us by Dr. A. Marquet, C.N.R.S., Thiais, France. 3 The sunthetic plan employed is outlined in scheme 1. The sunthesis of the sulfone $\underline{3}$ is straight forward and details are available in the Experimental Section. The structures of intermediates were established on the basis of their IR and NMR spectra. The resultant sulfone $\hat{3}$ exhibited spectral properties in agreenent with the assigned structure. 
1

Scheme 1
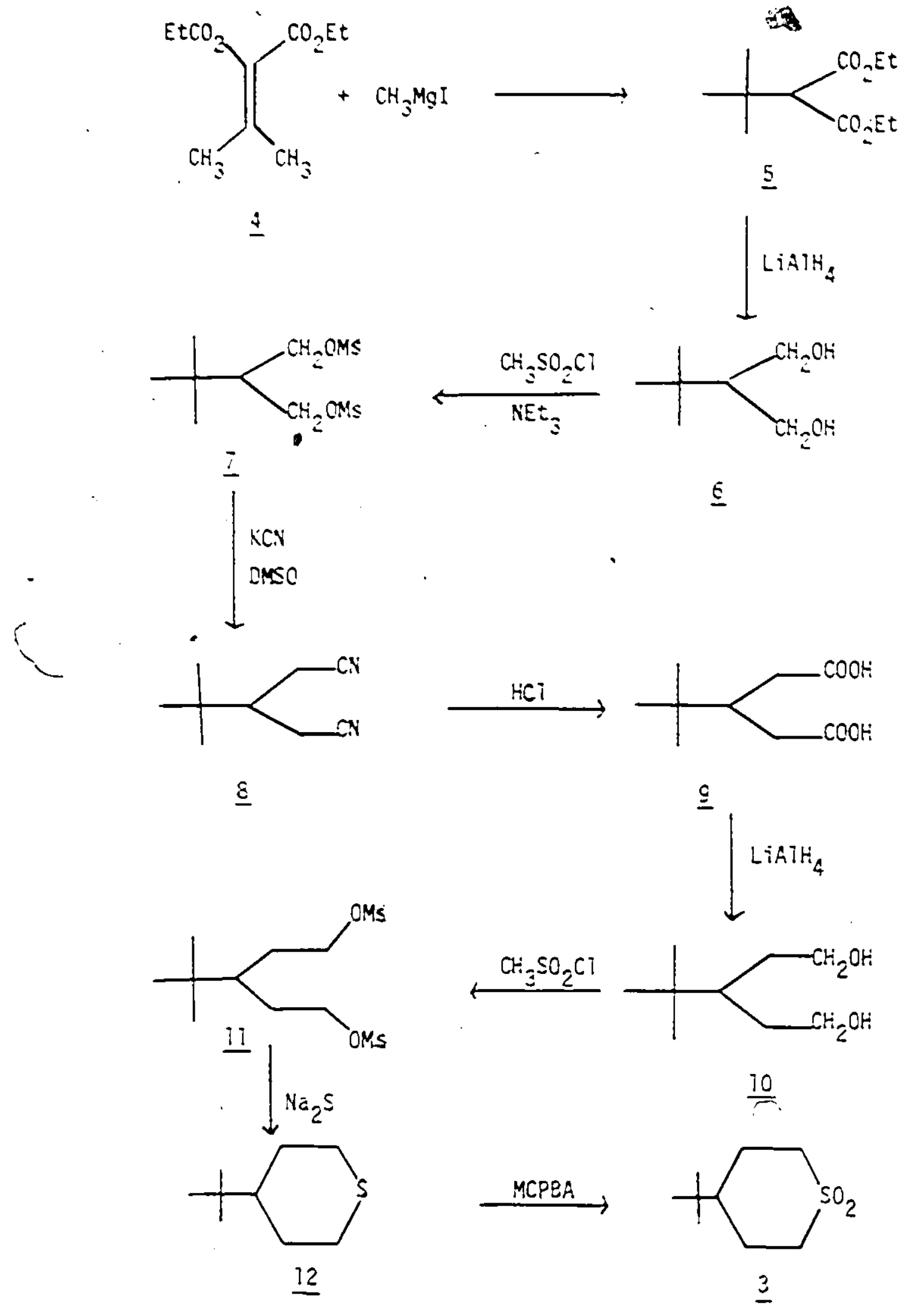


\section{Results and Discussion}

In agreement with the previous observation of Legault the carbanion of 1 when quenched with $\mathrm{H}_{2} \mathrm{O}$ gave the isomeric sulfone $\underline{2}$.
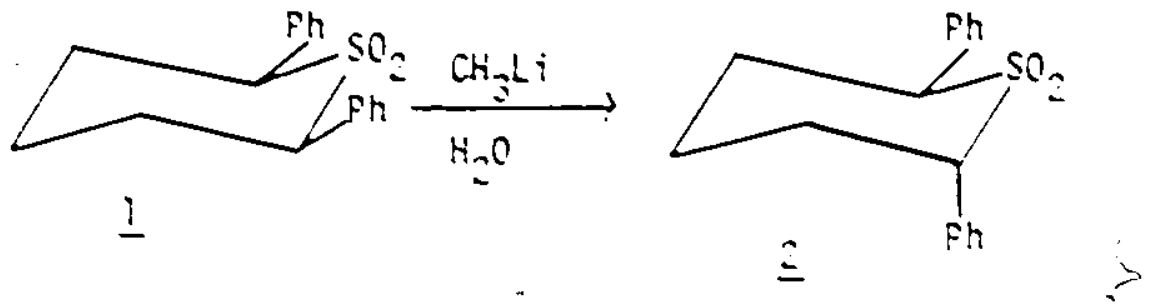

However. contrary to Legault's claim, reaction of a with $\mathrm{CH}_{3} \mathrm{Li}$ at temperatures from $-i \mathrm{~S}^{\circ}$ to $+25^{\circ}$ followed by $\mathrm{H}_{2} \mathrm{O},\left(\mathrm{O}_{2} \mathrm{O}\right)$ did not give $\underline{i}$, but regenerated oni $\underline{\underline{2}} \underline{\underline{2}}$. This means that the key resuit $\underline{\underline{a}} \longrightarrow \underline{\underline{I}}$ which suggested the existence of two isomeric carbanions was not repeatable in my hands.

The titans stereochemistry of the suifone 2 was clearly established on the basis of its spectral data.

Thus, the benzylic hydrogen at $i=5.30$ showed I's of 7.2 and $4.2 \mathrm{~Hz}$, a result of averaging ac and ee and 2ae intereactions respectiveiy, because of rapic ring inversion of 2. Other absorptions in the 'H NMR occured at $27.8-2.2(m, 2 H) 2.2-,2.9(m, 4 H)$ and $7.3-7.8(m, 10 H)$.

The ${ }^{13} \mathrm{C}$ MMR data for both the cis and trans 2,6-diphenyithiane 1,7 -dioxide is presented below. (Table I) In particular the shielding of $(-4$ in the trans isomer (23.4 vs. 27.9) is indicative of an axial phenyi group. This gauche $y$ fffect is well known (z). 


\section{Table I}

${ }^{13} \mathrm{C}$ NMR Data for Cis and Trans 2,6-diphenylthiane-1,1-dioxide

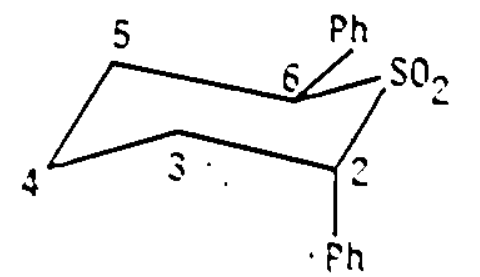

\begin{tabular}{l|c}
$c$ & $s$ \\
$3 \sqrt{5}$ & 67.2 \\
32.6
\end{tabular}

$4 \quad 23.4$

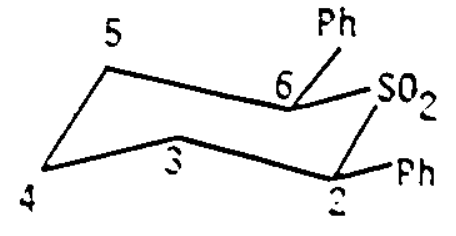

$\underline{c} \underline{\varepsilon}$

$2,6 \quad 70.3$

$3,5 \quad 34.3$

$4 \quad 27.9$

Others $135.9,132.2,130.4$

Others $134.6,132.2,130.4$

It was also shown that the carbanion of $I$ or 2 reacted with $\mathrm{CH}_{3} \mathrm{I}$ to give a singie product assigned structure $\underline{13}$ on the basis of its complete equilibration to 14 .

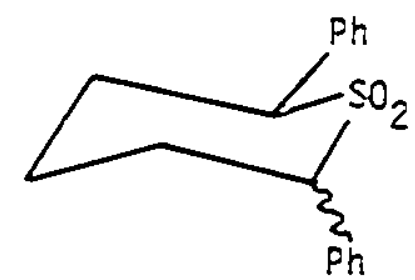

cis or trans
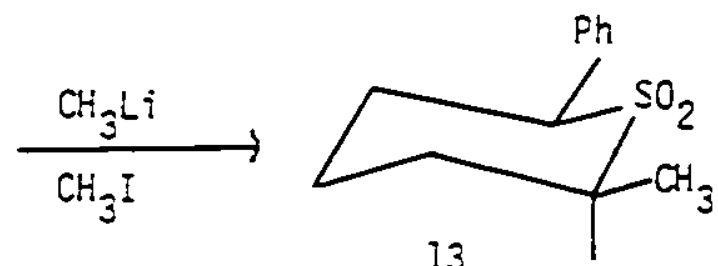

13 NaOMe $\mathcal{M E O H}$

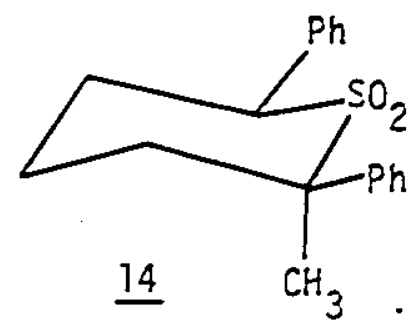


In summary, it has been shown that generation and subsequent trapping of the carbanion of either $\underline{1}$ or $\underline{2}$.results in incorporation of the electrophile in the equatorial position of the ring.
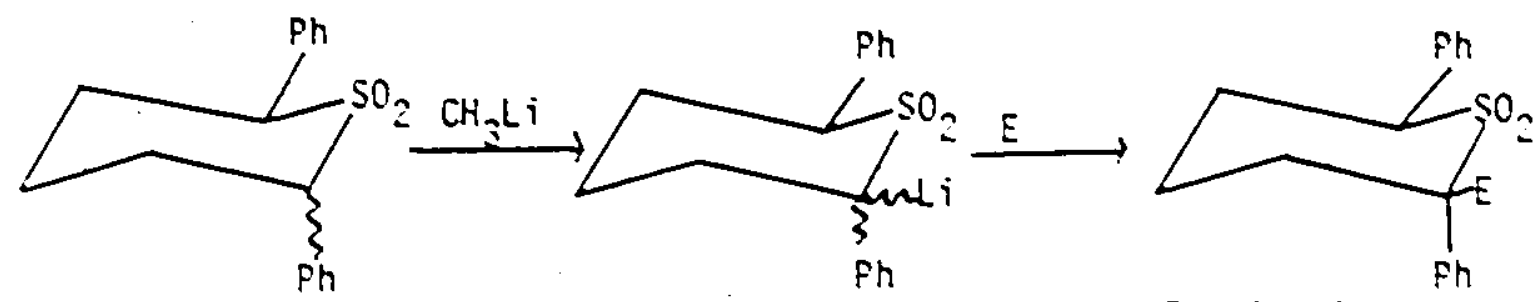

$\mathrm{E}=\mathrm{H}_{3} \mathrm{O}, \mathrm{D}_{2} \mathrm{O}, \mathrm{CH}^{3} \mathrm{I}$

Such stereoelectivity has been observed in other systems in which a lithio carbanion has been stabilized by a sulfur function.

Thus, Durst (3) reported that a-lithio-s-sultones $\underline{16}$ or $\underline{17}$ when reacted with various electrophiles including $\mathrm{H}_{2} \mathrm{O}, \mathrm{O}_{2} \mathrm{O}, \mathrm{CH}_{3} \mathrm{I}$ and

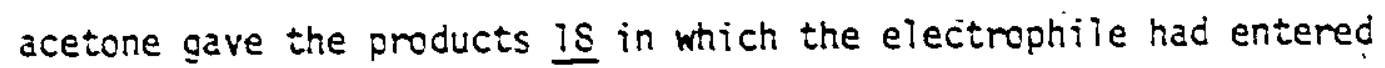
exclusiveiy in the equatorial position even when the products were the themodymamicaliy iess favoured ones. (Scheme 2)

Eliel and co-workers (4) obtained similar stereochemical results in the reactions of $2-1$ ithio-1,3-dithianes with electrophiles.

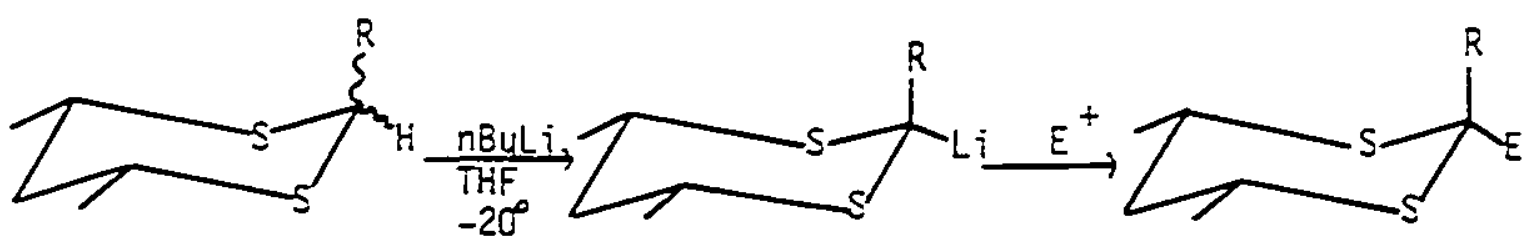




\section{Scheme 2}

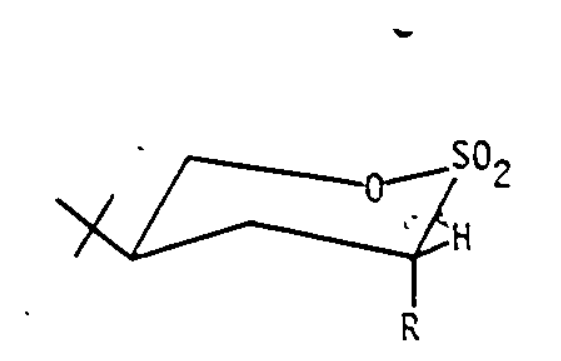

$\underline{19}$

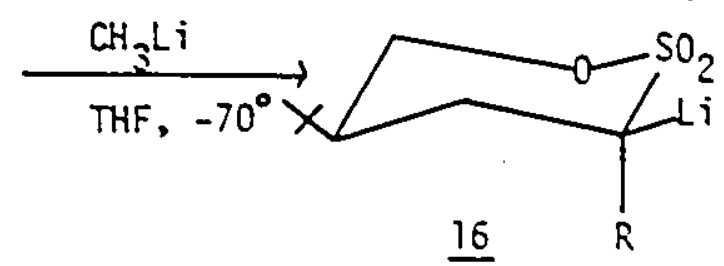

$\underline{16}$

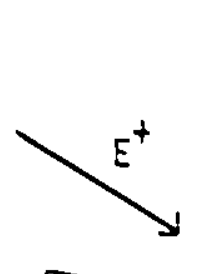

R

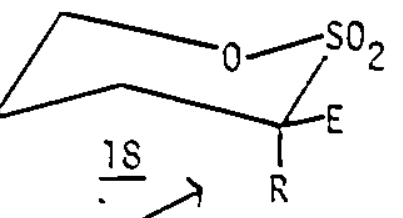

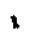

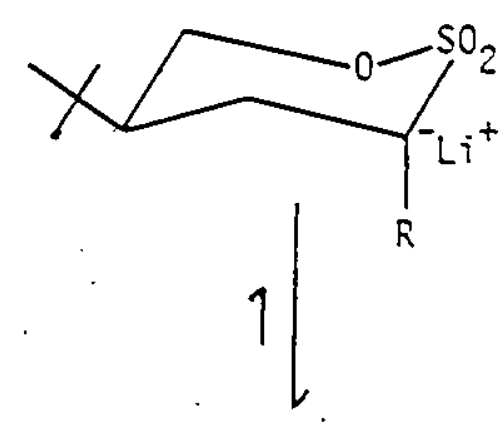

E

$\times \int_{\mathrm{H}}^{\mathrm{S}} \mathrm{SO}_{2} \frac{\mathrm{CH}_{3} \mathrm{Li}}{\mathrm{THF},-70^{\circ}}$ $\therefore 20$

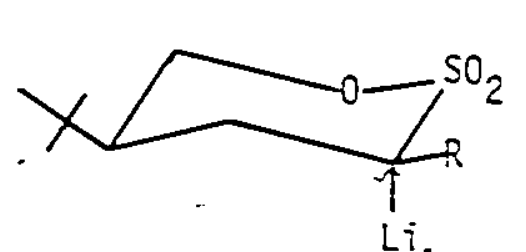

I7

A strong conformational preference for 1 ithio carbanions in acyclic compounds was first noted by Corey (5) and Cram (6) who observed overall retention in the base catalyzed $H-D$ exchange in optically active sulfones of the type $\mathrm{R}_{1} \mathrm{R}_{2}{ }^{\mathrm{C}} \mathrm{CHSO} \mathrm{P}_{2} \mathrm{Ph}$.

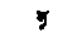

The: strong conformational bias for $\alpha$-sulfonyi carbanions is also supported by the theoretical studies by Wolfe and co-workers (7). 
On the basis of M.O. calculations on the somewhat simplified system ${ }^{\theta} \mathrm{CH}_{2}-\mathrm{SO}_{2} \mathrm{H}$ it was concluded that the pyramidal carbanion with the lone pair bisecting the $0-5-0$ angle has the lowest energy. It must be kept in mind that these calculations are strictly only applicable to the gas phase.

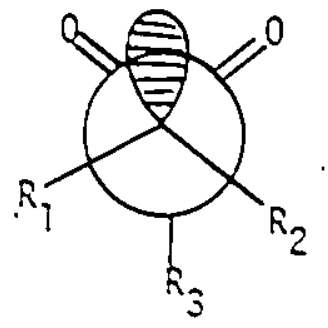

The extension of these results to carbanions in solution may not be justified. (aggregates, solvation effects, etc.)

The metallation and quenching results in the six membered ring series may be interpreted in terms of the intermediacy of $\mathrm{sp}^{3}$ hybridized species in which the lithium shows a very strong perference for the equatorial position or an $\mathrm{sp}^{2}$ species which reacts with electrophiles in a stereospecific manner with the electrophile approaching syn to the sulfone oxygens.

Conciusion

Thus, it has been shown that Legault's priginal claim cannot be substantiated, and that a-lithio sulfones in a six-membered ring have a strong conformational bias, as in the other systems discussed above, for incopporation of the electrophile in the equatorial position. 
$\underline{I_{H} \text { and }{ }^{13} \mathrm{C} \text { NMR of } \alpha \text {-Sulfonyl Carbanions }}$

As a probe to the structure of carbanions in solution we attempted to obtain ${ }^{1}$ or ${ }^{13} \mathrm{C}$ NMR data on the system $\underline{I}$ and $\underline{3}$.

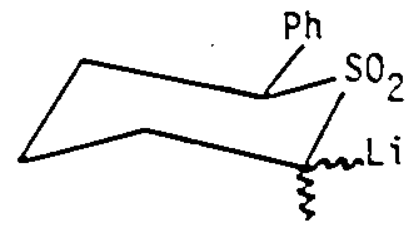

I

$\mathrm{Ph}$

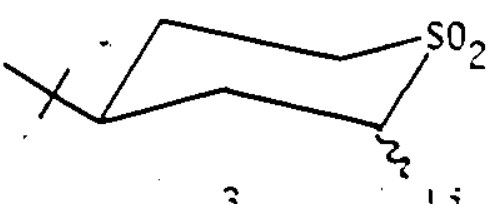

$\underline{3}$

Diphenyl Sulfone ?

The proton NMR of the carbanion from $I$ was obtained at $-7 S^{\circ}$. The remaining $H$ on $C-6$ displayed a large and a smali coupling constant suggesting that the ring still exists in a chair form.

Attempts to obtain ${ }^{13} \mathrm{C}$ NMR data for the carbanion of $I$ were not successfui due to decomposition of the sampie in the probe at room temperature.

\section{- 4-t-butylthiane-1,i-dioxide}

The carbanion of the sulfone $\underline{3}$ was generated in THF $\underline{d}-8$ by reaction with methyilithium/ether and the ${ }^{13} \mathrm{C}$ NMR was recorded at room temperature. The ${ }^{13} \mathrm{C}$ NMR data of the sulfone $\underline{3}$ and its a-lithio carbanion under identical conditions of solvent and temperature are presented beiow. 

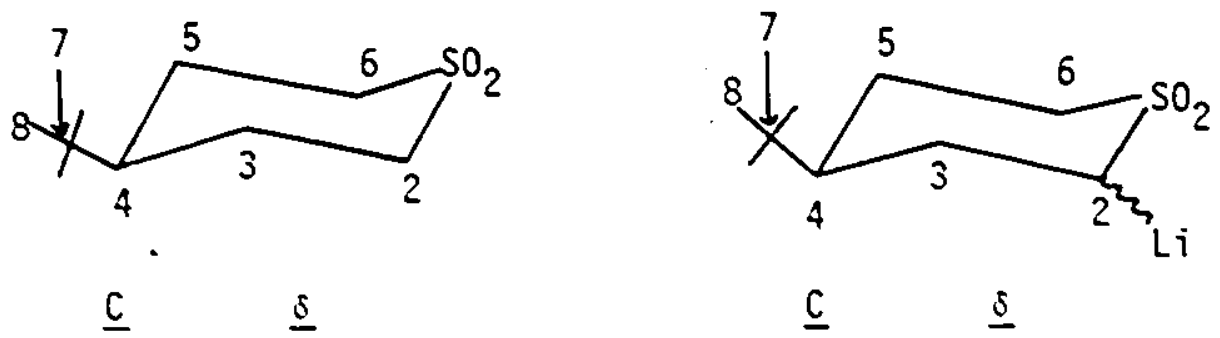

$\begin{array}{ll}2,6 & 52.0 \\ 3,5 & 26.3 \\ 4 & 46.4 \\ 7 & 32.6 \\ \mathrm{~s} & 27 . \mathrm{S} \\ & 9 \\ \mathrm{~J}^{i 3} \mathrm{C}_{2}-\mathrm{H} & =134.6 \mathrm{~Hz}\end{array}$

Chemical Shifts

244.2

$3 \quad 29.7$ or 27.7

$4 \quad 49.8$

529.7 or 27.7

$6 \quad 54.0$

$\begin{array}{llll}7 & 33.1 & 8 & 28.3\end{array}$

$\mathrm{J}^{13} \mathrm{C}_{2}-\mathrm{H}=140 \pm S \mathrm{~Hz}$

It is noteworthy that five different ring carbon absorptions are observed. This suggests that intra or intermolecular transfer of the lithium atom from the $a$ to the $a^{\prime}$ carbon in the carbanion is relatively slow on the NMR time scale.

The $7.7 \mathrm{ppm}$ upfield shift of the lithiated carbon atom is in good agreement with the results observed byChassaing and Marquet ( $(8)$ who observed an upfield shift of $9 \mathrm{ppm}$ in going from phenyl methyl sulfone to its a-lithio carbanion. These effects in the carbanion may be attributed to a charge increase producing the observed shielding effect.

\section{${ }^{13} \mathrm{C}-\mathrm{H}$ Coupling Constant}

Due to poor resolution in the fully coupled spectrum of the a-lithio carbanion it was not possible to determine the ${ }^{13} \mathrm{C}-\mathrm{H}$ coupling constant for the a $\mathrm{C}-\mathrm{H}$ bond in the 7 ithiated species to an accuracy of 
greater than $140 \pm 84 z \cdot\left({ }^{\prime} \mathrm{J}_{13 \mathrm{C}-\mathrm{H}}\right)$ for the neutral compound is 134.6 $\mathrm{Hz}$.

Such a large error in the coupling constant does not permit any useful conclusion to be drawn.

Marquet et al (S) observed no change in ${ }^{3} \mathrm{~J}_{13 \mathrm{C}-\mathrm{H}}$ in going from phenyl methyl sulfone to its a-lithio derivative.

In the case of phenyl methyl sulfide a decrease in ${ }^{3} \mathrm{~J}_{13 \mathrm{C}-\mathrm{H}}$ of $20 \mathrm{~Hz}$ was interpreted in terms of an $\mathrm{sp}^{3}$ configuration for the carbanion. This conclusion was drawn from a comparison of this system with the observed decrease in coupling constant $(-27 \mathrm{~Hz})$ observed in methylithium relative to methane.

The carbanion of phenyl methyl sulfoxide was found to experience a $16.5 \mathrm{~Hz}$ increase in coupling constant relative to the neutral compound. This was interpreted as being indicative of a carbanion with substantial $\mathrm{sp}^{2}$ character since a similar increase $(+15 \mathrm{~Hz})$ was observed for diphenyliithium vs. diphenyl methane. The sulfone case is thus intermediate between the sulfide and sulfoxide and the hybridization state was considered to be between $s p^{2}$ and $s p^{3}$. Marquet's study also showed that the coupling constant is dependent on the solvent and cation.

We became aware of Marquet's results with both cyclic sulfoxides and simple sulfides, sulfoxides, sulfones and sulfoximines during the course of our work and recognized that their study was being carried out at a more sophisticated level (use of crystalline $\mathrm{CH}_{3} \mathrm{Li}$, solvent effects, etc.) than our own. Thus, this project was not pursued. 


\section{EXPERIMENTAL.}

Melting points (m.p.) were determined with a Thomas Hoover apparatus and are uncorrected; boiling points (b.p.) are also not corrected. Infrared (IR) spectra were obtained as films on sodium chloride plates and in chloroform $\left(\mathrm{CHCl}_{3}\right)$ solution for solids on the. Beckman IR-20A and Unicam SP1100 Spectrophotometers. Absorptions are reported in $\mathrm{cm}^{-1}$ and are noted as strong $(s)$, medium ( $m$ ), weak (w) or broad. Proton nuclear magnetic resonance (NMR) spectra were obtained on Varian Associates Model HA-100 and Model T-60A with deuterochloroform as soivent (unless otherwise indicated), and tetramethylsilane (TMS) as internal standard. Peak positions are reported in $\delta$ units as parts per milition ( $\mathrm{ppm}$ ) from TMS. The following designations are used in characterising NMR signais: singlet (s), doublet (d), triplet ( $t$ ), doublet of doublets (dd), multiplet $(m)$ and broad(ened). ${ }^{13} \mathrm{C}$ nuciear magnetic resonance $\left({ }^{13} \mathrm{C}\right.$ iHAR) spectra were obtained on a Varian Associates FT-20 NMR spectrometer. Peak positions are reported in $\hat{\delta}$ units as parts per million (ppm) from TMS. The following designations are used in describing the signals from the off-resonance partially coupled spectra: doublet (d), triplet $(t)$, quartet ( $q$ ), quaternary. Combustion analys es were carried out by Gailbraith Laboratories, Knoxville, Tennessee. Mass spectra were recorded by Dr. John Krause of this department. Thin-layer (TLC) chromatography was carried out on Merck 60 F-254 precoated plates of $0.25 \mathrm{~mm}$ thickness. The adsorbant used for column 
chromatography was 60-200 mesh Baker Silica Gel. When used as a reaction solvent, tetrahydrofuran (THF) was always distilled from lithium aluminum hydride $\left(\mathrm{LiAlH}_{4}\right)$ under a nitrogen atmosphere immediately prior to use. Ethyl acetate and hexane were distilled before using. All carbanion and Grignard reactions were carried out under nitrogen. The Grignard reagent, methylmagnesium iodide ( $\mathrm{CH}_{3} \mathrm{MgI}$ ) was prepared in ether on a .5mole scale and the concentration was determined by titration (average of 3 determinations). The term usual workup refers to quenching the reaction mixture with excess $\mathrm{H}_{2} \mathrm{O}$ or amionium chloride, extraction with methylene chloride or ether, drying the organics over $\mathrm{MgSO}_{4}$ and evaporation of the soivent under reduced pressure.

Uniess otherwise stated, all compounds which are described were obtained as clear viscous oils after purification by column chromatography. These compounds were generally not distilled. Attempted distillation in severai instances was accompanied by considerable decomposition. Their structure follows from their method of synthesis, spectral properties and further conversion into compounds which were fully characterized.

Ali solids, unless otherwise described, were obtained as white granular solids. 
PART I

Preparation of Epoxy Sulfones

4-Phenyl thiobut-1-ene $\underline{52}$

To a potassium phenyl mercaptide solution (18.39;140 mole phenyl mercaptan, 9.69;170 mole potassium hydroxide) in $200 \mathrm{ml}$ of methanol was added $20.0 \mathrm{~g}$ (14S mole) of 4-bromo-1-butene dropwise at room temperature. The reaction mixture was stirred overnight and then diluted with $250 \mathrm{ml}$ of $\mathrm{H}_{2} \mathrm{O}$ and extracted with $2 \times 100 \mathrm{ml}$ of methylene chloride, The organic extracts were then washed with $3 \times 100 \mathrm{ml}$ of $5 \%$ $\mathrm{NaOH}$ solution. Drying and evaporation of the organic extracts provided $25 \mathrm{~g}$. (90\%) of the sulfide $\underline{52}$.

- NMR: $\delta 2.7-2.6(m, 2 H), 2.8-3.2(m, 2 H), 4.9-6.3(m, 3 H), 7.1-7.5(m, 5 H)$

4-Phenyisuil fonylbut-l-ene $\underline{53}$

To $52(20.5 \mathrm{~g} ; 125 \mathrm{mmole})$ dissolved in $100 \mathrm{ml}$ of methylene chloride at room temperature was added $50.5 \mathrm{~g}$ (250 mole) of MCPBA in small portions through the condensor. The reaction mixture was stirred overnight and then washed with $4 \times 100 \mathrm{ml}$ of $5 \% \mathrm{NaOH}$ solution. Drying and evaporation of the organics provided 20.7 (85\%) of sulfone $\underline{53}$ after chromatography (1:3 ethyl acetate/hexane).

NMR: $2.7-2.6(\mathrm{~m}, 2 \mathrm{H}), 2.9-3.3(\mathrm{~m}, 2 \mathrm{H}), 4.7-6.0(\mathrm{~m}, 3 \mathrm{H}), 7.3-7.9(\mathrm{~m}, 5 \mathrm{H})$ IR: $\mathrm{C}=\mathrm{C}, 1640(\mathrm{~m}) ; \mathrm{SO}_{2}, 1155(\mathrm{~s})$ and $1325(\mathrm{~s})$ 
4-Phenylsulfonyl-1,2-epoxybutane $\underline{54}$

4-Phenyisulfonylbut-l-ene $(5.0 \mathrm{~g} ; 25.0 \mathrm{mmole})$ was dissolved in $100 \mathrm{ml}$ of methylene chloride at room temperature and $5.0 \mathrm{~g}(25.0$ mole) of MCPBA was added all at once. The reaction mixture was refluxed for $3 \mathrm{hr}$ and then let cool to room temperature. The reaction mixture was then washed with $2 \times 100 \mathrm{ml}$ of $5 \% \mathrm{NaOH}$ and the organic layer was dried and evaporated. Chromatography (150g of silica gel with $1: 4$ ethyl acetate/hexane as eivent) furnished $4.8 g(95 \%)$ of the epoxy sulfone $\underline{54}$.

NMR: \& $\quad 1.7-3.5(m, 7 H), 7.4-7 . S(m, 5 H)$

Mesylate $\underline{55}$

4-Pentene-1-01 ( $9.9 \mathrm{~g} ; 115$ mole) was dissoived in $150 \mathrm{ml}$ methylene.. chloride containing $14.0 \mathrm{~g}$ ( 138 mole) of triethylamine. To this mixture, cooled to $0^{\circ}$ was added dropwise $11.4 \mathrm{~g}$ ( 138 mole) of methanesulfonyl chloride dissoived in $50 \mathrm{ml}$ of methylene chloride. The reaction mixture was washed successively with water and $5 \% \mathrm{HCl}$ solution and the organic extract was dried and evaporated. The crude yield of mesylate 55 was $18.0 \mathrm{~g}\left(96^{\%}\right)$.

NMR: $\bar{c} \quad 1.5-2.3(\mathrm{~m}, 4 \mathrm{H}), 2.92(\mathrm{~s}, 3 \mathrm{H}), 4.15(\mathrm{t} ; \mathrm{J}=6 \mathrm{~Hz}, 2 \mathrm{H}), 4.7-6.0(\mathrm{~m}, 3 \mathrm{H})$ 


\section{5-Phenylthiopent-1-ene 56}

The crude mesylate from above was added to a methanol solution containing $6 . \mathrm{Sg}(121 \mathrm{mmole})$ potassium hydroxide and $12.7 \mathrm{~g}$ (115 mole) phenyl mercaptan. The reaction mixture was stirred overnight and then diluted with $50 \mathrm{ml} \mathrm{H}_{2} \mathrm{O}$ and extracted with $5 \times 100 \mathrm{ml}$ of methylene chloride. The combined organic extracts were washed with $4 \times 100 \mathrm{ml}$ of $5 \% \mathrm{VaOH}$ solution, dried and evaporated yielding 7. s $(978)$ of $\underline{56}$.

NMR: $51.4-2.4(m, 4 H), 2.70(t, j=7 H=, 2 H), 4.7-6.0(m, 3 H), 7.0-7.4(m, 5 H)$

\section{S-Fhenyisuifonyipent-i-ene $\underline{5 i}$}

In $100 \mathrm{ml}$ of methylene chlorice was disscived $6.36 \subseteq$ ( 3.57 mole) of the sulfice 56. To this solution ccolec in a water bath was added $13.32 \mathrm{~g}$ ( 66 mole) of MCFEA in smail portions. After accition was complete the reaction mixture was stirred for 4 hr at room temperature and then washed with $2 \times 100 \mathrm{mi}$ of $\Sigma_{\kappa}^{\infty} \mathrm{NaOH}$ solution. Orying, evaporation and chromatography ( $1: 3$ ethyl acetate/hexane) furnished $5.0 \mathrm{~g}\left(66_{\kappa}^{\circ}\right)$ of the suifone $\underline{57}$.

$\cdots$

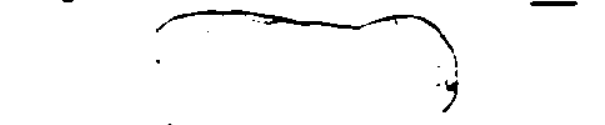

NMR: $\hat{\epsilon} 1 . \dot{4}-2.4(\mathrm{~m}, 4 \mathrm{H}), 2.9-3.2(\mathrm{~m}, 2 \mathrm{H}), 4.7-5.9(\mathrm{~m}, 3 \mathrm{H}), 7.2-7.9(\mathrm{~m}, 5 \mathrm{H})$

IR: $C=C, 1650(\mathrm{~m}) ; \mathrm{SO}_{2}, 1150(\mathrm{~s})$ and $1320(\mathrm{~s})$ 


\section{5-Phenylsulfonyl-1,2-epoxypentane $\underline{5 S}$}

Oxidation of $10.3 \mathrm{~g}$ (92 mole) of the sulfide 56 with $70.0 \mathrm{~g}$ (330 mole) of MCFEA in refluxing methylene chloride, overnight, followed by washing with $\$ \times 100 \mathrm{ml} \mathrm{NaOH}$ solution and further usual workup gave the epexy sultone 58 (1S.09:90\%) after chromatography on $250 \mathrm{~g}$ of silica sel using 1:3 ethyl acetate hexane as elvent.

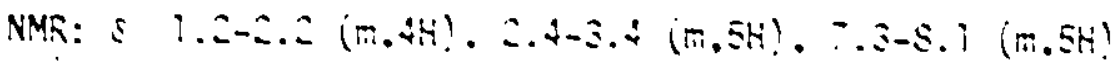

IR: $s 0_{2} \cdot 1310$ ( $s$ ) and 1145 (s!

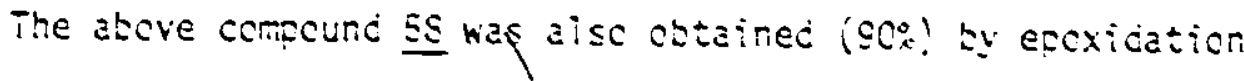
of $\underline{5}$ with one equivient of MCesa.

Senzyi Suifore $\underline{\text { Eq }}$

In 40 mi cf freshiy distiiled the was disscived $\$ 00$ mg ( 3.80

moie) of E-ghenvisuiforyipent-i-ene $\underline{57}$. After cocing to $-i \varepsilon^{\mathrm{c}}$ the carbanion was gererated by adition of a.s moie of n-butyijithium. To the resuitant yeijow soiution was accec ę4 me (4.0 mole) of berizyi bromide. After waming to rocm temperature the reaction mixture was poured into 50 mi of saturated emmorium chioride and extracted with lx50 mi of ether followed by $2 \times 50 \mathrm{ml}$ methylene chioride. The organics are combined, dried and the solvent stripped furnishing an oil which is chromatographed on $50 \mathrm{~g}$ of silicá gel (1:4 Ethyl acetáte/hexane). Compound 59 wäs obtäined in $64 \dot{\%}$ yield. 
NMR: $s \quad 1.5-2.3(m, 4 H), 2.5-3.5(m, 3 H), 4.6-5.7(m, 3 H), 7.0-6.0(m, 1 O H)$

IR: $C=C, 1640(\mathrm{~m}): S 0_{2}, 1140(\mathrm{~s})$ and $1300(\mathrm{~s})$

Epoxy sulfone io

A solution of $000 \mathrm{mg}$ ( $2.0 \mathrm{mmole}$ ) of 50 and $500 \mathrm{mg}$ ( $2.5 \mathrm{mmcle}$ ) of MCFEA was let stir overnight at room temperature. The soiution was then washed with $2 \times 50 \mathrm{mi}$ of $5 \% \mathrm{NaOH}$ solution. dried and the solvent removed. Chromatecraphy of the resultant oit on $50 \mathrm{~s}$ of silica gel ( $i:$ : ethyi acetate/hexane as eluent) frovided $590 \mathrm{~ms}$ ( $\$ 5 s$ ) of the epoxy suifone EO.

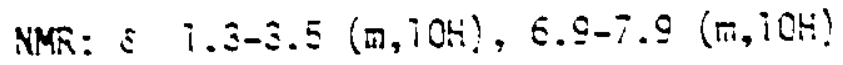

$\forall$

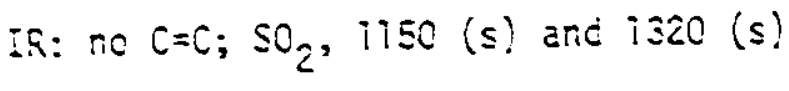

Chicro ester Ei

In a $500 \mathrm{mi}$ round bottomed flask was placed $75 \mathrm{mi}$ (excess) of comercial thF and . sog of zinc chioride. The flask was equipped with a refiux condenser and cooled in an ice beth. To this was added $170 \mathrm{~g}(1.41 \mathrm{~mole})$ of acetyi chioride, dropwise over $2 \mathrm{hr}$. The reaction mixture was then stirred at rocm temperature overnight and workup was affected by addition of $200 \mathrm{ml}$ of $\mathrm{H}_{2} \mathrm{O}$ and extraction with $2 \times 50 \mathrm{ml}$ of saturated sodium carbonate. The organic layer was colitected, dried anc concentrated on the rotary evaporator. The crude residue was then distilled at atmospheric pressure and the desired compound, the 
chloro ester 61 was collected at $180-185^{\circ}$ in $86 \%$ (130g) yield.

NMR: $s \quad 1.4-2.1(m, 4 H), 2.00(s, 3 H), 3.4-3.7(m, 2 H), 3.9-4.3(m, 2 H)$

IR: $C=0,1755(s)$

Hydróxy sulfide. $\underline{62}$

In $200 \mathrm{ml}$ of methanol was dissolved $16 . \mathrm{Sg}$ (300mole) potassium hrdroxtde and $32.3 \mathrm{~g}$ (291 mole) thiophenci. To the thiolate, at room temperature. was added $42.3 \mathrm{~g}$ (280 mole) of the chioro ester 61 in 100 . mi of methanol. The reaction mixture was stirred overnight and the ester was then saponified by addition of $26 \mathrm{~g}$ (excess) potassium hydroxide in $100 \mathrm{mi}$ of methanol. After stirring for an additional 24. $\mathrm{hr}$ the reaction mixture was poured into $200 \mathrm{ml}$ of $\mathrm{H}_{2} \mathrm{O}$ and extracted with $2 \times 100 \mathrm{mi}$ methyiene chioride. Drying and evaporation of the organic extracts fumished the hydroxy sulfide in $84_{\kappa}^{*}$ yield.

$z \quad$ NMR: $\bar{c} \quad 1.5-1.9(\mathrm{~m}, 4 \mathrm{H}), 2.6-3.1(\mathrm{~m}, 2 \mathrm{H}), 3.2-3.7\left(\mathrm{~m}, 3 \mathrm{H}, 2 \mathrm{H}\right.$ after $\mathrm{O}_{2} \mathrm{O}$ exchange), $6.8-7.2(\mathrm{~m}, 5 \mathrm{H})$

IR: $O H, 3440$ (broad)

Hydroxy sulfone $\underline{63}$

MCPBA (44g;220 [mole) was added in small portions to a solution of $20.0 \mathrm{~g}$ ( $110 \mathrm{mmole}$ ) the sulfide 62 in $30 \mathrm{~m}$ ) of methylene 
chloride. After addition was complete the reaction mixture was refiuxed for $3 \mathrm{hr}$. After this period the solution was let cool to room temperature and washed with $4 \times 100 \mathrm{ml}$ of $5 \% \mathrm{NaOH}$ solution. The organics were dried and the soivent was stripped on the rotary evaporator furnishing $2 \mathrm{l} .0 \mathrm{~g}(59 \%)$ of 63 which was purified, as needed, by column chromatography (1:1 ethyl acetate/hexane).

NMR: $s \quad 1.4-2.0(\mathrm{~m}, 4 \mathrm{H}), 2.6-2.9(\mathrm{OH}), 3.16(t, \mathrm{~J}=7 \mathrm{~Hz}, 2 \mathrm{H}),-3.5 S(t, \mathrm{~J}=6 \mathrm{~Hz}$, . $2 H), 7.4-7.9(m, 5 H)$

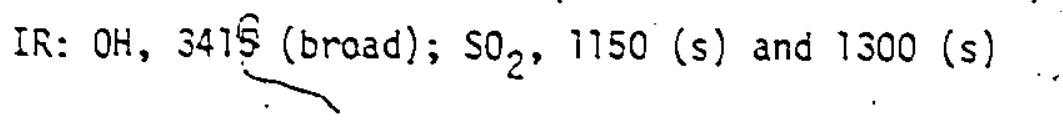

The hydroxy sulfone 63 was also prepared by hydroboration of 4-phenyisulfonylbut-tare 53 .

A $250 \mathrm{ml}$ three necked flask was equipped with a concienser. dropping funnel and a magnetic stirrer. The flask was charged with $1.14 \mathrm{~g}$ ( $30 \mathrm{mmole}$ ) of sodium borohydride in $50 \mathrm{ml}$ of freshiy distilied THF .. and $8.27 \mathrm{~g}$ (42.2 mmole) of 53. A solution of 40 mole of $B F_{3}\left(E t_{2} O\right)_{2}$ dissolved in $10 \mathrm{ml}$ of THF was added over a $1.5 \mathrm{hr}$ period. The temperature was maintained at $20-25^{\circ}$ by using a water bath. The flask was stirred for an additional 20 minutes and excess hydride was decomposed with $5 \mathrm{ml}$ - of $\mathrm{H}_{2} \mathrm{O}$. The trialkyl borane was then oxidized by dropwise addition of $15 \mathrm{mi}$ of $3 \mathrm{~N} \mathrm{NaOH}$ followed by $15 \mathrm{ml}$ of $30 \%$ hydrogen peroxide. The reaction mixture was then diluted with $50 \mathrm{ml}$ of $\mathrm{H}_{2} \mathrm{O}$ and extracted with $50 \mathrm{ml}$ of ether and $50 \mathrm{ml}$ of methyiene chloride. The organics were dried, concentrated and chromatographed on $200 \mathrm{~g}$ of 
silica gel ( $1: 1$ ethy) acetate/hexane) providing $6.39(70 \%)$ of the hydroxy sulfone $\underline{63}$.

Aidehyde $\underline{64}$

In $25 \mathrm{mi}$ of methylene chloride (dried over phosphorous pentoxide) was suspended $12 \mathrm{~g}(5.6 \mathrm{mmole})$ of pyridinium chlorochromate - and $24 \mathrm{~g}$ (22.6 mole) of sodium carbate. To this suspension at room temperature was added 5 -of (27.5 mole) of the hydroxy sulfide 62 in $5 \mathrm{mi}$ of methvleme chioride, dropwise over 15 minutes. After stirring an additional 10 minutes the resultant granuiar residue was filtered and washed with $50 \mathrm{mi}$ of methylene chioride. The methyiene chloride solution was concentrated and the biack residue was passed through $20 \mathrm{~g}$ of silica gel (hexane as eluent). The resultant yellow oif was chromatographed on $100 \mathrm{~g}$ of silica gel (hexane) and the aldehyde 64 was obtained in $70^{\circ}$ yield.

NMR: : $1.3-7.9(\mathrm{~m}, 2 \mathrm{H}), 2.1-2.6(\mathrm{~m}, 2 \mathrm{H}), 2.83(\mathrm{t}, \mathrm{J}=7 \mathrm{~Hz}, 2 \mathrm{H}), 6.8-7.2(\mathrm{~m}, 5 \mathrm{H})$, $10,00(s, 1 H)$

IR: $C=0,1710(s)$

Aldehyde $\underline{65}$

The hydroxy sulfpne $\underline{63}(2.0 \mathrm{~g} ; 9.8 \mathrm{mmole})$ was added 211 at once to a suspension of $3.8 \mathrm{~g}$ ( $17.5 \mathrm{mmole}$ ) pyridinium chlorochromate in $20 \mathrm{ml}$ of methylene chioride. The reaction mixture immediately became black 
and was let stir for 20 minutes. The reaction mixture was then diluted - with $50 \mathrm{ml}$ of ether and the supernatant riquid was decanted. This procedure was repeated twice and the combined washings were concentrated. The resultant black tar was chromatographed on $50 \mathrm{~g}$ of silica gel ( $1: 4$ ethyl acetate/hexane) and furnished $900 \mathrm{mg}\left(45^{\circ}\right)$ of the aldehyde 65 .

Yields of $70 \%$ were obtained by the addition of 4 equivalents of sodium carbonate before addition of the alcohol.

NMR: ${ }^{-}$E $1 . S-2.2(m, 2 H), 2.70(t, j=6 H z, 2 H), 3.20(t, j=6 H z, 2 H), 7.4-7.9(m, 5 H)$, $9.74(\mathrm{~s}, \mathrm{TH})$

IR: $\mathrm{CO}, 1715(\mathrm{~s}) ; \mathrm{sO}_{2}, 1150 \cdot(\mathrm{s})$ and $1310(\mathrm{~s})$

Dimethyibenzyisulfonium chioride 66 (35)

In a $500 \mathrm{ml}$ round bottomed flask was placed $100 \mathrm{~g}$ ( $\$ 00$ mole) of benzyl chioride, $50.4 \mathrm{~g}$ (810 moie) dimethyi suifide and $120 \mathrm{mi}$ of water. The two phase system was then refluxed for 2.5 days after which time a homogeneous solution was formed. The aqueous solution was then washed with $100 \mathrm{ml}$ of ether to remove any organics and then concentrated to give a solution that $67 \%$ by wt. sulfonium salt (determined by NMR).

Ethyl triphenyiphosphonium iodide 71

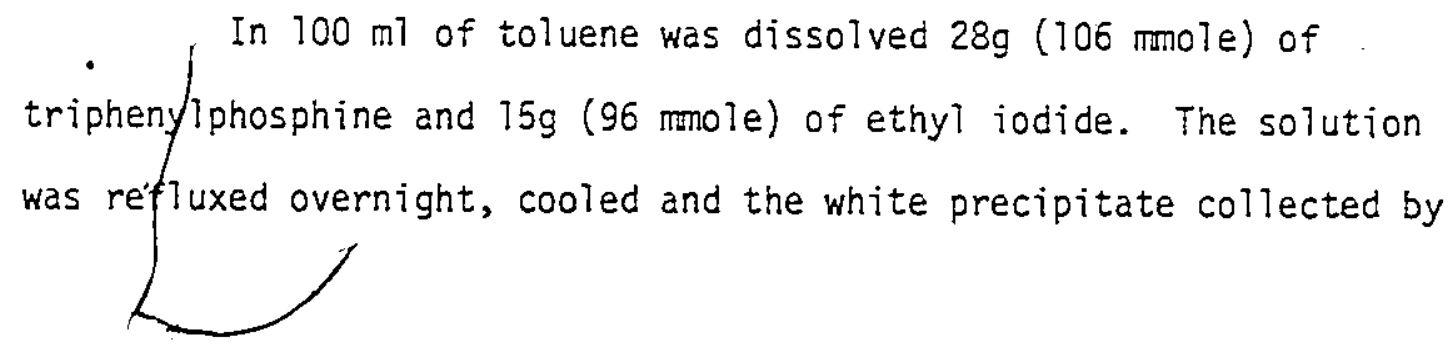


suction filtration. The phosphonium salt 71 was obtained in $80 \%(35 \mathrm{~g})$ yield and then, stored over phosphorous pentoxide and used as required.

Epoxy sulfone 69

To a $50 \mathrm{ml}$ methylene chioride solution of $1.2 \mathrm{~g}(5.6 \mathrm{mmole})$ of the aldehyde $65,2.0 \mathrm{~g}$ ( 5.0 mmole) of dimethylbenzyisulfonium chloride and $200 \mathrm{mg}$ of triethylbenzylammonium. chloride was added $10 \mathrm{~g}$ of $50 \%$ $\mathrm{NaOH}$ solution dropwise. The reaction mixture was stirred for 15 minutes and then $20 \mathrm{mi}$ of $\mathrm{H}_{2} \mathrm{O}$ was added, followed by extraction of this mixture with $2 \times 50 \mathrm{ml}$ methylene chloride. The organic extracts were dried and the solvent stripped. Chromatography of the crude product on $60 \mathrm{~g}$ of silica gel with $1: 2$ ethyl acetate/hexane provided $800 \mathrm{mg}\left(50^{\circ}\right)$ of the epoxy sulfone 69 .

NMR: $\bar{c} 7.5-2.](m, 4 H), 2.8-3.4(m, 3 H), 3.56(d, j=2 H z)$ and $4.04(d, j=4 H z)$ 1H), $7.7-8.0(\mathrm{~m}, \mathrm{TOH})$

IR: $\mathrm{SO}_{2}, 1150(\mathrm{~s})$ and $1310(\mathrm{~s})$

M.S.

$$
\frac{\text { Fragment }}{\mathrm{m} / \mathrm{e}}
$$

302

105

91

77
Rel. Abundance

$.07 \%$

100

74

62
Assignment

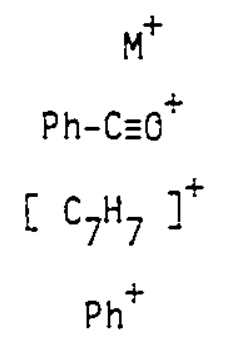




\section{6-Phenylthiohex-2-ene $\underline{67}$}

To $75 \mathrm{ml}$ of freshly distilled THF at room temperature was added $14.0 \mathrm{~g}$ ( 33.5 mmole) of the phosphonium salt $\underline{71}$. To the resultant suspension was added $14 \mathrm{ml}$ ( 36.4 mmole) of n-BuLi. After addition was complete the solution was stirred for an additional 15 minutes and the resultant red solution was cooled in an ice bath. To the cooled solution was added $4.9 \mathrm{~g}$ (22 mole) of the aldehyde 64 in $10 \mathrm{ml}$ of anhydrous THF. The reaction mixture immediately turned light orange and was stirred for an additional 5 minutes. The reaction mixture was then quenched with $50 \mathrm{ml}$ of $\mathrm{H}_{2} \mathrm{O}$, extracted with $1 \times 50 \mathrm{ml}$ of ether and IX50 $\mathrm{ml}$ of methylene chloride. Drying and evaporation of the organics furnished a crude oil which was chromatographed on $50 \mathrm{~g}$ of silica gel (hexane as eivent) providing $\underline{67}$ in $90 \%(4.1 \mathrm{~g})$ yieid.

NMR: $\delta \quad 1.0-1.7(m, 7 H), 1.7-2.3(m, 2 \mathrm{H}), 2.80(t, j=6 \mathrm{~Hz}, 2 \mathrm{H}), 4.7-5.4(\mathrm{~m}, 2 \mathrm{H})$, $6.7-7.7(\pi, 5 H)$

IR: $C=C, 1620(\mathrm{~m})$

Epoxy Sulfone $\underline{70}$

The sulfide olefin 67 was oxidized and epoxidized by dropwise addition of $16.0 \mathrm{~g}$ ( $80 \mathrm{mmole}$ ) of MCPBA in $100 \mathrm{ml}$ of methylene chloride to a solution of $4.0 \mathrm{~g}(20.8 \mathrm{mmole})$ of $\underline{67}$ in $100 \mathrm{mi}$ of methyiene chioride. After addition was complete the reaction mixture was refluxed overnight, cooled to room temperature, and washed with $2 \times 150 \mathrm{ml}$ of $5 \% \mathrm{NaOH}$ solution. 
Drying and evaporation of the organic layer, followed by chromatography on $100 \mathrm{~g}$ of silica gel (1:2 ethyl acetate/hexane) provided $4.2 \mathrm{~g}$ (85\%) of the epoxy sulfone 70 .

NMR: $\delta 1.1 S(d, J=5 H z)$ and $1.30(d, J=5 H z) 3 H, 1.0-2.1(m, 4 H), 2.3-3.4(m, 4 H)$, $7.4-5.0(m, 5 \mathrm{H})$

IR: $\mathrm{SO}_{2}, 1150(\mathrm{~s})$ and $1310(\mathrm{~s})$

M.S.

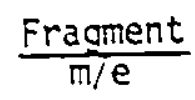

99

98

$\$ 2$

$7 i$

143
Rel. Abundance

21

100

62

42

38
Assignment

$\left[\mathrm{M}-\mathrm{SO}_{\mathrm{C}} \mathrm{Ph}\right]^{+}$

$\left[\mathrm{M}-\mathrm{PhSO}_{2} \mathrm{H}\right]^{+}$

$\left[98-\mathrm{CH}_{4}\right]^{+}$

$\mathrm{Ph}^{+}$

$\left[\mathrm{PhSO}_{2} \mathrm{H}_{2}\right]^{++}$

Epoxy suifide $\underline{72}$

The aldehyde $64(7.5 \mathrm{~g} ; 47.6$ mnole) was dissolved in $30 \mathrm{ml}$ of methyiene chioride and to this solution was added $30 \mathrm{mg}$ of TEBA and $8.5 \mathrm{~g}$ (45 mole) of the sulfonium salt $\underline{66}$. The reaction mixture was cooled in an ice bath and $40 \mathrm{~g}$ of $50 \% \mathrm{NaOH}$ solution were added dropwise via a dropping funnel. After stirring for $1 \mathrm{hr}$ the reaction mixture was diluted with $50 \mathrm{mi}$ of $\mathrm{H}_{2} \mathrm{O}$ and extracted with $1 \times 50 \mathrm{ml}$ of methylene chloride. Drying and evaporation of the solvent gave a crude oil which 
was chromatographed on $150 \mathrm{~g}$ of silica gel using $500 \mathrm{ml}$ of hexane followed by $5 \%$ ethyl acetate/hexane. The epoxy sulfide 72 was obtained in $71 \%$ $(8.0 \mathrm{~g})$ yield.

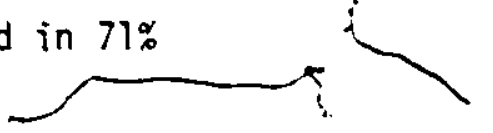

NMR: $\delta 1.4-2.0(m, 4 H), 2.5-3.0(m, 3 H), 3.40[(d, J=2 H z)$ and $3.83(d, J=4 H z)$ $1 \mathrm{H})] .6 .6-7.1(\mathrm{~m}, 10 \mathrm{H})$

IR: no aldehyde peak observed

The above mentioned material $5.2 \mathrm{~g}$ ( 19.3 mole) was epoxidized with S.Og (40 mole) of MCPBA. The epoxy sulfoine 69 was obtained in $S 7^{\circ}$ yieid after usual workup and chromatography' (1:2 ethyl acetate/hexane).

6-Phenylsul fony lisex-2-ene $-\underline{68}$

To a solution of the phosphonium salt $71(4.3 \mathrm{~g} ; 10.4$ mole) in THF at $-78^{\circ}$ was added $7.7 \mathrm{mi}$ of $1.6 \mathrm{M} \mathrm{CH} \mathrm{Li}(11.3$ mole). After 10 minutes the aldehyde $65(2.1 \mathrm{~g} ; 10$ mole) was added and the reaction mixture was let warm to room temperature over I hr during which time the initial orange colour of the solution was dissipated. The reaction mixture was then quenched with $10 \mathrm{ml}$ of saturated amonium chioride, extracted with $2 \times 50 \mathrm{mi}$ of ether, dried and the soivent stripped. The crude oil was chromatographed ( $1: 1$ ethyl acetate/hexane) on $50 \mathrm{~g}$ of silica gel thus furnishing $580 \mathrm{mg}(25 \%)$ of 68 .

NMR: co $1.1-2.3(\mathrm{~m}, 7 \mathrm{H}), 2.9-3.3(\mathrm{~m}, 2 \mathrm{H}), 4.9-5.6(\mathrm{~m}, 2 \mathrm{H}), 7.3-7.9(\mathrm{~m}, 5 \mathrm{H})$ 
The above mentioned material (500 $\mathrm{mg}, 2.5 \mathrm{mmole}$ ) was epoxidized with $700 \mathrm{mg}$ (3.5 mmole) of MCPBA. Usuat workup furnished $92 \%$ of the epoxy sulfone 70 .

\section{Base Induced Cyclizations}

3-Phenylsulfonyl cyclobutanol $\underline{73}$

To the epoxy suifone $54(9.0 \mathrm{~g} ; 43 \mathrm{mmole})$ dissolved in $100 \mathrm{mt}$ of freshly distilled THF under nitrogen was added $44 \mathrm{ml}$ ( $96 \mathrm{~mole}$ ) of $\mathrm{CH}_{3} \mathrm{MgI}$. The reaction mixture was stirred overnight and then poured into $100 \mathrm{ml}$ of saturated ammonium chloride solution, extracted with $1 \times 100$ ml ether followed by $2 \times 100$ mi methylene chloride. The organic extracts were combined,dried and the soivent stripped. The cyclobutanol 12 was obtained in SO: yield after chromatography on $250 \mathrm{~g}$ siica gel ( $1: 1$ ethyl acetate/hexane).

$$
\begin{aligned}
& \text { NMR: } \\
& 7.4-8.0(\mathrm{~m}, 5 \mathrm{H})
\end{aligned}
$$

IR: $\mathrm{OH}, 3500$ (broad); $\mathrm{SO}_{2}, 1150$ (s) and 1310 (s)

Anal. Caicd. for $\mathrm{C}_{10} \mathrm{H}_{12} \mathrm{O}_{3} \mathrm{~S}: \mathrm{C}, 56.60 ; \mathrm{H}, 5.66$ Found: $\mathrm{C}, 56.93 ; \mathrm{H}, 5.48$ 
3-Phenylsuif fonylcyclopentanol $\underline{75}$

5-phenylsul fonyl-1,2-epoxypentane $\underline{58}$ (4.4g; 19.4 mole) was dissolved in $50 \mathrm{ml}$ of dry ThF at $-70^{\circ}$ and reacted with 45 mole. of $\mathrm{CH}_{3} \mathrm{MgI}$ in ether. The solution was stirred and allowed to warm to room temperature and kept for is $\mathrm{hr}$. Workup was accomplished by pouring the reaction mixture into $100 \mathrm{ml}$ of saturated ammonium chloride solution and extracting with $100 \mathrm{ml}$ of ether, followed by $2 \times 100 \mathrm{ml}$ of methylene chloride. The organic extracts were combined, dried, and the solvent evaporated. Column . chromatography ( $1: 4$ ethyl kcetģte/hexane) gave $3.39(75 \%)$ of the desired cyciopentanol 15 .

NMR: $\delta \quad 1.7-2.4(\dot{m}, 6 H), 2.9-3.1(7 H, O H), 3.5-3.9(m, 7 H), 4.2-4.6(m, 1 H)$, IR: $\quad \mathrm{OH}, 3500$ (broad); $\mathrm{SO}_{2}, 1300$ (s) and $1150(\mathrm{~s})$

Anal. Caicd. for $\mathrm{C}_{71} \mathrm{H}_{74} \mathrm{O}_{3} \mathrm{~S}: \mathrm{C}, 58.47 ; \mathrm{H}, 6.19$ Found: $\mathrm{C}, 58.17 ; \mathrm{H}, 6.16$

"One-Pot" Preparation of Cyclobutanols and Cyciopentanols

Methyl phenyl sulfone $\underline{77}$

This compound was obtained in $90 \%$ yield by oxidation of thioanisole ( $30.0 \mathrm{ml}, 32 \mathrm{~g} ; 254$ moles) with MCPBA (100 g, 500 mmole). m.p. $86-87^{\circ}$ (methylene chloride/pentane) Lit. m.p. $88^{\circ}$. (59). 
NMR: $\delta 3.07(s, 3 H), 7.6-8.1(\mathrm{~m}, 5 \mathrm{H})$

IR: $\mathrm{SO}_{2}, 1120(\mathrm{~s})$ and $1300(\mathrm{~s})$

Benzyl phenyl sulfone $\underline{7 S}$

To the phenyl thiolate (10.7g; 9S mole phenyl thiol 6.0g; $107 \mathrm{~mole} \mathrm{KOH}$ ) in $100 \mathrm{ml}$ of methanol was added $12.6 \mathrm{~g}$ (100 mole) benzyl chloride. Usual workup afforded is.0g (90\%) of benzyl phenvi sulfide.

NMR: $s 4.00(\mathrm{~s}, 2 \mathrm{H}), 6 . \mathrm{s}-\mathrm{i} .3(\mathrm{~m}, \mathrm{iOH})$

The above sulfide $(5.3 \mathrm{~g} ; 26.5$ mole $)$ was oxidized with $71.0 \mathrm{~g}$ (55 mole) MCPEA. The sulfone $\underline{\text { is }}$ was obtained in $95^{\circ}$ as white crystais.

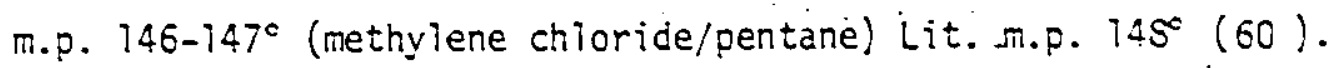

3-Phenyl-3-phenylsul fonyl cyclopentanol $\$ 0$

Benzyl phenyl sulfone ( $786 \mathrm{mg} ; 3: 3 \mathrm{mmole}$ ) was dissolved in $25 \mathrm{ml}$ of THF containing 1 mi of HMPTA. The solution was cooled to $-70^{\circ}$ ? and reacted with $3.6 \mathrm{mmole}$ of $\mathrm{CH}_{3} \mathrm{Li}$ followed by $543 \mathrm{mg}$ ( 3.6 mmole) of 4-bromo-1,2-epoxybutane. The reaction mixture, was warmed to room: temperature and kept untit the starting material had disappeared (TLC). The reaction mixture was ther ooled to $-70^{\circ}$ and treated with 2.1 equivaients of $\mathrm{CH}_{3} \mathrm{MgI}$, warmed to roon temperature and stirred for $48 \mathrm{hr}$. Workup was accomplished by pouring the reaction mixture in to saturated $\mathrm{NH}_{4} \mathrm{Cl}$. solution, extracting with $1 \times 50 \mathrm{ml}$ ether and then $1 \times 100 \mathrm{ml}$ methylene 
chloride, drying the organic extracts and evaporating the solvents. The crude product was purified by colamn chromatography (1:2 ethyl acetate/hexane). The yield of viscous oil was $750 \mathrm{mig}(75 \%)$.

NMR: $s \quad 2.0-3.4(\mathrm{~m}, 6 \mathrm{H}), 3.4-3 . \mathrm{s}(1 \mathrm{H}, \mathrm{OH}), 4.2-4.6(\mathrm{~m}, 1 \mathrm{H}), 7.0-7.0(\mathrm{~m}, 10 \mathrm{H})$

IR: $0 H, 3500$ (broad): $s 0_{2}, 1130$ (s) and 1300 (s)

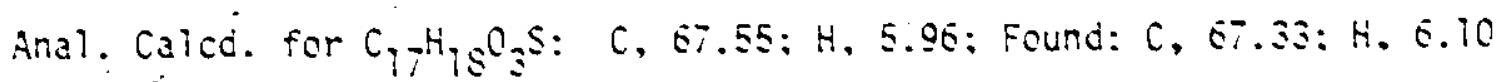

3-Phenyisuifonyicyciopentanol is

Using the above procedure methyl phenvi sulfone $(4.9 \mathrm{~g} ; 31.5$

mole) was converted to its carbanion ( $\mathrm{CH}_{3} \mathrm{~L}$; 35 mole), treated with 4-bromo-1,2-epoxvbutane (4.7g; 32 moie) and then with 65 mole of $\mathrm{CH}_{3} \mathrm{MgI}$. Workup as described above, followed by chromatography on $150 \mathrm{~g}$ of silica gel ( $3: 2$ ethyl acetate/hexane) furnished $2.5 \mathrm{~g}(35 \%)$ of $\dot{75}$.

3-Phenyi-3-Phenylsuifonyicyciobutanol 79

To the carbanion of benzyi phenyi sulfone $(3.5 \$ ; 15$ mole sulfone; $\mathrm{CH}_{3} \mathrm{Li}, 15.5 \mathrm{mmole}$ ) was added $2.4 \mathrm{ml}$ (excess) epibromohydrin folitowed by 35 momole of $\mathrm{CH}_{3} \mathrm{MgI}$. Workup and chromatography on $200 \mathrm{~g}$ of silica $g \in$ l ( $1: 2$ ethyl acetate/hexane) provided $2.6 \mathrm{~g}\left(60^{c}\right)$ of the above cyclobutanol. m.p. $132^{c}\left(\mathrm{CH}_{2} \mathrm{Cl}_{2} / \mathrm{CCl}_{4}\right)$ 
NMR: 5 2.9-3.3 $\left(\mathrm{m}, 5 \mathrm{H}, 4 \mathrm{H}\right.$ after $\mathrm{D}_{2} \mathrm{O}$ exchange), 4.15 (quintet, $J=6.5 \mathrm{~Hz}, \mathrm{H}$ ), - and $6.5-7.7\left(m_{1}, 3 \mathrm{OH}\right)$

IR: $\mathrm{OH}, 3500$ (broad): $\mathrm{SO}_{2} ; 1150(\mathrm{~s})$ and $1305(\mathrm{~s})$

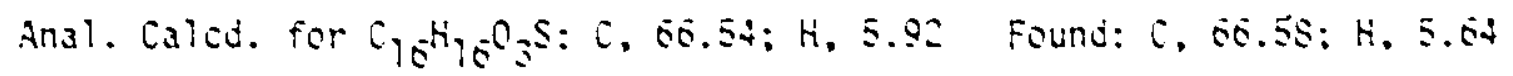

S-Fhenyisuifonyleycicbutanci is

This compound was obtained in $40 \%$ yield from $711 \mathrm{mg}$ (4. SE mole! of methyi pheny suifone, 4.7 mole $\mathrm{CH}_{3} \mathrm{Li}$, excess epitromohyoin and io moie of CH.Mei.

Creitization of Eexy Sulfones 69 and 70

2-Fhenyi-3-phenyisulfonyicycicpentanci \&l

in $50 \mathrm{mi}$ of freshiv distiiled thf was dissoived $2.0 \mathrm{~g}$ (E.E moie)

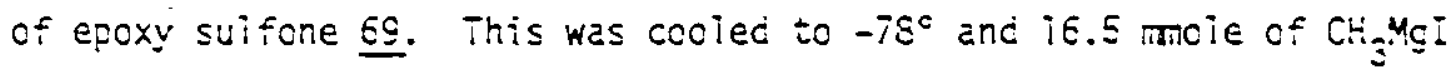
was adced. The resultant white suspension was ailowed to wam to room temperature and then stirred under nitrogen for $24 \mathrm{hr}$. At the end of this period $20 \mathrm{mi}$ of saturated amonium chioride was added and the solution extracted with $7 \times 50 \mathrm{mi}$ of ether followed by $2 \times 50$ mi of methylene chioride. The organic extracts were combined, dried and the solvent stripped. Chromatography of the resultant oil on $100 \mathrm{~g}$ of silica gel (2: $\varepsilon$ ethyl.actetate) hexane followed by $1: 1$ ethyl acetate/hexane) provided $1.35 g^{\prime}(67 \%$ ) of 21 was white crystals. m.p. 105-106 (methylene chloride/hexāne). 
NMR: $s \quad 1.7-2.6\left(m, 5 k, 4 H\right.$ after $D_{2} \mathrm{O}$ exchange $), 3.2-3.4,(m, i H), 3.5-3.8$ $(\mathrm{m}, 1 \mathrm{H}), 3.9-4.2(\mathrm{~m}, 1 \mathrm{H})$ and $6.5-7.5(\mathrm{~m}, 1 \mathrm{OH})$

In: OH, 3500 (broad): $s_{2}, 1145$ (s) and 1310 (s)

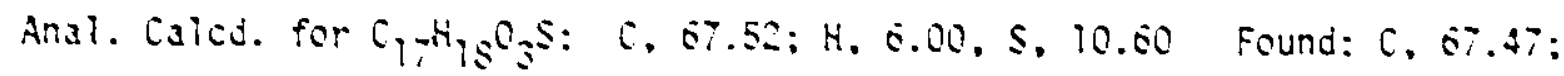
H. B.0s: s, 10.99

Reaction of Ee with LDA

Treatment of epoxy sulfone Eg (i.4ls: 4.7 mole! with 5.1 mole of LDA (prepared from $\equiv .1$ mole of diisopropylamine and $\$ .2$ mole of $n-E u L i$ ) in 50 mi of ThF frovided i.i@s (75s) of the cyciopentanci si. This material was icenticai in ail respects to gi cttained Ey the reaction of Eq with 2 equivaients of Chiggi."

2-Methyi-î-Fhenyisuifonvicyciopentanci $\underline{\underline{z}}$

io i.og (4.2 moie) of epoxy suifone 70 disṣoived in $50 \mathrm{mi}$ of . enhycrous itF at $-78^{\circ}$ was addec io moie of $\mathrm{CH}_{3} \mathrm{MgI}$. The resuitant white suspension was stirred for 24 hr at ambient temperature and then quenched with 50 mi of seturated amonium chiorice solution. Extraction with $2 \times 100 \mathrm{mi}$ of methyiene chioride followed by drying of the orgenic phase provided the cyciopentanol 22 , as a clear oil after chromatography ( $1: i$ ethyl actatate/hexante), in $50 \%$ (.5g) yieid.

NMR: $i \quad 1.02(d, J=6 H z, 3 H), 1.6-2.5(\mathrm{~m}, 5 \mathrm{H}), 2.5-2.9(\mathrm{OH}), 3.0-3.3(\mathrm{~m}, \mathrm{HH})$, 


\section{$3.6-3.9(m, 1 H), 7.4-7.9^{\circ}(m, 5 H)$}

IR: $\mathrm{OH}, 3450$ (broad); $\mathrm{SO}_{2}, 1150$ (s) and $1310(\mathrm{~s}$ )

Anal. Calcd. for $C_{12}{ }_{1}{ }_{10} O_{3} C: C, C, 60.00 ; H, 6.66$ Found: $C, 59.93 ; H, 6.83$

The above cyclopentancl $\underline{S \Omega}$ ( $110 \mathrm{mg} ; .45$ mole) was dissolved in $10 \mathrm{mi}$ of "spectrogirade "acetone at $\sigma^{\circ}$ and treated with. 50 mole of $\therefore$ iones reagent. The reaction mixture was then stirred for $5 \mathrm{~min}$. and then $5 \mathrm{mi}$ of saturated sodium suiphite added. Extraction with $20 \mathrm{mi}$ of methyiene chioride followed by drying the organic phase provided a solid material which was recrystallized from methylene chioride/hexane, thus furnishing $95 \mathrm{mg}\left(S_{*}^{*}\right)$ of 2-methyi-3-phenyisulfonyl cyciopentanone $\$ 3 . \quad \pi . p . \$ 2.5-\$ 3^{c}$

WMR: $\varepsilon \quad i .13(\dot{d}, \mathrm{j}=6 \mathrm{~Hz}, 3 \mathrm{H}), 2.0-2 . \&(\mathrm{~m}, 5 \mathrm{H}), 3.3-3.5(\mathrm{~m}, 1 \mathrm{H}), 7.5-8.0(\mathrm{~m}, 5 \mathrm{H})$

IR: $C=0,1750(s) ; \mathrm{SO}_{2} ; 1750(s)$ and $1310(s)$

Anal. Caicd. for $\mathrm{C}_{12} \mathrm{H}_{14} \mathrm{O}_{3} \mathrm{~S}: \mathrm{C}, 60.50 ; \mathrm{H}, 5.88 ; s, 13.44$ Found: C, 60.50; $H, 6.07 ; \leq, 13.32$

Reaction of Epoxy Sulfone 7 e with LDA

Epoxy suifone 70 (600 mg; 2.5 mmole) was added to an LDA solution (75 ml THF, 3.08 mole diisopropylamine, 3.2 mole $\underline{n}-8 u L i$ ) at $-78^{\circ}$ and stirred for $24 \mathrm{hr}$ at ambient temperature. After this period 
- the reaction mixture was quenched by addition of $10 \mathrm{ml}$ of saturated armonium chloride solution and extracted with $1 \times 50 \mathrm{ml}$ of ether, followed by $2 \times 50 \mathrm{~m}$ ? of methylene chloride. After drying and evaporation of the organics the crude residue was chromatographed on $50 \mathrm{~g}$ of silica gel using 1:2 ethyl acetate/hexane as eluent. This provided $450 \mathrm{mg}$ of a slightly vellow oil.

NMR: $51.0-1.2(\mathrm{~m}, 6 \mathrm{H}), 1.5-2.5(\mathrm{~m}, 1 \mathrm{H}), 2.7-3.2\left(\mathrm{~m}, 3 \mathrm{H}, 2 \mathrm{H}\right.$ after $\mathrm{D}_{2} \mathrm{O}$ exchange) $3.6-3.9(\mathrm{~m}, 2 \mathrm{H}), 7.5-\mathrm{S} .1(\mathrm{~m}, 1 \mathrm{OH})$

IR: $\mathrm{OH}_{,}, 3400$ (broad); $\mathrm{SO}_{2}, 1155(\mathrm{~s})$ and $131 \mathrm{~s}(\mathrm{~s})$

To $400 \mathrm{mg}$ of the product(s) obtained in the above reaction in $20 \mathrm{mi}$ of "spectrograde" acetone was added 4 mole of Jones reagent. Workup provided $300 \mathrm{mg}$ of an, oil which was examined by NMR and IR.

NMR: $: 1.0-1.2(\mathrm{~m}, 3 \mathrm{H}), 1.8-3.0(\mathrm{~m}, 14 \mathrm{H}), 3.0-4.1(\mathrm{~m}, 3 \mathrm{H}), 7.1-8.0(\mathrm{~m}, 10 \mathrm{H})$

IR: no OH; $C=0,1715(s)$ and $1745(s) ; S_{2}, 1155(s)$ and. $1310(s)$ 
Synthesis of Non-Sulfur Containing Derivatives From the 3-Phenylcycloalkanols

Aikylation of 3-phenylcyclobutanols and-cyclopentanols

General Procedure:

A solution of the cycloalkanol was dissolved in $50 \mathrm{ml}$ of freshily distilled THF at $-70^{\circ}$ and converted to the dianion upon treatment with 2 equivalents of $\mathrm{CH}_{3} \mathrm{Li}$. The dianion formation was allowed to proceed for $5 \mathrm{~min}$. and 1 equivalent of alkylating agent was introduced. The acetone-dry ice bath was then removed and the reaction stirred until the disappearance of starting material on the TLC. Workup was accompiished by addition of $10 \mathrm{ml}$ of saturated amonium chioride solution, followed by extraction with $1 \times 50 \mathrm{ml}$ of ether and $2 \times 50 \mathrm{mi}$ of methylene chloride. After drying and evaporation of the organics the crude products were purified by colusn chromatography using ethy?. acetate/hexane as eluent.

3-Butyi-3-phenylsul fonyl cyclobutanol 90

This compound was prepared by alkylation of the dianion of 3-phenyisul fonylcyclobutanol. This alcohol ( $412 \mathrm{mg}, 1.95$ mimole) was dissoived in $25 \mathrm{ml}$ of THF at $-70^{\circ}$ and treated with $3.3 \mathrm{ml}$ (4.2 mole) of $\mathrm{CH}_{3} \mathrm{Li}$. Excess ( $\mathrm{l} \mathrm{ml}$ ) of bromobutane was added and the reaction was stirred-and allowed to warm to room temperature. Workup and chromatography with $1: 3$ ethyl acetate/hexane gave $354 \mathrm{mg}(68 \%)$ of

- product 90. 
NMR: $\delta \quad 0.8-1.8(\mathrm{~m}, 9 \mathrm{H}), 2.4-3.0\left(\mathrm{~m}, 5 \mathrm{H}, 4 \mathrm{H}\right.$ after $\mathrm{D}_{2} \mathrm{O}$ exchange $)$, 4.0-4.6 $(m, 1 H), 7.4-7.9(m, 5 H)$.

IR: $\mathrm{OH}, 3500$ (broad); $\mathrm{SO}_{2} 1120(\mathrm{~s})$ and 1310 (s)

3-Isopropyl-3-phenylsul fonyl cyclobutanol 94

3-Phenyl sul fonyl cyclabutanol ( $634 \mathrm{mg}, 3.0$ mole) was

dissoived in $40 \mathrm{mi}$ of THF at $-70^{\circ}$ and converted to its dianion upon addition of $4.0 \mathrm{mi}$ (6.S minole) of $\mathrm{CH}_{3} \mathrm{Li}$. Isopropyliodide $(0.7 \mathrm{ml}$ ) was then added and the reaction mixture was stirred and allowed to warm to room temperature over a $2.5 \mathrm{hr}$ period, quenched with water and extracted with $50 \mathrm{ml}$ of ether and $2 \times 50 \mathrm{ml}$ of methylene chloride. Further workup gave a crude product which was chromatographed on silica gel using 1:10 ethyl acetate/methylene chloride as eivent. The vield of 3isopropyl-3-phenylsulfonylcyciobutanol as a colourless oil was $544 \mathrm{mg}$ $(71 \%)$.

NMR: $=0.90(d, J=6 H z, 6 H), 7.8-3.4(m, 6 H), 4.1-4.6(m, i H), 7.4-8.0$ - $(m, 5 \mathrm{H})$

IR: $\mathrm{OH}, 3480$ (broad); $\mathrm{SO}_{2}, 1140(\mathrm{~s})$ and $1300(\mathrm{~s})$

Anal. Calcd. for $\mathrm{C}_{13} \mathrm{H}_{18} \mathrm{O}_{3} \mathrm{~S}: \mathrm{C}, 61.42 ; \mathrm{H}, 7.09$ : Found $\mathrm{C}, 61.74$; H, 7.28 
3-Iodo-3-phenylsul fonylcyciobutanol $\underline{95}$

The yellowish dianion of 3-phenylsulfonyl cyclobutanol was prepared as above from $593 \mathrm{mg}$ (2.8 mole) of sulfone alçohol and 6 mole $\mathrm{CH}_{3} \mathrm{Li}$ and then reacted with $406 \mathrm{mg}\left(0.5\right.$ equiv.) of $\mathrm{I}_{2}$. Usual workup gave after chromatography on $50 \mathrm{~g}$ of silica gel (1:2 ethyl acetate/ hexane) $300 \mathrm{mg}(32 \%)$ of 3 -iodo-3-phenylsulfonylcyclobutanol. m.p. 102$104^{\circ}$; (methylene chloride/hexane).

NMR: $8 \quad 2.6-3.4(m, 5 H), 4.4-4.5(m, 1 H), 7.4-5.0(m, 5 H)$

IR: $\mathrm{OH}, 3480$ (broad); $\mathrm{SO}_{2}, 1140(\mathrm{~s})$ and 1300 (s)

Anal. Caicd. for $\mathrm{C}_{70} \mathrm{H}_{17} \mathrm{IO}_{3} \mathrm{~S}: \mathrm{C}, 35.51 ; \mathrm{H}, 3.26 ; \mathrm{I}, 37.56$ Found $\mathrm{C}, 35.23$, $H, 3.32 ; I, 37.66$.

3-Methyl thio-3-phenyisui fonyl cyciobutanol $\underline{96}$

The dianion from $763 \mathrm{mg}$ (3.6 mole) of 3-phenyisulfonyl cyclobutanol and 7.5 mole of $\mathrm{CH}_{3} \mathrm{Li}$ was treated with $800 \mathrm{mg}$ (excess) of dimethy] disulfide. Upon warming of the reaction mixture a yellowish solution containing a white precipitate was obtained. Workup and chromatography - on $50 \mathrm{~g}$ of silica gel using $1: 3$ ethyi acetate/hexane as eluent furnished $574 \mathrm{mg}(62 \%)$ of the desired product $\underline{96}$.

NMR: cे $2.20(s, 3 H), 2.3-3.9(m, 5 H), 4.2-4.9(m, 7 H), 7.4-7.8(m, 5 H)$ IR: $\mathrm{OH}, 3450$ (broad); $\mathrm{SO}_{2}, 1120(\mathrm{~s})$ and $1310(\mathrm{~s})$ 
3-Butyi-3-phenylsulfonyleyelopentanol 91

3-Phenyl sulfonyl cyclopentanol (789 mg; 3.5 mole) was converted to its dianion ( 7.2 mole $\mathrm{CH}_{3} \mathrm{Li}$ ) and quenched with $520 \mathrm{mg}$ ( 3.7 mole) of $\underline{n}$-butyl bromide. Workup and chromatography on $50 \mathrm{~g}$ of silica gel (1:3 ethyl acetate/hexane) provided $781 \mathrm{mg}\left(50^{*}\right)$ of $9 ?$ as a clear oil.

NMR: $s \quad 0.8-1 . S(\mathrm{~m}, 15 \mathrm{H}), 3.4-3.7(\mathrm{~m}, \mathrm{IH}, \mathrm{OH}), 4.2-4.6(\mathrm{~m}, \mathrm{IH}), 7.4-5.0$ $(m, 5 \mathrm{H})$

IR: $\mathrm{OH}, 3500$ (broad); $\mathrm{SO}_{2}, 1150$ (s) and 1300 (s)

Anal. Calcd. for $\mathrm{C}_{15} \mathrm{H}_{22} \mathrm{O}_{3} \mathrm{~S}: \mathrm{C}, 63.53 ; \mathrm{H}, 7.80$ Found $\mathrm{C}, 63.93, \mathrm{H}, \mathrm{T.97}$

3-Heptyl-3-phenyl suifonyicyclopentanol 92

n-Heptyi bromide (604 mg; 3.3 moie) was added to the dianion of the parent cycloalkanol $(652 \mathrm{mg} ; 2.9$ mole 3 -phenylsulfonyl cyclopentanol; 6.5 mole $\mathrm{CH}_{3} \mathrm{Li}$ ). Workup and chromatography (3:7 ethyl acetate/hexane) furnished $833 \mathrm{mg}\left(88_{\kappa}^{\%}\right)$ of the 3-heptyl derivative $\underline{92}$.

NMR: $\bar{c} 0.8-2.8(\mathrm{~m}, 21 \mathrm{H}), 3.4-3.6(7 \mathrm{H}, 0 \mathrm{H}), 4.2-4.6(\mathrm{~m}, \mathrm{lH}), 7.4-7.9(\mathrm{~m}, 5 \mathrm{H})$

IR: $O H, 3500$ (broad); $\mathrm{SO}_{2}, 1750$ (s) and 1300 (s)

An acceptable analysis was obtained for the DNP of the corresponding cyclopentenone (see below). 
3-Benzyl-3-phenyl sul fonyl cyclopentanol $\underline{93}$

The dianion of 3-phenylsul fonyl cyclopentanol ( $457 \mathrm{mg} ; 2.0$ mole) was generated by addition of 4.4 mole of $\mathrm{CH}_{3} \mathrm{Li}$. The yellow dianion was quenched at $-70^{\circ}$ with 2.4 mole of benzyl bromide. Workup and chromatography on $50 \mathrm{~g}$ of silica gel using 2:S ethyl acetate; hexane provided $474 \mathrm{mg}(76 \%)$ of the 3-benzyl derivative 93 .

NMR: $s \quad 0.8-2.5(\mathrm{~m}, 6 \mathrm{H}), 3.3-3.4(1 \mathrm{H}, \mathrm{OH}), 2.96(\mathrm{~s})$ and $3.04(\mathrm{~s}) 2 \mathrm{H}$, $7.0-5.2(m, 10 H)$

IR: $\mathrm{OH}, 3480$ (broad); $\mathrm{SO}_{2}, 1110(\mathrm{~s})$ and $1310(\mathrm{~s})$

Anal. Caicd. for $\mathrm{C}_{18} \mathrm{H}_{20} \mathrm{O}_{3} \mathrm{~S}: \mathrm{C}, 68.35 ; \mathrm{H}, 6.33$ Found $\mathrm{C}, 68.17 ; \mathrm{H}, 6.28$

Conversion of 3-phenylsulfonvicycloalkanols into Cycloal kenones

General Procedure:

About $500 \mathrm{mg}$ of the 3-pheny] suifonylcycioaikanol was dissolved in $5 \mathrm{ml}$ of reagent grade acetone at room temperature and reacted with 1.1 equivaient of Jones reagent; dropwise addition over $10 \mathrm{~min}$. The progress of the reaction was followed by TLC; most oxidations were complete within 30 min. Excess oxidizing agent was destroyed by addition of $10 \% \mathrm{Na}_{2} \mathrm{SO}_{3}$ solution. The reaction mixture was then poured into saturated $\mathrm{NH}_{4} \mathrm{Cl}$ solution and extracted with $2 \times 50 \mathrm{ml}$ of methylene chioride. The organic layer was dried over $\mathrm{MgSO}_{4}$ and concentrated to a few mi on 
a rotary evaporator. To this crude product was added about $1 \mathrm{ml}$ of triethylamine. The reaction was followed by TLC. When complete, the product was isolated by washing with $2 \times 25 \mathrm{ml}$ of $5 \% \mathrm{HCl}$ solution, drying and evaporating the organic soivent. The cycloalkenones mere purified by column chromatography using 1:4 ethyl acetate/hexane as eluent.

\section{3-Isopropylcyciobutenone $\underline{97}$}

3-Isopropyl-3-phenyisulfonyl cyclobutanol (261 mg; 1 mole) was oxidized with 1.2 mole of Jones reagent in $5 \mathrm{mil}$ of spectrograde acetone. The crude product after workup was dissolved in $5 \mathrm{ml}$ of pethylene chloride and treated with 2 mole of triethylamine for $30 \mathrm{~min}$. at room temperature. Usual workup followed by filtration through $20 \mathrm{~g}$ of silica gel provided $S S \mathrm{mg}\left(\mathrm{SO}_{\%}^{*}\right)$ of $\underline{97}$ as a clear $0 i 1$.

NMR: $\hat{0} \quad 1.16(\mathrm{~d}, \mathrm{~J}=\mathrm{THz}, 6 \mathrm{H}), 2.4-3.0(\mathrm{~m}, \mathrm{TH}), 3.1(\mathrm{~s}, 2 \mathrm{H}), 5.8$ (broad $5,1 \mathrm{H})$

IR: $C=0,1770(\mathrm{~s}), C=C, 1595(\mathrm{~m})$

3-Heptyl cyclobutenone 110

This compound was obtained in $83 \%$ yield from $200 \mathrm{mg}$ of 3heptyl-3-phenylsulfonylcyclobutanol (available in these laboratories) using the same procedure as for the 3-isopropyl derivative.

NMR: $00.85(\mathrm{~m}, 3 \mathrm{H}), 1.1-2.0(\mathrm{~m}, 1 \mathrm{OH}), 2.57(\mathrm{t}, 2 \mathrm{H}), 3.15(\mathrm{~s}, 2 \mathrm{H}), 5.87(\mathrm{~s}, 7 \mathrm{H})$ 
Attempted Diels - Alder Reaction of 110 with trans, trans-hexa-2,4-diene.

To $100 \mathrm{mg}$ of 3-heptylcyclobutenone 110 in $25 \mathrm{ml}$ of carbon tetrachloride at room temperature was added excess trans, transhexa-2,4-diene and a few drops of $\mathrm{BF}_{3}\left(E t_{2} \mathrm{O}\right)_{2}$. The reaction was let stir for $2 \mathrm{hr}$ and then $10 \mathrm{ml}$ of $\mathrm{H}_{2} \mathrm{O}$ was added. The layers were separated and the aqueous phase was extracted with $25 \mathrm{ml}$ of methylene chioride. Drying and evaporation of the organics provided a material which by NMR was identical to a mixture of the starting components.

Crclopent-2-enones

3-Phenylcyciopent-2-enone פS

3-Phenyl-3-phenylsuifonylcyclopentanol (340 mg; 1.1 mole) was treated with $i .5$ moie of Jones reagent followed by $i .5$ mole of triethylamine. Usual workup foliowed by chromatography using $1: 3$ ethy? acetate/hexane provided $140 \mathrm{mg}\left(75^{\circ}\right)$ of 98 as a ciear $0 i 1$.

NMR: $\hat{0}$ 2.5-2.7 (m,2H), 2.9-3.2 (m,2H), 6.52 (narrow spaced tripiet, IH), $-7.2-7.7(\mathrm{~m}, 5 \mathrm{H})$

IR: $\quad C=0,1690(\mathrm{~s}) ; \quad C=C, 1610(\mathrm{~m})$ 


\section{3-Benzylcyclopent-2-enone 99}

This compound was obtained from $460 \mathrm{mg}$ ( 1.4 mole) of 3-benzyl3-phenylsulfonylcyclopentanol, 2 mole Jones reagent, and 2 mole of triethylamine. Chromatography ( $1: 4$ ethyl acetate/hexane) of the crude product after workup provided $192 \mathrm{ing}(S 7 \%)$ of 99 as a clear oil.

NMR: $s \quad 2.3-2.7(m, 4 H), 2.74(5,2 H), 5 . S S($ broad $s, i H), 7.7-7.5(m, 5 H)$

IR: $C=0,1725(\mathrm{~s}), C=C, 1630(\mathrm{~m})$

3-Butylcyciopent-2-enone 101

To $550 \mathrm{mg}$ (1.9 mmole) of 3-butyl-3-phenylsul fonyicyclopentanol

was added $2.2^{2}$ mole of Jones reagent followed by 2.5 mmole of triethylamine after oxidation was complete. The cruce product after workup was chromatographed on $20 \mathrm{~g}$ of silica gel using $1: 4$ ethyl acetate/ hexane as eivent, thus was obtained 101 in $86 \%$ yield.

NMR: $c 0.98(t, J=7 \mathrm{~Hz}, 3 \mathrm{H}), 1.2-1.8(\mathrm{~m}, 4 \mathrm{H}), 2.3-2.8(\mathrm{~m}, 6 \mathrm{H}), 5.8-6.0$ $(m, T H)$

IR: $C=0,1715(\mathrm{~s}) ; C=C, 1630(\mathrm{~m})$ 
3-Heptyl cyclopent-2-enene 100

3-Heptyl-3-phenylsul fonyicyclopentanol (535 mg; 1.6 mole) was oxidized by addition of 2 mole of Jones reagent. The phenylsulfonyl group was remaved by stirring the crude product obtained from the : oxidation step with 2 mole of triethylamine. Chromatography (1:4 ethyl acetate/hexane) of the residue after workup provided $225 \mathrm{mg}\left(75^{\%}\right)$ of the enone 100.

NMR: $\& \quad 0.7-2.5(m, 13 H), 2.3-2.7(m, 6 H), 5.5-6.0(m, 1 H)$

IR: $C=0, i 720(\mathrm{~s}) ; C=C, 1625(\mathrm{~m})$

Calcd. for the DNP derivative. $\mathrm{C}_{18} \mathrm{H}_{24} \mathrm{O}_{4} \mathrm{~N}_{4}: \mathrm{C}, 60.00 ; \mathrm{H}, 6.66 ; \mathrm{N}, \mathrm{in}^{15.55}$ Found $\mathrm{C}, 59.89, \mathrm{H}, 6.76 ; \mathrm{N}, 75.44$.

2-Pheny cyciopent-2-enone 102

In $10 \mathrm{mi}$ of "spectrograde" acetone was dissolved $660 \mathrm{mg}$ (2.2 mole) of the cyclopentanoi 81 . To this was added 2.5 mmole of Jones reagent to affect oxidation and after oxidation and workup the crude product was treated with 2.5 mole of triethylamine. Chromotography $(1: 3$ ethyi acetate/hexane) of the crude product provided the enone $\underline{102}$ in $75 \%$ (260 mg) yield as white crystals, m.p. 67-68 (ether) (Lit. m.p. $\left.77^{\circ}(44)\right)$.

NMR: $\dot{c} \quad 2.3-2.6(\mathrm{~m}, 4 \mathrm{H}), 7.7-7.2(\mathrm{~m}, 3 \mathrm{H}), 7.3-7.5(\mathrm{~m}, 3 \mathrm{H})$

IR: $C=0,1725$ (s) (Lit. $1726(44))$. 
Cyclopropyl Sulfone 117

In $200 \mathrm{ml}$ of THF at $-78^{\circ}$ was dissolved $6.8 \mathrm{~g}$ (32mmole) of the epoxy sulfone 54 and to this was added 35 mole of $\mathrm{CH}_{3} \mathrm{Li}$. The reaction mixture was allowed to warm to room temperature and then stirred at room temperature overnight. Workup was accomplished by addition of $20 \mathrm{mi}$ of saturated amonium chloride, extracting with $1 \times 100 \mathrm{ml}$ of ether and $2 \times 100 \mathrm{ml}$ of methylene chloride. The organics were combined, dried and the crude $0 i 1$ was chromatographed on silica gel using $3: 2$ ethyl acetate/hexane as eluent. The vield of clear oil was $4.59\left(67^{\circ}\right)$.

$$
\text { NMR: } \begin{aligned}
\varepsilon & 1.0-7 . i(\mathrm{~m}, 2 \mathrm{H}), 1.9-2.2(\mathrm{~m}, 1 \mathrm{H}), 2.3(\mathrm{H}, \mathrm{OH}), 3.4-3.5(\mathrm{~m}, 2 \mathrm{H}), \\
& 7.4-8.0(\mathrm{~m}, 5 \mathrm{H})
\end{aligned}
$$

IR: $\mathrm{OH}, 3450$ (broad); $\mathrm{SO}_{2}, 1120 .(\mathrm{s})$ and $1310(\mathrm{~s})$

Attempted Alkylation of $\underline{117}$

Cyclopropyl sulfone 117 ( 1 mole) was dissolved in $20 \mathrm{ml}$ of THF at $-78^{\circ}$ and 2 mole of $\mathrm{CH}_{3} \mathrm{Li}$ was added. After stirring for $5 \mathrm{~min}$. the reaction was quenched with $\mathrm{O}_{2} \mathrm{O}$. This reaction was repeated at room temperature and quenched after 15 min. with $\mathrm{O}_{2} \mathrm{O}$.

Other trials involved attempted generation of the dianion of 117 at room temperature and quenching with methyl iodide after 15 min. and after $30 \mathrm{~min}$. In all the above cases no incorporation of the electrophile was observed as evidenced by the $\mathrm{PhSO}_{2}-\mathrm{CH}$ (o 2.4-2.7, $\mathrm{m}, \mathrm{TH}$ ) which still remained in the NMR and no methyl signal was observed after 
the reactions were quenched with methyl iodide.

\section{Cyclobutanols $\underline{124}$ and $\underline{125}$}

The desulfonylations were carried out by treating the sulfone. in dry methanol, in the presence of 4 equivalents of disodium hrurogen phosphate, with excess of $6 \% \mathrm{Na}-\mathrm{Hg}$ amalgam at room temperature. When the reaction was complete, as evidenced by the disappearance of starting materiai on TLC, the reaction mixture was worked up by pouring into $20 \mathrm{ml}$ of saturated $\mathrm{NaCl}$ solution, extracting with ether ( $2 \times 50 \mathrm{ml}$ ), drying and evaporation of the soivent. The crude product, which contained traces of phenyisulfinic acid, was passed through $20 \mathrm{~g}$ of sirica gel ( $1:$ o ethyi acetate/hexane).

3-Phenylcyclobutanol $\underline{124}$

From $288 \mathrm{mg}$ (1 mole) 3-phenyl-3-phenyisuifonyl cyciobutanol 79 was obtained $178 \mathrm{mg}\left(80^{\circ}\right)$ of 124 .

NMR: : $1.7-2.9\left(\mathrm{~m}, 5 \mathrm{H}, 4 \mathrm{H}\right.$ after $\mathrm{O}_{2} \mathrm{O}$ exchange $), 3 . i-3.9(\mathrm{~m}, 7 \mathrm{H}), 3.9-4.6$ $(m, I H), 7.2$ (broadened $s, 5 H$ )

IR: $O H, 3500$ (broad)

3-Benzylcyclobutanol $\underline{125}$

Obtained in $85 \%$ yield from $122 \mathrm{mg}$ of 3-benzyl-3-phenylsulfonyl cyclobutanol 123 (available in these laboratories). 
NMR: is $1.5-2.8(\mathrm{~m}, \mathrm{SH}), 4.0-4.7(\mathrm{~m}, \mathrm{H}), 7.3$ (broadened $\varepsilon$

IR: OH, 3500 (broad)

\section{Stereochemistry and Mechanism}

3-Eenayl-3-phenylsulfonvicyclopentanoi. 132

In $50 \mathrm{ml}$ of freshly distilled ThF was dissoived $1.0 \mathrm{~g}$ ( 3.2 mole) of the epoxy sulfone 60 . After cocling to $-i \Sigma^{\circ}, i . E$ mole of $\mathrm{CH}_{3} \mathrm{MgI}$ was added. The white suspension was let stir under nitregén for $24 \mathrm{hr}$ at ambient temperature. After this period the reaction mixture was poured into $100 \mathrm{ml}$ of saturated amonium chioride, extracted with $1 \times 75 \mathrm{ml}$ ether followed by $2 \times 100 \mathrm{ml}$ of methylene chlorice The organics were combined, dried and the soivent stripped. Chromatography of the residue on silica gel ( $3: \&$ etivl acetate/hexane) provided $\$ 00 \mathrm{mg}$ $(80 \%)$ of the cyciopentanol 132 as a clear oil.

NMR: $=0.8-i . i(m, 6 H), 2.96(\mathrm{~s}, 2 \mathrm{H}), 3.2(\mathrm{HH}, \mathrm{OH}), 3.7-3.9(\mathrm{~m}, \mathrm{iH})$, $7.0-7.3(\mathrm{~m}, 5 \mathrm{H}), 7.5-8.0(\mathrm{~m}, 5 \mathrm{H})$

${ }^{13}$ C NMR: $\hat{c} 29.1(t), 35.8(t), 39.4(t), 40.8(t), 72.9$ (quatemary and doubiet)

Aromatics: $135.6,134.6,134.0,133.7,130.8,130.6,129.2$, $129.0,128.8,128.5,127.4,126.9$ 
X-Ray Analysis of 3-Phenyl-3-phenylsulfonylcyclobutano I

Suitable crystals of $\underline{79}$ were grown from methanol and a crystal structure determination was carried out by Dr. J. Blount at Hof fmann- - LaRoche Inc., Nutlev, New Jersey. A computer generated representation of the unit cell and tables of bond lengths, bond angles, selected torsion angles and the final atomic parameters are included on the following pages.

The unit cell contains two independent molecules; ie. two' molecules which are unrelated by crystal symetry (thus the problem became one of locating 40 nonhydrogen atoms instead of only 20). The two molecules were designated as unprimed and primed. The confomations of the two incependent molecules are essentially the same except for a rotation of about $15^{\circ}$ aroung the $S-C(3)$ bond (see the torsion angies). The dihedrai angles between the plane $c(1)-c(2)-c(3)$ and the plane $C(1)-C(4)-C(3)$ are $32 . \&$ and $32.3^{\circ}$ in the unprimed and primed molecules, and the dihedral angles between the planes $c(2)-C(3)-C(4)$ and $C(2)-C(1)-C(4)$ are 33.2 and $3 \hat{z} .8^{\circ}$.

The crystals were monoclinic, space group $P 2, / n$, with a $=18.399(2), b=10.607(2), c=15.384(3) \mathrm{A}, E=107.24(1)^{\circ}$ and $d$ calcd $=1.335 \mathrm{~g} \mathrm{~cm}^{-3}$ for $Z=\varepsilon\left(\mathrm{C}_{16} \mathrm{H}_{76_{3}} \mathrm{O}_{3} \mathrm{~S}, M=288.36\right)$. The intensity data were measured on a Hilger-Hatts diffractometer (Ni filtered $\mathrm{Cu}$ Ka radiation, $\varepsilon-20$ scans, pulse height discrimination). A crystal fragment measuring approximately $0.15 \times 0.5 \mathrm{~mm}$ was used for data collection: the data were corrected for absorption $\left(u=19.9 \mathrm{~cm}^{-1}\right)$. 
A total of 3727 reflections were measured for $0<57^{\circ}$, of which 3322 were considered to be observed $(1>2.50(1))$. The structure was soived by a multiple solution procedure (G. Germain, P. Main and M. M. Woolfson, Acta Cryst. A27, 368 (1971). The final refinement was carried out by block-diagonal least squares in which the matrix was partitioned into two blocks. In the final refinement anistropic themal parameters were used for the heavier atoms and isotropic temperature factors were used for the hydrogen atoms. The hydrogen atoms were included in the structure factor calculations but their parameters were not refined. The final discrepancy indices are $R=0.057$ and $W R=0.075$ for the 3322 observed reflections. The final difference map has no peaks greater than $\pm 0.3 e A^{-3}$. 


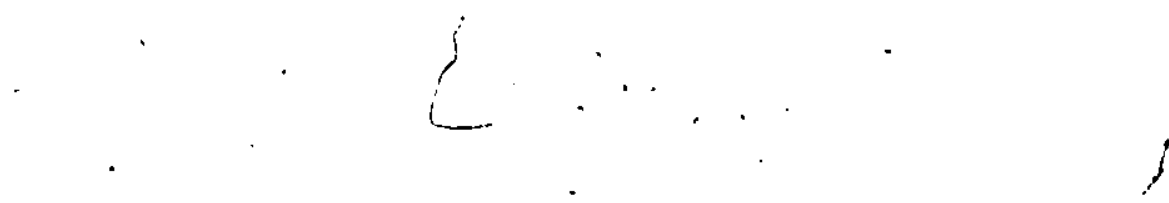

Computer Generated Representation of the Unit Eell for 3-Phenyl-trans-3phenyisul fonyl cyclobutanol 79

$\omega$
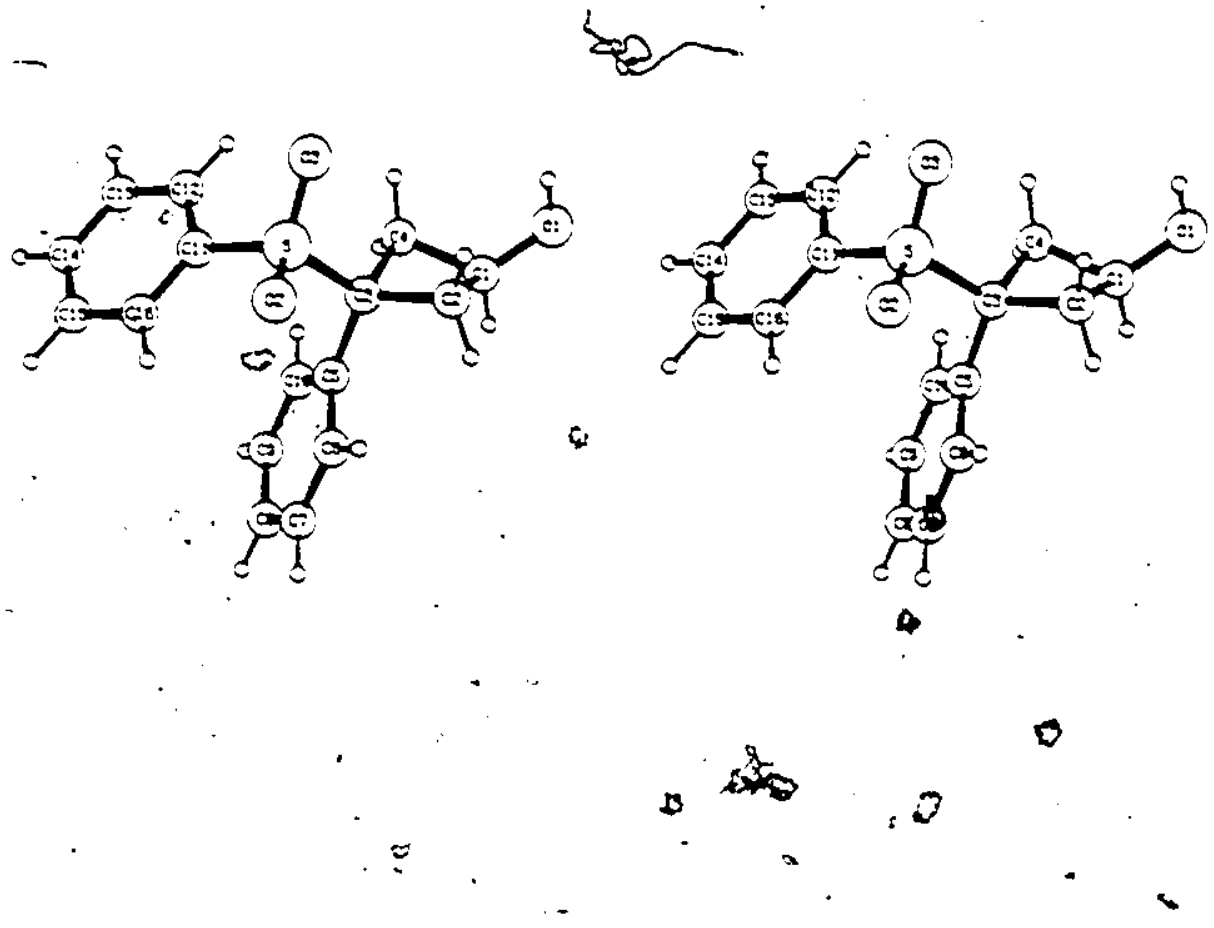
Table I. Bond Lengths (A) in

unprimed primed

$\begin{array}{rll}S-O(2) & 1.441 & 1.434 \\ S-O(3) & 1.438 & 1.449 \\ S-C(3) & 1.810 & 1.803 \\ S-C(11) & 1.764 & 1.764 \\ O(1)-C(1) & 1.408 & 1.418 \\ C(1)-C(2) & 1.537 & 1.524 \\ C(1)-C(4) & 1.534 & 1.534 \\ C(2)-C(3) & 1.556 & 1.558 \\ C(3)-C(4) & 1.567 & 1.545 \\ C(3)-C(5) & 1.502 & 1.522 \\ C(5)-C(6) & 1.385 & 1.354 \\ C(5)-C(10) & 1.386 & 1.394 \\ C(6)-C(7) & 1.352 & 1.383 \\ C(7)-C(8) & 1.361 & 1.358 \\ C(8)-C(9) & 1.370 & 1.382 \\ C(9)-C(10) & 1.375 & 1.412 \\ C(11)-C(12) & 1.359 & 1.356 \\ C(11)-C(16) & 1.384 & 1.383 \\ C(12)-C(13) & 1.381 & 1.385 \\ C(13)-C(14) & 1.368 & 1.381 \\ C(14)-C(15) & 1.369 & 1.371 \\ C(151-C(16) & 1.393 & 1.393\end{array}$

Estimated standard deviation for a typical $\mathrm{C}-\mathrm{C}$ bond length is $0.007 \mathrm{~A}$.

.8. 
Table II. Bond Angles ( ) in

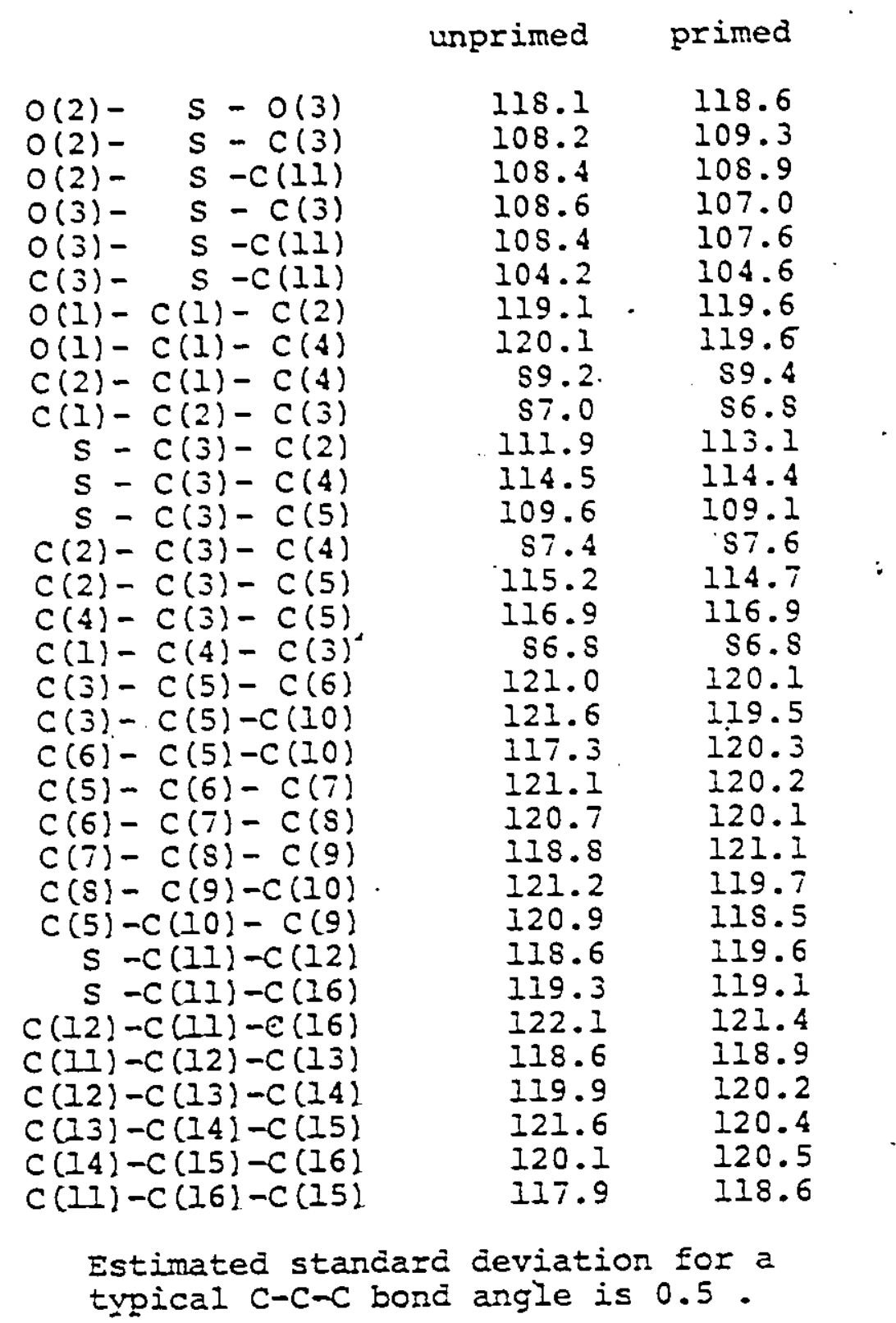


Table III. Torsion Angles ( ) in

unprimed primed

$C(4)-C(1)-C(2)-C(3)$

$C(1)-C(2)-C(3)-C(4)$

$c(2)-c(3)-C(4)-C(1)$

$C(3)-C(4)-. C(1)-C(2)$

$c(2)-c(3)-c(5)-c(6)$

$C(2)-C(3)-C(5)-C(10)$

$C(4)-C(3)-C(5)-C(6)$

$c(4)-C(3)-C(5)-C(10)$

$C(2)-C(3)-S-O(2)$

$C(2)-C(3)-S-O(3)$

$C(2)+C(3)-S-C(11)$

$c(3)-\quad s-C(11)-c(12)$

$C(4)-C(3)-s-O(2)$

$c(4)-C(3)-S-O(3)$

$C(4)+C(3)-S-C(11)$

$C(3)-S-C(11)-C(16)$
$23.5 \quad .23 .0$

$-23.0 \quad-22.8$

$23.0 \quad 22.6$

$-23.3-23.1$

$50.2 \quad 43.3$

$-133.7 \quad-139.1$

$150.7 \quad 143.8$

$-33.2 \quad-38.6$

$-65.2 \quad-75.2$

$64.2 \quad 51.3$

$179.6 \quad 165.3$

$-\$ 2.2 \quad-75.7$

$-162.6 \quad-176.5$

$-33.2 \quad-46.9$

$52.2 \quad 67.1$

$95.2 \quad 105.2$

Estimated standard deviation for a typical $\mathrm{C}-\mathrm{C}-\mathrm{C}-\mathrm{C}$ torsion angle is 0.6 . 
Table IV. Final Atomic Parameters for with Standard Deviations in Parentheses

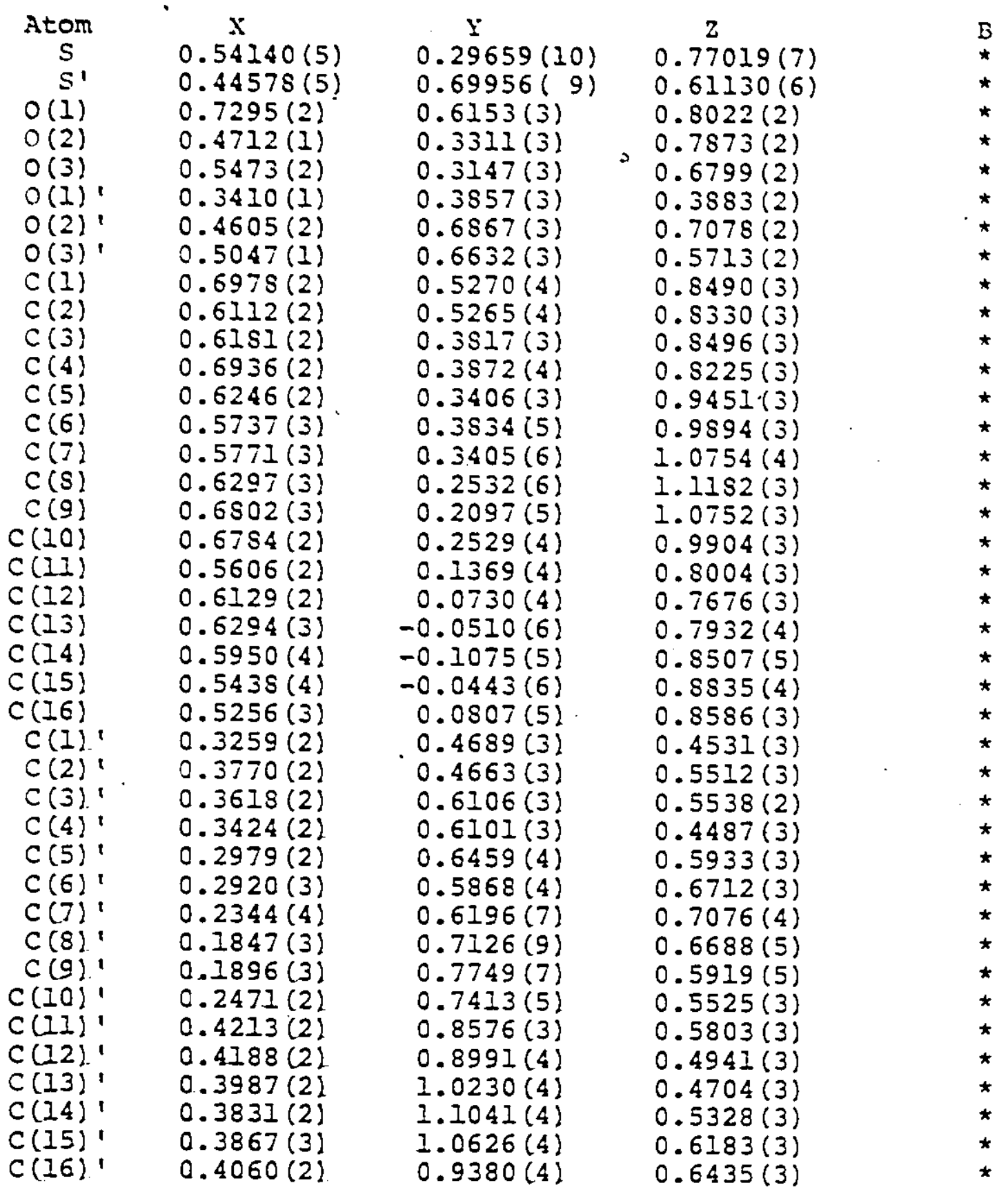


Table IV (continued) for

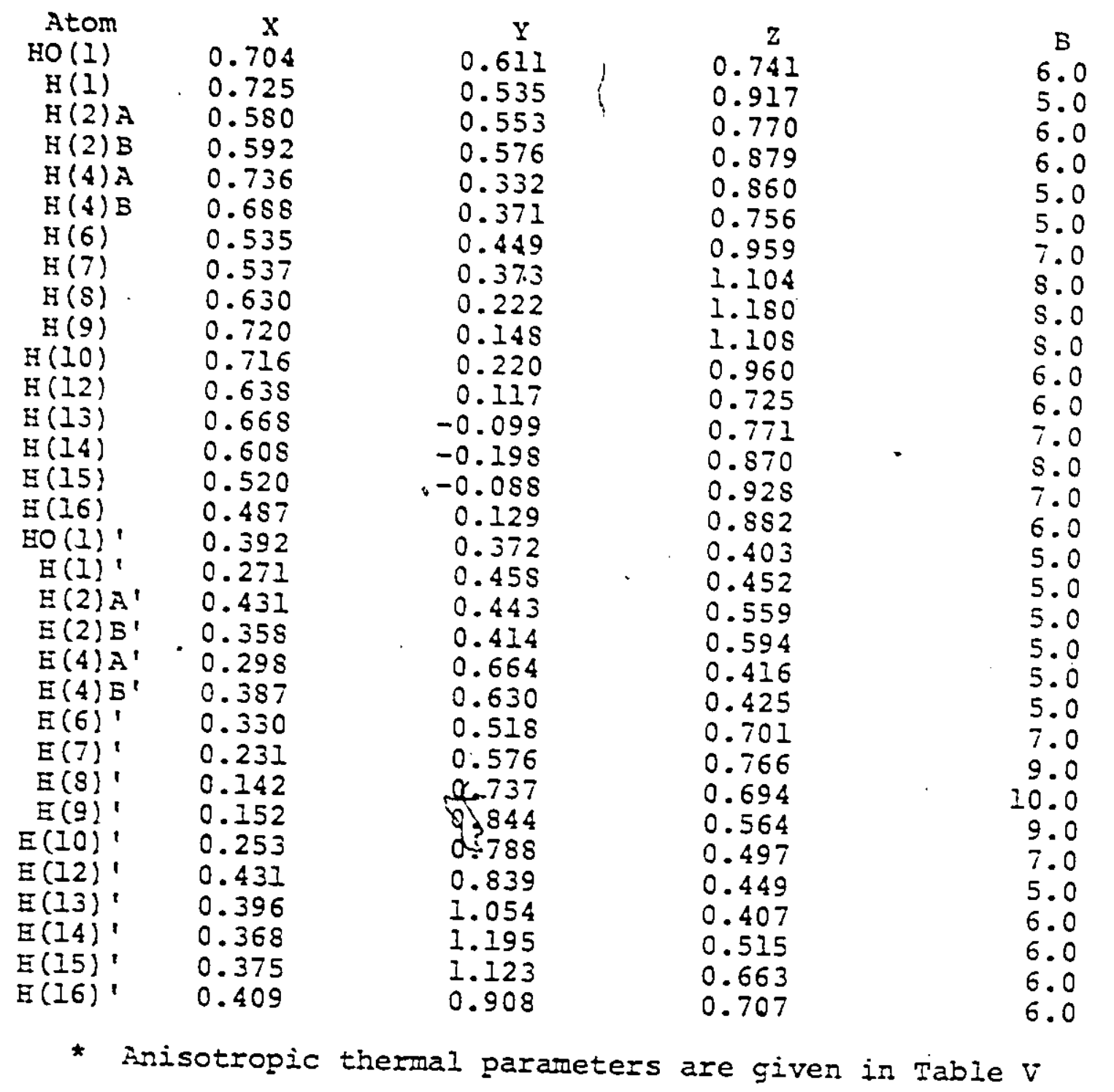


Table V. Final Anisotropic Thermal Parameters for with Standard Deviations in Parentheses

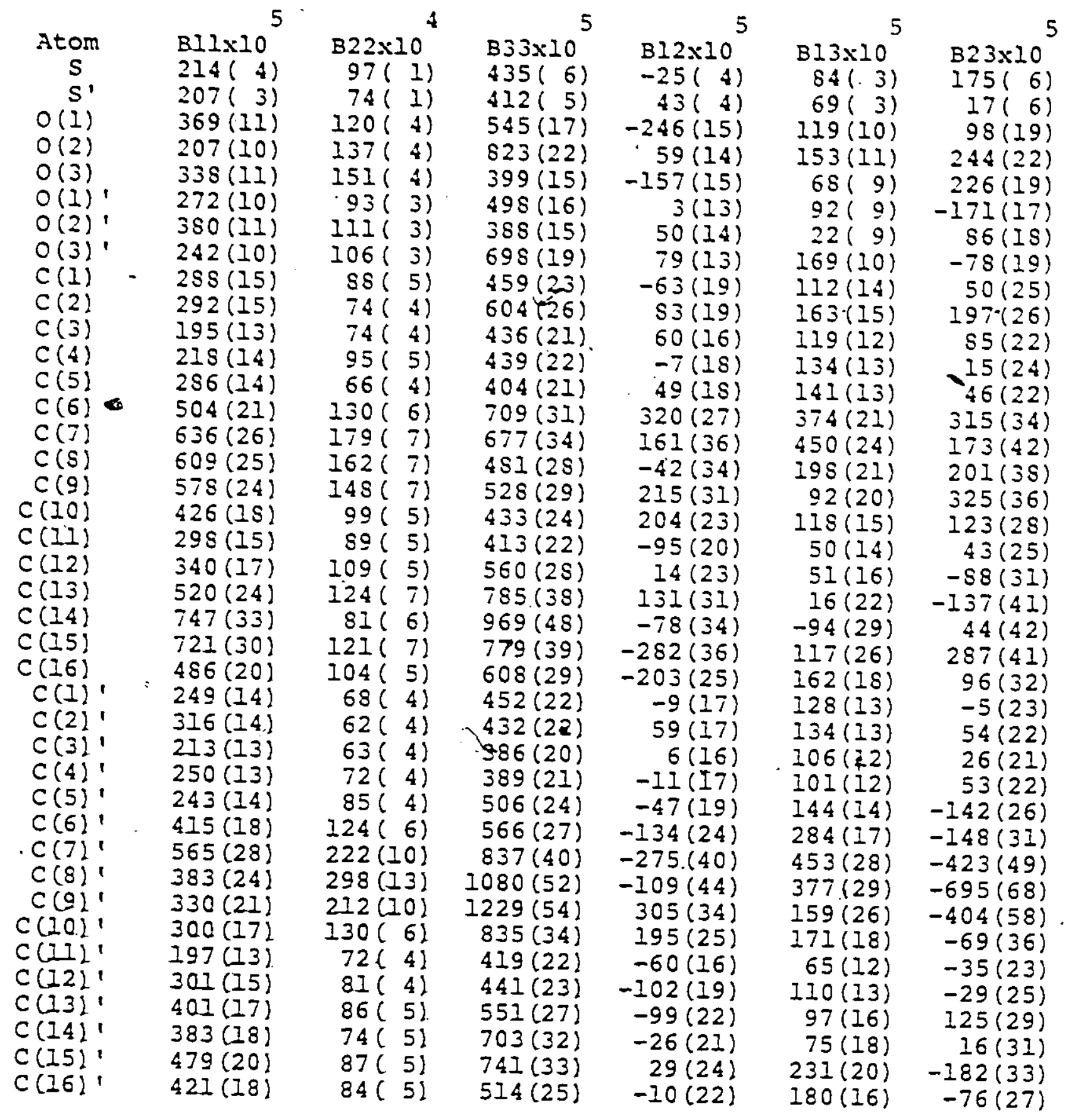

The anisotropic temperature factor has the form $\left.\exp \left(-\dot{h}^{2} \mathrm{Bl} I+\dot{k}^{2} \mathrm{~B} 22+{ }^{2} \mathrm{~B} 33+2 \mathrm{hkB} 12+2 \mathrm{hB} 13+2 k \mathrm{~B} 23\right)\right)$ 
Preparation of THP derivative 135

4-Phenyisulfonyl-1,2-epoxyoctane 133

4-Phenylsulfonyl-but-1-ene $\underline{53}(2.73 \mathrm{~g} ; 13.9$ mmole) was dissolved in $40 \mathrm{ml}$ of freshly distilled THF at $-75^{\circ}$ and converted to its carbanion with 14 mole of n-Buli. To the yellow solution of the carbanion at $-7 S^{\circ}$ was added $1.92 \mathrm{~g}$ ( 14 mole) of n-butyl bromide via syringe. The solution was let warm to room temperature and stirred for an additional $\mathrm{hr}$. After usual workup the crude product was chromatographed on $50 \mathrm{~g}$ of silica gel using $2: 8$ ethyl acetate/hexane as eluent, thus providing $2.50 \mathrm{~g}(71 \%)$ of 4-phenylsuifonyloct-1-ene as a clear oil.

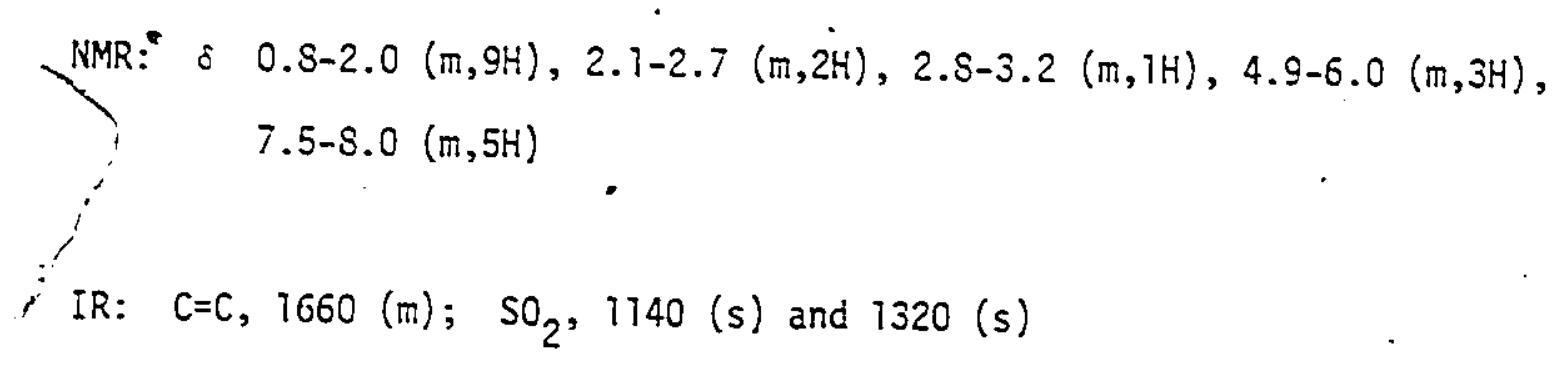

The above compound $(2.0 \mathrm{~g} ; 7.9$ mmole) in $50 \mathrm{mi}$ of methviene chloride was epoxidized to 133 by addition of 10 mole of MCPBA followed by refluxing the reaction mixture overnight. Usual workup furnished an oil which was chromatographed on $50 \mathrm{~g}$ of silica gel (2:8 ethyl acetate hexane). The epoxy sulfone 133 was obtained in $98 \%(2.1 \mathrm{~g})$ yield.

NMR: $\quad 0 \quad 0.8-2.2(\mathrm{~m}, 7 \mathrm{H}), 2.4-2.6(\mathrm{~m}, 7 \mathrm{H}), 2.7-2.9(\mathrm{~m}, 7 \mathrm{H}), 3.0-3.3(\mathrm{~m}, 2 \mathrm{H})$, $7.5-8.0(m, 5 H)$

IR: $\mathrm{SO}_{2}, 1140(\mathrm{~s})$ and $1320(\mathrm{~s})$ 
Bromohydrin $\underline{134}$

A three necked flask was equipped with a condenser, drying tube, and a dropping funnel. To the flask was added $359 \mathrm{mg}$ (16. mole) of magnesium metal and $50 \mathrm{ml}$ of anhydrous ether. To this was added, dropwise, $3.0 \mathrm{~g}$ (16 mole) of dibromobutane in $10 \mathrm{mi}$ of ether. After addition was complete the reaction was stirred for an additional 30 min. To this was then added $3.319(12.3$ mole) of the epoxy sulfone 133 in $5 \mathrm{ml}$ of sther, dropwise, via the dropping funnel. After stirring for $1 \mathrm{hr}$ at rod temperature the reaction mixture was then diluted with $50 \mathrm{mi}$ of $\mathrm{H}_{2} \mathrm{O}$ and the layers were separated. The aqueous layer was then extracted with $20 \mathrm{ml}$ of methylene chloride. Drying, evaporation, and chromatography (2:8 ethyl acetate/hexane) of the crude oil furnished $2.77 \mathrm{~g}(70 \%)$ of the bromohydrin $\underline{134}$ as a clear oil.

NMR: o $0.7-2.5(\mathrm{~m}, \mathrm{TH}), 3.0-3.6(\mathrm{~m}, 4 \mathrm{H}), 3.7-4.4(\mathrm{~m}, \mathrm{iH}), 7: 5-8.0(\mathrm{~m}, 5 \mathrm{H})$

IR: $\mathrm{OH}, 3450$ (broad); $\mathrm{SO}_{2}, 1150(\mathrm{~s})$ and $1310(\mathrm{~s})$

THP Derivative $\underline{135}$

In $25 \mathrm{ml}$ of methylene chloride was dissoived $2.50 \mathrm{~g}$ ( $7.6 \mathrm{mmole}$ ) of the bromohydrin $134,1.30 \mathrm{~g}$ (15.0 mole) of 2,3-dihydropyran and 1 drop of trifloroacetic acid. The mixture was let stir at room temperature for 2 days (complete by TLC). The solution was then concentrated on the rotary evaporator and chromatographed using 2:8 ethy? acetate/hexane. 
The yield of 135, as a clear oil, was $87 \%(2.74 \mathrm{~g})$.

$$
\begin{aligned}
\text { NMR: } \delta \quad & 0.5-1.0(\mathrm{~m}, 3 \mathrm{H}), 1.1-2.4(\mathrm{~m}, 14 \mathrm{H}), 3.0-4.2(\mathrm{~m}, 6 \mathrm{H}), 4.4-5.1(\mathrm{~m}, \mathrm{lH}), \\
& 7.5-5.0(\mathrm{~m}, 5 \mathrm{H})
\end{aligned}
$$

IR: no $\mathrm{OH} ; \mathrm{SO}_{2}, 1150(\mathrm{~s})$ and $1310(\mathrm{~s})$

Treatment of 135 with $\mathrm{CH}_{3} \mathrm{MgI}$

The THP derivative 135 ( 1 mole) was dissolved in freshly distilled THF and varying amounts of $\mathrm{CH}_{3} \mathrm{MgI}$ were added. Three runs, 1 equiv., 2.5 equiv., and 3 equiv., with reaction times ranging from $1-i$ days. The only products observed by NMR were starting material and halide exchanged starting material.

Preparation of THP derivative 139

Iodohydrin 138

Treatment of $4.0 \mathrm{~g}$ (18.8 mole) of epoxy sulfone $\underline{54}$ in $100 \mathrm{ml}$ of THF at $-78^{\circ}$ with 20 mole of $\mathrm{CH}_{3} \mathrm{MgI}$ followed by warming to room temperature and quenching with $20 \mathrm{~m}$ l of saturated ammonium chloride solution provided, after usual workup, $5.4 \mathrm{~g}(85 \%)$ of the iodohydrin 138 , m.p. $88-89^{\circ}$ (methylene chloride/hexane).

NMR: of $1: 6-2.3(\mathrm{~m} ; 2 \mathrm{H}), 2.6($ broad, $\mathrm{TH}, \mathrm{OH}), 3.2-3.4(\mathrm{~m}, 4 \mathrm{H}), 3.5-3.9$

$$
(m, 7 H), 7.4-8.0(m, 5 H)
$$




\section{${ }^{13}$ C NMR: \& $13.8(t), 29.4(t), 69.0(d)$ Aromatics $127.9,129.4,133.9$}

IR: $\mathrm{OH}, 34 \mathrm{SO}$ (broad); $\mathrm{SO}_{2}, 1150(\mathrm{~s})$ and $1310(\mathrm{~s})$
Anal. Caicd. for $\mathrm{C}_{10} \mathrm{H}_{13} \mathrm{O}_{2} \mathrm{SI}: \mathrm{C}, 35.30 ; \mathrm{H}, 3 . \mathrm{S2} ; \mathrm{S}, 9.41$ Found $\mathrm{C}, 36.51$, $H, 4.03 ; 5,9.58$

THP derivative 139

In $50 \mathrm{ml}$ of methylene chloride was dissoived $5.11 \mathrm{~g}$ ( 15.03 mole) of the iodohydrin $13 \mathrm{~S}$ and $200 \mathrm{mg}$ of para-toulene suifonic acid. To this solution at room temperature was added $2.52 \mathrm{~g}$ ( 30 mmole) of 2,3-dihydropyran. The mixture was stirred until starting material had disappeared on TLC $(30 \mathrm{hr})$. The mixture was then diluted with $50 \mathrm{ml}$ of $\mathrm{H}_{2} \mathrm{O}$ and the layers were separated. The aqueous layer was then extracted with $50 \mathrm{mi}$ of methylene chioride. The organfics were combined, dried, and the solvent removed. Chromatography of the resultant yellow oil (2:8 ethyl acetate/hexane) furnished $5.0 \mathrm{~g}$ (78\%) of the THP derivative 139 .

NMR: $\quad 0.8-2.7(m, 8 H), 2.9-4.2(m, 7 H), 4.3-4.9(m, 1 H), 7.0-7.9(m, 5 H)$

IR: no $\mathrm{OH} ; \mathrm{SO}_{2}, 1150(\mathrm{~s})$ and $1310(\mathrm{~s})$ 
Reaction of 139 with $\mathrm{CH}_{3} \mathrm{MgI}$

In $100 \mathrm{ml}$ of freshly distilled THF was added $1.33 \mathrm{~g}(3.13$ mole) of 139 . The solution was cooled to $-75^{\circ}$ and 6.3 mole of $\mathrm{CH}_{3} \mathrm{MgI}$ in ether was added. A white precipitate formed immediately upon addition of the Grignard reagent. The reaction was then allowed to warm to room temperature and stirred for an additional $24 \mathrm{hr}$. NMR and TLC analysis of the reaction mixture after workup indicated that only starting material was present.

Hydrolysis of the reaction product with $5 \% \mathrm{KCl} /$ methanol provided the iodohydrin $13 S\left(\mathrm{SO}_{\kappa}^{*}\right)$.

sis

The reaction was repeated with 3 and 4 equivalents of Grignard reagent with reaction times varying from $24 \mathrm{hr}$ to 4 days. No cyciized material was observed.

In one run the reaction mixture from 3.6 mole THP derivative and 9 mole $\mathrm{CH}_{3} \mathrm{MgI}$ was quenched after $24 \mathrm{hr}$ with 3.6 mole of benzophenone. Chromatography of the reaction mixture (2:8 ethyl acetate/hexane) gave the starting THP derivative $(90 \%)$ and $600 \mathrm{mg}(85 \%)$ of $1: 1$ diphenylethanol 140.

NMR: c $1.80(\mathrm{~s}, 3 \mathrm{H}), 2.3(\mathrm{HH}, \mathrm{OH}), 6.7-7.2(\mathrm{~m}, \mathrm{TOH})$ 


\section{Synthesis of Cyclobutyl Phenyl Sulfone}

1-bromo-4-phenylsuifonylbutane 141

In $100 \mathrm{ml}$ of absolute ethanol, was dissolved $20.0 \mathrm{~g}$ (92.6 mole) of 1,4 -dibromobutane and $76.0 \mathrm{~g}$ ( $97.5 \mathrm{mmole}$ ) of sodium phenyisulfinate. The solution was then refluxed for $24 \mathrm{hr}$, cooled and $200 \mathrm{ml}$ of $\mathrm{H}_{2} \mathrm{O}$ was added. The resulting solution was extracted with $2 \times 100 \mathrm{ml}$ methylene chioride and the organic extracts were-dried and the solvent stripped on the rotary evaporator. The remaining ethanol was removed by azeotropic distillation with benzene. Chromatography of the crude material ( $1: 3$ ethyl acetate/hexane) furnished $4.6 \mathrm{~g}(18 \%)$ of the bromosulfone 141 as white needles, m.p. $58-59^{\circ} \mathrm{C}$ (methylene chioride/ hexane).

NMR: of $1.7-2.7(\mathrm{~m}, 4 \mathrm{H}), 3.12(t, \mathrm{~J}=6 \mathrm{~Hz}, 2 \mathrm{H}), 3.36(t, \mathrm{~J}=6 \mathrm{~Hz}, 2 \mathrm{H}), 7.4-7.9$ $(m, 5 t)$
M.S. - Fragment
Ret. Abundance
Assignment
276,278
$<7 \%$
$M^{+}$
197
3.8
$[\mathrm{M}-\mathrm{HBr}]^{+}$
135,137
30
$\left[\mathrm{M}-\mathrm{SO}_{2} \mathrm{Ph}\right]^{+}$
77
38
$\mathrm{Ph}^{+}$
55
100
$\left[\mathrm{C}_{4} \mathrm{H}_{7}\right]^{+}$ 
Reaction of 141 with 1 equivalent of $\mathrm{CH}_{3} \mathrm{MgI}$

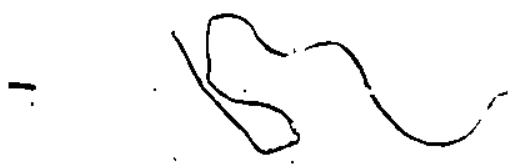

In $25 \mathrm{ml}$ of freshly distilled THF was dissoived $332 \mathrm{mg}(1.2$ mmole) of the bromosulfone 141. The solution was cooled to $-75^{\circ}$ and 1.5 mole of $\mathrm{CH}_{3} \mathrm{MgI}$ was added. A white precipitate formed immediately. The solution was let warm to room temperature and stirred for a further $12 \mathrm{hr}$. After this time the solution was poured into saturated ammonium chloride and extracted with $1 \times 50 \mathrm{ml}$ ether, followed by $1 \times 50 \mathrm{ml}$ methylene chloride. Drying and evaporation of the combined organic extracts furnished a solid which was analyzed by ${ }^{l} H$ NMR. The following approximate product distribution was found.

$\mathrm{PhSO}_{2}-\mathrm{C}_{4}-\mathrm{I} * \quad 70$

$\mathrm{PhSO}_{2}-\mathrm{C}_{4} \quad$ is

$\mathrm{PhSO}_{2}-\mathrm{C}_{4}-\mathrm{CH}_{3} \quad 10$

* recrystallation of the crude reaction mixture furnished a pure sample of the iodo sulfone which was identical in all respects to an authentic sample.

1-Iodo-4-phenyisuifony ibutane $\underline{142}$

In $30 \mathrm{ml}$ of "spectrograde"acetone was dissolved $3.0 \mathrm{~g}(10.8$ mole) of the bromosulfone 141 and $7.8 \mathrm{~g}$ ( $12 \mathrm{mmole}$ ) of sodium iodide at room temperature. The solution was stirred for $12 \mathrm{hr}$, poured into $100 \mathrm{ml}$ of $\mathrm{H}_{2} \mathrm{O}$ and then extracted with $2 \times 50 \mathrm{mT}$ of methylene chloride. Evaporation of the solvent from the dried organic extracts 
furnished a solid material which was recrystallized from methylene chloride/hexane yielding $2.9 \mathrm{~g}(83 \%)$ of 142 as white needles. m.p. $74-75^{\circ}$.

NMR: $\delta \quad 1.7-2.1(m, 4 H), 3.0-3.3(m, 4 H), 7.5-8.0(m, 5 H)$

M.S.

$\frac{\text { Fragment }}{\mathrm{m} / \mathrm{e}}$

324

197

143

77

55
Rel. Abundance

$<]_{*}^{*}$

54

60

66

100
Assignment

$$
M^{+}
$$

$[M-I]^{+}$

$\left[\mathrm{PhSO}_{2} \mathrm{H}_{2}\right]^{+}$

$\mathrm{Ph}^{+}$

$\left[\mathrm{C}_{4} \mathrm{H}_{7}\right]^{+}$

Reaction 142 with 1 equivalent of $\mathrm{CH}_{3} \mathrm{MgI}$

In $25 \mathrm{ml}$ of freshly distilled THF was dissolved $380 \mathrm{mg}$ (1.17 mole) of the iodosulfone 142 . To this solution at $-78^{\circ}$ was added 1.5 mole of $\mathrm{CH}_{3} \mathrm{MgI}$. The solution was let warm to room temperature and stirred overnight. Usual workup afforded an oily substance whose NMR qualitatively indicated the following product distribution.
$\mathrm{PhSO}_{2}-\mathrm{C}_{4}$
45
$\mathrm{PhSO}_{2}-\mathrm{C}_{4}-\mathrm{I}$
45
$\mathrm{PhSO}_{2}-\mathrm{C}_{4}-\mathrm{CH}_{3}$
$5-10$ 
Reaction of 142 with 2 equivalents of $\mathrm{CH}_{3} \mathrm{MgI}$

The iodosulfone $142(1.34 \mathrm{~g} ; 4.1 \mathrm{mmole})$ was dissoived in $25 \mathrm{ml}$ of freshly distilled THF. The solution was cooled to $-78^{\circ}$ ' (dry ice - acetone) and $10 \mathrm{mmole}$ of $\mathrm{CH}_{3} \mathrm{MgI}$ was added. This solution 'was let warm to room temperature and then stirred for $24 \mathrm{hr}$. The reaction mixture was then poured into $50 \mathrm{ml}$ of saturated ammonium chloride and extracted with $1 \times 50 \mathrm{ml}$ ether followed by $1 \times 50 \mathrm{ml}$ methylene chloride. The organic extracts were combined, dried and the solvent stripped thus providing a crude oil which was chromatographed on $40 \mathrm{~g}$ of silica gel using 1:9 ethyl acetate/hexane. The yield of cyclobutyl phenylsuifone 143 was $90 \%$ (700 mg).

NMR: $\delta \quad 1.8-2.6(\mathrm{~m}, 6 \mathrm{H}), 3.56$ (quintet; $\mathrm{J}=8 \mathrm{~Hz}, 7 \mathrm{H}), 7.4-7.9(\mathrm{~m}, 5 \mathrm{H}$ )

${ }^{13}$ C NMR: o $16.8(t), 22.8(t), 56.9(d)$ Aromatics $128.2,129.2,133.5$ 
2 Equivalents vs. I Equivalent in the Grignard Induced Cyclization of Epoxy Sulfone $\underline{54}$

Epoxy sulfone 54 was treated, in parallel runs, with 1 equivalent (run A) and 2 equivalents (run B) of $\mathrm{CH}_{3} \mathrm{MgI}$. The Grignard reagent was standardized just prior to use.

Run A In $25 \mathrm{ml}$ of anhydrous THF was dissolved $507 \mathrm{mg}$ (2.4mole) of the epoxy sulfone $\underline{54}$. The solution was cooled to $-7 \mathrm{~S}^{\circ}$ and stirred under nitrogen: To this solution was added 2.4 mole of $\mathrm{CH}_{3} \mathrm{MgI}$. The progress of the reaction was followed by taking $1 \mathrm{ml}$ aliquots (via syringe) of the reaction mixture as various times and examining the $T_{H}$ NMR spectrum. The reaction mixture was let warm to room temperature.

Run $B$ The same procedure, as in Run $A$, was followed except for the following modifications. The epoxy sulfone ( $485 \mathrm{mg} ; 2.3$ mole) was dissolved in $25 \mathrm{ml}$ of THF, cooled as above and 5.7 mole of $\mathrm{CH}_{3} \mathrm{MgI}$ was added.

The above reactions were allowed to stir for $52 \mathrm{hr}$ at ambient temperature and are then quenched with $10 \mathrm{ml}$ of saturated ammonium chloride solution. Upon quenching the reaction mixtures gas evolution was observed in both cases. The results are presented in Table VI. 


\section{PART II}

To $150 \mathrm{ml}$ of glacial acetic acid containing $25 \%$ concentrated sulfuric acid was added $4.0 \mathrm{~g}$ (22 mole) of diphenylmethanol and $3.8 \mathrm{~g}$ (23 mole) of sodium phenylsulfinate. After stirring at room temperature for $5 \mathrm{hr}$ the, solution was diluted with $500 \mathrm{ml}$ of $\mathrm{H}_{2} \mathrm{O}$, and extracted with $2 \times 100 \mathrm{ml}$ of methylene chloride. The organic extracts were then treated with $10 \% \mathrm{Na}_{2} \mathrm{CO}_{3}$ solation until the aqueous phase was rendered basic. The organics were then dried and the solvent evaporated. Chromatography (1:4 ethyl acetate/hexane) of the residue furnished $5.2 \mathrm{~g}\left(76^{\circ}\right)$ ) of the sulfone 17. m.p. $185-186^{\circ}$ (Lit. m.p. 1ST$\left.188^{\circ}(16)\right)$.

NMR: ${ }^{\prime} \quad 5.30(\mathrm{~s}, \mathrm{TH}), 7.0-7.8(\mathrm{~m}, \mathrm{~T} 5 \mathrm{H})$

IR: $\mathrm{SO}_{2}, 1140(\mathrm{~s})$ and $1300(\mathrm{~s})$.

Reaction of 17 with $\mathrm{CH}_{3} \mathrm{Li} / \mathrm{O}_{2}$

In $200 \mathrm{ml}$ of anhydrous THF at room temperature was dissolved $947 \mathrm{mg}(3.07 \mathrm{mmole})$ of the sulfone 17 . To this solution was added 3.5 mole of $\mathrm{CH}_{3} \mathrm{Li}$. The reddish solution of the carbanion was stirred for $20 \mathrm{~min}$. at room temperature and then $\mathrm{O}_{2}$ was introduced via a gas 
dispersion tube. The red colour disappeared within 5 min. oxygen was then bubbled through the solution for a further $45 \mathrm{~min}$. after which time the reaction mixture was poured into $50 \mathrm{ml}$ of saturated ammonium chloride and worked up in the usual manner. Chromatography of the residue remaining after evaporation of the solvent provided $420 \mathrm{mg}$ $(75 \%)$ of benzophenone which was identical in all respects to an authentic sample. m.p. $44-45^{\circ}$ (Iit. m.p. $48.1^{\circ}(17)$ ).

Reaction of IT with $\mathrm{CH}_{3} \mathrm{Li} / \mathrm{S}_{\mathrm{S}}$

The sulfone II (3.66g; 11.5 mole) was dissolved in $200 \mathrm{ml}$ of freshly distilled THF at $-78^{\circ}$. To this solution was added 12.8 mole of $\mathrm{CH}_{3} \mathrm{Li}$ and the solution was stirred for $15 \mathrm{~min}$. at $-78^{\circ}$ after which time $2.9 \mathrm{~g}(11.5 \mathrm{mmol} \dot{\mathrm{e}})$ of $\mathrm{S}_{\mathrm{S}}$ was added. The solution became greenish blue immediately and after $30 \mathrm{~min}$. at ambient temperature the solution became dark blue. After stirring for an additional 30 min. the solution was quenched with $50 \mathrm{ml}$ of saturated ammonium chloride and then extracted with $1 \times 50$ of ether followed by $2 \times 50 \mathrm{mi}$ of methylene chloride. The organics were combined, dried and the solvent was removed on the rotary evaporator. The blue solid was allowed to stand in the air for $24 \mathrm{hr}$ after which time the colour has disappeared and $2.03 \mathrm{~g}(95 \%)$ of benzophenone was recovered.

Q-Methylbenzyl Phenyl-Sulfone $\underline{23}$

In $100 \mathrm{ml}$ of glacial acetic acid containing $25 \%$ concentrated 
sulfuric acid was dissolved $6.0 \mathrm{~g}$ ( $36.5 \mathrm{mmole}$ ) of sodium phenylsulfinate and $4.5 \mathrm{~g}$ ( 37 mmole) of phenethyl alcohol. The solution was stirred at room temperature for $6 \mathrm{hr}$ and then diluted with $400 \mathrm{ml}$ of $\mathrm{H}_{2} \mathrm{O}$. The solution was then extracted with $2 \times 100 \mathrm{ml}$ of methylene chloride. The organic extracts were then treated with $10 \% \mathrm{Na}_{2} \mathrm{CO}_{3}$ solution until the aqueous phase was found to be basic. The resultant crude solid was chromatographed on $200 \mathrm{~g}$ of silica gel (1:S ethyl acetate/hexane) thus was provided $7.5 \mathrm{~g}\left(78_{*}^{*}\right)$ of the sulfone $\underline{23}$. m.p. 106-108.

NMR: $\delta 1.76(d, J=6 \mathrm{~Hz}, 3 \mathrm{H}), 4.20(q, J=6 \mathrm{~Hz}, 1 \mathrm{H}), 6.9-7.6(\mathrm{~m}, 10 \mathrm{H})$

IR: $\mathrm{SO}_{2}, 1120(\mathrm{~s})$ and $1310(\mathrm{~s})$

Reaction of 23 with $\mathrm{CH}_{3} \mathrm{Li} / \mathrm{O}_{2}$ and $\mathrm{SF}(\mathrm{OMe})_{2} / \mathrm{H}_{2} \mathrm{O}_{2}$

Treatment of 23 ( $747 \mathrm{mg} ; 2.8$ moie) with 3 mole of $\mathrm{CH}_{3} \mathrm{Li}$ followed by introduction of $\mathrm{O}_{2}\left(1\right.$ run at $-78^{\circ}$ and 1 run at $\left.0^{\circ}\right)$ yielded a product which was identical to starting material (TLC and NMR).

Treatment of $\underline{23}$ ( 1 mole) with excess . $\mathrm{BF}(\mathrm{OMe})_{2} / \mathrm{H}_{2} \mathrm{O}_{2}$ gave a product which, by NMR, showed no acetophenone. No acetophenone was detected by TLC. 
cis 4-t-Butylcyclohexyl Phenyl. Sulfone $\underline{24}$

Available in these laboratories, m.p. $113-114^{\circ}$ (chromatographed on silica gel with 1:4 ethyl acetate/hexane), (Lit. m.p. $115-116^{\circ}(18)$ ). NMR: $\delta .87(\mathrm{~s}, 9 \mathrm{H}), 7.3-2.6(\mathrm{~m}, \mathrm{SH}), 2.8-3.2(\mathrm{~m}, \mathrm{lH}), 7.4-8.0(\mathrm{~m}, 5 \mathrm{H})$

Treatment of the carbanion of 24 (generated from 1 mole of 24 and 7.2 mole $\mathrm{CH}_{3}(i)$ with $\mathrm{O}_{2}$ at room temperature or $-75^{\circ}$ gave after quenching only epimerized starting material by NMR. № cyclohexanone was detected by TLC or NMR.

The carbanion of 24 , when treated with excess $B F(\mathrm{OMe})_{2} / \mathrm{H}_{2} \mathrm{O}_{2}$, gave intractable materiai. Once again, no cyclohexanone was observed.

Benzyl Phenyl sulfone $\underline{25}$

Reaction of 25 with $\mathrm{CH}_{3} \mathrm{Li} / \mathrm{O}_{2}$ At $-78^{\circ}$.

The carbanion of $\underline{25}$ ( 1.4 mmole $\underline{25}, 1.6$ mole $\mathrm{CH}_{3} \mathrm{Li}$ ) when treated with $\mathrm{O}_{2}$ at $-78^{\circ}$ for $\mathrm{i} \mathrm{hr}$ gave, after quenching, and workup, a product which was mainly starting material (95\%). Benzaldehyde was detected by NMR (5\%), TLC and by its distinctive odor.

\section{At Room Temperature}

The yellow carbanion of 25 was generated by addition of 4.5 
mole of $\mathrm{CH}_{3} \mathrm{Li}$ to $\mathrm{l} .0 \mathrm{~g}$ ( 4.3 mole) of $\underline{25}$ at room temperature. $\mathrm{O}_{2}$ was introduced into the solution for $\mathrm{l} \mathrm{hr}$ during which time the solution - pecame clear. Quenching with $\mathrm{H}_{2} \mathrm{O}$ followed by usual workup provided the hydroxy sulfone 26 in $85 \%$ yield.

NMR: $\quad \delta 4.2-4.5\left(m, 2 \mathrm{H}, \mathrm{IH}\right.$ after $\mathrm{O}_{2} \mathrm{O}$ exchange $), 5.6-6.1(\mathrm{~m}, \mathrm{IH}), 6.7-7 . \mathrm{S}$ $(m, 15 H)$

IR: $\mathrm{OH}, 3450$ (broad); $\mathrm{SO}_{2}, 1120(\mathrm{~s})$ and $1300(\mathrm{~s})$

Treatment of a solution of the carbanion of 25 ( 1.5 mmole) containing 1.6 mole cupric chloride also gave only the adduct $\underline{26}$ as evidenced by NMR.

Reaction of the carbanion of $\underline{25}$ with $S_{S}$ gave $5 \%$ starting material and unidentified products while treatment with $B F(O M e)_{2}$ gave tar like substances.

Sulfonamide $\underline{27}$

To a two phase system containing excess aqueous dimethylamine (25-30\% by wt.) and $25 \mathrm{ml}$ of chloroform was added $1.4 \mathrm{~g}$ ( 7.6 mnole) of benzylsulfonyl chloride. The solution was stirred at room temperature for $2 \mathrm{hr}$ and then poured into $200 \mathrm{ml}$ of $\mathrm{H}_{2} \mathrm{O}$. Workup afforded $1.2 \mathrm{~g}$ (79\%) of the sulfonamide 27 . m.p. $99^{\circ}$ (Lit. m.p. $100-101^{\circ}\left(19^{\circ}\right)$ ).

NMR: $\quad 0 \quad 2.70(\mathrm{~s}, 6 \mathrm{H}), 4.06(\mathrm{~s}, 2 \mathrm{H}), 7.23(\mathrm{~s}, 5 \mathrm{H})$ 
Reaction of Sulfonamide 27 with $\mathrm{CH}_{3} \mathrm{Li} / \mathrm{O}_{2}$

To $680 \mathrm{mg}$ ( 3.4 mole) of the sulfonamide $\underline{27}$ at $-78^{\circ}$ was added 3.6 mole $\mathrm{CH}_{3} \mathrm{Li}$. After stirring for $20 \mathrm{~min}$. $\mathrm{O}_{2}$ was introduced for 1.5 $\mathrm{hr}$ at $-78^{\circ}$ and the reaction mixture was then quenched with $5 \mathrm{ml}$ of saturated ammonium chloride. Usual workup and examination of the NMR of the crude product revealed that mainiy starting material ( $50 \%$ ) was oresent. No benzaldehyde was detected.

The above experiment $\left(724 \mathrm{mg} ; 2.1\right.$ mole $2 \mathrm{~J}, 2.2$ mole $\mathrm{CH}_{3} \mathrm{Li}$ ) was also carried out at room temperature. A result identical to the above was obtained.

Benzyl Phenyl Sulfoxide 29

Available in these laboratories, m.p. $120-121^{\circ}$ (Lit. m.p. $\left.122-123^{\circ}(20)\right)$.

NMR: $\quad c 4.00(\mathrm{~s}, 2 \mathrm{H}), 6.8-7.5(\mathrm{~m}, 1 \mathrm{OH})$

Reaction of 29 with $\mathrm{CH}_{3} \mathrm{Li} / \mathrm{O}_{2}$

The $\alpha$-suifinyl carbanion of 29 was generated by treatment of 29 (631 mg; 2.9 mole) with 2.9 mole $\mathrm{CH}_{3} \mathrm{Li}$ at $-78^{\circ}$ under nitrogen. The solution of the carbanion was stirred for 20 min. at $-78^{\circ}$ and $\mathrm{O}_{2}$ was passed through the solution for $\mathrm{l} \mathrm{hr}$. After this period the reaction mixture was quenched with $\mathrm{O}_{2} \mathrm{O}$ followed immediately by $20 \mathrm{mi}$ of saturated ammonium chloride. The NMR of the product, after usual 
workup, revealed that incorporation of deuterium $\alpha$ to the sulfoxide was essentially complete as judged by the integration of the NMR spectrum.

NMR: $\delta 4.0$ (broadened triplet, $1 \mathrm{H}), 6.7-7.8(\mathrm{~m}, 10 \mathrm{H})$ 


\section{PART III}

Dibenzyl Sulfone $\underline{4}$

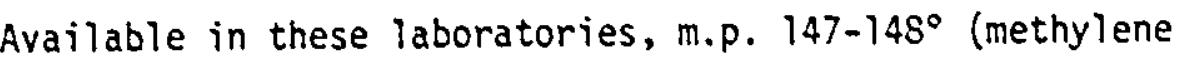
chioride/pentane) (Lit. m.p. $150^{\circ}(9)$ ).

2,6-Diphenyl thiạne-1,1-dioxide $\underline{I}$

To $200 \mathrm{ml}$ of freshiy distilled THF, under nitrogen, was added $4.3 \mathrm{Sg}$ ( 43 mole) of disopropylamine. This solution was cooled to $-7 S^{\circ}$ and 46 mole of $\mathrm{CH}_{3} \mathrm{Li}$ was added slowly via syringe. The solution was stirred for $20 \mathrm{~min}$. at $-7 \mathrm{~S}^{\circ}$ and then $4.84 \mathrm{~g}$ ( $19 \mathrm{~mole}$ ) of dibenzyi sulfone 4 was added. After $15 \mathrm{~min}$. at $-7 \mathrm{~S}^{\circ}, 3.14 \mathrm{~g}$ (20 mole) of bromo chloropropane was added. The resultant solution was let warm to room temperature and then stirred overnight. The solution was then quenched with $\mathrm{H}_{2} \mathrm{O}$ and extracted with $1 \times 50 \mathrm{ml}$ of ether followed by $2 \times 50 \mathrm{ml}$ of methyiene chioride. The organics were combined, dried and the solvent stripped. The crude solid was chromatographed on silica gel using 2:8 ethyl acetate/hexane as the eluent. The white crystalline sulfone $I$ was obtained in $80 \%$ yield. m.p. $217-218^{\circ}$ (methylene chloride/pentane).

NMR: $c \quad 1.5-2.9(\mathrm{~m}, 6 \mathrm{H}), 4.16(\mathrm{dd}, \mathrm{J}=11.9$ and $3.1 \mathrm{~Hz}, 2 \mathrm{H}), 7.2-7.6(\mathrm{~m}, 1 \mathrm{OH})$

IR: $\mathrm{SO}_{2}, 1720(\mathrm{~s})$ and $1300(\mathrm{~s})$ 


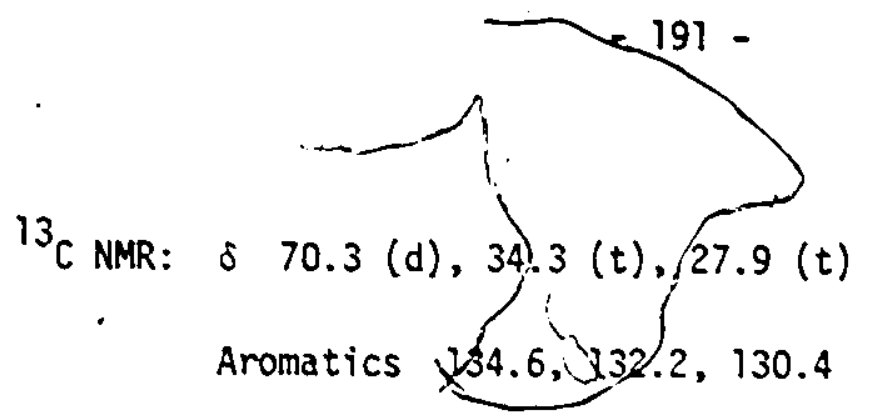

Anal. Calcd. for $\mathrm{C}_{17} \mathrm{H}_{15} \mathrm{O}_{2} \mathrm{~S}: \mathrm{C}, 71.33 ; \mathrm{H}, 6.29$ Found $\mathrm{C}, 71.50$; H, 6.19

Synthesis of 4 -t-Butylthiane-1) -dioxide 3 and $64 \mathrm{~g} ; 450$ mole $\mathrm{CH}_{3} \mathrm{I}$ ) was added a solution of $50 \mathrm{~g}$ of isopropylidene in $50 \mathrm{ml}$ of anhydrous ether, dropwise over $2 \mathrm{hr}$. The reaction mixture was then stirred for an additional $4 \mathrm{hr}$ after which time $200 \mathrm{ml}$ of saturated ammonium chloride were added slowiy over 20 min. This solution was then extracted with $2 \times 100 \mathrm{mi}$ of ether. The extracts were combined, dried and the ether removed on the rotary evaporator. Distillation of the resultant liquid furnished $60 \mathrm{~g}(71 \%)$ of the diester 5. mediun vacuum pump)..

NMR: $\quad \hat{~} 1.06(s, 9 H), 1.27(t, j=6 \mathrm{~Hz}, 6 \mathrm{H}), 3.00(\mathrm{~s}, 7 \mathrm{H}), 4.12(q, \mathrm{~J}=6 \mathrm{H}, 4 \mathrm{H})$

Diol $\underline{6}$

In a $250 \mathrm{ml}$ round bottomed flask equipped with a condensor and drying tube was suspended $9.5 \mathrm{~g}$ (250 mole) of $\mathrm{LiAlH}_{4}$. To this suspension was added a solution of $42 \mathrm{~g}$ (194 mole) of the diester 5 in 
$50 \mathrm{ml}$ of anhydrous ether, dropwise at $0^{\circ}$. After addition was complete, the solution was refluxed for $2 \mathrm{hr}$ and then worked up in the manner described in Feiser and Feiser (10). Evaporation of the ether provided $2 \mathrm{ig}(82 \%)$ of the diol $\underline{6}$ after distillation. b.p. $59-95^{\circ}, 5 a_{x}$

NMR: $s 1.10(\mathrm{~s}, 9 \mathrm{H}), 1.5-1.9$ (broad, $\mathrm{IH}), 3.5-3.9\left(\mathrm{~m}, 6 \mathrm{H}, 4 \mathrm{H}\right.$ after $\mathrm{D}_{2} \mathrm{O}$ exchange)

IR: $O H, 3500$ (broad)

Dimesyiate $I$

In $200 \mathrm{ml}$ of methylene chloride was dissolved $46 \mathrm{~g}$ (456 mole) of triethylamine and $25 \mathrm{~g}$ (190 mole) of the diol $\underline{6}$. The solution was cooled to ice temperature and a solution of 418 mole methanesuifonyl chloride (freshly distilled) in $50 \mathrm{ml}$ methylene chloride was added dropwise over a $1 \mathrm{hr}$ period. The reaction mixture was stirred for 2 $\mathrm{hr}$ and then $100 \mathrm{ml}$ of $\mathrm{H}_{2} \mathrm{O}$ was added slowily. The organic layer was. drawn off and the aqueous layer was then extracted with $2 \times 100 \mathrm{ml}$ of methylene chiorith. The organic extracts were combined, washed with $100 \mathrm{ml}$ of $5 \% \mathrm{HCl}$, dried and the solvent removed furnishing $52 \mathrm{~g}(94 \%)$ of the dimesylate $\underline{7}$.

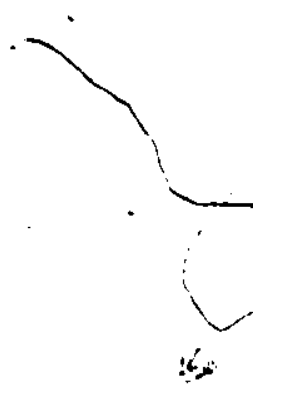

NMR: o $1.70(\mathrm{~s}, 9 \mathrm{H}), 1.7-2.0(\mathrm{~m}, \mathrm{lH}), 3.02(\mathrm{~s}, 6 \mathrm{H}), 4.2-.45(\mathrm{~m}, 4 \mathrm{H})$ 
Dinitrile $\underline{s} .$.

The crude mesylate $(85 \mathrm{~g}, 90 \%$ by NMR) was dissolved in $300 \mathrm{ml}$ of DMSO and $32.5 \mathrm{~g}(0.5$ mole) of potassium cyanide was added. The solution was heated at $100^{\circ}$ for $48 \mathrm{hr}$ during which time the reaction mixture turned black. After this period $300 \mathrm{ml}$ of $\mathrm{H}_{2} \mathrm{O}$ were added and the solution was extracted with $2 \times 100$ ol of methylene chloride. The organic layers were combined, dried and evaporated. The resuitant crude oil was distilled, thus was furnished $1 \mathrm{Sg}\left(45^{\circ}\right)$ of the dinitrile $\underline{\mathrm{s}}$. b.p. $100-105^{\circ}, 5$ in.

NMR: $=1.00(\mathrm{~s}, \mathrm{OH}), 1.7-2.0(\mathrm{~m}, \mathrm{TH}), 2.5(\mathrm{~d}, \mathrm{~J}=5 \mathrm{~Hz}, 4 \mathrm{H})$

IR: $C \equiv N, 2210(m)$

Diacid $\underline{9}$

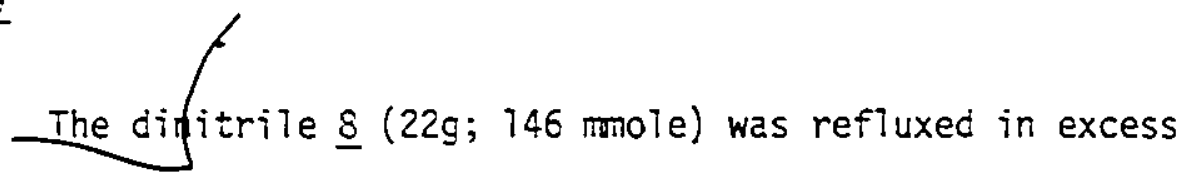
concentrated $\mathrm{HCl}$ (Sp. gr. 1.18) for $4 \mathrm{hr}$. The reaction mixture was then diluted with $100 \mathrm{mi}$ of $\mathrm{H}_{2} \mathrm{O}$ and extracted with $2 \times 100 \mathrm{mi}$ of methylene chloride. The organic extracts were combined and the solvent stripped. The crude product was dissolved in excess $5 \% \mathrm{NaOH}$ and the aqueous layer was washed with $100 \mathrm{ml}$ of ether. The basic extracts were reacidified and the diacid was recovered by extraction with $200 \mathrm{ml}$ of ether, which upon drying and eyaporation of the solvent furnished $22 \mathrm{~g}(87 \%)$ of the diacid $\underline{9}$. 
NMR: $\delta .95(\mathrm{~s}, 9 \mathrm{H}), 2.1-2.6(\mathrm{~m}, 5 \mathrm{H}), 10.5$ (broad, $2 \mathrm{H})$

Diol 10

In $150 \mathrm{ml}$ of anhydrous ether was suspended $15 \mathrm{~g}$ (400 mole) of LiAiH $_{4}$. To this suspension at $0^{\circ}$ was added $21 \mathrm{~g}$ ( 111 mole) of the diacid $\underline{g}$ in $100 \mathrm{ml}$ of ether. After addition was complete, the reaction was refluxed for $3 \mathrm{hr}$. Usual workup gave the diol 10 in $56 \%$ (15g) yield.

NMR: $s .9(\mathrm{~s}, 9 \mathrm{H}), 1.1-2.1(\mathrm{~m}, 5 \mathrm{H}), 3.3-3.5(\mathrm{~m}, 6 \mathrm{H})$ $D_{2} \mathrm{O}$ exchange $\delta 3.66,(t, \mathrm{~J}=6 \mathrm{~Hz}, 4 \mathrm{H})$

IR: $\mathrm{OH}, 3400$ (broad)

Dimesylate $\underline{11}$

In $200 \mathrm{ml}$ of methylene chloride was dissolyed $23 \mathrm{~g}$ (220 mole) of triethylamine and $15 \mathrm{~g}$ (94 mole) of dior 10. To this solution at $0^{\circ}$ was added $24 \mathrm{~g}$ (210 mole) of freshiy distilled methanesulfonyl chloride dropwise over a $1 \mathrm{hr}$ period. The solution was then diluted with $100 \mathrm{ml}$ of $\mathrm{H}_{2} \mathrm{O}$ and worked up in the usual. manner. The yield of dimesylate II was $24 \mathrm{~g}\left(95_{\%}^{\circ}\right)$.

NMR: $c .90(s, 9 H), 1.1-2.3(m, 5 H), 2.96(s, 6 \mathrm{H}), 4.18(t, j=6 \mathrm{~Hz}, 4 \mathrm{H})$

IR: no OH 


\section{4- $\underline{t}$-Butylthiane $\underline{12}$}

To a solution of $25 \mathrm{~g}$ (79 mole) of the dimesylate II dissolved in $100 \mathrm{ml}$ of $95 \%$ ethanol was added $34 \mathrm{~g}$ of sodium sulfide nonahydrate. The solution was refluxed overnight and then worked up by addition of $100 \mathrm{ml}$ of saturated amonium chloride and extracted with $2 \times 100 \mathrm{ml}$ of methylene chloride. The organics were. dried and the solvent stripped. The crude oil was purified by distillation. Thus was obtained $8.0 \mathrm{~g}(52 \%)$ of 12 . b.p. $60-62^{\circ}, 2 \mu$.

NMR: $\delta .90(s, 9 H), 1.0-2.0(m, 5 H), 2.3-2.6(m, 4 H)$

4-t-Eutyithiane-1, 1-dioxide $\underline{\underline{3}}$

The sulfice $12(3.5 \mathrm{~g} ; 22$ mole) was dissolved in $100 \mathrm{ml}$ of methylene chloride and to this solution at room temperature was added $10.0 \mathrm{~g}$ (60 mole) of MCPBA in several portions over a $1 \mathrm{hr}$ period. After an additional $\mathrm{hr}$ at reflux the solution was cooled to room temperature and washed with $2 \times 50 \mathrm{mi}$ of $5 \% \mathrm{NaOH}$. Extraction with $2 \times 100 \mathrm{ml}$ of methylene chioride followed by drying and evaporation of the organics yielded $4.0 \mathrm{~g}\left(95^{\circ}\right)$ of the sulfone $\underline{3}$. m.p. $108^{\circ}$ (methyiene chloride/ pentane).

NMR: co $.95(\mathrm{~s}, 9 \mathrm{H}), 1.7-2.4(\mathrm{~m}, 5 \mathrm{H}), 2.8-3.2(\mathrm{~m}, 4 \mathrm{H})$

IR: $\mathrm{SO}_{2}, 1110(\mathrm{~s})$ and $1310(\mathrm{~s})$ 
M.S.

$\frac{\text { Fragment }}{\mathrm{m} / \mathrm{e}}$

190

175

134

57
Rel. Abundance

10

75

92

100
Assignment

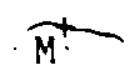

$\left[{\mathrm{M}-\mathrm{CH}_{3}}^{+}\right.$

$\left[\mathrm{M}-\mathrm{C}_{4} \mathrm{H}_{7}\right]^{+}$

$\left[\mathrm{C}_{4} \mathrm{H}_{9}\right]^{+}$

Reactions of the a-sulfonyl carbanion of 2,6-diphenvithiane-1,1-dioxide 1 and 2 with electrophiles

$\mathrm{H}_{2} \mathrm{O}$

The carbanion of the cis isomer I was generated in THF by reaction of $I$ with 1.1 equivaients of $\mathrm{CH}_{3} \mathrm{Li}$. The reaction was worked up by quenching the reaction mixture with $\mathrm{H}_{2} \mathrm{O}$ followed by extraction with $7 \times 50 \mathrm{ml}$ of ether and $2 \times 50 \mathrm{ml}$ of methylene chloride. The individual trials are sumarized below.

Temperature

$-78^{\circ}$

$0^{\circ}$

$0^{\circ}$

R.T.

R.T.
Time

1 min.

1 min.

15 min.

$1 \min$.

$40 \mathrm{hr}$. 
The only product observed after workup in all the above cases was the

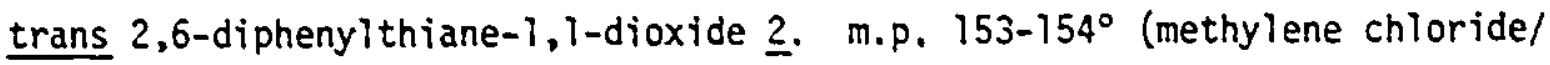
pentane).

NMR: $\delta 1.8-2.2(\mathrm{~m}, 2 \mathrm{H}), 2.2-2.9(\mathrm{~m}, 4 \mathrm{H}), 4.30(\mathrm{dd}, \mathrm{J}=7.2$ and $4.2 \mathrm{~Hz}, 2 \mathrm{H})$, $7.3-7.5(\mathrm{~m}, 10 \mathrm{H})$

IR: $\mathrm{SO}_{2}, 1120(\mathrm{~s})$ and $1310(\mathrm{~s})$

${ }^{13} \mathrm{CNMR}: \& 23.4(t), 32.6(t), 67.2(d)$ Aromatics $135.9,132.2,130.4$

Trans 2,6-diphenylthiane-1,1-dioxide (1 mole) when converted to its carbanion with $\mathrm{CH}_{3} \mathrm{Li}$ and quenched with $\mathrm{H}_{2} \mathrm{O}$ regenerated only starting material under ail the reaction conditions listed below.

$\begin{aligned} \text { Temperature } & \text { Time } \\ -78^{\circ} & 1 \mathrm{~min} . \\ -78^{\circ} & 2 \mathrm{~min} . \\ -78^{\circ} & 2 \mathrm{hr} \\ 0^{\circ} & - \\ \text { R.T. } & 5 \mathrm{~min} . \\ & 1 \mathrm{hr}\end{aligned}$


$\underline{D_{2} \mathrm{O}}$

The carbanion of the cis isomer I was generated at $-78^{\circ}$ from $179 \mathrm{mg}$ (.63 mole) of the sulfone $I$ and .70 mole of $\mathrm{CH}_{3} \mathrm{Li}$. The reaction mixture was stirred for $10 \mathrm{~min}$. at $-75^{\circ}$ and then quenched with $\mathrm{O}_{2} \mathrm{O}$. Usual workup provided a product which was examined by ${ }_{H}$ NMR.
NMR: $\delta 1.8-2.3(\mathrm{~m}, 2 \mathrm{H}), 2.3-2.9(\mathrm{~m}, 4 \mathrm{H}), 4.20$ (broadened triplet, $\mathrm{IH}$ ), $7.2-7.5(\mathrm{~m}, 1 \mathrm{OH})$

In $20 \mathrm{ml}$ of THF at $-78^{\circ}$ the trans isomer $\underline{2}(62 \mathrm{mg} ; .22$ mole) was treated with .26 mole of $\mathrm{CH}_{3} \mathrm{Li}$ and quenched with $\mathrm{D}_{2} \mathrm{O}$. Usual workup provided a product which was identical (TLC and NMR) to the product obtained by quenching the carbanion of the cis isomer with $\mathrm{D}_{2} \mathrm{O}$.

$\underline{\mathrm{CH}_{3} \mathrm{I}}$

The cis isomer 1 (25.9mg; .9 mole) was treated, at $-78^{\circ}$ in THF, with 1.1 mmole of $\mathrm{CH}_{3} \mathrm{Li}$. The solution was stirred for 2 min. at $-78^{\circ}$ and then quenched with excess $\mathrm{CH}_{3} \mathrm{I}$. Usual workup provided $90 \%$ of a product 13 which showed incorporation of 1 methyl group.

NMR: $01.70(\mathrm{~s}, 3 \mathrm{H}), 1.7-2.9(\mathrm{~m}, 6 \mathrm{H}), 3.93(\mathrm{dd}, \mathrm{J}=12$ and $3 \mathrm{~Hz}, \mathrm{lH})$, $7.2-8.0(\mathrm{~m}, 10 \mathrm{H})$ 
Treatment of the trans sulfone 2 (93mg; .32 mmole) under the same conditions as above provided the same product (TLC and NMR) as was obtained above.

The product 13 obtained above (100ms; .33 mmole) was refluxed overnight in $\mathrm{MeOH} / \mathrm{NaOMe}$. Usual workup provided $55 \mathrm{mg}$ ( $85 \%$ ) of a crystalline material which was recrystallized from methylene chloride/ hexane. m.p. 204-205

NMR: $\delta 1.97(\mathrm{~s}, 3 \mathrm{H}), 1.5-3.0(\mathrm{~m}, 6 \mathrm{H}), 4.3(\mathrm{dd}, \mathrm{J}=12.5$ and $3.2 \mathrm{~Hz}, \mathrm{lH})$, $7.2-7.8(\mathrm{~m}, 10 \mathrm{H})$

${ }^{13} \mathrm{C}$ NMR: $\delta 20.9,21.3,31.3,34.8,63.5,68.4$

Aromatics $135.9,130.9,130.2,130.0,128.9,128.4,128.2$

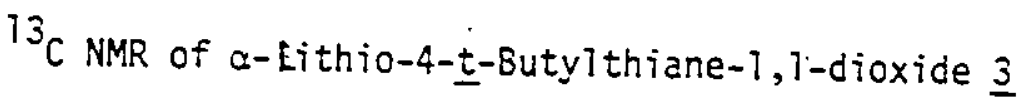

$A{ }^{13} \mathrm{C}$ NMR tube was fitted with a septum cap and two needles, one as a nitrogen iniet and the other as an outlet. The tube was purged with nitrogen and $103 \mathrm{mg}$ (.54 mole) of the sulfone $\underline{3}$ was placed in the tube. To this was added $1 \mathrm{ml}$ of THF- $\mathrm{d}_{8}$ from a freshly opened ampule. This solution was then cooled in a dry ice-acetone bath to $-78^{\circ}$ and .54 mole of $\mathrm{CH}_{3} \mathrm{Li}$ was added with a micro syringe. The tube was then slowly warmed to room temperature and the septum cap was replaced with a plastic tube cap. The ${ }^{13} \mathrm{C}$ NMR was then recorded and the results are presented on pg. 127. 


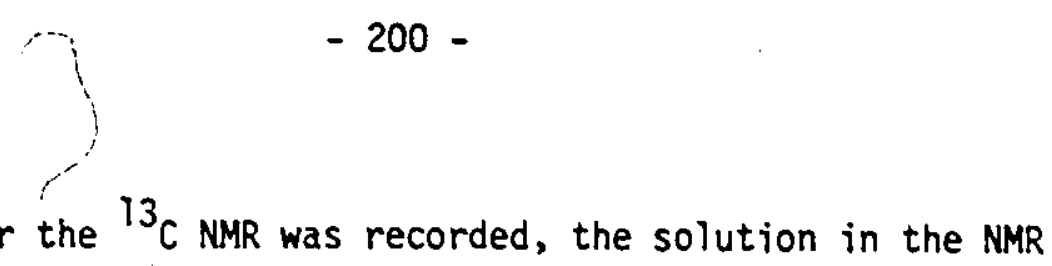
tube was cooled to ice temperature and excess $\mathrm{CH}_{3} \mathrm{I}$ was added. The reaction mixture was then poured into $\mathrm{H}_{2} \mathrm{O}$ and extracted with $1 \times 25 \mathrm{ml}$ of methylene chloride. Drying and evaporation of the organics provided an $88 \%$ recovery of the $\alpha$-methyl derivative.

NMR: $\delta .98(\mathrm{~s}, 9 \mathrm{H}), 1.2-2.2(\mathrm{~m}, \mathrm{SH}), 2.7-3.2(\mathrm{~m}, 3 \mathrm{H})$ 


\section{REFERENCES .}

\section{PART I}

\section{F}

1. R.E. Parker and N.S. Isaacs, Chem. Rev., 59, 737 (1959)

2. J.G. Pritchard and T.H. Siddiqui, J. Chem. Soc., Perkin II, $1309(1972)$

3. N.S. Enikolopiyan, Pure App. Chem. 4S, 317 (1976)

4. J.E. Baldwin, J.C.S. Chem. Corm., 734 (1976)

5. A.C. Knipe and C.J.M. Stirling, J. Chem. Soc., (ㅁ), 67 (1965)

6. L. Tenud, S. Farooq, J. Seibl and A. Eschenmoser, Helv. Chim. Acta, $\underline{53}, 2059(1970)$

7. G. Stork, L.D. Cama and R.D. Coulson, J. Am. Chem. Soc., פo, $5268(1974)$

S. G. Stork and J.F. Cohen, J. Am. Chem. Soc., 96, 5270 (1974)

פ. R. F. Sauers, R.A. Parent and S.E. Bamle, J.Am. Chem. Soc., SS, $2257(1966)$

10. J.Y. Lallemand and M. Onanga, Tetrahedron Lett., 585 (1975)

11. R. Achini and W. Oppolzer, Tetrahedron Lett., 369 (1975)

12. M. Kodama, Y. Matsuki and S. Ito, Tetrahedron Lett., 3065 (1975)

13. M. Kodama, Y. Matsuki and S. Ito, Tetrahedron Lett., 1121 (1976)

14. M. Kodama, S. Yakoo, H. Yamoda and S. Ito, Tetrahedron Lett., 3121 (1978)

15. V. Rautenstrauch, J.C.S. Chem. Corm., 519 (1978)

16. Y. Gaoni, Isr. J. Chem., 63 (1971) 
17. V.N. Yandooski and B.A. Ershov, Russ. Chem. Rev., 41. 403 (1972)

18. P.A. Cruickshank and M. Fishman, J. Org. Chem., 34, 4060 (1969)

19. Y. Gaoni, Tetrahedron, 28, 5525 (1972)

20. Y. Gaoni, Tetrahedron, 28, 5533 (1972)

21. G. Hodgson, D.F. MacSweeney and T. Money, Tetrahedron Lett., $3683(1972)$

22. J. Babler and A. Tortorel10, J. Org. Chem., 41, SS5 (1976)

23. A. Turcant and M. Lecarre, Tetrahedron Lett., iS9 (1977)

24. C.R. Johnson, J.E. Keiser and J.C. Sharp, J. Org. Chem., 34, $\$ 60$ (1969)

25. R.J. Shutzz; W.H. Staas and L.A. Spurlock, J. Org. Chem., 3S, $3091(1973)$

26. L.A. Spurlock and R.G. Fayter Jr., J. Am. Ohem. Soc., 94, 2707 (1972)

27. N.R. Wiltiams, Advan. in Carbohvd. Chem., 25, 109 (1970) and references therein

28. M.C. Sacquet, B. Graffe and P. Maitte, Tetrahedron Lett., 4453 (1972)

29. A. Murai, M. Ono and T. Masamune, J.C.S. Chem. Conm., 864 (1972)

30. T. Masamune, M. Ono, S. Sato and A. Murai, Tetrahedron Lett., 371 (1978)

31. Y. Gaoni, Tetrahedron Lett., 503 (1976)

32. B. Corbel and T. Durst, J. Org. Chem., 41, 3648 (1976)

33. Leo Paquette in "Modern Heterocyclic Chemistry", Chapter 1, W.A. Benjamin, Inc., Reading, 1968.

34. E.J. Corey and J.W. Suggs, IEtrahedron Lett., 2647 (1975) 
35. M.S. Hatch, J. Org. Chem., 34, 2133 (1969)

36. L.R. Feiser and M. Feiser, "Reagents for Organic Synthes is ". Vol. 1, p. 430, John Wiley and Sons, New York, 1967

37. K. Kondo and D. Tunemoto, Tetrahedron Lett., 1007 (1975)

35. M. Julia and 6. Badet, Bull. Soc. Chim. Fr., 1363 (1975)

39. W.A. Sonner and R.A. Grim in "The Chemistry of Organic Sulfur Compounds", Vol. 2, p. 115; Pergamon Press, Oxford, 1966

40. W.E. Truce, D.P. Tate and P.N. Surdge, J. Am. Chem. Soc., gi, $2872(1960)$

41. G.M. Posner and 0.J. Bruneile, Tetrahedron Lett., 935 (1973)

42. B.M. Trost, H.C. Arndth, P.E. Stage and T.R. Verhoeven, Tetrahedron Lett., 3477 (1976)

43. H.E. Baumgarten (Ed), Oroanic Sunthesis, Vol. 5, p. 310, John Wiley and Sons, Inc., New York, N.Y., 1973

44. Y. Amiel, A. Loffler and D. Ginsburg, J. Am. Chem. Soc., i6, 3625 (1954)

45. E.J. Corey, Ann. N.Y. Acd. Sci., 180, 24 (1971)

46. J.E. Sieja, J. Am. Chem. Soc., 93, 2481 (1971)

47. H. Wasseman, J.U. Piper and E.V. Dehmiow, J. Org. Chem., 38, 1451 (1973)

48. H. Mays and R. Huisgen, Angew. Chem. Int. Ed. Engl., 14, 499 (1975)

49. T.R. Kelly and R.W. McNutt, Tetrahedron Lett., 285 (1975)

50. Hous "Modern Synthetic Reactions", 2nd Ed., p. 643, W.A. Benjamin Inc., Menlo Park, Calif., 1972

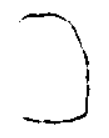


51. E. Ritchie and W.C. Taylor, Aust. J. Chem., 24, 2137 (1971)

52. P.C. Conrad and P.L. Fuchs, J. Am. Chem. Soc., 100, 346 (1978)

53. Y. Chang and H.W. Pinnick, J. Org. Chem., 43, 373 (1978)

54. B.M. Trost, Private Communication

55. W.A. Kerr and C.R. Johnson, J. Am. Cheh. Soc., 92, 4979 (1970) and references therein

56. M.S. Kharasch and 0. Reinmouth, "Grignand Reactions of Non-Metallic $=\quad$ Substances", p. 1297, Prentice-Hall, New York, N.Y., 1954

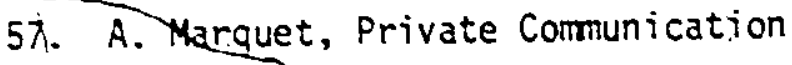

59 B. Corbel, Rrivate Communication

59. R.L. Shriner, H.C: Struck and W. Jorison, 3. Am. Chem. Soc., 52, 2066 (1930)

60. Beilstein, 6455 


\section{PART II}

1. E. Muller and T. Toppel, Chem. Ber., 72,273 (1939)

2. D.A. Konen, L.S. Si Tbert and P.E. Pfeffer, J. Org. Chem., 40 , 3253 (1957)

3. E. Vedejs, J. Am. Chem. Soc., 96, 5944 (1974)

4. W. Adam and 0.Cueto, J. Org. Chem., 42, 3s(1977).

5. S.J. Selikson and D.J. Watt, J. Ora. Chem., 40,267 (1975)

6. H.H. Wasseman and B.H. Lipschutz, Tetrahedron Lett., 1731 (1975)

i. G. Rauchswalbe and M. Schlosser, Helv. Chim. Acta., 5S, 4 (1975)

S. T.C. Brilkina and V.A. Shustunov, "Reactions of Organic Compound's with Oxvoen and Peroxides", Chemical Rubber Publishing Co., Cleveland, Ohio, 1969

9. C. Walling and S. Buckler, J. Am. Chem. Soc., i7, 6032 (1955)

10. G.A. Russe11, Adv. Chem. Ser., $5 \mathrm{I}, 112$ (1965); 프, 174 (1968)

11. E.J. Panek, L.R. Kaiser and G. M. Whitesides, 3. Am. Chen. Soc., $\underline{99}, 3708(1977)$

12. A. Schoberl and A. Wagner in Houben-Weyl, "Method der Organishen Chemie", p. 250, Thieme Verlag, Stuttgart, 1955

13. D. Seebach, Angew. Chem.; Int. Ed. Engl., g, 639 (1969)

14. R. Mayer, Synthesis and Properties of Thiocarbonyl Compounds, in M.J. Janssen (Ed.) "Organosulfur Chemistry", Interscience Publ., New York, 1967

15. S. Oae, "Organic Chemistry of Sulfur", Pienum Press, New York, 1977 
16. F.G. Bordwell and B.M. Pitt, 3. Am. Chem. Soc., 77, 572 (1955)

17. CRC Handbook of Chemistry and Physics, 51st Ed., The Chemical Rubber Co., Cleveland, Ohio, 1970

18. E.L. Eliel and R.S. Ro, J. Am. Chem. Soc., 79, 5995 (1957)

19. L.A. Paquette and M. Rosen, Tetrahedron Lett., 703 (1967)

20. Beilstein $6(1), 225$

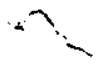




\section{PART III}

I. R. Legault and T. Durst, Private Communication

2. J.B. Stothers, "Carbon-13 NMR Spectroscopy", p. 411, Academic Press, New York, N.Y., 1972

3. T. Durst, Tetrahedron Lett., 4171 (1971) -

4. E.L. Eliel, A.A. Hart and A.G. Abatjoglui. J. Am. Chem. Soc.,

- ge $\log 7$ (1974)

5. E.J. Corey and T.H. Lowry, Tetrahedron Lett., T93 (1965)

- 6. 0.j. Cram and A.S. Wingrove, J. Am. Chem. Soc., S5, 1100 (1963)

i. S. Wolfe, A. Rauk and I.G. Csizmadia, J. An. Chem. Soc., gl, i567 (1969)

S. E. Chassaing and A. Marquet, Tetrahedron, 34, 1390 (isis)

Q. Seilstein 6,456 


\section{CLAIMS TO ORIGINAL RESEARCH}

1. Corbel's intial results on $\gamma$-epoxy sulfone cyclization have been extended to include a variety of s-epoxy sulfones.

2. All s-epoxy sulfones studied yield on iy 3-phenyisulfonyl cyclopentanol derivatives on treatment with 2 equivalents of $\mathrm{CH}_{3} \mathrm{MgI}$. Some unexpected results were obtained in the case of the reaction of s-epoxy sulfones with LDA.

3. Both 3-phenylsulfonyicyclobutanol and 3-phenyisuifonyl cyclopentanol were readily alkylated a to the sulfone group via dianion formation followed by quenching with an electrophile.

4. Several 3-phenyisulfonvicyciobutanols and -cyciopentanois were prepared via a "one-pot" process.

5. 3-aikyi-cyciopent-2-enones were readily obtained from 3-phenylsuifonyicyciopentanol derivatives by an oxidation/elimination sequence.

6. It has been established that both 3-phenyisuifonyi cyclobutanol and -cyclopentanol fomation is stereospecific. In one instance an X-ray structure detemination showed that the hydroxyl and phenyisulfonyi groups occupy a cis relationship to each other. Furthermore, NMR analysis suggests that all 3-phenylsulfonyl cycloalkanols prepared by the Grignard route belong to the same stereochemical series.

7. Several cyclobutanols were generated by treatment of -3-phenylsulfonylcyciobutanols with $\mathrm{Na}(\mathrm{Hg})$ amalgam. 
8. Several aspects of the mechanism of the Grignard induced epoxy sulfone cyclization have been studied. It was shown that 2 equivalents of Grignard reagent are required to promote cyclization.

9. The oxidation of various sulfur-stabilized carbanions was attempted with several types of reagents such as $0_{2}, S_{S}$ and $B F(O M e)_{2}$. Oxidation of a-lithio benzhydryl phenyl sulfone was found to proceed smoothly upon treatment with $\mathrm{O}_{2}$ or $\mathrm{S}_{S}$. The reaction with $\mathrm{S}_{S}$ may constitute a potential method for the synthesis of diaryl thioketones.

10. The a-sulfonyl carbanion of 2,6-diphenylthiane-1,7-dioxide was shown to react with electrophiles in a stereospecific manner with incorporation of the electrophiles $\left(\mathrm{H}_{2} \mathrm{O}, \mathrm{O}_{2} \mathrm{O}, \mathrm{CH}_{3} \mathrm{I}\right)$ in the equatorial position of the ring.

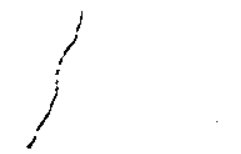

